INSTITUTO DE PESQUISAS ENERGÉTICAS E NUCLEARES

Autarquia associada à Universidade de São Paulo

\title{
ESTUDO DE LIGAS E ÍMÃS PREPARADOS PELO PROCESSO HIDROGENAÇÃO, DESPROPORÇÃO, DESSORÇÃO E RECOMBINAÇÃO (HDDR) À BASE DE Pr-Fe-B COM ADIÇÃO DE DOPANTES E ELEMENTOS DE LIGA
}

EGUIBERTO GALEGO

Tese apresentada como parte dos requisitos para obtenção do Grau de Doutor em Ciências na Área de Tecnologia Nuclear - Materiais.

Orientador:

Dr. Rubens Nunes de Faria Jr.

São Paulo

2008 
À minha esposa Marilene 
O número explica o universo - Lema dos Pitagóricos 


\section{AGRADECIMENTOS}

Agradeço ao PhD. Rubens Nunes de Faria Jr. pela orientação deste trabalho, pela amizade e apoio.

Agradeço ao Dr. José Mestnik Filho pela ajuda e tempo dedicado na etapa dos cálculos teóricos utilizados nesta tese, ao apoio e valiosas discussões.

Agradeço à Professora Dra. Helena Maria Petrilli pela ajuda na introdução aos cálculos teóricos (ab-initio), pelo tempo dedicado e por permitir o uso de sua área de processamento de dados no CCE-USP.

Agradeço ao PhD. Hercílio Rodolfo Rechenberg e Sergio Antonio Romero ambos do Instituto de Física da Universidade de São Paulo, Departamento de Física dos Materiais e Mecânica, Grupo de Materias Magnéticos e Espectroscopia Mössbauer, pelas medidas magnéticas realizadas a baixa temperatura.

Ao Laboratório Nacional de Luz Síncrotron - LNLS pela utilização de suas instalações nas medidas de difração de raios X - linha XPD.

À minha esposa Dr ${ }^{\text {anda }}$ Marilene Morelli Serna pelo incentivo, apoio, compreensão e a imprescindível ajuda em todas as fases deste trabalho principalmente quando da aplicação do método de Rietveld na utilização do programa GSAS.

Às instalações de microscopia eletrônica do CCTM-IPEN pela utilização de seu microscópio eletrônico de varredura, nas pessoas do Celso e Nildemar, por permitirem a operação.

À FAPESP por parte do financiamento deste trabalho.

Ao IPEN pela oportunidade concedida.

Ao pessoal do laboratório de materiais magnéticos, MsC. Edson Soares, Dr. Hidetoshi Takiishi, Dr ${ }^{\text {anda }}$ Mara, Dr ${ }^{\text {ando }}$ Élio, pelo convívio e eventuais ajudas.

Aos amigos: Dr. Cristiano S. Mucsi, MsC. Francisco José "Kiko" Breda, Dra. Marina Fuser Pillis, Dr. Jesualdo Luiz Rossi pelo incentivo e companheirismo.

À todos que direta ou indiretamente tornaram possível a realização deste trabalho. 


\title{
Estudo de Ligas e Ímãs Preparados pelo Processo Hidrogenação, Desproporção, Dessorção e Recombinação (HDDR) à Base de Pr-Fe-B com Adição de Dopantes e Elementos de Liga
}

\author{
Eguiberto Galego
}

\section{RESUMO}

A adição de elementos dopantes e elementos de liga aos magnetos permanentes policristalinos à base de terras raras tem como objetivo a melhora das propriedades magnéticas. Neste trabalho estudou-se a adição de $0,1 \%$ at. dos elementos: Ti, V, Cr, Ni, $\mathrm{Zr}$, Nb ou Mo na composição $\operatorname{Pr}_{14} \mathrm{Fe}_{\mathrm{bal}} \mathrm{Co}_{16} \mathrm{~B}_{6}$; as adições de $0,1 \%$ at., 0,3 \% at. e 0,5\% at. dos elementos $\mathrm{Al}, \mathrm{Si}, \mathrm{P}, \mathrm{Cu}$ ou $\mathrm{Ga}$ na composição $\operatorname{Pr}_{14} \mathrm{Fe}_{\mathrm{bal}} \mathrm{Co}_{16} \mathrm{~B}_{6} \mathrm{Nb}_{0,1}$; e a variação de cobalto de $0 \%$ at. até $16 \%$ at. ao sistema $\operatorname{Pr}_{2} \mathrm{Fe}_{14-\mathrm{x}} \mathrm{Co}_{\mathrm{x}} \mathrm{B}$. Através de processo HDDR (hidrogenação, desproporção, dessorção e recombinação) obteve-se pós com tamanho de grão da ordem de 200 a $300 \mathrm{~nm}$ para quase todas as composições estudadas. Os pós foram utilizados para a confecção de magnetos consolidados por cianoacrilato de baixa viscosidade. De maneira geral, a adição destes dopantes resultou no aumento ou diminuição da remanência e da coercividade intrínseca da liga quando comparadas com os valores obtidos para magnetos de referência sem adição de dopantes. Porém, não foram observadas correlações entre as composições estudadas quer quanto ao número atômico ou em relação à concentração do elemento adicionado. Os resultados obtidos com a adição de $\mathrm{Al}, \mathrm{Si}, \mathrm{P}, \mathrm{Ti}, \mathrm{V}, \mathrm{Cr}, \mathrm{Ni}, \mathrm{Cu}, \mathrm{Ga}, \mathrm{Zr}$ ou $\mathrm{Nb}$ indicaram que alguns elementos atuam como substituintes do átomo de ferro na estrutura cristalina da fase magnética dura ou como modificador da microestrutura da liga. A determinação dos parâmetros da célula unitária, as posições atômicas, os sítios de substituição do ferro pelo cobalto (fator de ocupação) para a sistema $\operatorname{Pr}_{2} \mathrm{Fe}_{14-\mathrm{x}} \mathrm{Co}_{\mathrm{x}} \mathrm{B}$ foi realizada pelo refinamento dos padrões de pó obtidos por difração de raios X pelo método de Rietveld. Estes dados foram utilizados no cálculo das 
propriedades magnéticas por ab-initio com base na teoria do funcional densidade empregando o método LAPW (linearized augmented plane wave). A comparação dos resultados teórico e experimental apresentou forte concordância mostrando que este método é importante para o estudo da adição de dopantes ao sistema Pr-Fe-Co-B. 


\title{
Study of alloys and magnets prepared by the hydrogenation, disproportionation, desorption and recombination process (HDDR) based on the Pr-Fe-B system with dopants and alloying additions
}

\author{
Eguiberto Galego
}

\begin{abstract}
The study of the additions of dopants and alloying elements on permanent magnets based on rare earth alloys has the objective the enhancement of the magnetic properties. In this work, it was studied the addition of the 0.1 at\% to the elements: $\mathrm{Ti}, \mathrm{V}, \mathrm{Cr}, \mathrm{Ni}, \mathrm{Zr}, \mathrm{Nb}$ and Mo for the composition $\operatorname{Pr}_{14} \mathrm{Fe}_{\mathrm{bal}} \mathrm{Co}_{16} \mathrm{~B}_{6}$; the addition of the 0.1 at $\%, 0.3$ at $\%$ and 0.5 at $\%$ of the elements: $\mathrm{Al}, \mathrm{Si}, \mathrm{P}, \mathrm{Cu}$ and $\mathrm{Ga}$ on the composition $\operatorname{Pr}_{14} \mathrm{Fe}_{\mathrm{bal}} \mathrm{Co}_{16} \mathrm{~B}_{6} \mathrm{Nb}_{0.1}$; and the cobalt in the range 0 to 16 at $\%$ for the $\operatorname{Pr}_{2} \mathrm{Fe}_{14-\mathrm{x}} \mathrm{Co}_{\mathrm{x}} \mathrm{B}$ system. The hydrogenation, disproportionation, desorption and recombination process was used to produce powders with crystalline size around 200 at $300 \mathrm{~nm}$ to almost all the composition studied. These alloys were used to prepare magnets consolidated with low viscosity cyanoacrylato adhesive. In general, the addition of these dopants enhanced or diminished the magnetic properties when compared to the values of the reference magnets without addition of dopants. Nevertheless, it has not been observed correlations between the compositions studied and the atomic number or concentration of the added element. The results obtained with addition of the $\mathrm{Al}, \mathrm{Si}, \mathrm{P}, \mathrm{Ti}, \mathrm{V}, \mathrm{Cr}, \mathrm{Ni}, \mathrm{Cu}, \mathrm{Ga}, \mathrm{Zr}$ or $\mathrm{Nb}$ indicate that these some elements substitutes of the $\mathrm{Fe}$ in the crystalline structure of the hard magnetic phase or modify the alloy microstructure. The determination of the lattice parameters, atomic positions, sites of the substitution of $\mathrm{Co}$ (occupation factor) for $\mathrm{Fe}$ in the $\operatorname{Pr}_{2} \mathrm{Fe}_{14-\mathrm{x}} \mathrm{Co}_{\mathrm{x}} \mathrm{B}$ system was carried out by Rietveld refinement of the powder diffraction X-ray patterns.
\end{abstract}


Rietveld refinement data was used in the calculation of the magnetic properties by the $a b$ initio based on density functional theory employing the linearized-argumented-plane-wave (LAPW) method. The agreement between the theoretical and experimental results showed that this method is important for the study of the addition of dopants in the Pr-Fe-Co-B system. 


\section{ÍNDICE DE TABELAS}

TABELA 3.1 - Coordenadas atômicas (x,y,z) dos átomos da fase $\operatorname{Pr}_{2} \mathrm{Fe}_{14} \mathrm{~B}$ em unidades dos parâmetros de rede a = 8,796(1) $\AA$ e c = 12.228(1) $\AA$ (adaptada de Herbst e Yelon, 1986).

TABELA 3.2 - Efeitos das variáveis do processo HDDR (adaptada de Gutfleisch, 1996).

TABELA 3.3 - Porcentagem de ocupação do hidrogênio nos diferentes sítios intersticiais (não equivalentes) para os diferentes compostos $\mathrm{Nd}_{2} \mathrm{Fe}_{14} \mathrm{BH}_{\mathrm{x}}$, onde $\mathrm{x}=1,2,3$ e 4 (adaptada de Isnard et al., 1995)

TABELA 3.4 - Parâmetros de rede $(a$ e $c$ ), volume da célula unitária $(v)$ e variação do volume por átomo de hidrogênio absorvido no $\mathrm{Nd}_{2} \mathrm{Fe}_{14} \mathrm{BH}_{\mathrm{x}}$ (adaptada de Isnard, 1995)

TABELA 3.5 - Temperatura de Curie $\left(\mathrm{T}_{\mathrm{C}}\right)$ para as ligas $\operatorname{Pr}_{14} \mathrm{Fe}_{79,9-\mathrm{x}} \mathrm{Co}_{\mathrm{x}} \mathrm{B}_{6} \mathrm{Nb}_{0,1}$ com $\mathrm{x}=0$, 4, 8, 12, 16 (adaptada de Barbosa, 2005).

TABELA 3.6 - Valores de magnetização de saturação, do campo de anisotropia e temperatura de Curie (adaptada de Jurczyr e Chistjakov, 1989)

TABELA 3.7 - Valores obtidos para ligas $\mathrm{Nd}_{2}(\mathrm{Fe}, \mathrm{Co}, \mathrm{M}){ }_{14} \mathrm{~B}$ processadas por HDDR (adaptada de Jin et al., 2003).

TABELA 4.1 - Composição química em \% em massa, fornecida pelo fabricante, para as ligas $\operatorname{Pr}_{14} \mathrm{Fe}_{\mathrm{bal}} \mathrm{Co}_{16} \mathrm{~B}_{6} \mathrm{M}_{0.1} \quad(\mathrm{M}=\mathrm{Ti}, \mathrm{V}, \mathrm{Cr}, \mathrm{Ni}, \mathrm{Zr}, \mathrm{Nb}$ ou $\mathrm{Mo})$.

TABELA 4.2 - Composição química em \% massa, fornecida pelo fabricante, para as ligas $\mathrm{Pr}_{14} \mathrm{Fe}_{\mathrm{bal}} \mathrm{Co}_{16} \mathrm{~B}_{6} \mathrm{Nb}_{0,1} \mathrm{X}_{0.1}(\mathrm{X}=\mathrm{Al}, \mathrm{Si}, \mathrm{P}, \mathrm{Cu}$ ou $\mathrm{Ga})$

TABELA 4.3 - Composição química em \% massa, fornecida pelo fabricante, para as ligas $\mathrm{Pr}_{14} \mathrm{Fe}_{\mathrm{bal}} \mathrm{Co}_{16} \mathrm{~B}_{6} \mathrm{Nb}_{0,1} \mathrm{X}_{0,3}(\mathrm{X}=\mathrm{Al}, \mathrm{Si}, \mathrm{P}, \mathrm{Cu}$ ou $\mathrm{Ga})$

TABELA 4.4 - Composição química em \% massa, fornecida pelo fabricante, para as ligas $\mathrm{Pr}_{14} \mathrm{Fe}_{63.6} \mathrm{Co}_{16} \mathrm{~B}_{6} \mathrm{Nb}_{0,1} \mathrm{X}_{, .5}(\mathrm{X}=\mathrm{Al}, \mathrm{Si}, \mathrm{P}, \mathrm{Cu}$ ou $\mathrm{Ga})$

TABELA 4.5 - Composição química em \% massa, fornecida pelo fabricante, para as ligas com variação de cobalto.

TABELA 4.6 - Parâmetros do anel de armazenamento de elétrons do LNLS. 57

TABELA 4.7 - Variáveis de processamento adotadas no cálculo teórico.

TABELA 5.1 - Propriedades magnéticas das ligas $\operatorname{Pr}_{14} \mathrm{Fe}_{\mathrm{bal}_{1}} \mathrm{Co}_{16} \mathrm{~B}_{6} \mathrm{M}_{0,1}$ onde $\mathrm{M}$ representa o elemento adicionado.

TABELA 5.2 - Valores dos desvios da remanência e coercividade intrínseca em relação à liga de referência $\operatorname{Pr}_{14} \mathrm{Fe}_{\mathrm{bal}} \mathrm{Co}_{16} \mathrm{~B}_{6}$ - isotrópico (iso.) e anisotrópico (anis.) 
TABELA 5.3 - Propriedades magnéticas das ligas $\operatorname{Pr}_{14} \mathrm{Fe}_{\mathrm{bal}} \mathrm{Co}_{16} \mathrm{~B}_{6} \mathrm{Nb}_{0,1} \mathrm{X}_{0,1}$ onde $\mathrm{X}$ representa o elemento dopante adicionado.

TABELA 5.4 - Propriedades magnéticas das ligas $\operatorname{Pr}_{14} \mathrm{Fe}_{\mathrm{bal}_{1}} \mathrm{Co}_{16} \mathrm{~B}_{6} \mathrm{Nb}_{0,1} \mathrm{X}_{0,3}$ onde $\mathrm{X}$ representa o elemento dopante adicionado.

TABELA 5.5 - Propriedades magnéticas das ligas $\operatorname{Pr}_{14} \mathrm{Fe}_{\mathrm{bal}} \mathrm{Co}_{16} \mathrm{~B}_{6} \mathrm{Nb}_{0,1} \mathrm{X}_{0,5}$ onde $\mathrm{X}$ representa o elemento dopante adicionado.

TABELA 5.6 - Valores de desvio da remanência e coercividade intrínseca em relação à liga de $\operatorname{Pr}_{14} \mathrm{Fe}_{\text {bal }} \mathrm{Co}_{16} \mathrm{~B}_{6} \mathrm{Nb}_{0,1}$

TABELA 5.7 - Propriedades magnéticas para os magnetos com variação de cobalto obtidas no permeâmetro da LDJ

TABELA 5.8 - Propriedades magnéticas das ligas com variação de cobalto obtido no MAV

TABELA 5.9 - Parâmetros de rede obtidos para ligas com variação de cobalto.

TABELA 5.10 - Posição dos átomos não equivalentes para fase magnética $\operatorname{Pr}_{8} \mathrm{Fe}_{56-\mathrm{x}} \mathrm{Co}_{\mathrm{x}} \mathrm{B}_{4}$ na liga $\operatorname{Pr}_{14} \mathrm{Fe}_{\text {bal }} \mathrm{B}_{6} \mathrm{Nb}_{0,1}$

TABELA 5.11 - Posição dos átomos não equivalentes para fase magnética $\operatorname{Pr}_{8} \mathrm{Fe}_{56-\mathrm{x}} \mathrm{Co}_{\mathrm{x}} \mathrm{B}_{4}$ na liga $\operatorname{Pr}_{14} \mathrm{Fe}_{\mathrm{bal}} \mathrm{Co}_{4} \mathrm{~B}_{6} \mathrm{Nb}_{0,1}$

TABELA 5.12 - Posição dos átomos não equivalentes para fase magnética $\operatorname{Pr}_{8} \mathrm{Fe}_{56-\mathrm{x}} \mathrm{Co}_{\mathrm{x}} \mathrm{B}_{4}$ na liga $\operatorname{Pr}_{14} \mathrm{Fe}_{\mathrm{bal}} \mathrm{Co}_{8} \mathrm{~B}_{6} \mathrm{Nb}_{0,1}$

TABELA 5.13 - Posição dos átomos não equivalentes para fase magnética $\operatorname{Pr}_{8} \mathrm{Fe}_{56-\mathrm{x}} \mathrm{Co}_{\mathrm{x}} \mathrm{B}_{4}$ na liga $\operatorname{Pr}_{14} \mathrm{Fe}_{\text {bal }} \mathrm{Co}_{12} \mathrm{~B}_{6} \mathrm{Nb}_{0,1}$

TABELA 5.14 - Posição dos átomos não equivalentes para fase magnética $\operatorname{Pr}_{8} \mathrm{Fe}_{56-\mathrm{x}} \mathrm{Co}_{\mathrm{x}} \mathrm{B}_{4}$ na liga $\operatorname{Pr}_{14} \mathrm{Fe}_{\text {bal }} \mathrm{Co}_{16} \mathrm{~B}_{6} \mathrm{Nb}_{0,1}$

TABELA 5.15 - Distâncias interatômicas entre o átomo base e seu(s) vizinho(s) para fase magnética $\operatorname{Pr}_{8} \mathrm{Fe}_{56-\mathrm{x}} \mathrm{Co}_{\mathrm{x}} \mathrm{B}_{4}$ para a liga $\mathrm{Pr}_{14} \mathrm{Fe}_{\mathrm{bal}} \mathrm{B}_{6} \mathrm{Nb}_{0,1}$.

TABELA 5.16 - Distâncias interatômicas entre o átomo base e seu(s) vizinho(s) para fase magnética $\mathrm{Pr}_{8} \mathrm{Fe}_{56-\mathrm{x}} \mathrm{Co}_{\mathrm{x}} \mathrm{B}_{4}$ para a liga $\mathrm{Pr}_{14} \mathrm{Fe}_{\text {bal }} \mathrm{Co}_{4} \mathrm{~B}_{6} \mathrm{Nb}_{0,1}$

TABELA 5.17 - Distâncias interatômicas entre o átomo base e seu(s) vizinho(s) para fase magnética $\mathrm{Pr}_{8} \mathrm{Fe}_{56-\mathrm{x}} \mathrm{Co}_{\mathrm{x}} \mathrm{B}_{4}$ para a liga $\mathrm{Pr}_{14} \mathrm{Fe}_{\mathrm{bal}} \mathrm{Co}_{8} \mathrm{~B}_{6} \mathrm{Nb}_{0,1}$

TABELA 5.18 - Distâncias interatômicas entre o átomo base e seu(s) vizinho(s) para fase magnética $\operatorname{Pr}_{8} \mathrm{Fe}_{56-\mathrm{x}} \mathrm{Co}_{\mathrm{x}} \mathrm{B}_{4}$ para a liga $\operatorname{Pr}_{14} \mathrm{Fe}_{\mathrm{bal}} \mathrm{Co}_{12} \mathrm{~B}_{6} \mathrm{Nb}_{0,1}$

TABELA 5.19 - Distâncias interatômicas entre o átomo base e seu(s) vizinho(s) para fase magnética $\operatorname{Pr}_{8} \mathrm{Fe}_{56-\mathrm{x}} \mathrm{Co}_{\mathrm{x}} \mathrm{B}_{4}$ para a liga $\operatorname{Pr}_{14} \mathrm{Fe}_{\text {bal }} \mathrm{Co}_{16} \mathrm{~B}_{6} \mathrm{Nb}_{0,1}$ 
TABELA 5.20 - Fator de ocupação (F.O.) e fração de átomos (F.A.) para os sítios não equivalentes da fase magnética $\mathrm{Pr}_{8} \mathrm{Fe}_{56-\mathrm{x}} \mathrm{Co}_{\mathrm{x}} \mathrm{B}_{4}$ para as ligas

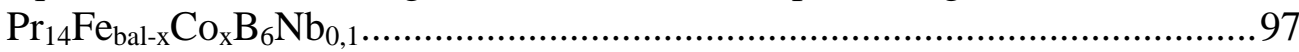

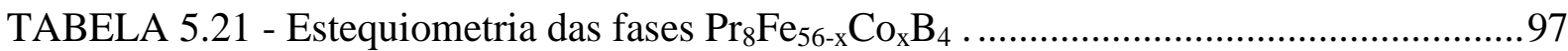

TABELA 5.22 - Tamanho do cristalito obtido pelo refino da estrutura cristalina da fase magneticamente dura pelo método de Rietveld, onde: \|| é a dimensão paralela e $\perp$ é a dimensão ortogonal em relação ao plano basal da estrutura cristalina........................................................................ 98

TABELA 5.23 - Números de átomos utilizados em cada sítio no cálculo teórico. .99 


\section{ÍNDICE DE FIGURAS}

FIGURA 1.1 - Resumo dos processos envolvidos na manufatura de magnetos consolidados por adesão (adaptada de Coey e O’Donnell,1997).

FIGURA 3.1 - Curvas de desmagnetização para os compostos $\mathrm{TR}_{13,5} \mathrm{Fe}_{80,9} \mathrm{~B}_{5,6}$ (adaptada de Croat et al., 1984)

FIGURA 3.2 - Diagrama de fase da liga Pr-Fe-B no corte isométrico na razão entre Pr:B de 2:1. A seta $A$ indica a fase $\varnothing$ coincidente com os valores de: $82,3 \%$ at. para o Fe; $11,8 \%$ at. para o $\operatorname{Pr}$ e 5,9\% at. para o B. Estes valores são equivalentes à estequiometria da célula básica $\operatorname{Pr}_{2} \mathrm{Fe}_{14} \mathrm{~B}$ (adaptada Neiva et al., 1995).

FIGURA 3.3 - Célula unitária da fase $\mathrm{Nd}_{2} \mathrm{Fe}_{14} \mathrm{~B}$ onde, por isomorfismo troca-se o átomo de $\mathrm{Nd}$ pelo Pr. A razão c/a na figura está exagerada para enfatizar o emaranhado da rede hexagonal dos átomos de Fe (adaptada de Herbst et al., 1984).

FIGURA 3.4 - (a) Projeção do plano basal e da primeira camada de átomos de Fe em z 1/6; (b) Projeção das três camadas de Fe entre o plano basal e z = 1/2; (c) Projeção da primeira camada de Fe e das camadas vizinhas de $\mathrm{Fe}\left(j_{2}\right)$ em z 1/4 (adaptada de Herbst, 1991).

FIGURA 3.5 - Prisma trigonal contendo um átomo de B na estrutura do $\operatorname{Pr}_{2} \mathrm{Fe}_{14} \mathrm{~B}$ (adaptada de Herbst, 1991).

FIGURA 3.6 - Ciclo térmico do processo HDDR.

FIGURA 3.7 - Curvas de desmagnetização de amostras desproporcionadas em diversos intervalos de tempo (adaptada de Ragg et al., 1997)

FIGURA 3.8 - Curvas de desmagnetização de amostras desproporcionadas em diversas pressões por 2 horas (adaptada de Ragg et al., 1997).

FIGURA 3.9 - Dependência de $\mathrm{T}_{\mathrm{C}}$ com a composição química $\mathrm{Nd}_{2} \mathrm{Fe}_{14-\mathrm{x}} \mathrm{M}_{\mathrm{x}} \mathrm{B}$, onde $M$ representa um átomo metálico (adaptada de Burzo, 1998).

FIGURA 3.10 - Variação dos parâmetros de rede com a concentração de Co no composto $\mathrm{Pr}_{2} \mathrm{Fe}_{14-\mathrm{x}} \mathrm{Co}_{\mathrm{x}} \mathrm{B}$ (adaptada de Pedziwiatr et al., 1986a)

FIGURA 3.11 - Comportamento da magnetização de saturação e do campo de anisotropia em função da concentração de Co para o composto $\operatorname{Pr}_{2} \mathrm{Fe}_{14-\mathrm{x}} \mathrm{Co}_{\mathrm{x}} \mathrm{B}$ (adaptada de Pedziwiatr et al., 1986a).

FIGURA 3.12 - Variação dos parâmetros de rede com a concentração de Co no composto $\mathrm{Pr}_{2} \mathrm{Fe}_{14-\mathrm{x}} \mathrm{Co}_{\mathrm{x}} \mathrm{B}$ (adaptada de Bolzoni et al., 1987a) 
FIGURA 3.13 - Comportamento a magnetização de saturação em função da concentração de Co para o composto $\operatorname{Pr}_{2} \mathrm{Fe}_{14-\mathrm{x}} \mathrm{Co}_{\mathrm{x}} \mathrm{B}$ (adaptada de Bolzoni et al., 1987a).

FIGURA 3.14 - Propriedades magnéticas das ligas $\operatorname{Pr}_{14} \mathrm{Fe}_{79,9-\mathrm{x}} \mathrm{Co}_{\mathrm{x}} \mathrm{B}_{6} \mathrm{Nb}_{0,1}$, onde $\mathrm{x}$ representa a concentração de Co em porcentagem atômica substituta ao Fe para $\mathrm{x}=0,4,8,12$ e 16 (adaptada de Barbosa, 2005).

FIGURA 3.15 - Dependência dos parâmetros de rede da célula unitária com a concentração de elementos substituintes ao átomo de $\mathrm{Fe}$ na fase $\mathrm{Pr}_{2} \mathrm{Fe}_{14} \mathrm{~B}$ (adaptada de Kowalczik, 1989).

FIGURA 3.16 - Efeito da composição química sobre a $T_{C}$ da fase magnética $\operatorname{Pr}_{2} \mathrm{Fe}_{14} \mathrm{~B}$ (adaptada de Kowalczik, 1989).

FIGURA 3.17 - Variação do parâmetro de rede $a$ e $c$ para as ligas processadas (adaptada Jurczyk e Chisjakov, 1989).

FIGURA 3.18 - Padrões de difração de raios $\mathrm{X}$ obtidos para liga $\mathrm{Nd}_{12,5} \mathrm{Fe}_{70-\mathrm{x}} \mathrm{Co}_{11,5} \mathrm{Ga}_{\mathrm{x}} \mathrm{B}_{6}$ para $x=0,1,2,3,4$ ou 5 , hidrogenadas a $874{ }^{\circ} \mathrm{C}$ por $1 \mathrm{~h}$ (adaptada de Uehara et al., 1993).

FIGURA 3.19 - Mecanismo de nucleação e crescimento da fase Nb-Fe-B(adaptada Ahmed et al., 1994)

FIGURA 3.20 - Curvas de magnetização de amostras anisotrópicas produzidas por HDDR (adaptada de Takeshita e Morimoto, 1996)

FIGURA 3.21 - Dependência do campo de anisotropia com a temperatura (adaptada de Kou et al., 1991b e Grössinger et al., 1990a).

FIGURA 3.22 - Dependência da expansão térmica com a temperatura para o $\mathrm{Lu}_{2} \mathrm{Fe}_{14} \mathrm{~B}$ e o $\mathrm{Lu}_{2} \mathrm{Fe}_{14} \mathrm{C}$ (adaptada de Kou et al, 1991b).

FIGURA 3.23 - Redução do campo de anisotropia em função da composição química para compostos $\mathrm{TR}_{2} \mathrm{Fe}_{14-\mathrm{x}} \mathrm{M}_{\mathrm{x}} \mathrm{B}$, com TR $=\mathrm{Y}$ e Nd (adaptada de Burzo, 1998).....47

FIGURA 4.1 - Micrografias típicas obtidas por microscopia eletrônica de varredura (MEV) por detector de elétrons retro-espalhados no estado: (a) como recebida e (b) homogeneizada após tratamento térmico à $1100{ }^{\circ} \mathrm{C}$ por $20 \mathrm{~h}$. As fases foram identificadas nas micrografias por dispersão de energia (energy dispersion spectrometer, EDS).

FIGURA 4.2 - Sistema HDDR utilizado neste trabalho, onde: 1 - conjunto forno controlado e retorta; 2 - bomba de vácuo e sistema de manipulação de atmosfera da retorta; 3 - cilindro de gás hidrogênio e regulador (adaptada de Takiishi, 2001).

FIGURA 4.3 - Linha D10B XPD: (a) detalhe do goniômetro Huber; (b) vista geral. .57

FIGURA 4.4 - Fluxograma de pré-processamento do Wien2k. 
FIGURA 4.5 - Fluxograma do programa principal de cálculo (adaptada Blara et al., $2001)$

FIGURA 5.1 - Gráfico da variação da remanência $\Delta \mathrm{B}_{\mathrm{r}}$ relativo aos magnetos isotrópico e anisotrópico em função ao elemento dopante $(\mathrm{Z})$ adicionado.

FIGURA 5.2 - Gráfico da variação da coercividade intrínseca $\Delta_{\mathrm{i}} \mathrm{H}_{\mathrm{c}}$ relativo aos magnetos isotrópico e anisotrópico em função ao elemento $(\mathrm{Z})$ dopante adicionado.

FIGURA 5.3 - Micrografias de fratura do grão dos materiais processados por HDDR das ligas $\operatorname{Pr}_{14} \mathrm{Fe}_{\mathrm{bal}} \mathrm{Co}_{16} \mathrm{~B}_{6} X_{0,1}$ onde (a) $X=\mathrm{Ti}$;(b) $X=\mathrm{V}$; (c) $X=\mathrm{Cr}$; (d) $X=\mathrm{Ni}$

FIGURA 5.4 - Micrografia de fratura do grão das ligas processadas por HDDR:

(a) $\mathrm{Pr}_{14} \mathrm{Fe}_{\text {bal }} \mathrm{Co}_{16} \mathrm{~B}_{6} \mathrm{Nb}_{0,1}$; (b) $\operatorname{Pr}_{14} \mathrm{Fe}_{\text {bal }} \mathrm{Co}_{16} \mathrm{~B}_{6}$

FIGURA 5.5 - Micrografia da fratura do grão do material processado por HDDR da liga $\mathrm{Pr}_{14} \mathrm{Fe}_{\mathrm{bal}} \mathrm{Co}_{16} \mathrm{~B}_{6} \mathrm{Zr}_{0,1}$

FIGURA 5.6 - Micrografia da fratura do grão do material processado por HDDR da liga $\mathrm{Pr}_{14} \mathrm{Fe}_{\mathrm{bal}} \mathrm{Co}_{16} \mathrm{~B}_{6} \mathrm{Mo}_{0,1}$

FIGURA 5.7 - Gráfico da variação da remanência $\left(\Delta \mathrm{B}_{\mathrm{r}}\right)$ em comparação com a liga base. As variações quanto a quantidade adicionada estão indicadas por cores: $0,1 \%$ at. (vermelho), $0,3 \%$ at. (verde) e $0,5 \%$ at (azul).

FIGURA 5.8 - Gráfico da variação da coercividade intrínseca $\left(\Delta_{\mathrm{i}} \mathrm{H}_{\mathrm{c}}\right)$ em comparação com a liga base. As variações quanto a quantidade adicionada estão indicadas por cores: $0,1 \%$ at. (vermelho), $0,3 \%$ at. (verde) e $0,5 \%$ at. (azul).

FIGURA 5.9 - Micrografia da fratura do grão das ligas processadas por HDDR $\mathrm{Pr}_{14} \mathrm{Fe}_{\text {bal }} \mathrm{Co}_{16} \mathrm{~B}_{6} \mathrm{Nb}_{0,1} \mathrm{Al}_{\mathrm{x}}$, onde $\mathrm{x}=$ (a) $0,1 \%$ at.; (b) $0,3 \%$ at.; (c) $0,5 \%$ at. ....74

FIGURA 5.10 - Micrografia da fratura do grão das ligas processado por HDDR $\operatorname{Pr}_{14} \mathrm{Fe}_{\text {bal }} \mathrm{Co}_{16} \mathrm{~B}_{6} \mathrm{Nb}_{0,1} \mathrm{Si}_{\mathrm{x}}$, onde $\mathrm{x}=$ (a) $0,1 \%$ at.;(b) $0,3 \%$ at.; (c) $0,5 \%$ at...... 75

FIGURA 5.11 - Micrografia da fratura do grão das ligas processadas por HDDR $\mathrm{Pr}_{14} \mathrm{Fe}_{\text {bal }} \mathrm{Co}_{16} \mathrm{~B}_{6} \mathrm{Nb}_{0,1} \mathrm{P}_{\mathrm{x}}$, onde $\mathrm{x}=$ (a) $0,1 \%$ at.; (b) $0,3 \%$ at. e (c) $0,5 \%$ at...76

FIGURA 5.12 - Micrografia da fratura do grão das ligas processadas por HDDR

(a) $\operatorname{Pr}_{14} \mathrm{Fe}_{\text {bal }} \mathrm{Co}_{16} \mathrm{~B}_{6} \mathrm{Nb}_{0,1}$ (b) $\operatorname{Pr}_{14} \mathrm{Fe}_{\text {bal }} \mathrm{Co}_{16} \mathrm{~B}_{6} \mathrm{Nb}_{0,1} \mathrm{Cu}_{0,1}$ .77

FIGURA 5.13 - Micrografia da fratura do grão das ligas processadas por HDDR $\mathrm{Pr}_{14} \mathrm{Fe}_{\text {bal }} \mathrm{Co}_{16} \mathrm{~B}_{6} \mathrm{Nb}_{0,1} \mathrm{Cu}_{\mathrm{x}}$, onde $\mathrm{x}=$ (a) $0,3 \%$ at.; (b) $0,5 \%$ at. .77

FIGURA 5.14 - Micrografia da fratura do grão das ligas processadas por HDDR $\operatorname{Pr}_{14} \mathrm{Fe}_{\text {bal }} \mathrm{Co}_{16} \mathrm{~B}_{6} \mathrm{Nb}_{0,1} \mathrm{Ga}_{\mathrm{x}}$, onde $\mathrm{x}=$ (a) $0,1 \%$ at.; (b) $0,3 \%$ at. e (c) $0,5 \%$ at 78

FIGURA 5.15 - Curvas de histerese da liga $\operatorname{Pr}_{14} \mathrm{Fe}_{\text {bal }} \mathrm{B}_{6} \mathrm{Nb}_{0,1}$ nas temperatura: (a) 4,2 $\mathrm{K}$ e (b) $300 \mathrm{~K}$.

FIGURA 5.16 - Curvas de histerese da liga $\operatorname{Pr}_{14} \mathrm{Fe}_{\mathrm{bal}} \mathrm{Co}_{4} \mathrm{~B}_{6} \mathrm{Nb}_{0,1}$ nas temperatura: (a) 4,2 $\mathrm{K}$ e (b) $300 \mathrm{~K}$. 
FIGURA 5.17 - Curvas de histerese da liga $\operatorname{Pr}_{14} \mathrm{Fe}_{\text {bal }} \mathrm{Co}_{8} \mathrm{~B}_{6} \mathrm{Nb}_{0,1}$ nas temperatura: (a) 4,2 $\mathrm{K}$ e (b) $300 \mathrm{~K}$.

FIGURA 5.18 - Curvas de histerese da liga $\operatorname{Pr}_{14} \mathrm{Fe}_{b_{b a l}} \mathrm{Co}_{12} \mathrm{~B}_{6} \mathrm{Nb}_{0,1}$ nas temperatura: (a) 4,2 $\mathrm{K} \mathrm{e} \mathrm{(b)} 300 \mathrm{~K}$.

FIGURA 5.19 - Curvas de histerese da liga $\operatorname{Pr}_{14} \mathrm{Fe}_{\mathrm{bal}} \mathrm{Co}_{16} \mathrm{~B}_{6} \mathrm{Nb}_{0,1} \mathrm{n}$ as temperatura: (a) $4,2 \mathrm{~K}$ e (b) $300 \mathrm{~K}$

FIGURA 5.20 - Gráficos da remanência (a) e da coercividade intrínseca (b) para as ligas em função da variação de Co

FIGURA 5.21 - Gráficos dos refinamentos da amostra $\operatorname{Pr}_{14} \mathrm{Fe}_{\mathrm{bal}} \mathrm{B}_{6} \mathrm{Nb}_{0,1}$ - (a) $7 \mathrm{keV}$ e

(b) $8 \mathrm{keV}$.

FIGURA 5.22 - Gráficos dos refinamentos da amostra $\operatorname{Pr}_{14} \mathrm{Fe}_{\mathrm{bal}} \mathrm{Co}_{4} \mathrm{~B}_{6} \mathrm{Nb}_{0,1}$ - (a) $7 \mathrm{keV}$ e (b) $8 \mathrm{keV}$

FIGURA 5.23 - Gráficos dos refinamentos da amostra $\operatorname{Pr}_{14} \mathrm{Fe}_{\mathrm{bal}} \mathrm{Co}_{8} \mathrm{~B}_{6} \mathrm{Nb}_{0,1}$ - (a) $7 \mathrm{keV}$ e (b) $8 \mathrm{keV}$.

FIGURA 5.24 - Gráficos dos refinamentos da amostra $\operatorname{Pr}_{14} \mathrm{Fe}_{\mathrm{bal}} \mathrm{Co}_{12} \mathrm{~B}_{6} \mathrm{Nb}_{0,1}$ - (a) $7 \mathrm{keV}$ e (b) $8 \mathrm{keV}$.

FIGURA 5.24 - Gráficos dos refinamentos da amostra $\operatorname{Pr}_{14} \mathrm{Fe}_{\mathrm{bal}} \mathrm{Co}_{18} \mathrm{~B}_{6} \mathrm{Nb}_{0,1}$ - (a) $7 \mathrm{keV}$ e (b) $8 \mathrm{keV}$

FIGURA 5.26 - Variação dos parâmetros de rede das ligas com variação de Co. .89

FIGURA 5.27 - Gráfico da variação do momento magnético por átomo em cada sítio não equivalente em função da variação da concentração de Co (x).

FIGURA 5.28 - Gráfico da magnetização total em função variação da concentração do Co. 


\section{SUMÁRIO}

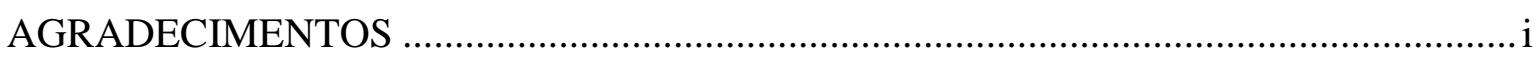

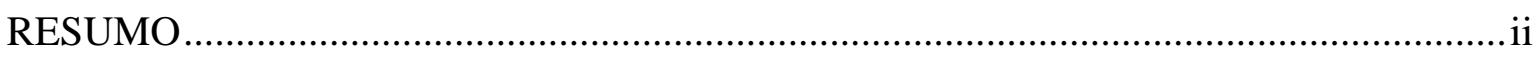

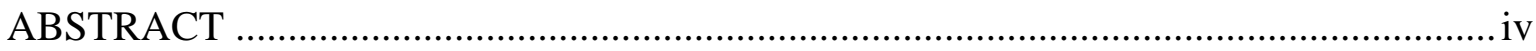

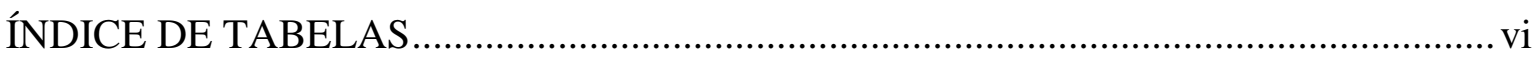

ÍNDICE DE FIGURAS ……………………………………...................................

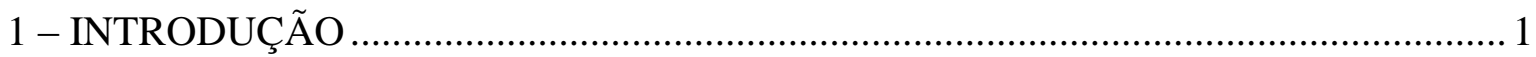

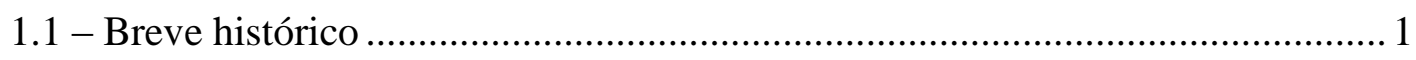

1.2 - Preparação dos pós magnéticos........................................................................ 2

1.3 - Imãs consolidados por adesão e suas características. ........................................ 4

1.4 - Substituição química e adição de dopantes.......................................................... 6

1.5 - Aplicações .................................................................................................

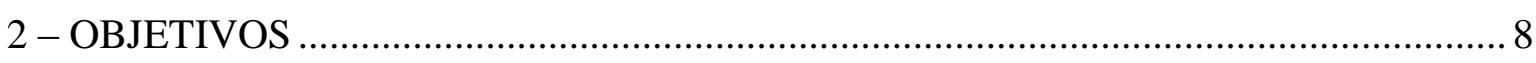

3 - REVISÃO BIBLIOGRAFICA. .........................................................................

3.1 - Materiais magnéticos a base de TR-Fe-B ………………………………………..... 9

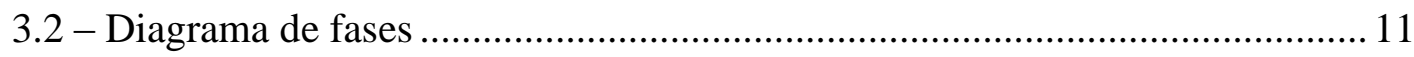

3.3 - Estrutura cristalina e características magnéticas do $\mathrm{TR}_{2} \mathrm{Fe}_{14} \mathrm{~B}$....................... 13

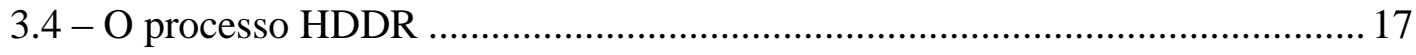

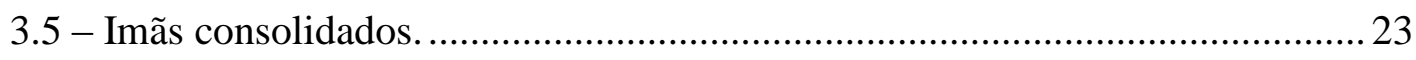

3.6 - Compostos $\mathrm{TR}_{2} \mathrm{Fe}_{14} \mathrm{~B}$ multielementares em substituição ao $\mathrm{Fe}$.........................24

3.7 - Adição de dopantes e elementos de liga. …………………………………….... 31

3.8 - A questão da anisotropia............................................................................ 43

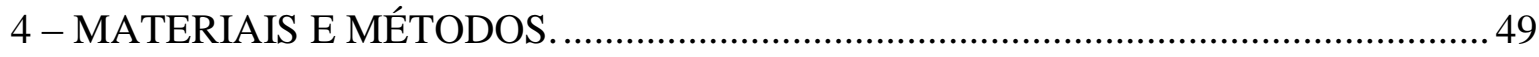

4.1 - Composição química das ligas......................................................................... 49

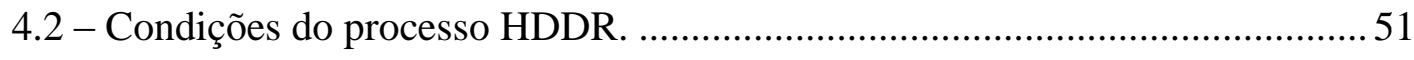

4.3 - Confecções dos magnetos consolidados ............................................................5 54 
4.4 - Caracterização das propriedades magnéticas................................................ 54

4.5 - Preparação das amostras para microscopia.................................................. 55

4.6 - Análises por difração de raios X.............................................................. 55

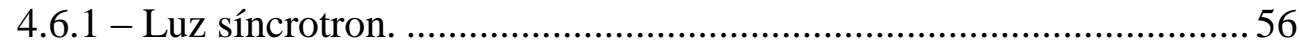

4.6.2 - Análise pelo método de Rietveld. ................................................ 58

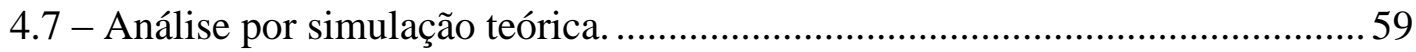

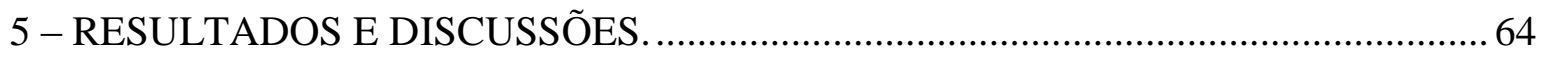

5.1 - Adição de 0,1\% atômico dos elementos dopantes à liga Pr-Fe-Co-B. ........... 64

5.1.1 - O efeito da adição do Ti, V, Cr ou Ni............................................ 66

5.1.2 - O efeito da adição do Zr, Nb ou Mo ............................................. 68

5.2 - Adição de $0,1 \%, 0,3 \%$ e $0,5 \%$ atômico dos elementos dopantes à liga

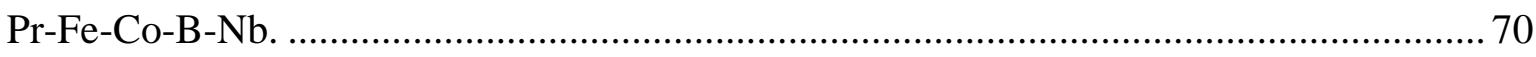

5.2.1 - O efeito da adição Al, Si ou P................................................... 73

5.2.2 - O efeito da adição do $\mathrm{Cu}$ ou $\mathrm{Ga}$.................................................. 76

5.3 - Adição de Co à liga Pr-Fe-B-Nb ................................................................. 78

5.3.1 - Medidas magnéticas das ligas com variação de Co........................ 78

5.3.2 - Determinação dos parâmetros cristalográficos. .............................. 83

5.3.3 - Alargamento devido ao tamanho da partícula (cristalito)............... 98

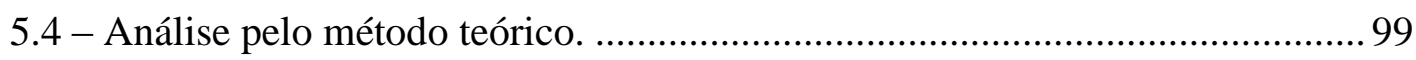

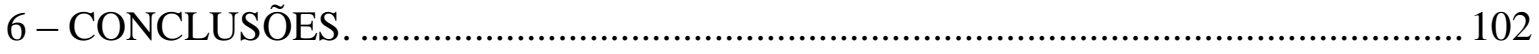

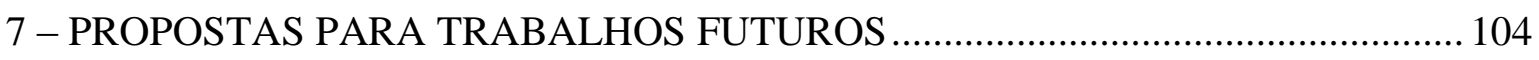

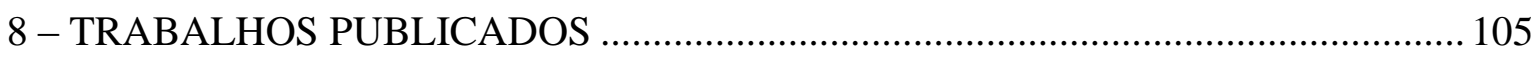

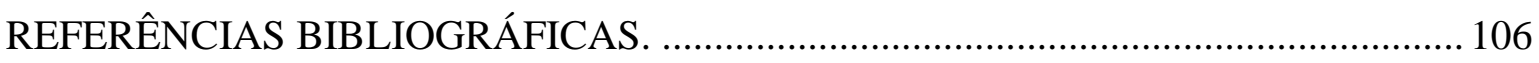




\section{1 - INTRODUÇÃO}

\section{1 - Breve histórico}

A partir do final do século 19, houve um crescimento no estudo de materiais utilizados como ímãs permanentes. Inicialmente estes ímãs foram fabricados com açocarbono, passando por ALNICO (liga de alumínio - níquel - cobalto) e pelas ferrites. A partir do início da década de 1970 chegou-se ao desenvolvimento dos ímãs baseados na combinação dos elementos da família das terras-raras (TR) com metais de transição (M). Os autores Strnat et al. (1967) estudaram as propriedades do composto $\mathrm{YCo}_{3}$ para confecção de ímãs permanentes. Na seqüência, outros pesquisadores desenvolveram ímãs a base de $\mathrm{SmCo}_{5}$ onde o produto de energia $(\mathrm{BH})_{\text {máx. }}$ medido é da ordem de $160 \mathrm{~kJ} / \mathrm{m}^{3}$. A produção de ímãs com esta composição cresceu continuamente com ampla aplicação na indústria e afins. Por serem o samário e o cobalto pouco abundantes (e este último também ser um elemento estratégico de alto custo), tornou-se relevante o desenvolvimento de um material alternativo para confecção de ímãs com um produto de energia da ordem do $\mathrm{SmCo}_{5}$.

Um material alternativo estava disponível para estudo, as ligas do composto binário TR-Fe, onde o uso de TR mais leves (TRL), como praseodímio e o neodímio, seria mais conveniente devido a maior abundância na crosta terrestre. Os compostos binários TRL-Fe apresentam maiores valores de magnetização de saturação devido ao acoplamento ferromagnético dos elementos desta fase binária e a ação do campo cristalino da estrutura onde é esperada uma anisotropia magnetocristalina, uma vez que a TRL carrega o momento orbital do composto (Cullity, 1972). Porém, este composto binário magnético apresenta alguns problemas: a temperatura de Curie $\left(\mathrm{T}_{\mathrm{C}}\right)$ é muito baixa para aplicação tecnológica (por exemplo, os compostos de $\mathrm{TRL}_{2} \mathrm{Fe}_{17}$ possui $\mathrm{T}_{\mathrm{C}}$ próxima a temperatura ambiente); formam poucas fases intermetálicas estáveis e das que formam nenhuma 
apresenta anisotropia magnetocristalina (Cullity, 1972). Assim mesmo, os estudos prosseguiram pois havia a possibilidade de se conseguir um composto com boas propriedades magnéticas, com aumento da $\mathrm{T}_{\mathrm{C}}$ e a formação de fases intermetálicas estáveis adicionando-se um ou mais elementos ao composto TRL-Fe.

No ano de 1983, Sagawa et al (1984) e Croat et al. (1984) comunicaram a descoberta de um novo material para ímãs permanentes duros baseados nos elementos neodímio, ferro e boro formando um composto estável e com $\mathrm{T}_{\mathrm{C}}$ aceitável para sua aplicabilidade. A fase magnética principal deste composto intermetálico é a $\mathrm{Nd}_{2} \mathrm{Fe}_{14} \mathrm{~B}$ em sua fórmula reduzida, tendo estrutura tetragonal e anisotropia magnetocristalina uniaxial ortogonal ao plano basal (paralelo ao eixo $c$ da estrutura cristalina). Os ímãs confeccionados com este novo composto apresentaram propriedades magnéticas por muito tempo procuradas. Medidas do valor da magnetização de saturação $\left(\mathrm{M}_{\mathrm{s}}\right)$ em monocristais do composto $\mathrm{Nd}_{2} \mathrm{Fe}_{14} \mathrm{~B}$ foram em torno de 1,6 $\mathrm{T}$ o que permite prever um produto de energia $(\mathrm{BH})_{\text {máx }}$ ao redor de $512 \mathrm{~kJ} / \mathrm{m}^{3}$. Em medidas realizadas em laboratório conseguiuse $(\mathrm{BH})_{\text {Max }}$ em torno de $400 \mathrm{~kJ} / \mathrm{m}^{3}$.

A partir desta descoberta, inúmeros grupos pelo mundo afora se dedicaram ao estudo do composto $\mathrm{Nd}_{2} \mathrm{Fe}_{14} \mathrm{~B}$, tendo em vista a melhora de sua qualidade e na fabricação de dispositivos. O neodímio em comparação com o samário e o ferro em comparação com o cobalto mostraram-se muito mais atrativos devido a maior abundância e baixo custo embora persistisse o problema da $\mathrm{T}_{\mathrm{C}}$ do composto ser ainda baixa para algumas aplicações ( $\approx 680 \mathrm{~K})$, quando comparada como os ímãs confeccionados com $\mathrm{SmCo}_{5} \operatorname{com} \mathrm{T}_{\mathrm{C}}$ ao redor de $990 \mathrm{~K}$.

Por motivos tecnológicos, um dos maiores desafios na época era o de aumentar a $T_{C}$. Este aumento foi conseguido através da substituição de parte dos átomos de ferro da estrutura. Matsuura et al. (1985) mostraram que a substituição de ferro por cobalto provoca um aumento significativo na $\mathrm{T}_{\mathrm{C}}$. Também, havia a possibilidade da substituição do neodímio por outra TRL não-magnética, permitindo o estudo da contribuição do metal de transição para as propriedades magnéticas deste composto ternário. Assim, o estudo dos efeitos da substituição química na liga se tornou de grande interesse.

\section{2 - Preparação dos pós magnéticos}

Nos últimos anos houve um crescente interesse nos magnetos permanentes consolidados por adesão a base de TR-Fe-B. Neste tipo de magneto, um pó coercivo é misturado a polímeros termoplásticos ou termo-endurecíveis que podem ser moldados por 
diversos processos a fim de se obter magnetos próximos a sua forma final (near net shape). Os pós podem ser preparados pelos processos: melt-spinning, mechanical alloying ou pelo processo de hidrogenação, desproporção, dessorção e recombinação (HDDR) utilizado neste trabalho.

O único processo utilizado para produção em larga escala de magnetos consolidados por adesão (Nd-Fe-B) é o melt-spinning. Este processo é utilizado principalmente por companhias japonesas para produção de pós a serem empregados nos processos de conformação por compressão e moldagem por injeção. Uma liga produzida por melt-spinning com composição $\mathrm{Nd}_{14} \mathrm{Fe}_{81} \mathrm{~B}_{5}$ consiste de grãos esféricos rugosos de diâmetro entre $20 \mathrm{~nm}$ a $100 \mathrm{~nm}$ com as paredes de domínio ancoradas nos contornos de grão. O material é completamente isotrópico devido a orientação aleatória dos grãos e por não ocorrer interação entre eles. A remanência típica deste material é da ordem de $0,8 \mathrm{~T}$, e a coercividade intrínseca de $1,2 \mathrm{kA} / \mathrm{m}^{2}$. Através do método melt-spinning combinando o processo de prensagem a quente pode-se produzir magnetos com grãos alinhados, porém estes processos são de alto custo para produção em larga escala de ímãs anisotrópicos consolidados por adesão. A melhora da remanência nestes materiais, dada pela condição da equação (1.1), ocorre para os materiais nano cristalinos devido à interações de troca através dos contornos de grão.

No processo de mechanical alloying para a liga $\mathrm{Nd}_{2} \mathrm{Fe}_{14} \mathrm{~B}$, os pós são produzidos por moagem em moinho de bolas. Neste processo, inicialmente o ferro e o neodímio transformam-se em um material parcialmente amorfo ou com uma estrutura de camadas nanométricas, com um pó de boro submicrométrico embebido nas interfaces Fe-Nd. Este pó é então recozido para formar a fase $\mathrm{Nd}_{2} \mathrm{Fe}_{14} \mathrm{~B}$. Assim como no processo por meltspinning, o deslocamento da estequiometria para o excesso de neodímio aumenta a coercividade. Isto ocorre possivelmente pela formação de uma região rica em neodímio no contorno de grão a qual ancora a parede de domínio quando da magnetização/desmagnetização.

O processo hidrogenação, desproporção, dessorção, recombinação - HDDR - foi desenvolvido para produzir magnetos de $\mathrm{TR}_{2} \mathrm{Fe}_{14} \mathrm{~B}$ com uma estrutura de grão refinada. Neste processo o material, com tamanho de cristalito, $\mathrm{d}_{\mathrm{c}}$, maior ou igual $50 \mu \mathrm{m}$, é aquecido em atmosfera de hidrogênio a cerca de $700{ }^{\circ} \mathrm{C}$, onde a fase $\mathrm{TR}_{2} \mathrm{Fe}_{14} \mathrm{~B}$ se desproporciona em uma mistura de $\mathrm{TRH}_{2}+\mathrm{Fe}_{2} \mathrm{~B}+\alpha-\mathrm{Fe}$. A dessorção do hidrogênio da fase $\mathrm{TRH}_{2}$ ocorre durante o recozimento a vácuo acima de $700{ }^{\circ} \mathrm{C}$, levando a recombinação do composto 
original com tamanho de cristalito da ordem de $300 \mathrm{~nm}$ a $500 \mathrm{~nm}$. Assim como nos processos melt spinning e mechanical alloying o produto final é normalmente isotrópico.

\section{3 - Imãs consolidados por adesão e suas características}

A fabricação de magnetos permanentes pela rota de consolidação tem várias vantagens sobre o processo de sinterização. Magnetos isotrópicos e anisotrópicos podem ser manufaturados. Para os magnetos anisotrópicos é necessária uma etapa intermediária de alinhamento do pó em um campo magnético.

A FIG. 1.1 resume os processos utilizados na fabricação destes tipos de magnetos.

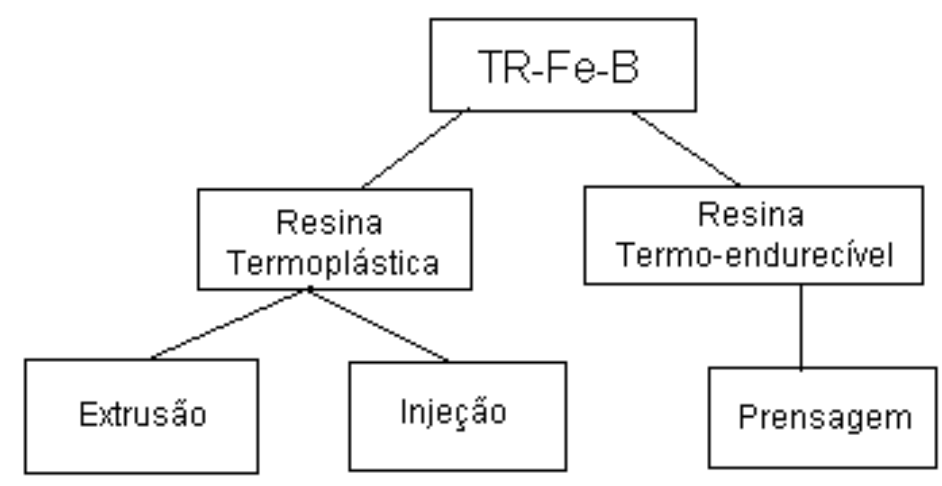

FIGURA 1.1- Resumo dos processos envolvidos na manufatura de magnetos consolidados por adesão (adaptada de Coey e O’Donnell,1997).

Nestes processos, as características de controle mais importantes do pó magnético são: $d_{p}$, tamanho da partícula do pó e $d_{c}$, tamanho dos cristalitos individuais.

Nos magnetos permanentes consolidados por adesão com resina, a coercividade intrínseca não sofre alteração significativa quando o pó é incorporado a uma resina orgânica. Entretanto, a magnetização (momento magnético por unidade de volume) é diminuída pela resina devido a diminuição da densidade. A magnetização pode ser maximizada pelo controle da forma e do tamanho das partículas do pó. Para um pó constituído de partículas esféricas o fator de preenchimento é de 0,68 para um dado volume. Valores maiores de preenchimento podem ser obtidos pelo uso de partículas na forma de plaquetas ou pelo uso de uma distribuição de tamanho de partículas que preencham os vazios na estrutura de Bernal $^{1}$.

A figura de mérito utilizada para a avaliação dos magnetos permanentes é o produto

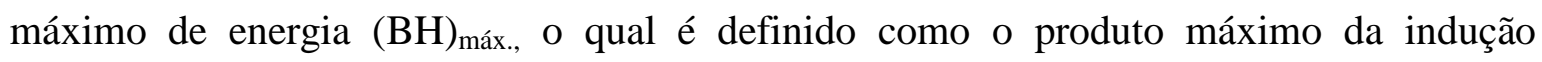

\footnotetext{
${ }^{1}$ É o maior preenchimento possível de um volume obtido dado por uma distribuição gaussiana de tamanho de partículas.
} 
magnética $\vec{B}$ e o campo aplicado $\vec{H}$ no segundo quadrante da curva de histerese. Fisicamente o $(\mathrm{BH})_{\text {máx }}$ representa a medida do campo que pode ser produzido fora do imã por uma unidade de volume do material magnético. Em termos tecnológicos pode-se dizer que quanto maior for o valor de $(\mathrm{BH})_{\text {máx }}$ maior será o potencial para a redução de tamanho e peso do dispositivo que emprega este magneto. O produto de energia para pós magnéticos é reduzido a praticamente à metade do valor obtido para magnetos com densidade máxima. A perda mais drástica de desempenho ocorre quando o pó é isotrópico onde este é composto por cristalitos com o eixo de magnetização da estrutura cristalina distribuídos aleatoriamente e que interagem fracamente entre si. Neste caso,

$$
M_{r} \leq \frac{M_{s}}{2}
$$

onde, $M_{r}$ momento magnético por unidade de volume e $M_{s}$ é a magnetização espontânea.

Se o "loop" de histerese for um quadrado com

$$
H_{c}>\frac{f_{m} M_{s}}{2}
$$

onde, $H_{c}$ é a coercividade intrínseca; $f_{m}$ fator de preenchimento. Neste caso o produto de energia será quatro vezes menor quando comparado com o do magneto completamente alinhado de mesma densidade. $\mathrm{O}$ produto de energia para um magneto consolidado por adesão quando ocorrer a condição da equação (1.2) em uma primeira aproximação pode ser dado por:

$$
(B H)_{\text {máx }}=\frac{\mu_{0} M_{s}^{2} f_{m}^{2} \phi^{2}}{4}
$$

onde:

$$
\phi=\frac{M_{r \|}}{\left(M_{r \|}+M_{r \perp}\right)}
$$

Os índices $\|$ e $\perp$ representam a magnetização medida na direção paralela e perpendicular a direção de alinhamento, respectivamente. Quando o eixo $c$ está aleatoriamente distribuído $\phi=0,5$ e $\phi=1$ quando está perfeitamente alinhado.

A melhora da remanência está associada com uma nanoestrutura específica dos grãos magnéticos que estão em contato íntimo e com tamanho de grão da ordem de $20 \mathrm{~nm}$, o que maximiza a troca ferro-magnética intergranular. A energia de troca cresce com o 
aumento da área de superfície de contato intergranular, enquanto que a energia de anisotropia varia com o volume do grão. Entretanto, para grãos suficientemente pequenos chega-se a uma acomodação onde a direção de magnetização de cada grão desvia-se do eixo de magnetização em relação ao eixo de magnetização dos seus vizinhos.

\section{4 - Substituição química e adição de dopantes}

A substituição química por outros elementos na liga ternária TR-Fe-B, tem como meta estudar o efeito sobre a remanência e coercividade intrínseca não mudando a estrutura cristalina do composto. Um dos elementos estudado foi o praseodímio em substituição ao neodímio. Este elemento é similar ao neodímio em suas propriedades na substituição à liga ternária TR-Fe-B mantendo a estrutura tetragonal, modificando somente os parâmetros de rede. Outra mudança ocasionada nesta substituição ocorre na $\mathrm{T}_{\mathrm{C}}$ da liga. Com o praseodímio a $\mathrm{T}_{\mathrm{C}}$ fica ao redor de $569 \mathrm{~K}$ enquanto que na liga com neodímio o valor fica em torno de $586 \mathrm{~K}$ (Barbosa, 2005). Para o praseodímio a $\mathrm{M}_{\mathrm{S}}$ máxima é da ordem de 1,56 $\mathrm{T}$ enquanto que no neodímio a $\mathrm{M}_{\mathrm{S}}$ máxima é da ordem de 1,60 $\mathrm{T}$ (Corfield et al., 2000).

Outro estudo com substituição química é a do ferro por cobalto. O efeito principal é a sua influência no aumento da $\mathrm{T}_{\mathrm{C}}$. Na estrutura TR-Fe-B há 56 átomos de ferro. $\mathrm{A}$ substituição do ferro até um número de 16 átomos de cobalto apresenta um ganho na $\mathrm{T}_{\mathrm{C}}$ de aproximadamente $50 \mathrm{~K}$ por átomo (Pedziwiatr et al., 1986a). Para maiores substituições o ganho na $\mathrm{T}_{\mathrm{C}}$ é de somente $11 \mathrm{~K}$ por átomo adicionado. Assim, esta substituição se faz interessante do ponto de vista do custo até 16 átomos.

O primeiro trabalho adicionando silício e alumínio como dopante a liga foi publicado por McCallum et al. (1987). McCallum relatou a melhora da remanência na liga $\mathrm{Nd}_{2} \mathrm{Fe}_{14} \mathrm{~B}$ preparada pelo processo de melt-spinning encontrando valores de remanência da ordem de 0,9 T a 1,0 T com a razão $\mathrm{M}_{\mathrm{r}} / \mathrm{M}_{\mathrm{s}} \approx 0,6$ e produto de energia acima de $160 \mathrm{~kJ} / \mathrm{m}^{3}$.

Diversos autores reportaram que adições de elementos como dopantes podem induzir a produção de pós anisotrópicos empregando o processamento HDDR. Os principais elementos utilizados foram: zircônio, háfnio, gálio, nióbio. Nestes pós o eixo $c$ da estrutura cristalina dos grãos originais fica retido por "sítios de memória" os quais atuam como centros de nucleação para o subseqüente crescimento do grão quando da dessorção-recombinação. Outros trabalhos indicam que os aditivos podem não ser essenciais para se obter cristalitos recombinados de $\mathrm{TR}_{2} \mathrm{Fe}_{14} \mathrm{~B}$ com orientação preferencial no processo HDDR propondo que, quando da hidrogenação, o $\mathrm{TRH}_{2}$ apresenta uma textura 
relacionada (orientação preferencial) com o alinhamento dos cristalitos do material original.

\section{5 - Aplicações}

Os magnetos permanentes a base de terras raras possuem um amplo campo de aplicações como, por exemplo: no mecanismo de propulsão de trens magneticamente levitáveis, relógios eletrônicos, amplificadores de ondas progressivas, motores para eletroeletrônicos, cabeças de disco rígido, giroscópios, alto-falantes, dispositivos biomédicos. $\mathrm{Na}$ área nuclear umas das mais importantes aplicações está nos motores das unidades ultracentrífugas utilizadas para separação isotópica. 


\section{2 - OBJETIVOS}

O principal objetivo deste trabalho foi estudar a adição de dopantes e elementos de liga no sistema ternário Pr-Fe-B processados por hidrogenação, desproporção, dessorção e recombinação (HDDR) visando a otimização das propriedades magnéticas. A escolha dos elementos químicos adicionados para realização deste trabalho teve como base estudos correlatos, encontrados na literatura, em ligas do sistema ternário $\mathrm{Nd}-\mathrm{Fe}-\mathrm{B}$, sendo quase todos inéditos no sistema ternário Pr-Fe-B.

Como objetivos específicos, o trabalho foi dividido em três etapas:

- Para a primeira etapa foi prevista a preparação de magnetos consolidados à base de Pr-Fe-Co-B com adições a baixa concentração (dopante) de: Al, Si, P, Ti, V, Cr, Ni, $\mathrm{Cu}, \mathrm{Ga}, \mathrm{Zr}, \mathrm{Nb}$ ou Mo processados por HDDR e caracterizá-los quanto as suas propriedades magnéticas. Em seguida avaliá-los em relação à liga base e estabelecer correlações. As ligas estudadas possuem as seguintes composições:

○ $\operatorname{Pr}_{14} \mathrm{Fe}_{\mathrm{bal}} \mathrm{Co}_{16} \mathrm{~B}_{6} \mathrm{M}_{0,1}$ com M=Ti, V, Cr, Ni, Zr, Nb ou Mo;

○ $\operatorname{Pr}_{14} \mathrm{Fe}_{\text {bal }} \mathrm{Co}_{16} \mathrm{~B}_{6} \mathrm{Nb}_{0,1} \mathrm{X}_{\text {conc }}$, onde $\mathrm{X}=\mathrm{Al}, \mathrm{Si}, \mathrm{P}, \mathrm{Cu}$ ou $\mathrm{Ga}$; e conc $=0,1 \%$; $0,3 \%$ ou $0,5 \%$ atômico.

- Para a segunda etapa, obter dados por difração de raios $\mathrm{X}$ das ligas $\operatorname{Pr}_{14} \mathrm{Fe}_{\text {bal-x } \mathrm{x}} \mathrm{Co}_{\mathrm{x}} \mathrm{B}_{6} \mathrm{Nb}_{0,1}$ onde $\mathrm{x}=$ 0, 4, 8, 12 ou $16 \%$ atômico processadas por HDDR. Para em seguida, utilizar o método de Rietveld com objetivo de determinar os parâmetros cristalográficos devido à substituição do ferro pelo cobalto, tais como: parâmetros de rede, posições atômicas e fator de ocupação.

- A terceira etapa deste trabalho visou determinar por método teórico (ab-initio) as características magnéticas das ligas estudadas na segunda etapa e compará-las com as medidas magnéticas experimentais. Com isto, estabelecer um método indireto para aplicação no estudo da adição de dopantes a magnetos baseados em terras-raras. 


\section{3 - REVISÃO BIBLIOGRÁFICA}

A revisão bibliográfica apresentada nesta seção tem o objetivo de procurar o entendimento das propriedades magnéticas relacionado-as com: os parâmetros do processo de obtenção do ímã, a estequiometria da liga, as características microestruturais e a adição de outros elementos químicos em baixa concentração (dopantes).

\section{1 - Materiais magnéticos a base de TR-Fe-B}

Dentre as terras raras estudadas para a formação da fase $\mathrm{TR}_{2} \mathrm{Fe}_{14} \mathrm{~B}$ o neodímio apresentou as melhores propriedades magnéticas e os estudos se concentraram em materiais utilizando este elemento, resultando no desenvolvimento da tecnologia necessária para a produção de magnetos em escala industrial.

Considerando o isomorfismo da estrutura cristalina e as semelhanças químicas entre os elementos da família das terras raras estes estudos serviram e ainda servem de base para o estudo de magnetos à base de praseodímio, elemento alvo de estudo desta tese.

O trabalho pioneiro de Sagawa et al. (1984) com magnetos do sistema Nd-Fe-B mostrou que a fase magnética $\mathrm{Nd}_{2} \mathrm{Fe}_{14} \mathrm{~B}$ era obtida majoritariamente quando se utilizava a liga com composição atômica $\mathrm{Nd}_{15} \mathrm{Fe}_{79} \mathrm{~B}_{6}$, dentre aquelas estudadas pelo autores. Esta composição também apresentou os melhores valores de magnetização de saturação, produto máximo de energia e remanência. Os autores observaram que o aumento do teor de boro na liga implicava no aumento da coercividade intrínseca $\left({ }_{i} \mathrm{H}_{c}\right)$. As observações da microestrutura mostraram que o material era composto predominantemente por duas fases: a fase magnética $\mathrm{Nd}_{2} \mathrm{Fe}_{14} \mathrm{~B}$ e outra fase não magnética rica em neodímio e baixo ponto de fusão, situada no contorno do grão da fase magnética.

Croat et al. (1984) estudaram o sistema ternário TR-Fe-B, onde TR representa lantânio, cério, praseodímio, neodímio, samário, gadolínio, térbio e disprósio. Através dos resultados obtidos para as ligas $\mathrm{TR}_{13,5} \mathrm{Fe}_{80,9} \mathrm{~B}_{5,6}$ foi possível determinar que as melhores propriedade magnéticas estavam relacionadas com o uso de neodímio e praseodímio, conforme os dados apresentados na FIG. 3.1. As ligas baseadas nos outros elementos da família das terras raras apresentaram valores de coercividade intrínseca excessivamente 
baixos e consequientemente para o produto máximo de energia. Os autores atribuíram o caráter magnético deste novo material à formação da fase magnética $\mathrm{TR}_{2} \mathrm{Fe}_{14} \mathrm{~B}$ observada para todas as ligas estudadas.

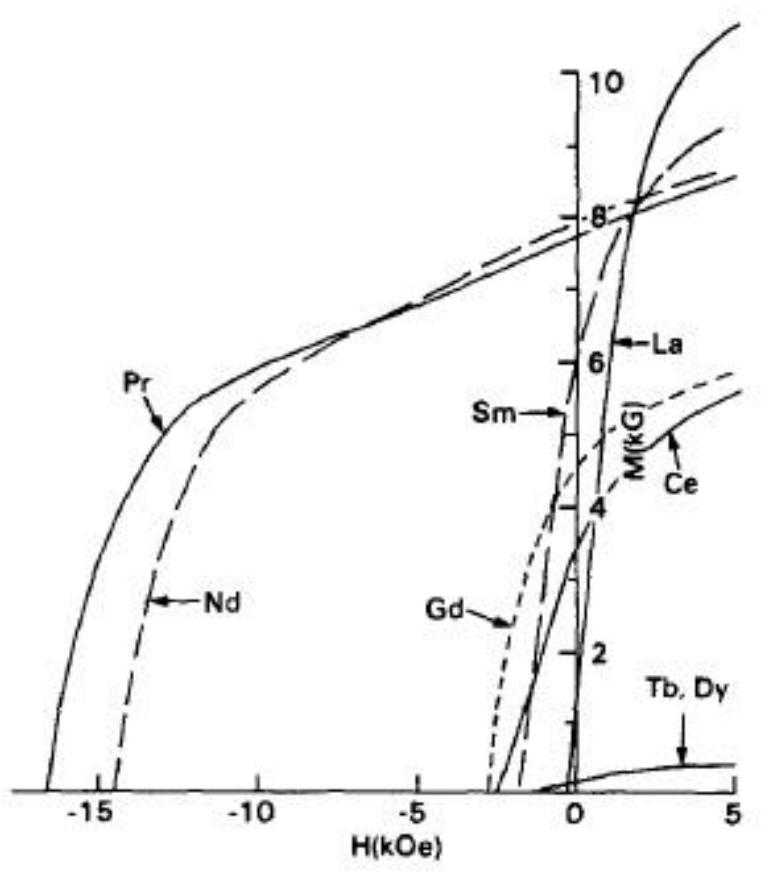

FIGURA 3.1 - Curvas de desmagnetização para os compostos $\mathrm{TR}_{13,5} \mathrm{Fe}_{80,9} \mathrm{~B}_{5,6}$ (adaptada de Croat et al., 1984).

A partir destes trabalhos iniciais um grande número de estudos foram realizados para a compreensão das propriedades magnéticas da fase $\mathrm{TR}_{2} \mathrm{Fe}_{14} \mathrm{~B}$ e para a obtenção de ligas TR-Fe-B que tivessem emprego tecnológico. Os resultados apresentados por Croat et al. (1984) deixaram claro que as ligas à base de praseodímio e neodímio eram as mais promissoras para o desenvolvimento de um material de uso industrial. Inicialmente, as pesquisas deram maior enfoque às ligas de neodímio.

Lembrando que o neodímio e o praseodímio fazem parte do conjunto das terras raras leves (TRL), inclusive sendo vizinhos na tabela periódica, esperam-se grandes similaridades em seu comportamento, o que realmente foi verificado nos trabalhos de investigação das ligas a base de praseodímio. 


\section{2 - Diagrama de fases}

Através do diagrama de fases é possível determinar a existência e obtenção de compostos intermetálicos, sendo uma ferramenta imprescindível no estudo destes compostos. Os processos metalúrgicos envolvidos durante a produção de ímãs permanentes de TR mais metal de transição só podem ser completamente entendidos através do diagrama de fases. Para isto, faz-se necessário o conhecimento prévio do equilíbrio e transformações de fases durante as etapas de obtenção do produto final. $\mathrm{O}$ diagrama de fases é a ferramenta ideal para se encontrar tais informações que ajudam a compreender o processo de obtenção de ímãs permanentes através da metalurgia do pó.

Para melhor conhecer as propriedade dos ímãs de $\mathrm{Pr}-\mathrm{Fe}-\mathrm{B}$, em destaque o campo coercivo (coercividade) a altas temperaturas, faz-se necessário um conhecimento detalhado das relações entre as fases na liga. Neiva et al. (1995) fizeram o estudo detalhado do diagrama de fases de várias composições da liga ternária Pr-Fe-B. Estes autores apresentaram seções verticais do diagrama de fases relativas à estas composições. As seções são definidas por um corte isotérmico no diagrama de fases da liga Pr-Fe-B, ou seja, no balanço estequiométrico da liga $\mathrm{Pr}-\mathrm{Fe}-\mathrm{B}$ considerando-se a proporção de ferro em relação aos outros componentes.

No diagrama de fases apresentado na FIG. 3.2, a razão entre Pr:B foi fixada na razão de 2:1, onde o Fe é a variável. A seta $A$ indica a fase $\varnothing$ coincidente com os valores de: $82,3 \%$ at. para o ferro; $11,8 \%$ at. para o praseodímio e; $5,9 \%$ at. para o boro. Esta proporção equivale à estequiometria da fórmula mínima $\operatorname{Pr}_{2} \mathrm{Fe}_{14} \mathrm{~B}$ em valor porcentual. $\mathrm{O}$ limite final das fases sólidas da liga ternária Pr-Fe-B relativa a FIG. 3.2, começa no vértice do ferro, entra no campo ferro $+\varnothing$, passa através de $\varnothing$, e finalmente entra no campo $\varnothing+\eta$ $+\operatorname{Pr}$, onde $\eta=\operatorname{Pr}_{1-x} \mathrm{Fe}_{4} \mathrm{~B}_{4}$.

Através da FIG. 3.2 pode-se entender a formação da fase $\varnothing$ a partir do resfriamento líquido. Verifica-se que para composições muito próximas à composição da fase $\varnothing$ a primeira fase a se cristalizar é o $(\alpha-\mathrm{Fe})$ coexistindo com o líquido. A medida que a temperatura diminui a fase $\emptyset$ se forma através de uma reação peritética, ou seja: líquido + ferro $\rightarrow$ fase $\emptyset$. De antemão, sabe-se que as reações peritéticas freqüentemente não se completam devido ao aprisionamento da fase sólida inicial, que no caso é o ferro, pela nova fase sólida formada, que no caso é a fase $\varnothing$, isolando-a da fase líquida. O prosseguimento da reação exige difusão em contracorrente com o $\alpha$-Fe, com o praseodímio e com o boro através da fase $\varnothing$. Ainda existe o problema da velocidade de difusão dos átomos ser muito pequena o que faz com que a reação não se complete e continue restando 
certa quantidade de $\alpha$-Fe. A existência desta fase foi encontrada em todas as amostras como recebidas utilizadas neste trabalho, sendo necessário tratamento térmico para sua eliminação. No caso deste trabalho onde há a substituição do ferro pelo cobalto a fase formada é $\alpha-(\mathrm{FeCo})$.

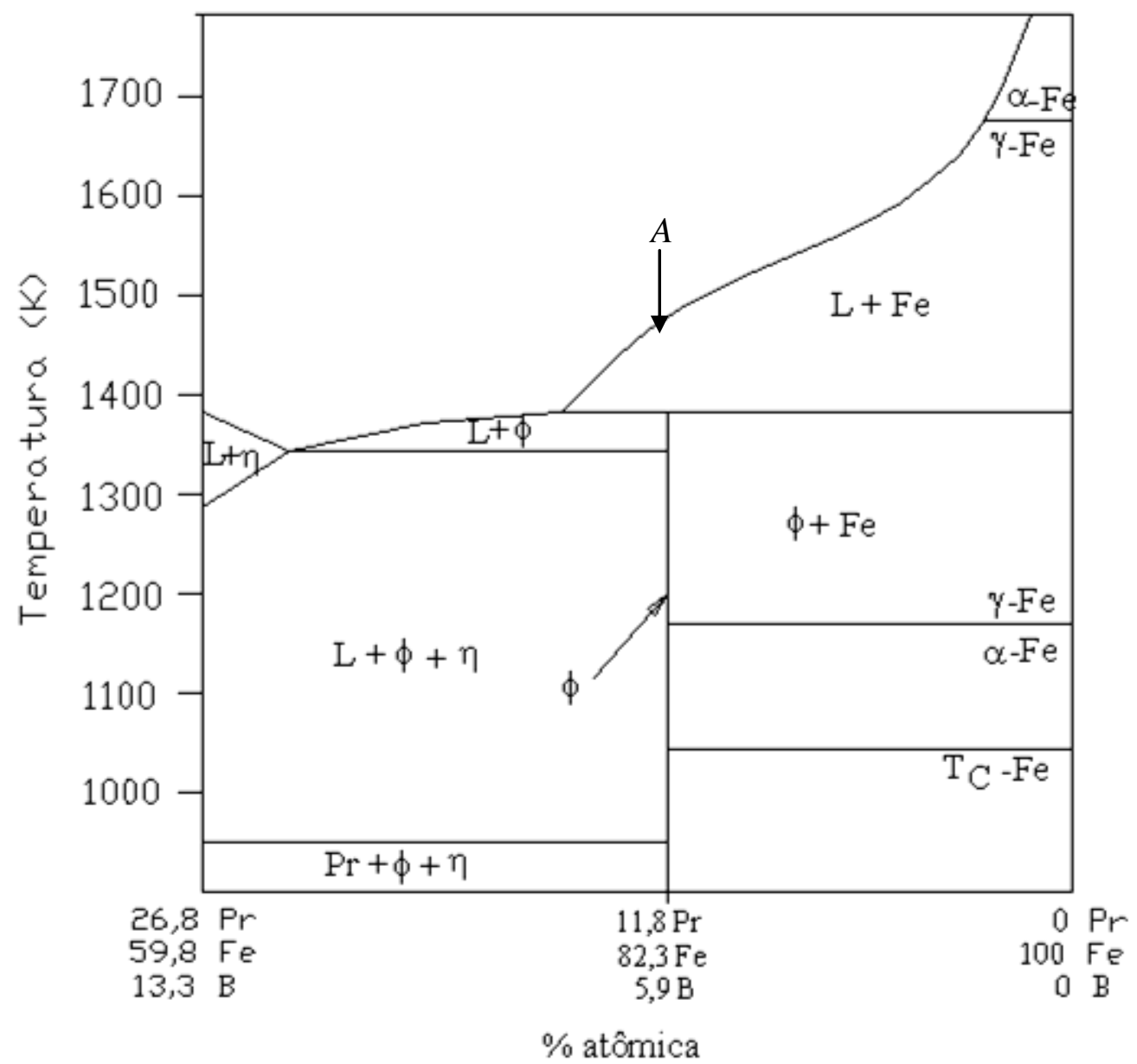

FIGURA 3.2 - Diagrama de fase da liga Pr-Fe-B no corte isométrico na razão entre Pr:B de $2: 1$. A seta $A$ indica a fase $\varnothing$ coincidente com os valores de: $82,3 \%$ at. para o Fe; $11,8 \%$ at. para o Pr. e 5,9 \% at. para o B. Estes valores são equivalentes à estequiometria da fórmula mínima $\operatorname{Pr}_{2} \mathrm{Fe}_{14} \mathrm{~B}$ (adaptada de Neiva et al., 1995).

Faz-se necessário alertar que as composições usadas neste trabalho não estão na proporção Pr:B de 2:1, o que implica que a explanação anterior baseada na FIG. 3.2 só pode ser usada para ilustrar a seqüencia de solidificação da liga na proporção indicada. 


\section{3 - Estrutura cristalina e características magnéticas do $\mathbf{T R}_{2} \mathrm{Fe}_{14} \mathrm{~B}$}

Neste item será dada ênfase à estrutura cristalina do composto $\operatorname{Pr}_{2} \mathrm{Fe}_{14} \mathrm{~B}$ que foi estudado neste trabalho.

A estrutura cristalina e a estequiometria exata do composto $\operatorname{Pr}_{2} \mathrm{Fe}_{14} \mathrm{~B}$ foram determinadas por Herbst e Yelon, (1985) e Jinghua et al (1987), como sendo uma estrutura isomórfica à estrutura do $\mathrm{Nd}_{2} \mathrm{Fe}_{14} \mathrm{~B}$, onde os átomos de praseodímio ocupam as posições do neodímio. Herbst e Yelon utilizaram o método de Rietveld, assumindo que a estrutura do cristal era isomorfa com a estrutura da fase $\mathrm{Nd}_{2} \mathrm{Fe}_{14} \mathrm{~B}$.

A estrutura do $\operatorname{Pr}_{2} \mathrm{Fe}_{14} \mathrm{~B}$ é tetragonal, do grupo espacial $P 4_{2} / m n m$, contendo quatro fórmulas unitárias por célula. Os átomos de ferro ocupam os sítios: 32 átomos distribuídos nos sítios $16 k_{1}$ e $16 k_{2} ; 16$ átomos distribuídos nos sítios $8 j_{1}$ e $8 j_{2} ; 8$ átomos distribuídos nos sítios $4 c$ e $4 e$, perfazendo 56 átomos de ferro no total. Os átomos de praseodímio ocupam os sítios $4 f$ e $4 g$, perfazendo 8 átomos no total. Os átomos de boro ocupam o sítio $4 g$ perfazendo 4 no total. A soma total de átomos para estrutura é de 68 átomos. Na TAB. 3.1 são apresentadas as posições atômicas nesta estrutura.

Esta estrutura pode ser considerada bem estabelecida em função dos vários estudos realizados na determinação da estrutura da fase $\mathrm{Nd}_{2} \mathrm{Fe}_{14} \mathrm{~B}$ da qual a fase $\operatorname{Pr}_{2} \mathrm{Fe}_{14} \mathrm{~B}$ é isomorfa (Herbst et al., 1984; Herbst et al., 1985b; Shoemaker et al., 1984).

TABELA 3.1 - Coordenadas atômicas $(\mathrm{x}, \mathrm{y}, \mathrm{z})$ dos átomos da fase $\mathrm{Pr}_{2} \mathrm{Fe}_{14} \mathrm{~B}$ em unidades dos parâmetros de rede $\mathrm{a}=8,796(1) \AA \mathrm{e}$ c $=12.228(1) \AA$ (adaptada de Herbst e Yelon, 1986).

\begin{tabular}{llll}
\hline Átomo & $\boldsymbol{X}$ & $\boldsymbol{Y}$ & $\boldsymbol{Z}$ \\
\hline $\operatorname{Pr}(4 f)$ & $0,2678(10)$ & $0,2678(10)$ & 0 \\
$\operatorname{Pr}(4 g)$ & $0,1386(9)$ & $-0,1386(9)$ & 0 \\
$\mathrm{Fe}\left(16 k_{1}\right)$ & $0,2237(4)$ & $0,5679(3)$ & $0,1279(2)$ \\
$\mathrm{Fe}\left(16 k_{2}\right)$ & $0,0385(3)$ & $0,3598(4)$ & $0,1765(3)$ \\
$\mathrm{Fe}\left(8 j_{1}\right)$ & $0,0980(4)$ & $0,0980(4)$ & $0,2057(3)$ \\
$\mathrm{Fe}\left(8 j_{2}\right)$ & $0,3173(3)$ & $0,3173(3)$ & $0,2463(4)$ \\
$\mathrm{Fe}(4 e)$ & 0,5 & 0,5 & $0,1144(6)$ \\
$\mathrm{Fe}(4 c)$ & 0 & 0,5 & 0 \\
$\mathrm{~B}(4 \mathrm{~g})$ & $0,3704(10)$ & $-0,3704(10)$ & 0 \\
\hline
\end{tabular}

Como pode ser observado na FIG. 3.3, é possível notar a sobreposição de camadas de átomos de ferro sobre outra camada de átomos de praseodímio e boro, totalizando oito camadas, as quais resultam na formação de prismas trigonais de átomos de ferro contendo um átomo de boro no centro e com o átomo de praseodímio localizado próximo ao centro do hexágono de átomos de ferro. A ocorrência destes prismas é bastante comum em 
sistemas metais-metalóides, tanto em materiais cristalinos como amorfos (Gaskell, 1981) e podem impor o arranjo de ligações das camadas de ferro tanto quanto permitir espaço para os átomos de praseodímio no plano central destes prismas.

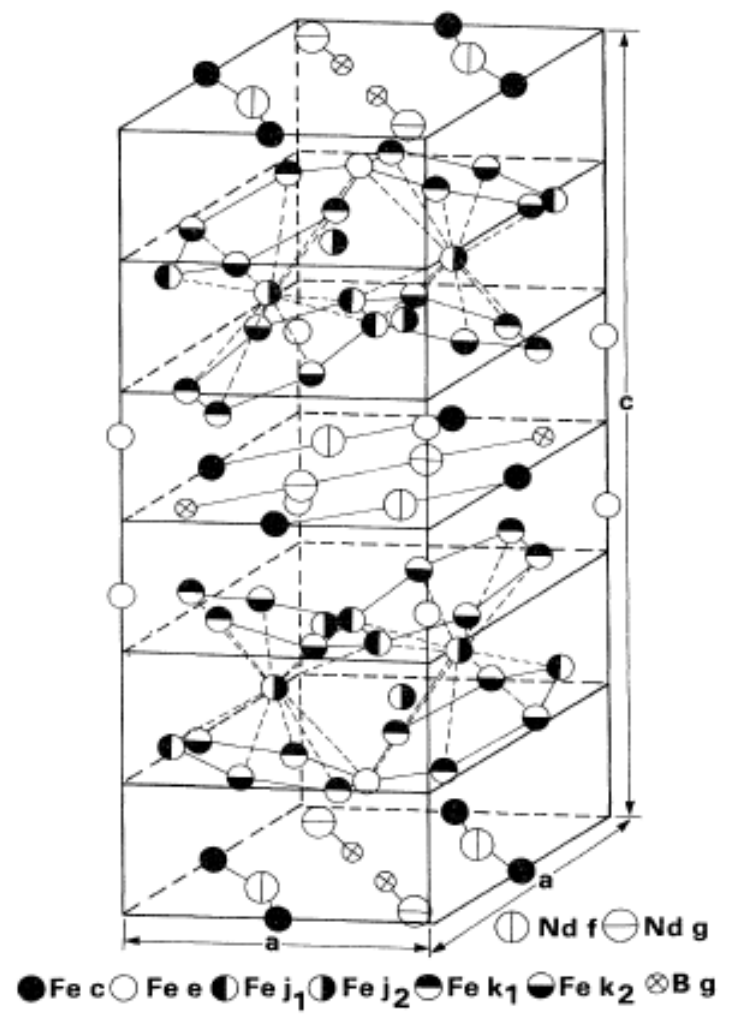

FIGURA 3.3 - Célula unitária da fase $\mathrm{Nd}_{2} \mathrm{Fe}_{14} \mathrm{~B}$ onde, por isomorfismo troca-se o átomo de Nd pelo de Pr. A razão c/a na figura está exagerada para enfatizar o emaranhado da rede hexagonal dos átomos de Fe (adaptada de Herbst et al., 1984).

A conexão entre a estrutura cristalina e as propriedades magnéticas mais importantes pode ser feita pela comparação com a fase $\mathrm{Nd}_{2} \mathrm{Fe}_{17}$. Esta fase apresenta estrutura cristalina do tipo romboédrica, grupo espacial $R-3 m$. As principais diferenças entre a fase $\mathrm{TR}_{2} \mathrm{Fe}_{14} \mathrm{~B}$ e a fase $\mathrm{Nd}_{2} \mathrm{Fe}_{17}$ são: $\mathrm{T}_{\mathrm{C}}=585 \mathrm{~K}$ e $\mathrm{T}_{\mathrm{C}}=330 \mathrm{~K}$, respectivamente, e a direção do momento magnético. $\mathrm{Na}$ fase $\mathrm{TR}_{2} \mathrm{Fe}_{14} \mathrm{~B}$ este momento está na direção do eixo $c$ e no $\mathrm{Nd}_{2} \mathrm{Fe}_{17}$ no plano basal. A origem destas diferenças está na estrutura cristalina. Apesar do número de coordenação do ferro ser maior na fase $\mathrm{Nd}_{2} \mathrm{Fe}_{17}$, somente metade da rede triangular é completada pelos átomos de ferro dos sítios $c$; os átomos de praseodímio interrompem as camadas de ferro na metade nesta estrutura. $\mathrm{Na}$ fase $\operatorname{Pr}_{2} \mathrm{Fe}_{14} \mathrm{~B}$ não há 
átomos de praseodímio para causar uma ruptura na rede triangular do ferro, como no caso do $\mathrm{Nd}_{2} \mathrm{Fe}_{17}$. Esta característica pode ser responsável pela maior $\mathrm{T}_{\mathrm{C}}$ desta fase.

A FIG. 3.4 apresenta as projeções do plano basal e das camadas de ferro em $z: \sim 1 / 6,1 / 2$ e $1 / 4$ que ilustram as considerações a respeito da estrutura cristalina exposta.
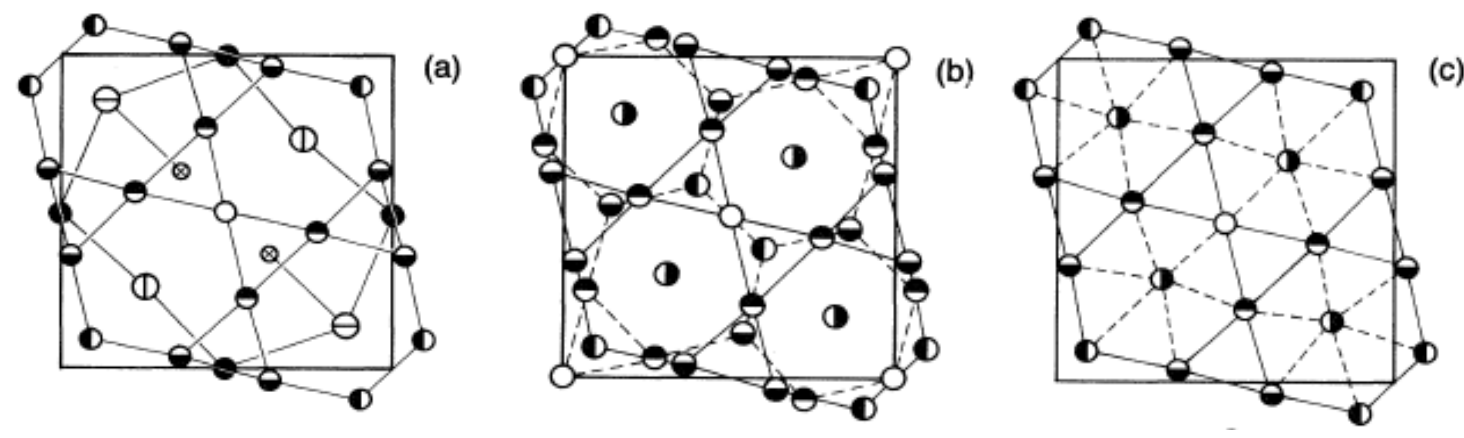

(1) Nd f $\ominus$ Ndg

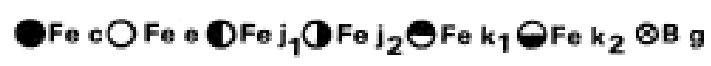

FIGURA 3.4 - (a) Projeção do plano basal e da primeira camada de átomos de Fe em z 1/6; (b) Projeção das três camadas de Fe entre o plano basal e $\mathrm{z}=1 / 2$; (c) Projeção da primeira camada de Fe e das camadas vizinhas de $\mathrm{Fe}\left(j_{2}\right)$ em z $\sim 1 / 4$ (adaptada de Herbst, 1991).

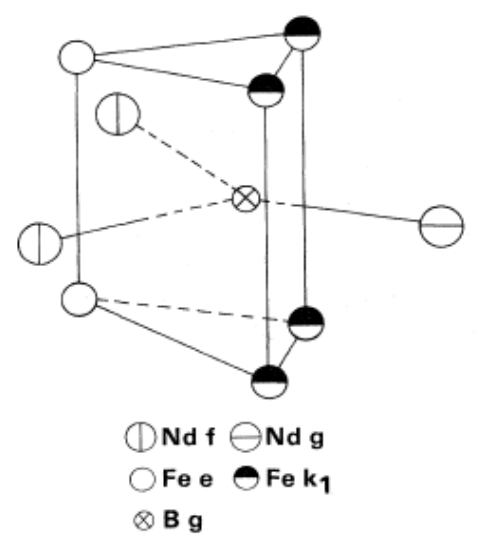

FIGURA 3.5 - Prisma trigonal contendo um átomo de B na estrutura do $\operatorname{Pr}_{2} \mathrm{Fe}_{14} \mathrm{~B}$ (adaptada de Herbst, 1991).

A coordenação do boro na estrutura cristalina do $\operatorname{Pr}_{2} \mathrm{Fe}_{14} \mathrm{~B}$ é simples e elegante. Cada boro ocupa o centro de um prisma trigonal, FIG. 3.5, formado pelos três átomos de ferro mais próximos abaixo e pelos três átomos de ferro acima do plano basal, na coordenada $z=1 / 2$. A FIG. 3.4(a) mostra que as faces dos prismas triangulares participam para completar as ligações hexagonais do átomo de ferro sobre o plano basal. $\mathrm{O}$ entrelaçamento dos prismas causado pelas ligações dos átomos de ferro é dado devido que o sítio $e$ e o sítio $k_{l}$ do ferro estão significantemente deslocados em direção ao plano do 
boro, no qual estão contidos, comparado com os outros átomos de ferro da rede; as ligações entre os átomos $\mathrm{B}-\mathrm{Fe}\left(k_{l}\right)$ e $\mathrm{B}-\mathrm{Fe}(e)$ são as ligações mais curtas na estrutura. Os elos das ligações entre as camadas de átomos de ferro abaixo e acima dos planos em que estão contidos os átomos de praseodímio e boro indicam que, os prismas formados, contribuem para a estabilidade da estrutura cristalina.

$\mathrm{O}$ composto intermetálico $\operatorname{Pr}_{2} \mathrm{Fe}_{14} \mathrm{~B}$ é um composto duro e quebradiço com apenas um plano de escorregamento (001) e duas direções de escorregamento [100] e [010] (Mishra, 1987).

Estudos conduzidos por Hirosawa et al. (1986), à temperatura de 4,2 K e $300 \mathrm{~K}$, indicam que a magnetização de saturação $M_{s}$ é de $37,6 \mu_{\mathrm{B}}$ a 4,2 K e $31,9 \mu_{\mathrm{B}}$ a $300 \mathrm{~K}$ por fórmula unitária. O campo de anisotropia é de $\left(\sim 16 \times 10^{6}\right) \mathrm{A} / \mathrm{m}$ a $4,2 \mathrm{~K}$ e $\left(\sim 6 \times 10^{6}\right) \mathrm{A} / \mathrm{m}$ a $300 \mathrm{~K}$. O valor do momento magnético do praseodímio foi estimado em $3,1 \mu_{\mathrm{B}}$ e para o ferro em 2,1 $\mu_{\mathrm{B}}$. Considerando que para o praseodímio o momento deve-se somente aos elétrons da camada $4 f$ e que no estado fundamental a camada $4 f$ é especificada pela regra de Hund, tem-se que o momento angular total $J$ é dado por $J=L-S=5-1=4$. Portanto, $g$ $=4 / 5$ (fator de Landé) o que implica que $g J=3,2$.

$\mathrm{O}$ fato de $\mu_{\mathrm{Pr}} \approx g J$, uma vez que o praseodímio possui momento angular orbital $L \neq$ 0 exerce uma contribuição significativa para a anisotropia magneto-cristalina. Isto sugere a ocorrência da separação do campo cristalino e que o momento no estado fundamental decorrente do valor do ferro livre é reduzido.

O fato de que no praseodímio a distribuição de cargas da camada $4 f$ ser uma esfera achatada nos pólos permite predizer que a direção de fácil magnetização será ao longo do eixo $c$.

$\mathrm{O}$ eixo de fácil magnetização da fase $\operatorname{Pr}_{2} \mathrm{Fe}_{14} \mathrm{~B}$ está relacionado com a alta anisotropia do retículo de ferro como pode ser observado na FIG. 3.5. Nesta fase há muitos mais átomos de ferro vizinhos acima de outro átomo de ferro do que abaixo. Comparandose com a fase $\mathrm{Nd}_{2} \mathrm{Fe}_{17}$, onde somente o átomo de ferro do sítio $c$ tem coordenação anisotrópica local já que o mesmo possui como vizinhos seis átomos de ferro acima em oposição a sete átomos de ferro abaixo. Portanto, a rede de ferro no $\operatorname{Pr}_{2} \mathrm{Fe}_{14} \mathrm{~B}$ é muito mais anisotrópica localmente na direção $c$ (eixo de fácil magnetização) do que o $\mathrm{Nd}_{2} \mathrm{Fe}_{17}$ que não apresenta esta característica. Este fato sugere que a contribuição do retículo de ferro para a anisotropia magneto-cristalina não é desprezível e, portanto, também para a coercividade. 
Uma das vantagens do uso da liga Pr-Fe-B para a confecção de magnetos permanentes, reside no fato que a fase magnética $\operatorname{Pr}_{2} \mathrm{Fe}_{14} \mathrm{~B}$ não apresenta reorientação de spin acima da temperatura de $150 \mathrm{~K}$, diferentemente do $\mathrm{Nd}_{2} \mathrm{Fe}_{14} \mathrm{~B}$. Algumas descontinuidades na curva do campo aplicado versus magnetização ao longo das direções de difícil magnetização foram verificadas por Pareti el al. (1985), Hiroyoshi et al. (1987a) e Verhoef et al. (1988). Hiroyoshi e Verhoef observaram campos induzidos no processo de magnetização de primeira ordem (indicativo da reorientação de spin), nas curvas de magnetização nas direções [100] e [110] a temperatura de 4,2 K com campos de intensidade aproximados de $\left(10 \times 10^{6}\right) \mathrm{A} / \mathrm{m}$ e $\left(13 \times 10^{6}\right) \mathrm{A} / \mathrm{m}$, respectivamente, porém de um tipo diferente daquele que ocorre na fase $\mathrm{Nd}_{2} \mathrm{Fe}_{14} \mathrm{~B}$, comprovadamente com reorientação de spin a $200 \mathrm{~K}$.

\section{4 - O processo HDDR}

O processo HDDR foi reportado primeiramente por Takeshita e Nakayama em 1989 (Takeshita e Nakayama, 1989) descrito pelos autores como um processo de hidrogenação e desidrogenação. Em 1991 Harris e McGuiness batizaram o processo como Hidrogenação, Desproporção, Dessorção e Recombinação (HDDR).

O processo HDDR constitui-se basicamente de duas etapas: a primeira é a hidrogenação e desproporção, na qual o hidrogênio difunde-se pelas estruturas cristalinas e reage com os elementos formadores de hidretos através de uma reação exotérmica e na desproporção ocorre a quebra das estruturas cristalinas devido a formação de novos compostos e expansão da célula unitária. Na etapa seguinte, após o aquecimento sobre o mesmo sistema, o hidrogênio é retirado (dessorção) e conseqüentemente há a ocorrência da etapa de recombinação dos átomos formando novamente o composto original. $\mathrm{O}$ resultado é a obtenção do material granulado de fácil moagem que depois de moído e peneirado estará pronto para conformação. A FIG. 3.6 representa esquematicamente o ciclo térmico HDDR. 


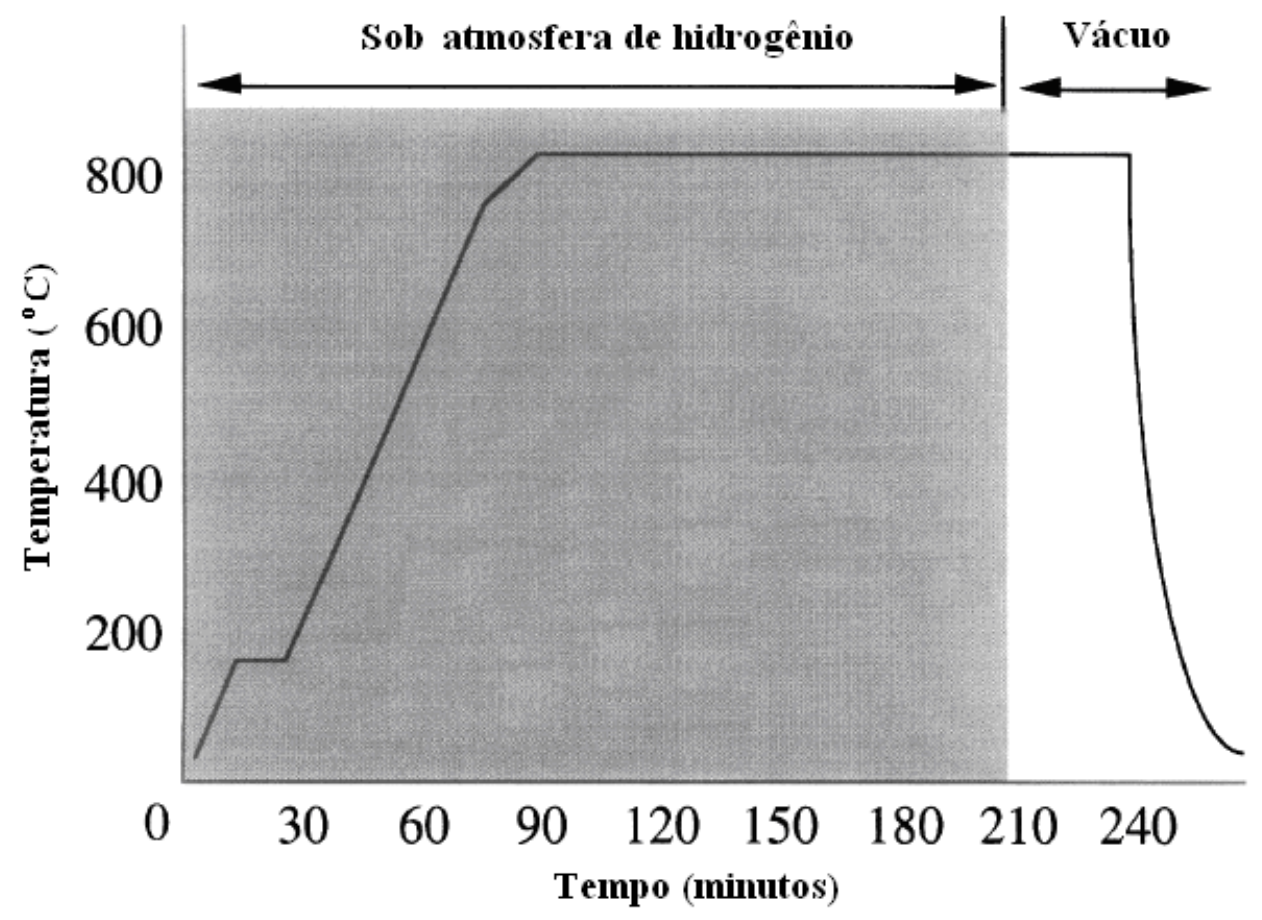

FIGURA 3.6 - Ciclo térmico do processo HDDR.

A equação química (3.1) que descreve a reação de desproporção para a fase $\mathrm{TR}_{2} \mathrm{Fe}_{14} \mathrm{~B}$, onde $\mathrm{TR}=\mathrm{Nd}$ ou $\mathrm{Pr}$ pode ser escrita como:

$$
T R_{2} \mathrm{Fe}_{14} \mathrm{~B}+(2 \pm x) \mathrm{H}_{2} \stackrel{860^{\circ} \mathrm{C}-\mathrm{H}_{2}}{\longrightarrow} 2 \mathrm{TRH}_{2 \pm x}+12(\alpha \mathrm{Fe})+\mathrm{Fe} e_{2} \mathrm{~B} \pm \Delta H
$$

A estequiometria do hidreto (variável $x$ ) de TRH depende da temperatura e da pressão de hidrogênio.

A equação para a recombinação do processo pode ser escrita como:

$$
2 T R H_{2 \pm x}+12(\alpha F e)+F e_{2} B \pm \Delta H \stackrel{860^{\circ} \mathrm{C} \text {-Vӑсио }}{\longrightarrow} T R_{2} F e_{14} B+(2 \pm x) H
$$

Os efeitos das principais variáveis do processo HDDR que determinam a qualidade dos materiais magnéticos, obtidos por este processo, são descritos na TAB. 3.2. 
TABELA 3.2 - Efeitos das variáveis do processo HDDR (adaptada de Gutfleisch e Harris, 1996).

\begin{tabular}{|c|c|}
\hline VARIÁVEL & EFEITO \\
\hline $\begin{array}{l}\text { Estado inicial da liga: } \\
\text { - Homogeneização; } \\
\text { - Composição, tamanho de grão, presença } \\
\text { de outras fases, orientação cristalográfica, } \\
\text { distribuição de precipitados; } \\
\text { - Quantidade de material processado. }\end{array}$ & $\begin{array}{l}\text { Propriedades magnéticas do pó recombinado. } \\
\text { Reprodutibilidade do pó recombinado. }\end{array}$ \\
\hline $\begin{array}{l}\text { Reações sob atmosfera de hidrogênio: } \\
\text { - } \quad \text { Pressão durante a desproporção; } \\
\text { - } \quad \text { Temperatura de introdução do } \mathrm{H}_{2} ; \\
\text { - } \quad \text { Esquema e taxa de aquecimento; } \\
\text { - } \quad \text { Patamar de temperatura; } \\
\text { - } \quad \text { Patamar de tempo; } \\
\text { - } \quad \text { Patamar de pressão. }\end{array}$ & $\begin{array}{l}\text { Temperatura e tempo de desproporção. } \\
\text { Calor envolvido. } \\
\text { Quantidade de calor envolvido. } \\
\text { Absorção de calor. } \\
\text { Escala de desproporção. } \\
\text { Propriedades magnéticas do pó recombinado. } \\
\text { Taxa de desproporção. } \\
\text { Escala de homogeneidade. } \\
\text { Propriedades magnéticas do pó recombinado. } \\
\text { Escala de homogeneidade e desproporção. } \\
\text { Custo do processo. } \\
\text { Propriedades magnéticas do pó recombinado. } \\
\text { Escala de homogeneidade e desproporção. } \\
\text { Taxa de recombinação. }\end{array}$ \\
\hline Temperatura de evacuação & $\begin{array}{l}\text { Propriedades magnéticas do pó recombinado. } \\
\text { Distribuição de tamanho de grão do pó } \\
\text { recombinado. }\end{array}$ \\
\hline Velocidade de evacuação & $\begin{array}{l}\text { Propriedades magnéticas do pó recombinado. } \\
\text { Extensão da recombinação. } \\
\text { Distribuição de tamanho de grão. }\end{array}$ \\
\hline Tempo em vácuo & $\begin{array}{l}\text { Propriedades magnéticas do pó recombinado. } \\
\text { Distribuição de tamanho de grão. }\end{array}$ \\
\hline Taxa de resfriamento & $\begin{array}{l}\text { Propriedades magnéticas do pó recombinado. } \\
\text { Distribuição de tamanho de grão. }\end{array}$ \\
\hline Tratamentos subseqüentes (térmicose/o & Propriedades magnéticas do pó recombinado. \\
\hline
\end{tabular}

$\mathrm{O}$ esquema de absorção de hidrogênio no $\mathrm{Nd}_{2} \mathrm{Fe}_{14} \mathrm{~B}$ foi estudado por Isnard et al. (1995) que demonstraram que a absorção do hidrogênio não modifica o grupo espacial, ocorrendo a ocupação de posições atômicas intersticiais. Cada célula unitária acomoda até 4 átomos de hidrogênio, a absorção de mais átomos de hidrogênio leva a desproporção. Na TAB. 3.3 são apresentadas as posições atômicas ocupadas pelos átomos de hidrogênio, seus primeiros vizinhos e a porcentagem de ocupação de cada sítio. 
TABELA 3.3 - Porcentagem de ocupação do hidrogênio nos diferentes sítios intersticiais (não equivalentes) para os diferentes compostos $\mathrm{Nd}_{2} \mathrm{Fe}_{14} \mathrm{BH}_{\mathrm{x}}$, onde $\mathrm{x}=1$, 2, 3 e 4 (adaptada de Isnard et al., 1995)

\begin{tabular}{l|r|l|llll}
\hline Sítio & \multirow{2}{*}{ Posição } & Primeiros vizinhos & $\begin{array}{l}\boldsymbol{x = 1} \\
(\boldsymbol{\%})\end{array}$ & $\begin{array}{l}\boldsymbol{x}=\mathbf{2} \\
(\boldsymbol{\%})\end{array}$ & $\begin{array}{l}\boldsymbol{x}=\mathbf{3} \\
(\boldsymbol{\%})\end{array}$ & $\begin{array}{l}\boldsymbol{x}=\mathbf{4} \\
(\boldsymbol{\%})\end{array}$ \\
\hline $\mathrm{H}(1)$ & $8 j$ & $2 \mathrm{x} \mathrm{Nd}(2), \mathrm{Nd}(1), \mathrm{Fe}(5)$ & 50 & 41 & 39 & 24 \\
$\mathrm{H}(2)$ & $16 k_{1}$ & $\mathrm{Nd}(2), \mathrm{Nd}(1), \mathrm{F} 3(3), \mathrm{Fe}(5)$ & 1 & 26 & 38 & 48 \\
$\mathrm{H}(3)$ & $16 k_{2}$ & $\mathrm{Nd}(2), \mathrm{Nd}(1), \mathrm{F} 3(3), \mathrm{Fe}(1)$ & 0 & 0 & 23 & 49 \\
$\mathrm{H}(4)$ & $4 e$ & $2 \mathrm{x} \mathrm{Nd}(2), 2 \mathrm{Fe}(5)$ & 0 & 0 & 9 & 37 \\
\hline
\end{tabular}

Na TAB. 3.3 a posição $8 j$ mostra-se inicialmente mais atrativa este comportamento é explicado por esta posição ser um ambiente mais rico em neodímio e possuir o maior raio de inserção da estrutura $(\mathrm{r}=0,45 \AA$ ). A inserção do segundo átomo de hidrogênio na estrutura ocorre na posição $16 k_{l}$. Esta posição provoca uma modificação na posição $8 j$ provocando uma diminuição na porcentagem de ocupação da mesma. Os preenchimentos das posições $16 k_{2}$ e $4 e$ são governados por considerações estereográficas no caso das terras raras leve como o neodímio e o praseodímio.

A inserção do hidrogênio na célula unitária conseqüentemente leva à expansão dos parâmetros de rede e do volume da célula unitária. Para até três átomos de hidrogênio absorvidos o volume da célula aumenta à razão de aproximadamente $(2,7 \AA)^{3}$ por átomo de hidrogênio absorvido. A partir do quarto átomo de hidrogênio absorvido a razão fica próxima de $(2,3 \AA)^{3}$. São apresentados na TAB. 3.4 os valores para os parâmetros de rede, o volume da célula unitária e a variação do volume devido ao número de hidrogênio(s) absorvido(s).

TABELA 3.4 - Parâmetros de rede $(a$ e $c$ ), volume da célula unitária $(v)$ e variação do volume por átomo de hidrogênio absorvido no $\mathrm{Nd}_{2} \mathrm{Fe}_{14} \mathrm{BH}_{\mathrm{x}}$ (adaptada de Isnard et al., 1995).

\begin{tabular}{|c|c|c|c|c|}
\hline $\bar{X}$ & $a(\AA)$ & $c(\AA)$ & $v\left(\AA^{3}\right)$ & $\Delta \mathrm{V} / \mathrm{H}\left(\AA^{3} /\right.$ at. $)$ \\
\hline 0 & 8.805 & 12.206 & 946 & - \\
\hline 1 & 8.841 & 12.242 & 957 & 2.7 \\
\hline 2 & 8.869 & 12.294 & 967 & 2.6 \\
\hline 3 & 8.906 & 12.327 & 978 & 2.7 \\
\hline 4 & 8.917 & 12.344 & 982 & 2.3 \\
\hline
\end{tabular}

Conforme descrito acima, a ocupação do interstício na estrutura $\mathrm{TR}_{2} \mathrm{Fe}_{14} \mathrm{~B}$ obedece a um esquema rígido. Era de se esperar que os parâmetros desta etapa do processo exercessem uma significativa influência sobre as propriedades magnéticas. Os estudos realizado por Ragg et al. (1997) mostraram a influência do tempo e da pressão de hidrogênio sobre as propriedades magnéticas da liga $\mathrm{Nd}_{16} \mathrm{Fe}_{76} \mathrm{~B}_{8}$. As curvas de 
desmagnetização apresentadas nas FIG. 3.7 e 3.8 mostram a influência do tempo e da pressão de hidrogênio respectivamente.

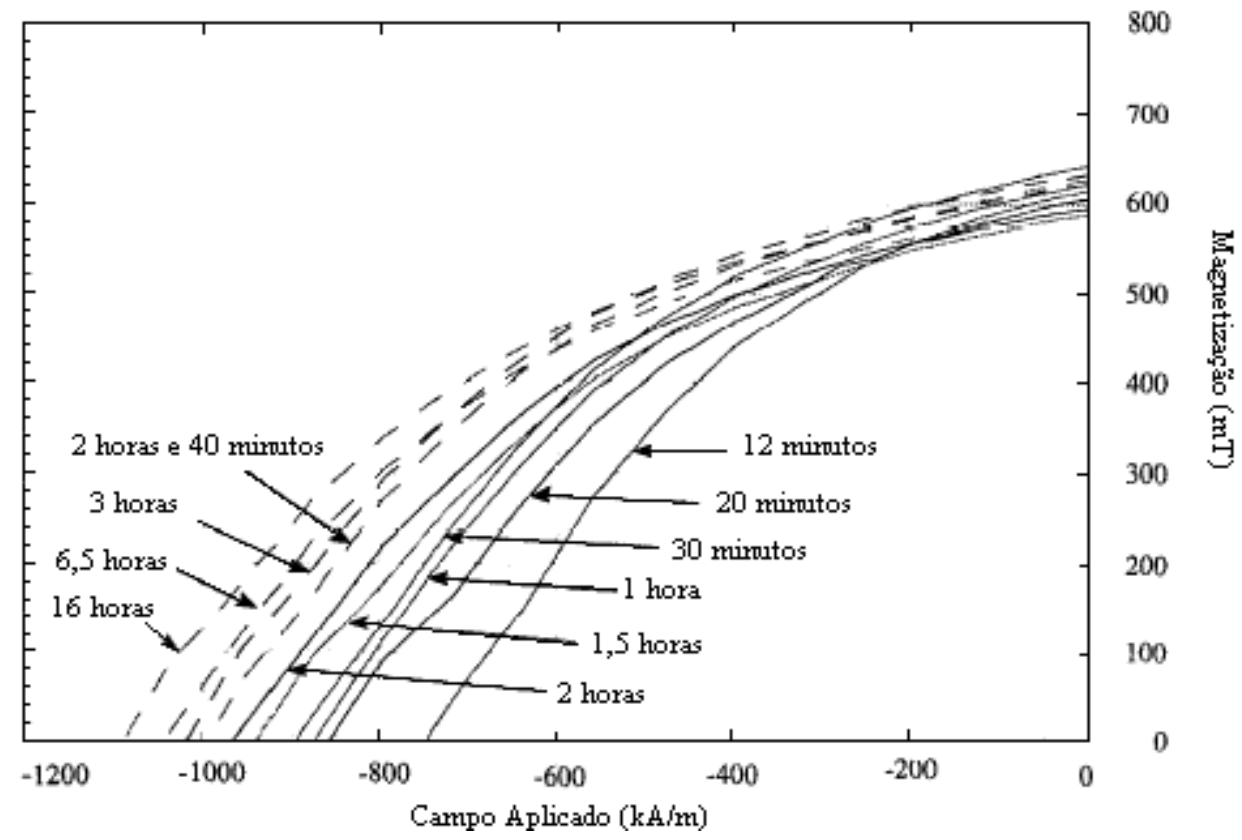

FIGURA 3.7 - Curvas de desmagnetização de amostras desproporcionadas em diversos intervalos de tempo (adaptada de Ragg et al., 1997).

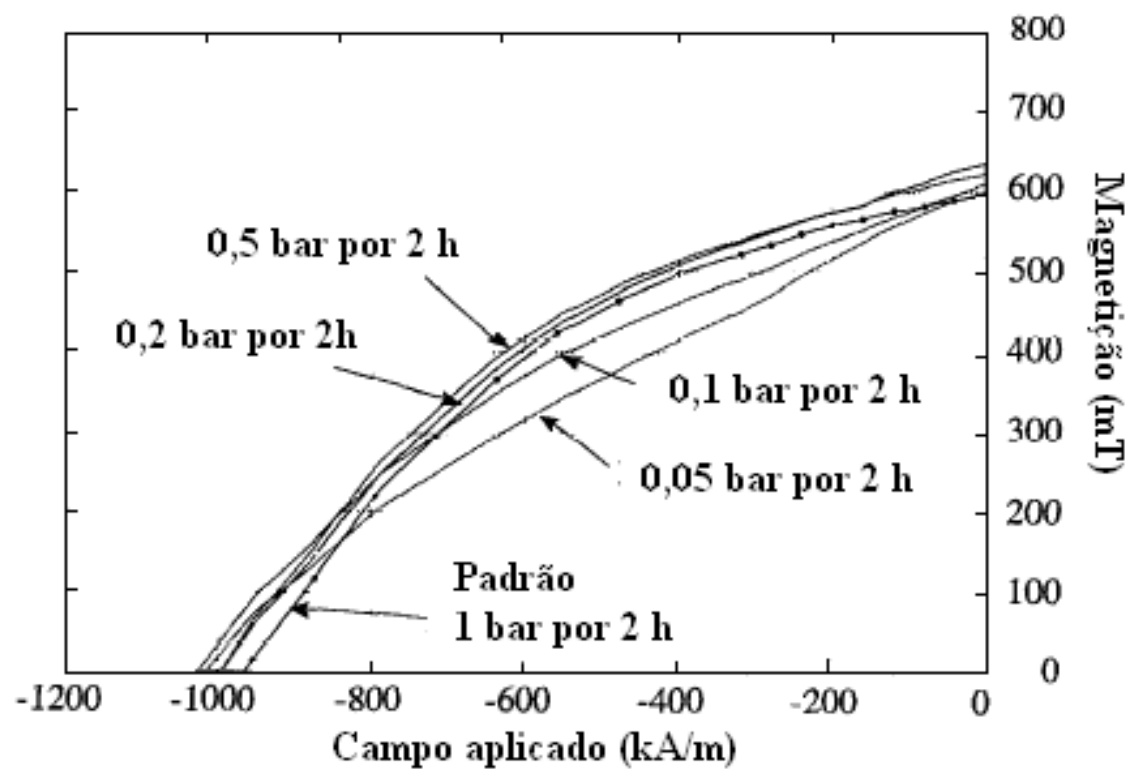

FIGURA 3.8 - Curvas de desmagnetização de amostras desproporcionadas em diversas pressões por 2 horas (adaptada de Ragg et al., 1997).

McGuiness et al. (1990a) verificaram que a fase $\mathrm{TR}_{2} \mathrm{Fe}_{14} \mathrm{~B}$ desproporciona ao redor de $200{ }^{\circ} \mathrm{C}$. Na fase rica em TR, a desproporção ocorre em temperatura elevada aproximadamente a $700{ }^{\circ} \mathrm{C}$ e a fase $\mathrm{Nd}_{2} \mathrm{Fe}_{4} \mathrm{~B}_{4}$ não absorve hidrogênio e conseqüentemente não sofre desproporção no tempo de exposição característico do processo HDDR. O 
processo de desproporção inicia-se pela fase rica em terra rara que atua como aceleradora na difusão de hidrogênio para a fase $\mathrm{TR}_{2} \mathrm{Fe}_{14} \mathrm{~B}$.

Investigações utilizando microscopia eletrônica de transmissão mostraram que no estado desproporcionado o material encontra-se formado por uma fase matriz de $\mathrm{Fe}-\alpha$ na qual estão distribuídos os hidretos de neodímio com morfologia cilíndrica e estas duas fases possuem o mesmo eixo de zona e plano de hábito, portanto possuindo uma relação de orientação: $N d H_{2}\{100\} \| \mathrm{Fe}-\alpha\{100\}$ e $N d H_{2}<001>\| \mathrm{Fe}-\alpha<001>$. A fase $\mathrm{Fe}_{2} \mathrm{~B}$ distribui-se aleatoriamente dentro desta microestrutura.

Quando o hidrogênio é dessorvido, ocorre a recombinação da fase $\mathrm{TR}_{2} \mathrm{Fe}_{14} \mathrm{~B}$ iniciado-se pela difusão dos átomos de ferro na estrutura $\mathrm{Nd}-\mathrm{Nd}_{2} \mathrm{H}$ formando inicialmente uma camada ao redor da fase $\mathrm{TR}_{2} \mathrm{Fe}_{14} \mathrm{~B}$. A elevada temperatura no processo promove o aumento de vacâncias na estrutura permitindo a difusão em sentidos contrários do ferro e do hidrogênio possibilitando a recombinação do material. Se a recombinação tiver um patamar de temperatura com tempo superior ao necessário para a recombinação da fase $\mathrm{TR}_{2} \mathrm{Fe}_{14} \mathrm{~B}$ o número de vacâncias de equilíbrio nesta temperatura produzem um crescimento anormal de grão.

Quando a dessorção não se completa os átomos de hidrogênio no interior da estrutura cristalina da fase $\mathrm{TR}_{2} \mathrm{Fe}_{14} \mathrm{~B}$ estarão localizados preferencialmente nas posições descritas na TAB. 3.2. Neste caso a presença destes átomos provoca um aumento na distância entre os átomos de ferro localizados nas posições $8 j_{1}$ que implica no aumento da $\mathrm{T}_{\mathrm{C}}$ deste composto.

Magneticamente a presença de dois ou mais átomos de hidrogênio resulta no aumento da magnetização devido ao aumento do momento magnético dos átomos de neodímio e ferro. Porém a modificação provocada ao redor dos átomos de neodímio é responsável por uma diminuição drástica da anisotropia magnética.

O pó recombinado, obtido em condições otimizadas, apresenta grãos esféricos de $\mathrm{TR}_{2} \mathrm{Fe}_{14} \mathrm{~B}$ com tamanho da ordem de $0,5 \mu \mathrm{m}$ com a fase rica em terra rara situada no contorno de grão, a qual contribui para o isolamento magnético dos grãos da fase $\mathrm{TR}_{2} \mathrm{Fe}_{14} \mathrm{~B}$ (McGuiness et al., 1990b). 


\section{5 - Ímãs consolidados}

Os pós HDDR são adequados para a fabricação de magnetos consolidados (Takeshita e Nakayama, 1989; McGuiness et al., 1990b; Nakayama et al., 1991). Na prática, os grãos extremamente finos das amostras solidificadas rapidamente evitam a orientação cristalográfica provocada pela moagem do material seguida por um alinhamento magnético.

Os pós são prensados e misturados com um ligante. Vários ligantes têm sido empregados para este processo incluindo resinas epoxy (Lee et al., 1985; Sagawa et al., 1990) ou teflon (politetrafluoretileno ou PTFE) (Hirosawa et al., 1990; Panchanathan et al., 1991). Os magnetos isotrópicos ligados com resina epoxi são conformados por compactação a frio enquanto que o PTFE é utilizando como ligante para a conformação por extrusão a quente.

A influência do tamanho de grão nas propriedades magnéticas da liga Nd-Fe-B utilizando ligante polimérico foi estudada por Handstein et al. (1991). A redução do valor de coercividade intrínseca para magnetos consolidados com partículas pequenas é devido a fases de óxidos que causam facilmente nucleação de processos de desmagnetização interna. Os autores concluíram que o teor de oxigênio aumenta monotonicamente com o decréscimo do tamanho das partículas. Um aumento drástico do teor de oxigênio foi verificado para partículas menores que $4 \mu \mathrm{m}$. No pó de Nd-Fe-Co-B-Zr-Ga o valor maior de remanência foi obtido para pó magnético com tamanho de partícula entre $50 \mu \mathrm{m}$ e 200 $\mu \mathrm{m}$. Para partículas menores que $50 \mu \mathrm{m}$ tanto a remanência, como o coercividade intrínseca são baixas quando em comparação com pós com partículas maiores (Takeshita e Morimoto, 1996). Além da oxidação da superfície das partículas, contribuiu para este comportamento as tensões internas decorrentes do processo de moagem. Geralmente, para os magnetos consolidados são utilizados pós com uma larga distribuição granulométrica (de preferência com uma distribuição gaussiana no seu tamanho). Isto ajuda na obtenção de ímãs mais densos a verde (prensagem mecânica ou isostática) e, portanto, com maior densidade final e conseqüentemente com maior produto de energia.

Os magnetos à base de $\mathrm{Nd}-\mathrm{Fe}-\mathrm{B}$ isotrópicos apresentam produto de energia da ordem de $96 \mathrm{KJ} \mathrm{m}^{-3}$. Para se obter ímãs com produto de energia maior são utilizados pós anisotrópicos. Doser et al. (1991) e Panchanathan et al. (1991) realizam uma pré magnetização das amostras em um campo pulsado após a mistura dos pós com a resina epoxi. Então, a mistura é moldada por compressão em um campo magnético transversal ou 
paralelo ao eixo de compressão a temperatura ambiente. Para os magnetos que usam como ligante o teflon, as amostras são prensadas em uma matriz a temperatura de $250{ }^{\circ} \mathrm{C}$ sob atmosfera de argônio. O produto máximo de energia dos imãs anisotrópicos depende da intensidade do campo aplicado para o alinhamento das partículas. No caso do composto $\mathrm{Nd}-\mathrm{Fe}-\mathrm{Co}-\mathrm{B}-\mathrm{Zr}-\mathrm{Ga}$ foram obtidos produtos de energia entre 148 a $164 \mathrm{~kJ} \mathrm{~m}^{-3}$ (Takeshita e Morimoto, 1996). Neste caso, a remanência é uma função do volume de fase magneticamente dura. Este comportamento foi atribuído a interações magnéticas entre as partículas (Tomka et al., 1993). Estes autores quantificaram as interações dipolares e verificaram que as interações aumentam rapidamente com a fração volumétrica, para ímãs com fração volumétrica da fase magneticamente dura baixa. Quando a fração da fase magnética é alta, as interações aumentam mais lentamente. A variação da coercividade intrínseca com a fração volumétrica é menor do que para a remanência segundo os autores.

Magnetos à base de Nd-Fe-B foram consolidados com vidros (Yao et al., 1996). Para este fim utilizou-se um vidro $\left(40 \% \mathrm{P}_{2} \mathrm{O}_{5}-45 \% \mathrm{SnCl}_{2}-15 \% \mathrm{PbCl}_{2}\right)$ como ligante. Magnetos com $20 \%$ de fase vítrea apresentaram $B_{r}=0,49 \mathrm{~T}$ a $0,5 \mathrm{~T}$ e $(\mathrm{BH})_{\max }=41,6$ $\mathrm{kJm}^{-3}$ a $44 \mathrm{kJm}^{-3}$, tendo sido utilizado pós obtidos por melt-spun.

\section{6 - Compostos $T R_{2} \mathrm{Fe}_{14} \mathrm{~B}$ multielementares em substituição ao ferro}

Os efeitos das múltiplas substituições nos sítios do ferro foram estudados. O aumento da $\mathrm{T}_{\mathrm{C}}$ pela adição de cobalto e para contrabalancear o correspondente decréscimo nas propriedades magnéticas desta substituição, foram adicionados elementos em baixas concentrações na tentativa de se otimizar estas propriedades.

A dependência da $\mathrm{T}_{\mathrm{C}}$ com a composição química no $\mathrm{Nd}_{2} \mathrm{Fe}_{14-\mathrm{x}} \mathrm{M}_{\mathrm{x}} \mathrm{B}$, onde $M$ representa um átomo metálico está apresentada na FIG. 3.9. A $\mathrm{T}_{\mathrm{C}}$ aumenta quando o ferro é substituído por cobalto, níquel, silício, cobre ou gálio e diminui quando o ferro é substituído por vanádio, cromo, manganês, rutênio, alumínio, germânio e berílio (Fuerts et al., 1986; Ku et al., 1986; Pedziwiatr et al., 1986a; Burzo, 1987; Jurczyk et al., 1987; Ku e Yen, 1987; Sagawa et al., 1987; Chuang et al., 1988; Kowalczyk e Wrzeciono, 1988 a,b; Kowalczyk et al.,1988; Xie et al., 1988; Burzo e Plugaru, 1990). 


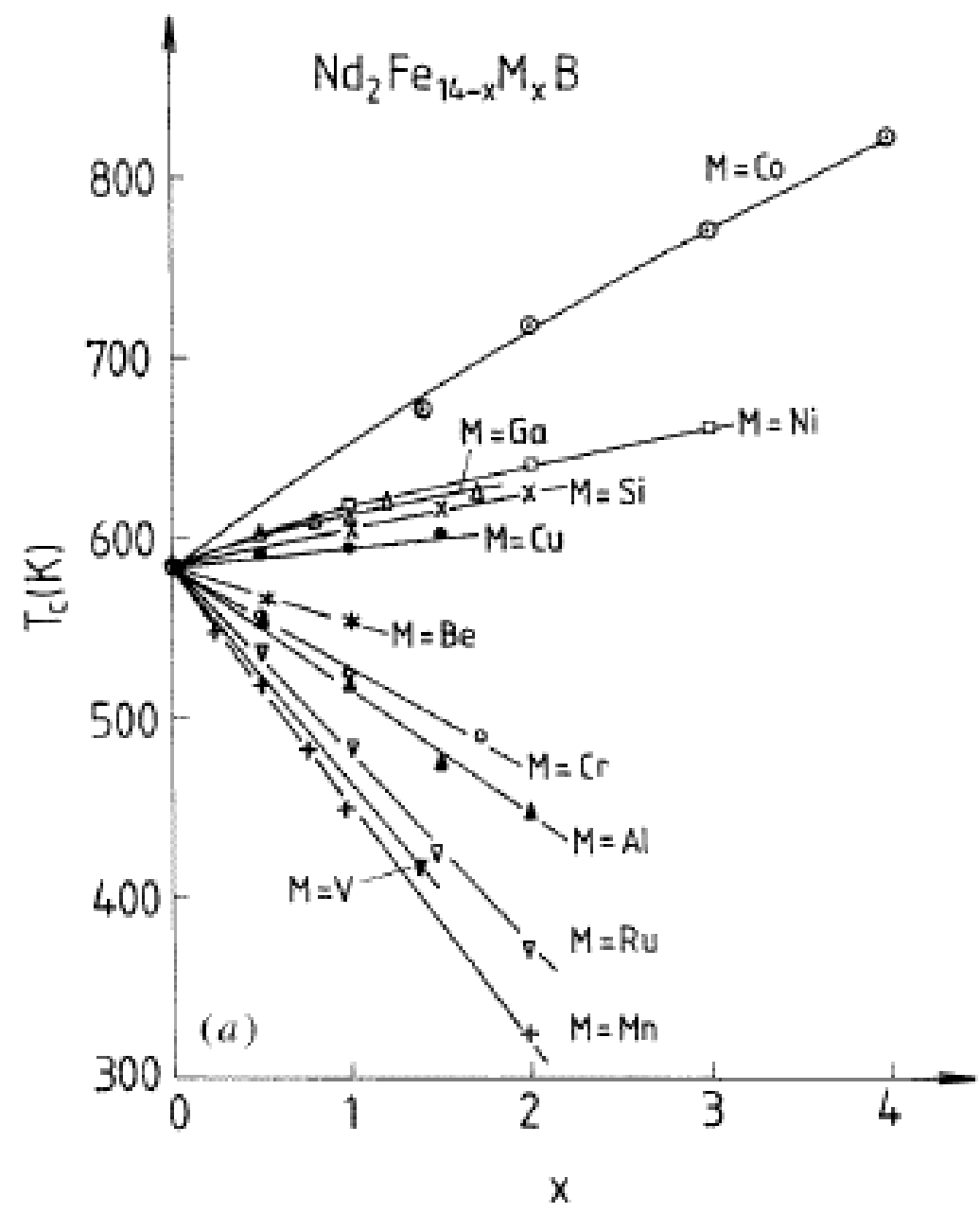

FIGURA 3.9 - Dependência de $\mathrm{T}_{\mathrm{C}}$ com a composição química $\mathrm{Nd}_{2} \mathrm{Fe}_{14-\mathrm{x}} \mathrm{M}_{\mathrm{x}} \mathrm{B}$, onde $M$ representa um átomo metálico (adaptada de Burzo, 1998).

A análise da dependência da $\mathrm{T}_{\mathrm{C}}$ com a composição é complexa. Burzo et al. (1985) e Pedziwiatr et al. (1987b) sugerem que quando o ferro é substituído por um elemento não magnético ou com caráter magnético fraco apresentam alguns efeitos opostos:

1. Há o decréscimo de ambas as interações de troca positiva e negativa pela quebra da interação de troca devido à substituição elementar, se o momento magnético do ferro não for afetado;

2. As interações de troca são diminuídas se o átomo substituinte ocupar sítios de ferro que possuam, como primeiros vizinhos, átomos de ferro situados a distâncias menores que aproximadamente $2,45 \AA$;

3. Quando os átomos substituintes são distribuídos nos sítios remanescentes, o efeito de diluição afeta as interações de troca positivas; 
4. Há um decréscimo nos momentos magnéticos dos átomos de ferro que contribuem para a diminuição das interações de troca positivas.

$\mathrm{O}$ sistema $\operatorname{Pr}_{2} \mathrm{Fe}_{14-\mathrm{x}} \mathrm{Co}_{\mathrm{x}} \mathrm{B}$ foi estudado por Pedziwiatr et al. (1986a). Neste sistema os parâmetros de rede decrescem monotonicamente com o aumento da concentração de cobalto, vide FIG. 3.10. Nota-se que o parâmetro $c$ decresce mais rapidamente que o parâmetro $a$, resultando que a variação da relação $c / a$ não é linear. A diminuição do parâmetro de rede resulta na alteração das interações de troca envolvendo os átomos das camadas $3 d$, que determinam a $\mathrm{T}_{\mathrm{C}}$. Neste composto as interações de troca entre $\mathrm{o}$ $\mathrm{Fe}\left(8 j_{1}\right)-\mathrm{Fe}\left(16 k_{2}\right)$ são fortemente negativas e entre os $\mathrm{Fe}\left(8 j_{1}\right)-\mathrm{Fe}\left(8 j_{2}\right)$ e $\mathrm{Fe}\left(8 j_{1}\right)-\mathrm{Fe}\left(16 k_{1}\right)$ são fortemente positivas, resultando no aumento da $\mathrm{T}_{\mathrm{C}}$ do composto. Neste caso o aumento na $\mathrm{T}_{\mathrm{C}}$ é dependente do teor de cobalto. Para $x$ menor que seis há um aumento de $50 \mathrm{~K}$ por átomo de ferro substituído, acima deste valor o aumento passa a ser de $14 \mathrm{~K}$ por átomo substituído. Isto indica que para baixas concentrações de cobalto os átomos substituem átomos de ferro envolvidos em interações de troca negativa, isto é, preferencialmente os sítios $16 k_{2}$ e $8 j_{2}$.

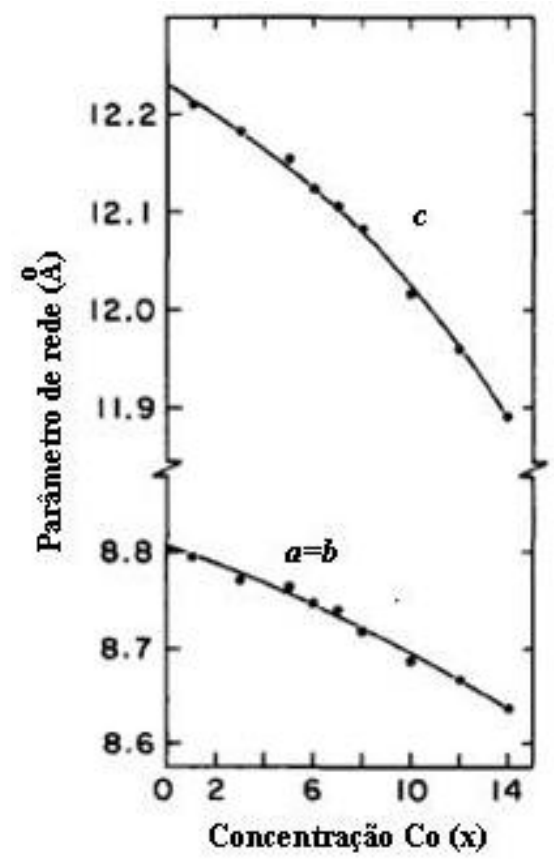

FIGURA 3.10 - Variação dos parâmetros de rede com a concentração de Co no composto $\mathrm{Pr}_{2} \mathrm{Fe}_{14-\mathrm{x}} \mathrm{Co}_{\mathrm{x}} \mathrm{B}$ (adaptada de Pedziwiatr et al., 1986a).

Os comportamentos da magnetização de saturação e do campo de anisotropia estão apresentados na FIG. 3.11 (a) e (b), respectivamente. O decréscimo inicial observado para 
o campo de anisotropia, FIG. 3.11 (b), pode ser explicado em função da diminuição do campo de troca que conseqüentemente leva à diminuição da magnetização dos átomos da camada $3 d$ com o aumento da concentração de cobalto. O aumento do campo de anisotropia com o aumento do teor de cobalto ainda não foi explicado. Pedziwiart et al. (1986a) sugerem que neste caso a anisotropia origina-se apenas devido ao átomo de praseodímio.
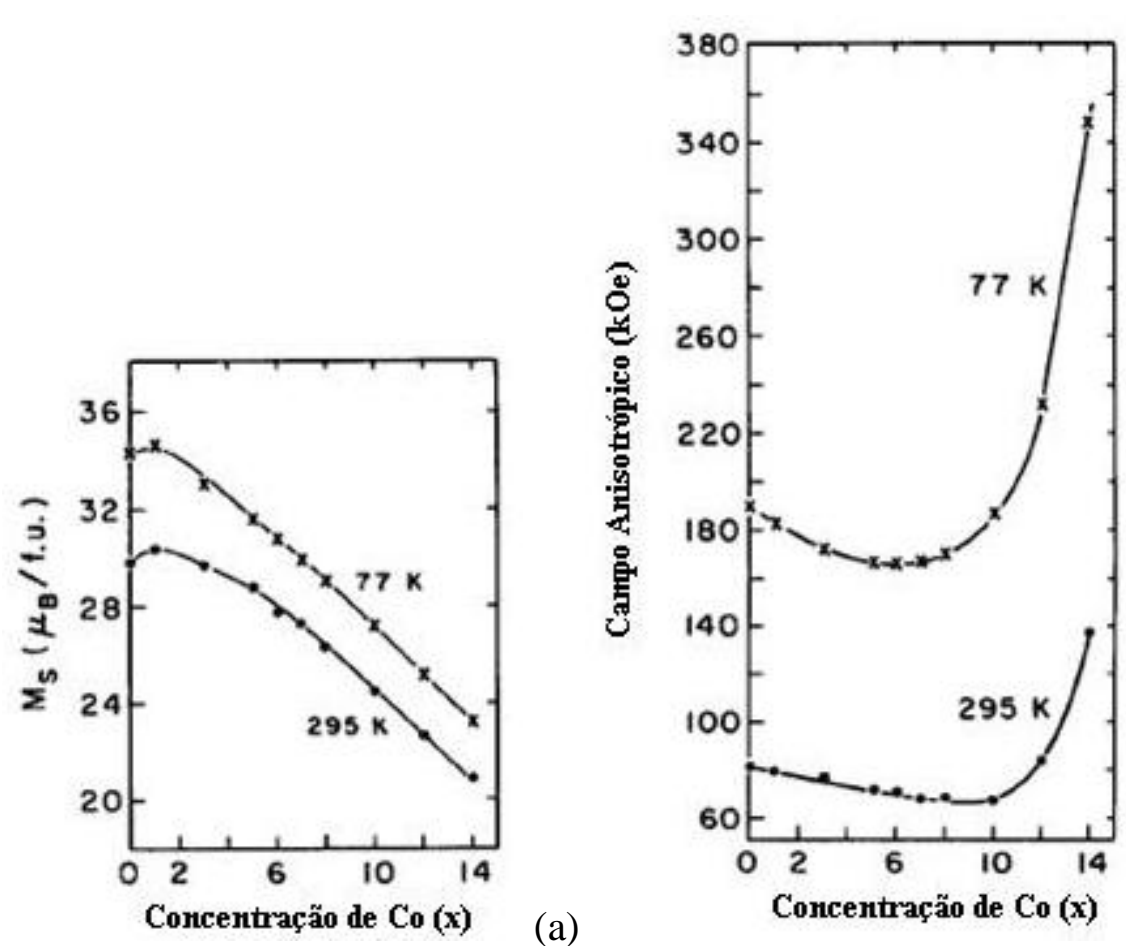

(a)

(b)

FIGURA 3.11 - Comportamento da magnetização de saturação e do campo de anisotropia em função da concentração de Co para o composto $\operatorname{Pr}_{2} \mathrm{Fe}_{14-\mathrm{x}} \mathrm{Co}_{\mathrm{x}} \mathrm{B}$ (adaptada de Pedziwiatr et al., 1986a).

Os resultados obtidos nos estudos realizados por Bolzoni et al. (1987a) foram semelhante ao realizado por Pedziwiatr (1986a) descrito acima, apresentando somente pequenas discrepâncias. Neste estudo a diminuição do parâmetro de rede $c$ apresenta comportamento semelhante ao descrito por Pedziwiatr et al. (1986a), porém o parâmetro $a$ possui uma redução mais acentuada até $x=6$, vide FIG. 3.12. Para valores maiores a curva mostra certa linearidade. A partir dos estudos utilizando espectroscopia Mossbauer, Bolzoni concluiu que o cobalto tem preferência pela ocupação dos sítios $8 j$, em particular o $8 j_{2}$ que fica entre as camadas de ferro. 

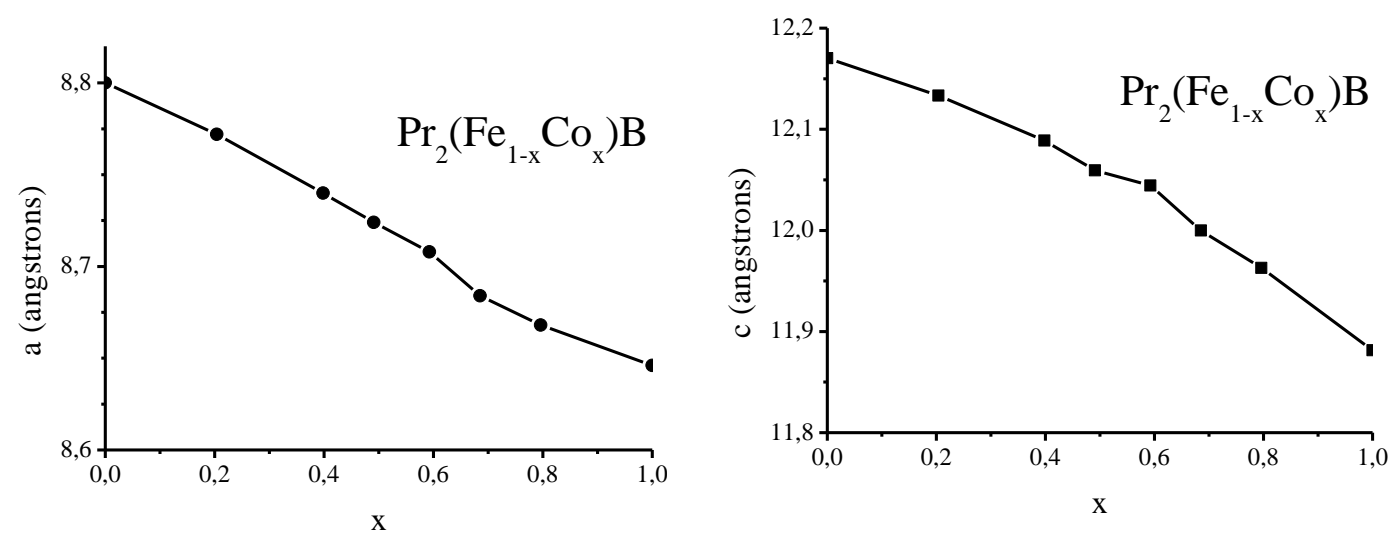

FIGURA 3.12 - Variação dos parâmetros de rede com a concentração de Co no composto $\mathrm{Pr}_{2} \mathrm{Fe}_{14-\mathrm{x}} \mathrm{Co}_{\mathrm{x}} \mathrm{B}$ (adaptada de Bolzoni et al., 1987a).

A variação da magnetização de saturação obtida por Bolzoni et al. (1987a) nas temperaturas de 4,2 K e $300 \mathrm{~K}$ em função da concentração de cobalto é apresentada na FIG. 3.13.

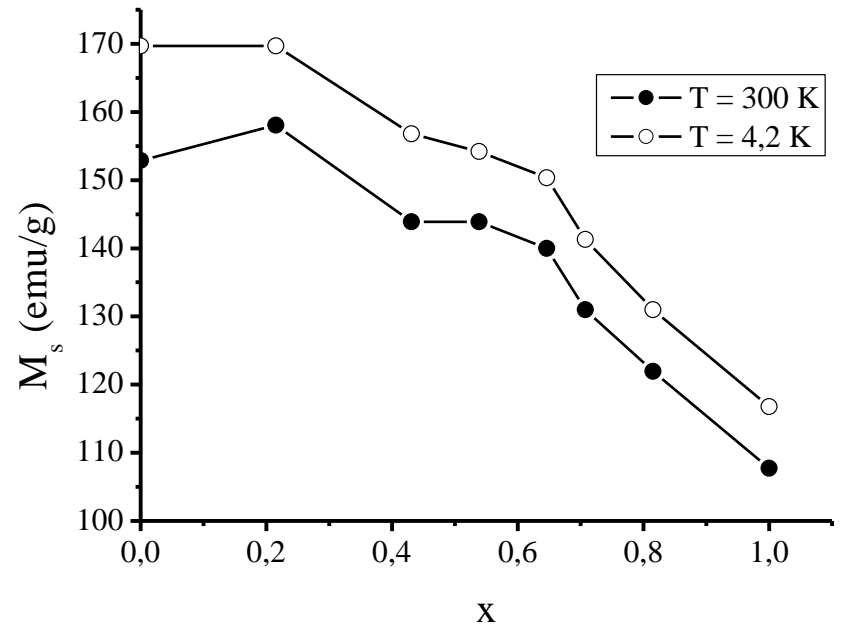

FIGURA 3.13 - Comportamento da magnetização de saturação em função da concentração de Co para o composto $\operatorname{Pr}_{2} \mathrm{Fe}_{14-\mathrm{x}} \mathrm{Co}_{\mathrm{x}} \mathrm{B}$ (adaptada de Bolzoni et al., 1987a).

Comparando-se os resultados obtidos por Pedziwiatr, FIG. 3.11(a), e Bolzoni, FIG. 3.13, pode-se inferir que a magnetização de saturação é dependente do sítio preferencialmente substituído. Uma vez nos estudos realizados por Pedziwiatr a substituição ocorreu preferencialmente no sítio $16 k_{1}$ e a máxima da saturação ocorre para $\mathrm{x}=2$. Enquanto, nos estudos realizados por Bolzoni, o sítio preferencial é o $8 j_{2}$ e neste caso o valor máximo de magnetização é atingido para $\mathrm{x}=4$. Nota-se um acréscimo na magnetização de saturação a baixa concentração na substituição do cobalto ao ferro. Para 
Pedziwiatr em $x=2$ e para Bolzoni em $x=4$. A explicação para esta elevação deve-se ao aumento da magnetização de saturação do ferro na presença do cobalto, efeito conhecido como curva de Slater-Pauling (Collins e Forwyth, 1963).

Barbosa et al. (2004) estudaram a influência da concentração de cobalto nas propriedades magnéticas e na $\mathrm{T}_{\mathrm{C}}$, nas ligas $\operatorname{Pr}_{14} \mathrm{Fe}_{79,9-\mathrm{x}} \mathrm{Co}_{\mathrm{x}} \mathrm{B}_{6} \mathrm{Nb}_{0,1}$ com $\mathrm{x}=$ 0, 4, 8, 12 e 16 . A FIG. 3.14 mostra o comportamento das propriedades magnéticas destas ligas em função do aumento da concentração de cobalto.
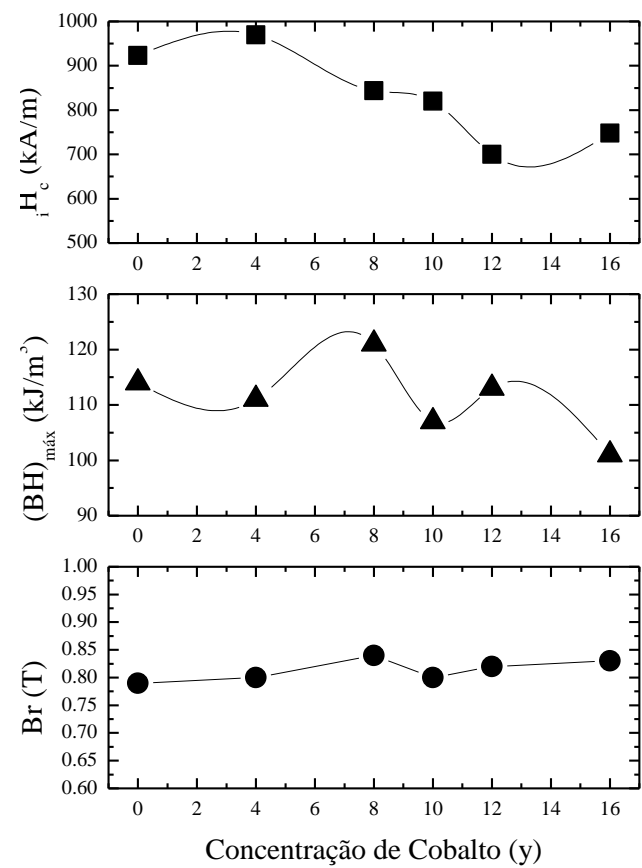

FIGURA 3.14 - Propriedades magnéticas das ligas $\operatorname{Pr}_{14} \mathrm{Fe}_{79,9-\mathrm{x}} \mathrm{Co}_{\mathrm{x}} \mathrm{B}_{6} \mathrm{Nb}_{0,1}$, onde $\mathrm{x}$ representa a concentração de Co em porcentagem atômica substituta ao $\mathrm{Fe}$ para $\mathrm{x}=0,4,8,12$ e 16 (adaptada de Barbosa, 2005).

Para esta liga, sob as condições de processamento utilizados em nosso laboratório a $\mathrm{T}_{\mathrm{C}}$ foi de $594 \mathrm{~K}$ para $\operatorname{Pr}_{14} \mathrm{Fe}_{79,9} \mathrm{~B}_{6} \mathrm{Nb}_{0,1}$ e aumenta a taxa de $(10,1 \pm 0,5) \mathrm{K}$ a cada $1 \%$ at. de cobalto substituído na liga.

TABELA 3.5 - Temperatura de Curie $\left(\mathrm{T}_{\mathrm{C}}\right)$ para as ligas $\operatorname{Pr}_{14} \mathrm{Fe}_{79,9-\mathrm{x}} \mathrm{Co}_{\mathrm{x}} \mathrm{B}_{6} \mathrm{Nb}_{0,1} \operatorname{com} \mathrm{x}=0$, 4, 8, 12, 16 (adaptada de Barbosa, 2005).

\begin{tabular}{l|l}
\hline Composição da liga (\% at.) & $\boldsymbol{T}_{\boldsymbol{C}}(\boldsymbol{K})$ \\
\hline $\mathrm{Pr}_{14} \mathrm{Fe}_{79,9} \mathrm{~B}_{6} \mathrm{Nb}_{0,1}$ & $567 \pm 1$ \\
$\mathrm{Pr}_{14} \mathrm{Fe}_{75,9} \mathrm{Co}_{4} \mathrm{~B}_{6} \mathrm{Nb}_{0,1}$ & $594 \pm 1$ \\
$\operatorname{Pr}_{14} \mathrm{Fe}_{71,9} \mathrm{Co}_{8} \mathrm{~B}_{6} \mathrm{Nb}_{0,1}$ & $642 \pm 1$ \\
$\mathrm{Pr}_{14} \mathrm{Fe}_{67,9} \mathrm{Co}_{12} \mathrm{~B}_{6} \mathrm{Nb}_{0,1}$ & $682 \pm 1$ \\
$\mathrm{Pr}_{14} \mathrm{Fe}_{63,9} \mathrm{Co}_{16} \mathrm{~B}_{6} \mathrm{Nb}_{0,1}$ & $725 \pm 1$ \\
\hline
\end{tabular}


Kowalczik (1989) estudou a substituição de ferro por silício, gálio, cromo e cobre na fase $\operatorname{Pr}_{2} \mathrm{Fe}_{14} \mathrm{~B}$. O efeito da composição sobre os parâmetros de rede da célula unitária da fase magnética $\operatorname{Pr}_{2} \mathrm{Fe}_{14} \mathrm{~B}$ e sobre a $\mathrm{T}_{\mathrm{C}}$ podem ser vistos nas FIG. 3.15. e FIG. 3.16, respectivamente.

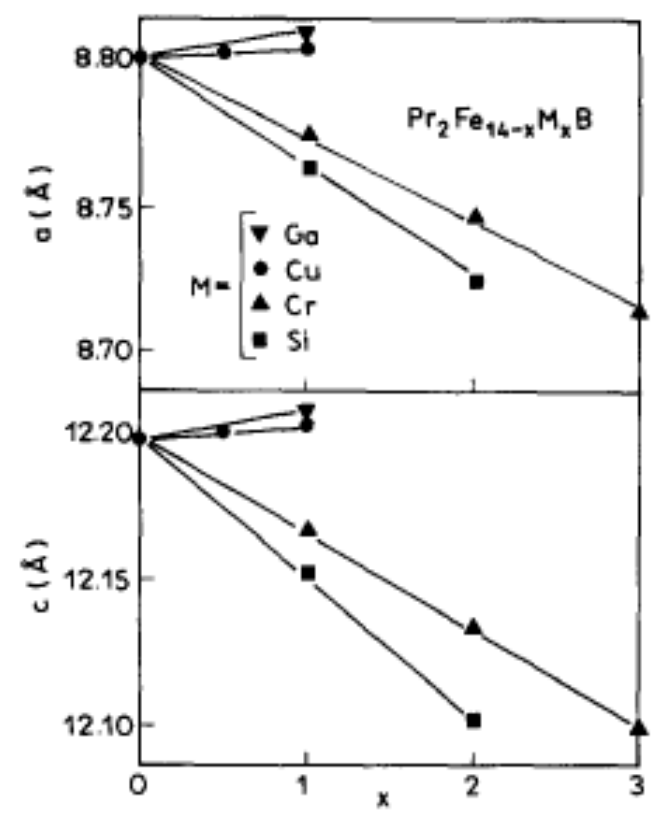

FIGURA 3.15 - Dependência dos parâmetros de rede da célula unitária com a concentração de elementos substituintes ao átomo de $\mathrm{Fe}$ na fase $\operatorname{Pr}_{2} \mathrm{Fe}_{14} \mathrm{~B}$ (adaptada de Kowalczik, 1989).

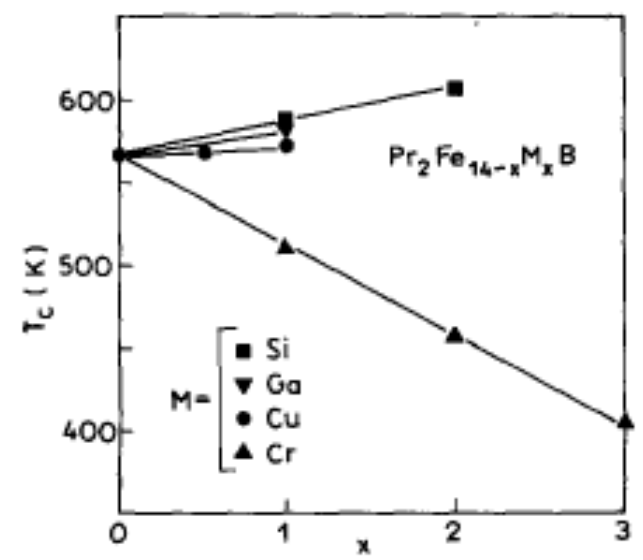

FIGURA 3.16 - Efeito da composição química sobre a $T_{C}$ da fase magnética $\operatorname{Pr}_{2} \mathrm{Fe}_{14} \mathrm{~B}$ (adaptada de Kowalczik, 1989).

$\mathrm{O}$ aumento da $\mathrm{T}_{\mathrm{C}}$ com o aumento da concentração de gálio, cobre e silício indica que a intensidade das interações de troca negativa sofreu um decréscimo. Isto sugere que os átomos do gálio e do cobre ocuparam preferencialmente posições com interações de troca negativas de alta intensidade $8 j_{1}-16 k_{2}$ ou $8 j_{1}-8 j_{1}$. A diminuição da $\mathrm{T}_{\mathrm{C}}$ com o 
aumento do teor de cromo indica que houve aumento da intensidade das interações de troca negativas.

\section{7 - Adição de dopantes e elementos de liga}

A substituição total e parcial dos elementos formadores da liga foi estudada objetivando-se o melhor entendimento das propriedades magnéticas e a maximização das mesmas.

Yelon et al. (1986) e Moze et al. (1989) realizaram estudos por difração de nêutrons indicando que: se o átomo substituinte possui raio menor que o raio do praseodímio, este preferencialmente ocupará o sítio $4 f$ na estrutura cristalina. Este resultado está de acordo com simples considerações estereográficas, uma vez que o volume associado com o sítio $4 f$ é um pouco menor que o do sítio $4 g$.

Moze et al. (1988) observaram que os metais de transição têm preferência para ocupar o sítio $j 2$ em seu estudo da substituição de cromo e manganês no sistema ítrio-ferroboro.

A motivação para a substituição do átomo de ferro foi a procura de um átomo substituinte que aumentasse a $\mathrm{T}_{\mathrm{C}}$, uma vez que o ferro metálico possui $\mathrm{T}_{\mathrm{C}}$ da ordem de 1000 K. Os elementos substituintes estudados para o ferro foram: alumínio, nióbio, cobalto, cromo, cobre, gálio, silício, zircônio e manganês.

O boro é o elemento que dá base à estrutura tetragonal da liga. A substituição deste na liga implicaria na modificação da estrutura cristalina. O único átomo possível na substituição é o carbono (Herbst, 1991).

A adição de outros elementos às ligas TR-Fe-B tem ainda por objetivo a formação de novas fases não magnéticas e magneticamente moles na região de contorno de grão e no interior do grão. Quando ocorre a formação de fase no interior dos grãos esta influencia a polarização espontânea, a $\mathrm{T}_{\mathrm{C}} \mathrm{e}$ a anisotropia magneto-cristalina. As fases formadas no contorno de grão alteram: as interações magnetoestáticas, interações dipolares de longa distância e interações de troca de acoplamento a curta distância entre os grãos da fase magnética (Angelo, 2005).

No caso específico dos magnetos consolidados por resina a força motora para os estudos da adição de novos elementos à liga foi a da obtenção de pós anisotrópicos visto que, os pós obtidos pelos processos de melt-spinning, mechanical alloying e HDDR são comumente isotrópicos. 
A obtenção da fase magnética $\operatorname{Pr}_{2} \mathrm{Fe}_{14} \mathrm{~B}$ em sua estequiometria correta é bastante difícil. Por este motivo foram estudadas diversas estequiometrias a fim de se obter um material com a menor quantidade de fases minoritárias e que apresente propriedades magnéticas muito próximas às propriedades intrínsecas da fase $\operatorname{Pr}_{2} \mathrm{Fe}_{14} \mathrm{~B}$, comportamento este também verificado no sistema Nd-Fe-B.

As ligas Pr-Fe-B foram extensivamente estudadas pelos diversos pesquisadores e alunos do grupo do Laboratório de Materiais Magnéticos do CCTM-IPEN; estes estudos permitiram o desenvolvimento da liga $\operatorname{Pr}_{14} \mathrm{Fe}_{\text {bal }} \mathrm{Co}_{16} \mathrm{~B}_{6} \mathrm{Nb}_{0,1}$, a qual apresenta a maximização das propriedades magnéticas dentre todas as ligas estudadas pelo grupo. Barbosa et al., (2004, 2005, 2004a) realizaram estudos da influência da variação do teor de praseodímio, ferro e boro no processamento das ligas por HDDR. Angelo (2005) estudou a influência do teor de cobalto, boro e nióbio nas propriedades magnéticas de ímãs sintetizados do sistema Pr-Fe-Co-B-Nb. Os resultados apresentados por Barbosa (2005) e Angelo (2005) mostraram que o comportamento das propriedades magnéticas é função da estequiometria da liga e dos parâmetros de processamento dos magnetos. Portanto, a comparação dos resultados das propriedades magnéticas entre diferentes processos somente pode ser realizada em um sentido qualitativo.

Mizoguchi et al (1986) estudaram as propriedades magnéticas dos sistemas $\mathrm{Nd}-\mathrm{Fe}$ B, Nd-Fe-B-Co $16 \%$ at., Nd-Fe-B-Al $1 \%$ at. e Nd-Fe-B-Co $16 \%$ at. - Al $2 \%$ at., em ímãs sinterizados. A coercividade em função do teor de boro para aos sistemas Nd-Fe-B com adição de $1 \%$ atômico de alumínio apresentou comportamento e valores semelhantes; para as ligas com cobalto $16 \%$ at. e com cobalto $16 \%$ at. $+2 \%$ at. de alumínio o comportamento foi semelhante. Contudo a adição de alumínio praticamente duplica os valores de coercividade para todos os teores de boro estudados. O estudo da influência do teor de alumínio na liga $\mathrm{Nd}_{15} \mathrm{Fe}_{63,5} \mathrm{~B}_{5,5} \mathrm{Al}_{\mathrm{x}}$, onde $x$ varia de $0 \%$ a $4 \%$ at. mostrou que a remanência diminui com o aumento do teor deste elemento enquanto que a coercividade atinge o valor máximo para a adição de $2 \%$ at. de alumínio e o produto máximo de energia diminui acentuadamente a partir da adição de $1 \%$ at. de alumínio. As análises por difração de raios $\mathrm{X}$ indicam que a adição de $16 \%$ at. de cobalto leva a formação da fase de Laves $\mathrm{Nd}(\mathrm{Fe}, \mathrm{Co})_{2}$ (cúbica de corpo centrada) onde o parâmetro de rede $a$ desta fase igual a 7,40 A. Nestas ligas o parâmetro de rede calculado foi de $a=7,42 \AA$ indicando que este aumento é decorrente da substituição de alumínio, uma vez que o raio do alumínio é maior que o raio do ferro ou do cobalto. Portanto, estes resultados indicam que ocorre substituição dos átomos de ferro e cobalto pelo alumínio tanto na fase matriz como na fase 
de Laves. Os autores defendem a tese que: os sítios de nucleação de domínios reversos ocorrem na fase matriz e na fase de Laves, também magnética, o que leva à redução da coercividade e que a adição de alumínio torna a fase de Laves não magnética podendo ser a causa do aumento da coercividade.

Jiang et al (1986) verificaram que as propriedades magnéticas da fase $\mathrm{PrFe}_{\mathrm{x}} \mathrm{Co}_{4-\mathrm{x}} \mathrm{B}$ (para x de 0 a 1,5) são dependentes das quantidades de ferro e cobalto, assim como os parâmetros de rede (sistema hexagonal). Os resultados apresentados pelos autores mostram que o parâmetro $a$ da estrutura cristalina é mais influenciado que o parâmetro $c$ pelo aumento do teor de ferro diferentemente da fase $\operatorname{Pr}_{2} \mathrm{Fe}_{14} \mathrm{~B}$. Nesta fase $\left(\mathrm{PrFe}_{\mathrm{x}} \mathrm{Co}_{4-\mathrm{x}} \mathrm{B}\right) \mathrm{o}$ aumento do teor de ferro ocasiona o aumento da $\mathrm{T}_{\mathrm{C}}$; para a faixa de valores estudada (de 0 a $1,5 \%$ at.) este aumento não apresentou um comportamento linear. Os resultados obtidos para os valores do momento magnético do átomo de cobalto permitiram verificar que: ocorre influência do teor de ferro na fase como se houvesse substituição do átomo de praseodímio por outro átomo de TR.

Schrey (1988) em seu trabalho determinou que a adição de nióbio na liga $\mathrm{Nd}_{14} \mathrm{Fe}_{78} \mathrm{Nb}_{1} \mathrm{~B}_{7}$ leva à formação da fase $\mathrm{NbFeB}$, hexagonal com $a \approx 0,6 \mathrm{~nm}$ e $c \approx 0,32 \mathrm{~nm}$, e que a morfologia desta fase é fortemente dependente dos tratamentos térmicos aos quais a liga é submetida. Enquanto no estado fundido a solubilidade do nióbio é da ordem de 0,4 $\%$ a $0,5 \%$ em massa; após o recozimento este valor cai para $0,1 \%$ em massa.

Kim (1988) estudou o sistema (Nd,Dy)-(Fe,Al)-B onde a troca do ferro por alumínio implica no aumento da coercividade intrínseca, porém com redução da remanência e da $T_{C}$. Em contra partida, a troca de neodímio por disprósio aumenta a $T_{C}$. Kim também verificou que, a adição de disprósio e alumínio pode implementar uma significante melhora nas propriedades magnéticas e na $\mathrm{T}_{\mathrm{C}}$. $\mathrm{O}$ estudo mostrou que quantidades atômicas iguais de disprósio e alumínio são as que oferecem melhores propriedades magnéticas. Esta liga quando comparada às ligas Nd-Dy-Fe-B ou Nd-Fe-AlB com equivalente quantidade de disprósio e alumínio possui uma coercividade intrínseca muito maior, com uma redução na remanência insignificante. $\mathrm{O}$ estudo também mostrou que o aumento da coercividade intrínseca é linear com o aumento da quantidade de disprósio. Os resultados sugerem que a substituição de ferro por alumínio pode tornar mais atrativo o custo destes materiais e assim aumentar sua gama de aplicações.

Rodewald e Wall (1989) estudaram a substituição do ferro por nióbio na liga $\mathrm{Nd}_{15.6} \mathrm{Fe}_{76.9-\mathrm{x}} \mathrm{Nb}_{\mathrm{x}} \mathrm{B}_{7.5} \mathrm{com} \mathrm{x}=0 ; 0,4 ; 0,8 ; 1,2 ; 1,6$ e 2,0. A concentração de nióbio na fase $\mathrm{Nd}_{2} \mathrm{Fe}_{14} \mathrm{~B}$ do material fundido situa-se na faixa de $0,5 \%$ a $0,7 \%$ em massa enquanto que 
nos magnetos sinterizados esta concentração mostrou-se fortemente dependente da temperatura de sinterização: a $630{ }^{\circ} \mathrm{C}$ por $1 \mathrm{~h}$ a concentração é da ordem de $0,1 \% \mathrm{em}$ massa e a $1080{ }^{\circ} \mathrm{C}$ é de $0,2 \%$ em massa. As análises por microscopia eletrônica de transmissão revelaram que a maior parte do nióbio adicionado forma o precipitado $\mathrm{Nb}-\mathrm{Fe}-\mathrm{B}$ de estrutura hexagonal na forma de finas plaquetas com diâmetros na faixa de $100 \mathrm{~nm}$ a $500 \mathrm{~nm}$, que seriam muito grandes para promover a ancoragem da parede de domínio. Segundo os autores as quantidades de nióbio adicionadas não permitiram observar alterações apreciáveis na polarização de saturação, na $T_{C}$, no coeficiente de temperatura da coercividade e na intensidade do campo de anisotropia.

Jurczyk e Chistjakov (1989) estudaram o efeito de diferentes teores de nióbio e disprósio nos sistemas Pr-Fe-B e Pr-Fe-Co-B nos valores da magnetização de saturação e do campo de anisotropia e na $\mathrm{T}_{\mathrm{C}}$. A TAB. 3.6 apresenta os resultados obtidos pelos autores.

$\mathrm{O}$ decréscimo da $\mathrm{T}_{\mathrm{C}}$ pela substituição do ferro pelo nióbio sugere que o nióbio ocupa preferencialmente os sítios do ferro que possuem interações de troca positiva, isto é, os sítios que possuem a maior distância interatômica, que para esta estrutura, são $j_{2}$ e $k_{l}$. Por outro lado, o cobalto deve ocupar os sítios de ferro com interação de troca negativa, ou seja, sítios $k_{2}$ e $j_{2}$.

TABELA 3.6 - Valores de magnetização de saturação $\left(\mathrm{M}_{\mathrm{s}}\right)$, do campo de anisotropia $\left(\mathrm{H}_{\mathrm{A}}\right)$ e $\mathrm{T}_{\mathrm{C}}$ (adaptada de Jurczyrk e Chistjakov, 1989).

\begin{tabular}{|c|c|c|c|}
\hline Composto & $\begin{array}{c}T_{C} \\
(K) \pm 2 K\end{array}$ & $\begin{array}{c}M_{s} \\
\left(\mu_{\mathrm{B}} / \text { f.u. }\right) \pm 0,2 \mu_{\mathrm{B}} \\
297 \mathrm{~K}\end{array}$ & $\begin{array}{c}H_{A}(k O e) \\
297 \mathrm{~K}\end{array}$ \\
\hline $\operatorname{Pr}_{2} \mathrm{Fe}_{14} \mathrm{~B}$ & 566 & 31,0 & 80 \\
\hline $\mathrm{Pr}_{2} \mathrm{Fe}_{13,9} \mathrm{Nb}_{0,1} \mathrm{~B}$ & 563 & 30,4 & 83 \\
\hline $\mathrm{Pr}_{2} \mathrm{Fe}_{13,8} \mathrm{Nb}_{0,2} \mathrm{~B}$ & 560 & 30,0 & 86 \\
\hline $\mathrm{Pr}_{2} \mathrm{Fe}_{13} \mathrm{Co}_{1} \mathrm{~B}$ & 628 & 31,2 & 79 \\
\hline $\mathrm{Pr}_{2} \mathrm{Fe}_{12,9} \mathrm{Nb}_{0,1} \mathrm{Co}_{1} \mathrm{~B}$ & 625 & 30,8 & 82 \\
\hline $\mathrm{Pr}_{2} \mathrm{Fe}_{12,8} \mathrm{Nb}_{0,2} \mathrm{Co}_{1} \mathrm{~B}$ & 621 & 30,3 & 86 \\
\hline $\mathrm{Pr}_{1,9} \mathrm{Dy}_{0,1} \mathrm{Fe}_{13} \mathrm{Co}_{1} \mathrm{~B}$ & 632 & 30,7 & 84 \\
\hline $\operatorname{Pr}_{1,9} \mathrm{Dy}_{0,1} \mathrm{Fe}_{12,9} \mathrm{Nb}_{0,1} \mathrm{Co}_{1} \mathrm{~B}$ & 630 & 30,2 & 87 \\
\hline $\operatorname{Pr}_{1,9} \mathrm{Dy}_{0,1} \mathrm{Fe}_{12,8} \mathrm{Nb}_{0,2} \mathrm{Co}_{1} \mathrm{~B}$ & 627 & 29,7 & 91 \\
\hline
\end{tabular}

A adição de nióbio tanto no sistema Pr-Fe-B quanto no Pr-Fe-Co-B ocasiona a diminuição da magnetização de saturação com o aumento do teor adicionado. Já o campo de anisotropia aumenta com o aumento do teor adicionado. A adição de disprósio nos 
sistemas estudados não apresentou resultados significativos em relação a $T_{C}$ porém, nas propriedades magnéticas o seu efeito foi deletério. Adicionalmente, ao seu objetivo principal os autores apresentaram os resultados obtidos para os parâmetros de rede $a$ e $c$ conforme mostrado na FIG. 3.17.

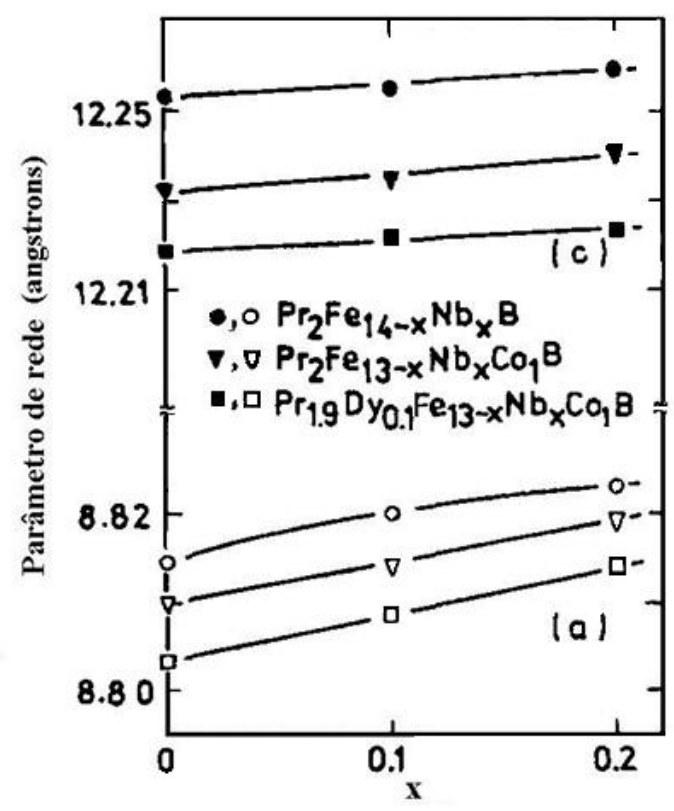

FIGURA 3.17 - Variação dos parâmetros de rede $a$ e $c$ para as ligas processadas (adaptada de Jurczyk e Chistjakov, 1989).

Noh et al. (1991) estudaram o efeito da moagem mecânica e da adição de cobre sobre a liga $\operatorname{Pr}_{15} \mathrm{Fe}_{80} \mathrm{~B}_{5}$ quanto às propriedades magnéticas e nas características microestruturais. Com o aumento do tempo de moagem ocorre a diminuição da coercividade, com exceção de um pico de alta intensidade que ocorre após $3 \mathrm{~h}$ de moagem atribuído a um refinamento da partícula; a diminuição da coercitividade é decorrente da formação de uma fase amorfa levemente magnética. As análises por difração de raios $\mathrm{X}$ mostraram que a fase magnética $\operatorname{Pr}_{2} \mathrm{Fe}_{14} \mathrm{~B}$ tornou-se amorfa com o aumento do tempo de moagem, enquanto que o pico do ferro livre presente no material de partida apresenta um alargamento devido a introdução de defeitos na rede cristalina. Os pós da liga foram recozidos por uma hora em diversas temperaturas, os melhores resultados de coercividade para os pós com tempo de moagem inferior a $20 \mathrm{~h}$ foram obtidos a $700{ }^{\circ} \mathrm{C}$. Para os tempos superiores de moagem a temperatura utilizada foi de $600{ }^{\circ} \mathrm{C}$. A difração de raios $\mathrm{X}$ dos pós recozidos mostra que o crescimento dos cristalitos da fase $\operatorname{Pr}_{2} \mathrm{Fe}_{14} \mathrm{~B}$ ocorre à temperatura de $500{ }^{\circ} \mathrm{C}$ e que a $800{ }^{\circ} \mathrm{C}$ estes cristalitos passam a ter um crescimento orientado. A adição 
$0,15 \%$ de $\mathrm{Cu}$ à liga com subseqüente moagem por 12 horas e recozimento a $600{ }^{\circ} \mathrm{C}$ por 1 hora resultou na melhora da coercividade para os menores tempos de moagem. Segundo Shimoda et al (1988) o cobre diminui a temperatura de fusão da fase rica em praseodímio, o que segundo os autores levaria a uma suavização do contorno de grão durante o recozimento proporcionando melhor coercividade. A liga dopada apresentou ${ }_{i} \mathrm{H}_{\mathrm{c}}$ de 1,57 $\mathrm{kA} / \mathrm{m}, \mathrm{B}_{\mathrm{r}}$ de $700 \mathrm{mT}$ e $(\mathrm{BH})_{\text {máx }}$ de $81,2 \mathrm{~kJ} / \mathrm{m}^{3}$.

Chen et al (1992) estudaram as propriedades magnéticas de ímãs sinterizados produzidos por prensagem a quente a partir do material fundido da liga $\operatorname{Pr}_{19} \mathrm{Fe}_{74,5} \mathrm{~B}_{5} \mathrm{Cu}_{1,5}$. Após a prensagem a quente, os magnetos sofreram tratamento térmico de recozimento. Os resultados indicam que a remanência, a coercividade e o produto máximo de energia aumentam com diminuição da espessura da fase rica. As análises microestruturais mostraram que com o aumento da redução da espessura a fase rica em praseodímio é "espremida" para fora do grão formando um filme fino ao redor do grão. A formação desta fina camada cria uma isolação entre os grãos de $\operatorname{Pr}_{2} \mathrm{Fe}_{14} \mathrm{~B}$. Portanto, há o desacoplamento magnético dos grãos da fase matriz servindo desta forma, como uma barreira para impedir a propagação de magnetização reversa de um grão para outro aumentando assim os valores de coercividade do material. $\mathrm{O}$ aumento da remanência, segundo sugerido pelos autores, é devido à formação de textura cristalografia durante a prensagem a quente, pois o $\operatorname{Pr}_{2} \mathrm{Fe}_{14} \mathrm{~B}$ possui apenas um plano de escorregamento (001) e duas direções de escorregamento [100] e [010]. O estudo também permitiu aos autores concluírem que o recozimento dos ímãs não alterou a textura cristalográfica originada na etapa de prensagem a quente. Os valores máximo de remanência e coercividade obtidos para este ímã foram 9,9 kG e 11,0 kOe, respectivamente, e o produto máximo de energia foi de 24,0 MGOe.

Uehara et al. (1993) estudaram a influência do gálio nas etapas de hidrogenação e desproporção durante o processo HDDR. A FIG. 3.18 apresenta os padrões de difração de raios $\mathrm{X}$ obtidos para liga $\mathrm{Nd}_{12,5} \mathrm{Fe}_{70-\mathrm{x}} \mathrm{Co}_{11,5} \mathrm{Ga}_{\mathrm{x}} \mathrm{B}_{6}$ onde $x$ varia de 0 a $5 \%$ at.,hidrogenadas a $1148 \mathrm{~K}$ por $1 \mathrm{~h}$. Conforme pode ser visto a intensidade dos picos da fase matriz $\mathrm{Nd}_{2}(\mathrm{Fe}, \mathrm{Co}){ }_{14} \mathrm{~B}$ aumenta com o aumento do teor de gálio. Isto indica que a adição de gálio desacelera a desproporção, fazendo com que haja diminuição na decomposição da fase $\mathrm{Nd}_{2}(\mathrm{Fe}, \mathrm{Co})_{14} \mathrm{~B}$ que favorece à formação de núcleos de cristalização preferencial. 


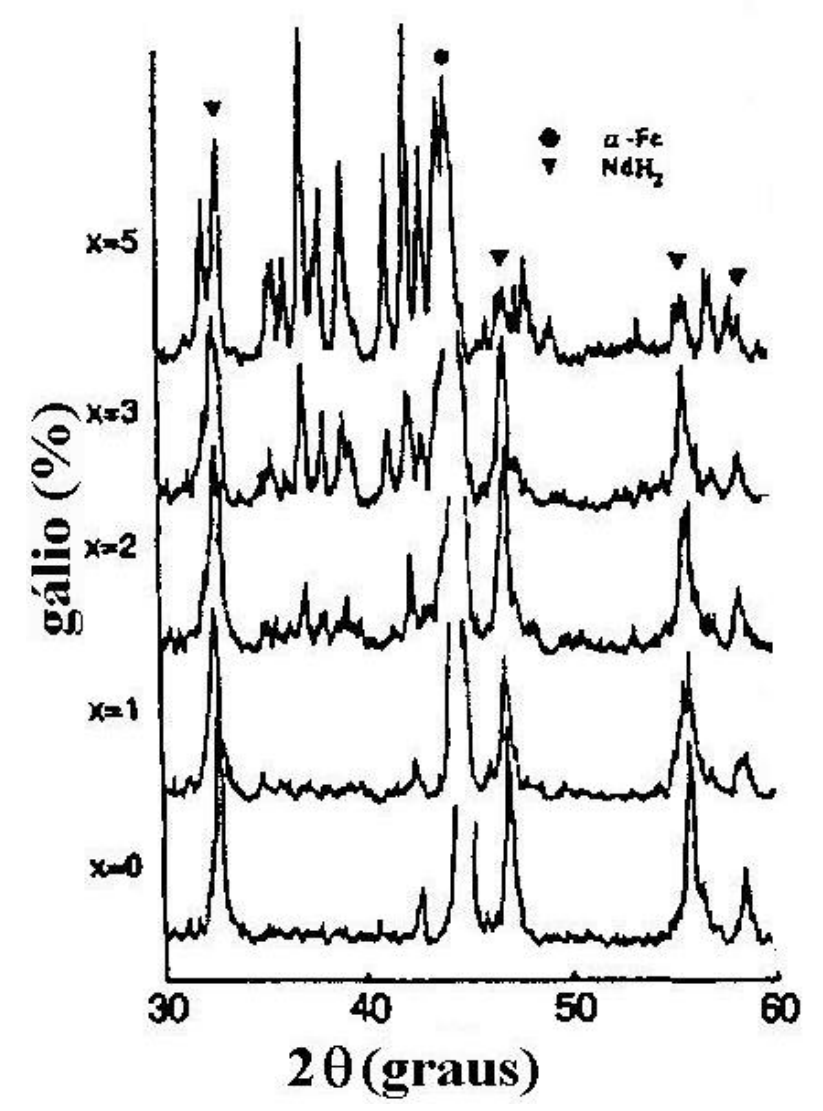

FIGURA 3.18 - Padrões de difração de raios $\mathrm{X}$ obtidos para liga $\mathrm{Nd}_{12,5} \mathrm{Fe}_{70-\mathrm{x}} \mathrm{Co}_{11,5} \mathrm{Ga}_{\mathrm{x}} \mathrm{B}_{6}$ para $x=0,1,2,3,4$ ou 5 , hidrogenadas a $874^{\circ} \mathrm{C}$ por $1 \mathrm{~h}$. (adaptada de Uehara et al.,1993).

Nakayama et al. (1994) verificaram melhores valores de remanência, coercividade e produto máximo de energia para as ligas $\mathrm{Nd}_{12,6} \mathrm{Fe}_{\mathrm{bal}} \mathrm{Co}_{11,5} \mathrm{~B}_{6,0} \mathrm{Ga}_{\mathrm{x}}$ e $\mathrm{Nd}_{12,6} \mathrm{Fe}_{\mathrm{bal}} \mathrm{Co}_{11,5} \mathrm{~B}_{6,0} \mathrm{Zr}_{\mathrm{x}}$ onde, $x$ variou de $0,5 \%$ a $2 \%$ at. para o gálio e foi mantido fixo em $0,1 \%$ at. para o zircônio. Observações realizadas por microscopia eletrônica de transmissão de alta resolução mostraram que a camada no contorno de grão tem largura de aproximadamente 1 nm sendo impossível sua análise. A adição de gálio e zircônio não ocasionou a precipitação de novas fases no interior dos grãos de $\mathrm{Nd}_{2} \mathrm{Fe}_{14} \mathrm{~B}$. A microestrutura dos pós anisotrópicos é a mesma que dos pós isotrópicos produzidos pelo processo HDDR em termos de tamanho de grão, morfologia do grão e estrutura de contorno do grão. A coercividade intrínseca parece ser devida ao tamanho do grão ao qual é muito próximo do tamanho do domínio magnético (aproximadamente $0,3 \mu \mathrm{m}$ ). Nenhuma diferença nesta estrutura foi vista com a adição de gálio ou zircônio. A coercividade dos imãs a base de Nd-Fe-Co-B aumentou com a adição de gálio nos ímãs sinterizados, nos ímãs resfriados rapidamente e nos ímãs deformados a quente. A melhora da coercividade destes magnetos 
é atribuída a existência de uma fina camada no contorno de grão que contém a fase rica em neodímio onde se acredita que o gálio esteja solubilizado. Entretanto, no caso dos pós magnéticos obtidos pelo processo HDDR, as fases no contorno de grão são quase inexistentes em qualquer região do seu contorno, por isto foi reportado que o gálio é solúvel no $\mathrm{Nd}_{2}(\mathrm{Fe}, \mathrm{Co})_{14} \mathrm{~B}$ e que o campo de anisotropia do composto aumenta cerca de 10 $\%$ at. substituindo ferro com $3 \%$ at. a $7 \%$ at. de gálio. A análise por difração de raios $\mathrm{X}$ realizada na superfície perpendicular do magneto consolidado por adesão mostra que as reflexões (004), (006) e (105) são mais intensas que o valor teórico e no caso da superfície paralela a reflexão mais intensa é a (410). Estes resultados são os mesmos que os obtidos para imãs sinterizados e indica que pós anisotrópicos possuem o eixo $c$ do composto $\mathrm{Nd}_{2}(\mathrm{Fe}, \mathrm{Co})_{14} \mathrm{~B}$ quase paralelo em cada grão. Os autores propõem que a anisotropia magnética (em relação a direção do eixo $c$ ) após o processo HDDR parece ocorrer ao longo da direção do eixo $c$ do cristal "grosseiro" do estado inicial (da liga antes do processo) ou homogeneizada antes do processo. Portanto, para a produção de um bom pó anisotrópico é importante que: as orientações cristalográficas entre os grãos grosseiros na liga antes do processo estejam alinhadas de um grão para outro. Os autores atribuem que a anisotropia está relacionada com a textura cristalográfica. A maior anisotropia das ligas em que foi adicionada zircônio está relacionada à menor dispersão de orientações em torno do eixo dos grãos do material de partida.

Ahmed et al (1994) propuseram o mecanismo descrito na FIG. 3.19 para a formação da fase $\mathrm{Nb}-\mathrm{Fe}-\mathrm{B}$ dentro de grãos da fase matriz das ligas $\mathrm{Nd}-\mathrm{Fe}-\mathrm{B}$ durante o recozimento da liga fundida. Os autores concluem que a adição de $\mathrm{Nb}$ exerce uma influência significativa na diminuição do teor de ferro livre, uma vez que o raio atômico do ferro $\left(r_{a}=1,27 \AA\right)$ é menor que o raio atômico do praseodímio $\left(r_{a}=1,82 \AA\right)$ permitindo sua difusão através da fase matriz para a formação da fase $\mathrm{Nb}-\mathrm{Fe}-\mathrm{B}$. 

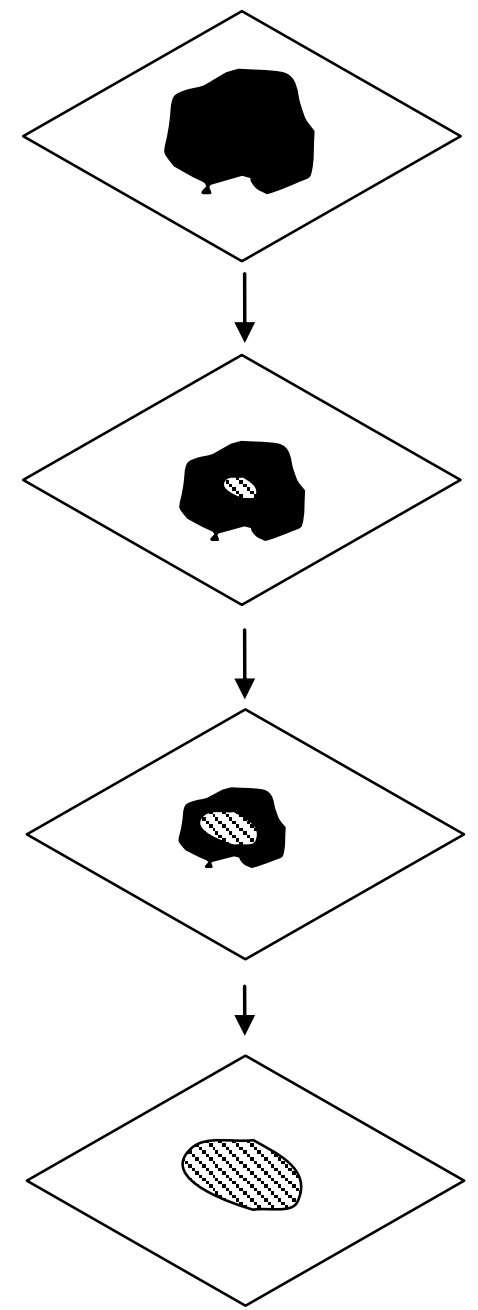

$\square$ Fase $\phi$
Estágio I: O ferro livre nucleia junto com a fase matriz. O ferro livre que está dentro da matriz reduz em tamanho e a concentração do $\mathrm{Nb}$ dentro do ferro livre aumenta. Neste mesmo estágio torna-se energeticamente favorável a nucleação da fase $\mathrm{Nb}-\mathrm{Fe}-\mathrm{B}$.

Estágio II: A fase ternária $\mathrm{Nb}-\mathrm{Fe}-\mathrm{B}$ nucleia dentro do ferro livre existente na fase matriz.

Estágio III: $\mathrm{O} \quad \mathrm{Nb}-\mathrm{Fe}-\mathrm{B}$ inicia o crescimento à custa do ferro livre e pela difusão do nióbio e boro.

Estágio $I V$ : A fase ternária $\mathrm{Nb}-\mathrm{Fe}-\mathrm{B}$ completa o crescimento e o ferro livre desaparece.

FIGURA 3.19 - Mecanismo de nucleação e crescimento da fase Nb-Fe-B.(adaptada de Ahmed et al, 1994)

Posteriormente, Ahmed et al. (1996) verificaram que dependendo do teor de nióbio ocorrem modificações microestruturais. Os autores estudaram a liga $\mathrm{Nd}_{11,8} \mathrm{Fe}_{82.3-\mathrm{x}} \mathrm{Nb}_{\mathrm{x}} \mathrm{B}_{5,9}$ $(\mathrm{x}=0,1,2,3,5)$ e verificaram que o tempo de homogeneização é altamente influenciado pelo teor de nióbio. Para a amostra sem nióbio foram necessárias $280 \mathrm{~h}$ de homogeneização, enquanto que para a amostra com o maior teor de nióbio foram somente necessárias $10 \mathrm{~h}$ para remover todo ferro livre. As análises por difração de raios $\mathrm{X}$ mostraram que para amostras com nióbio aparecem picos adicionais que foram atribuídos a fase $\mathrm{Nb}-\mathrm{Fe}-\mathrm{B}$ e ainda para as amostras com $3 \%$ e $5 \%$ at. aparece a fase $\mathrm{Nd}_{2} \mathrm{Fe}_{17}$. Os estudos da influência do teor de nióbio no processo HDDR mostram que para as amostras 
com $0 \%$ e $1 \%$ at. de nióbio não ocorre diferença significativa na absorção de hidrogênio. Já para amostras com $2 \%, 3 \%$ e $5 \%$ at. de nióbio a absorção de hidrogênio ocorre em temperaturas significativamente menores; e a temperatura em que ocorre a desproporção para estas amostras aumenta com o aumento do teor de nióbio. Isto pode ser indicativo de um aumento da estabilidade da fase Nd-Fe-B, devido a substituição do ferro pelo nióbio. A influência nas etapas de dessorção e recombinação é muito menor comparada as duas etapas iniciais. As amostras com teor acima de $2 \%$ at. apresentam duas etapas de dessorção. Uma referente a dessorção da fase rica (alto teor de $\mathrm{Nd}$ ) e a outra referente ao hidreto de neodímio formado pela desproporção da fase matriz (Nd-Fe-B). Os autores concluem que a desproporção inicia-se na interface da fase $\mathrm{Nd}-\mathrm{Fe}-\mathrm{B}$ e $\mathrm{Nb}-\mathrm{Fe}-\mathrm{B}$, que não há evidência de desproporção da fase $\mathrm{Nd}_{2} \mathrm{Fe}_{17}$ e que o nióbio parece refinar o grão do material recombinado.

Takeshita e Morimoto (1996) estudaram as ligas $\mathrm{Nd}_{12-13} \mathrm{Fe}_{\mathrm{bal}} \mathrm{B}_{5-8} \mathrm{Co}_{10-20} \mathrm{M}_{0,1-1}(\mathrm{M}=$ $\mathrm{Ga}, \mathrm{Zr}$ ) e observaram que o tamanho de partícula influencia a remanência e a coercividade intrínseca dos pós preparados pelo processo HDDR. Os maiores valores de remanência foram obtidos para pós com tamanho de partícula de $50 \mu \mathrm{m}$ a $200 \mu \mathrm{m}$ e, segundo os autores, isto sugere que o eixo de orientação $c$ dos grãos originais da fase $\mathrm{Nd}_{2}(\mathrm{Fe}, \mathrm{Co})_{14} \mathrm{~B}$ do material fundido pode estar sendo mantido durante o processo HDDR, os valores de coercividade são relativamente constantes entre $50 \mu \mathrm{m}$ a $420 \mu \mathrm{m}$. Portanto, segundo os autores, a dependência das propriedades magnéticas em função do tamanho de partícula é relativamente pequena implicando em um pó magnético com larga distribuição do tamanho de partícula que pode ser usado para a produção de magnetos consolidados por resina, permitindo a obtenção de magnetos de maior densidade e conseqüentemente maior

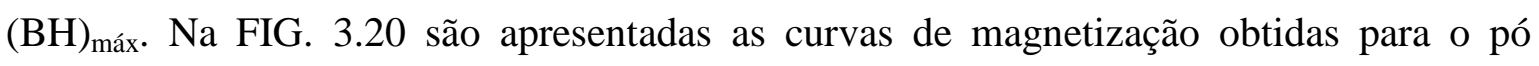
compactado e o pó consolidado por adesão que foram desmagnetizados magneticamente e termicamente. A amostra desmagnetizada magneticamente tem uma curva em forma de " $S$ " suavizado para baixa permeabilidade. Por outro lado, a amostra termicamente desmagnetizada exibe uma curva de desmagnetização que aumenta lentamente para campos baixos e mostra um ponto de inflexão ao redor de 795,8 kA/m (10 kOe) e então aumenta rapidamente para campos elevados. Este comportamento de magnetização sugere que a estrutura de domínios magnéticos de um pó anisotrópico HDDR no estado desmagnetizado magneticamente é diferente do outro no estado desmagnetizado termicamente e que é o movimento das paredes do domínio magnético que determina o comportamento destes pós magnéticos. Microestruturalmente as amostras apresentam o 
mesmo tamanho de grão e morfologia e, também, estruturas semelhantes na região de contorno de grão entre si.

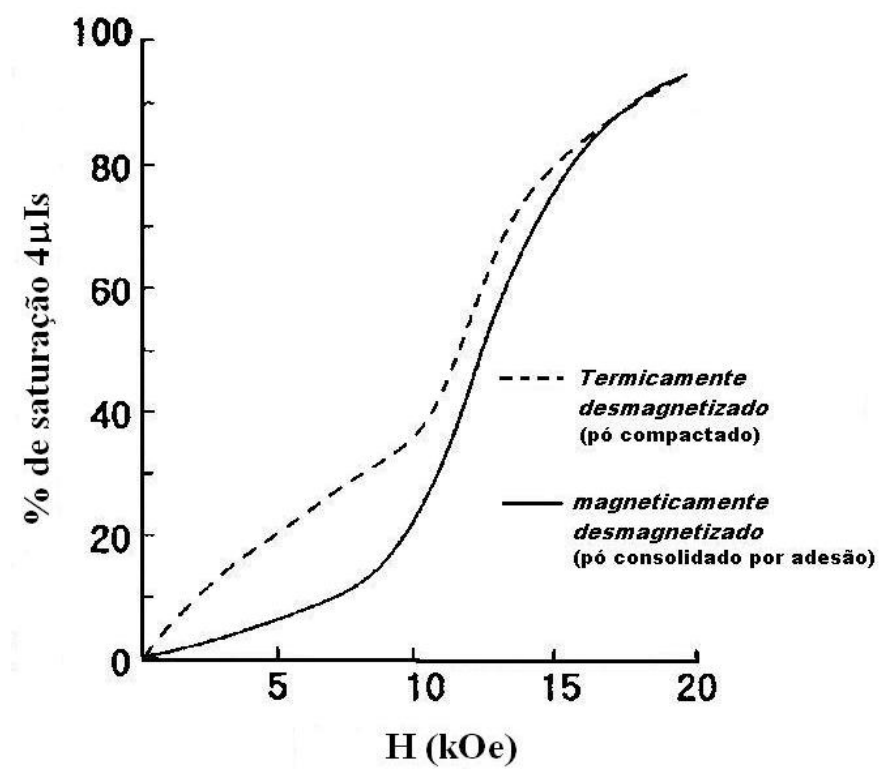

FIGURA 3.20 - Curvas de magnetização de amostras anisotrópicas produzidas por HDDR (adaptada de Takeshita e Morimoto, 1996).

Kim e Jeung (1998) estudaram os efeitos da adição de pequenas quantidades de gálio e zircônio em ligas Pr-Fe-B e Pr-Co-Fe-B, quanto à absorção e a dessorção do hidrogênio no processo HDDR. A adição de cobalto na faixa de (6 \% a $24 \%$ ) at. não afeta a reação de desproporção. No entanto, a temperatura da reação de recombinação diminui com o aumento do teor de cobalto. O gálio foi adicionado nos teores de 0,5\% at. e 1,5\% at. à liga $\operatorname{Pr}_{13} \mathrm{Fe}_{\text {bal }} \mathrm{B}_{6}$ e, também neste caso, a reação de desproporção não foi afetada $\mathrm{e}$ diminuindo a temperatura da reação de recombinação. A adição de gálio e cobalto simultaneamente ocasionou uma diminuição significativa na temperatura da reação de recombinação. A adição de zircônio levou a um aumento na faixa de temperatura em que ocorre a reação de desproporção. Com o aumento do teor de zircônio de $0,1 \%$ a $1 \%$ atômico a reação de desproporção inicia-se em uma temperatura menor e termina em uma temperatura maior do que na liga $\operatorname{Pr}_{13} \mathrm{~B}_{6} \mathrm{Fe}_{\text {bal }}$.

Jurczyk et al (1999) verificaram a influência da adição de $\mathrm{M}=\mathrm{Zr}, \mathrm{V}, \mathrm{Cr}, \mathrm{Ga}, \mathrm{Al}$ e Al-Cr nas ligas $\mathrm{Nd}_{12,6} \mathrm{Fe}_{69,8-\mathrm{x}} \mathrm{Co}_{11,6} \mathrm{M}_{\mathrm{x}} \mathrm{B}_{6}$ e $\mathrm{Nd}_{16} \mathrm{Fe}_{66,4-\mathrm{x}} \mathrm{Co}_{11,6} \mathrm{M}_{\mathrm{x}} \mathrm{B}_{6}$, obtidas pelo processo HDDR. A TAB. 3.7 apresenta os resultados obtidos para as ligas processadas a temperatura de recombinação de $1088 \mathrm{~K}$. Apesar da necessidade de maximização das condições de processamento para obtenção das melhores propriedades magnéticas, a temperatura da reação de recombinação foi fixada em $1088 \mathrm{~K}$ após diversos estudos que 
permitiram verificar que o teor de ferro livre remanescente é aceitável para as ligas estudadas.

TABELA 3.7 - Valores obtidos para ligas $\mathrm{Nd}_{2}(\mathrm{Fe}, \mathrm{Co}, \mathrm{M}){ }_{14} \mathrm{~B}$ processadas por HDDR (adaptada de Jin et al., 2003).

\begin{tabular}{l|ccc}
\hline Composto & ${ }_{i} \boldsymbol{H}_{\boldsymbol{c}}\left(\boldsymbol{k} \boldsymbol{A} \boldsymbol{m}^{-\boldsymbol{T}}\right)$ & $\boldsymbol{J}_{\boldsymbol{s}}(\boldsymbol{T})$ & $\boldsymbol{J}_{\boldsymbol{r}}(\boldsymbol{T})$ \\
\hline $\mathrm{Nd}_{12,6} \mathrm{Fe}_{69,3} \mathrm{Co}_{11,6} \mathrm{Zr}_{0,5} \mathrm{~B}_{6}$ & 776 & 1,14 & 0,66 \\
$\mathrm{Nd}_{16} \mathrm{Fe}_{65,9} \mathrm{Co}_{11,6} \mathrm{Zr}_{0,5} \mathrm{~B}_{6}$ & 955 & 1,35 & 0,82 \\
$\mathrm{Nd}_{16} \mathrm{Fe}_{66,275} \mathrm{Co}_{11,6} \mathrm{~V}_{0,125} \mathrm{~B}_{6}$ & 864 & 1,21 & 0,79 \\
$\mathrm{Nd}_{16} \mathrm{Fe}_{66,15} \mathrm{Co}_{11,6} \mathrm{~V}_{0,25} \mathrm{~B}_{6}$ & 880 & 1,20 & 0,87 \\
$\mathrm{Nd}_{16} \mathrm{Fe}_{66,025} \mathrm{Co}_{11,6} \mathrm{~V}_{0,375} \mathrm{~B}_{6}$ & 808 & 1,17 & 0,75 \\
$\mathrm{Nd}_{16} \mathrm{Fe}_{66,025} \mathrm{Co}_{11,6} \mathrm{~V}_{0,375} \mathrm{~B}_{6}$ & 176 & 1,15 & 0,42 \\
$\mathrm{Nd}_{16} \mathrm{Fe}_{66,275} \mathrm{Co}_{11,6} \mathrm{Cr}_{0,125} \mathrm{~B}_{6}$ & 958 & 1,23 & 0,79 \\
$\mathrm{Nd}_{12,6} \mathrm{Fe}_{66,15} \mathrm{Co}_{11,6} \mathrm{Cr}_{0,25} \mathrm{~B}_{6}$ & 810 & 1,17 & 0,72 \\
$\mathrm{Nd}_{16} \mathrm{Fe}_{66,15} \mathrm{Co}_{11,6} \mathrm{Cr}_{0,25} \mathrm{~B}_{6}$ & 976 & 1,22 & 0,87 \\
$\mathrm{Nd}_{16} \mathrm{Fe}_{65,4} \mathrm{Co}_{11,6} \mathrm{Cr}_{0,5} \mathrm{~B}_{6}$ & 896 & 1,20 & 0,80 \\
$\mathrm{Nd}_{16} \mathrm{Fe}_{65,4} \mathrm{Co}_{11,6} \mathrm{Cr}_{1,0} \mathrm{~B}_{6}$ & 792 & 1,29 & 0,66 \\
$\mathrm{Nd}_{16} \mathrm{Fe}_{64,4} \mathrm{Co}_{11,6} \mathrm{Cr}_{2,0} \mathrm{~B}_{6}$ & 680 & 1,25 & 0,55 \\
$\mathrm{Nd}_{16} \mathrm{Fe}_{66,15} \mathrm{Co}_{11,6} \mathrm{Ga}_{0,25} \mathrm{~B}_{6}$ & 568 & 1,19 & 0,67 \\
$\mathrm{Nd}_{16} \mathrm{Fe}_{66,15} \mathrm{Co}_{11,6} \mathrm{Ga}_{0,5} \mathrm{~B}_{6}$ & 648 & 1,17 & 0,70 \\
$\mathrm{Nd}_{16} \mathrm{Fe}_{66,15} \mathrm{Co}_{11,6} \mathrm{Al}_{0,25} \mathrm{~B}_{6}$ & 890 & 1,20 & 0,85 \\
$\mathrm{Nd}_{16} \mathrm{Fe}_{65,9} \mathrm{Co}_{11,6} \mathrm{Al}_{0,5} \mathrm{~B}_{6}$ & 856 & 1,18 & 0,80 \\
$\mathrm{Nd}_{16} \mathrm{Fe}_{65,4} \mathrm{Co}_{11,6} \mathrm{Al}_{1,0} \mathrm{~B}_{6}$ & 816 & 1,15 & 0,67 \\
$\mathrm{Nd}_{16} \mathrm{Fe}_{63,4} \mathrm{Co}_{11,6} \mathrm{Al}_{1} \mathrm{Cr}_{2} \mathrm{~B}_{6}$ & 840 & 1,13 & 0,63 \\
\hline
\end{tabular}

Jin et al. (2003) estudaram a adição de fósforo à liga $\operatorname{Pr}_{7} \mathrm{~Tb}_{1} \mathrm{Fe}_{87-\mathrm{x}} \mathrm{Nb}_{0,5} \mathrm{P}_{\mathrm{x}} \mathrm{B}_{4}$, em que $\mathrm{x}=0$ e 0,3 . Os pós nanométricos foram obtidos pelo processo melt-spinning variando-se a velocidade. Com o aumento da velocidade a solidificação foi rápida o suficiente para produzir partículas amorfas. Nas velocidades mais baixas, as partículas se depositavam com orientação preferencial do plano (001) em ambas as ligas. Porém, na liga com adição de fósforo o grau de orientação foi superior. As análises por difração de raios X mostraram que nas baixas velocidades ocorre a formação da fase Pr-P. Segundo os autores o fósforo atua com um elemento eutético diminuindo a temperatura de fusão da liga e como agente de refino do grão. 


\section{8 - A questão da anisotropia.}

A anisotropia do sub-retículado de ferro nos compostos $\mathrm{TR}_{2} \mathrm{Fe}_{14} \mathrm{~B}$ pode ser estudada utilizando-se compostos não magnéticos (lantânio, lutécio e ítrio) ou com a camada s completa (gadolínio).

Nos compostos referenciados acima a direção de fácil magnetização é paralela ao eixo $c$. A energia de anisotropia é expressa por:

$$
E_{a}=K_{1} \operatorname{sen}^{2} \theta+K_{2} \operatorname{sen}^{4} \theta+K_{3} \operatorname{sen}^{6} \theta
$$

onde: $\theta$ é o ângulo entre os eixos de magnetização.

O campo de anisotropia é dado por:

$$
H_{a}=\frac{2\left(K_{1}+2 K_{2}+3 K_{3}\right)}{B_{S}}
$$

As constantes de anisotropia foram determinadas a partir de isotermas de magnetização, utilizando curvas de torque ou pelo método $S P D^{2}$ (Asti e Bolzoni, 1980; Bolzoni e Cabassi, 2004). A dependência do campo de magnetização em função da energia de anisotropia pode ser facilmente calculada com base na equação empírica da energia de anisotropia, se a energia de Zeeman devido a interações de troca for muito maior que a energia do campo elétrico cristalino. Este é o caso de composto nos quais somente os íons de ferro possuem momento magnético ou nos compostos com terras raras com a camada $s$ completa (Sagawa et al., 1987).

Em alguns casos observaram-se diferenças entre os valores publicados por vários autores. A razão para estas discrepâncias são devidas, em muitos casos, aos diferentes métodos usados para se determina o campo de anisotropia (Grössinger et al., 1986). Por exemplo, no caso dos compostos $\mathrm{TR}_{2} \mathrm{Fe}_{14-\mathrm{x}} \mathrm{Co}_{\mathrm{x}} \mathrm{B}$ o campo de anisotropia medido pela técnica $S P D$ representa o campo de anisotropia relevante fisicamente incluindo todas as constantes dadas na expressão (3.3). Neste caso, o campo de anisotropia foi determinado considerando-se apenas o valor para a constante $K_{1}$ (Sagawa et al.,1985).

\footnotetext{
${ }^{2} S P D$ - Singular Point Detection - técnica do estudo da singularidade em curvas de magnetização para amostras policristalinas.
} 
As diferenças tornam-se apreciáveis para aquelas concentrações onde uma reorientação de $\operatorname{spin}$ do eixo $c$ para o plano basal ocorrer a altas temperaturas. Isto significa que a contribuição negativa do campo de anisotropia torna-se relativamente importante com o aumento da concentração de cobalto, as quais são intensas levando-se em conta somente $K_{1}$. Por outro lado, o campo de anisotropia determinado a partir da extrapolação das isotermas de magnetização pode não ser confiável se as medidas forem realizadas em campos externos relativamente baixos.

A dependência do campo de anisotropia com a temperatura nos compostos $\mathrm{TR}_{2} \mathrm{Fe}_{14} \mathrm{~A}$ ( $\mathrm{TR}=\mathrm{Gd}$ e Lu e A = B e C) é apresentada na FIG. 3.21 (Grössinger et al., 1990; Kou et al., 1990, 1991). O campo de anisotropia para os compostos com carbono a baixas temperaturas é maior que o dos compostos com boro. Já na faixa de temperaturas mais altas os compostos com carbono decrescem mais rapidamente devido as baixas temperaturas de Curie.
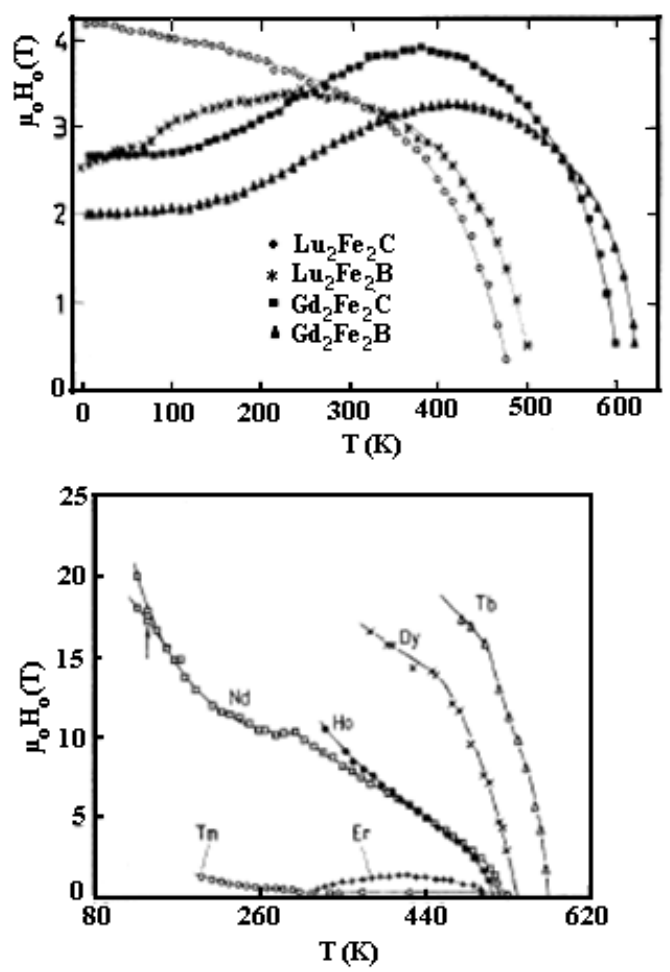

FIGURA 3.21 - Dependência do campo de anisotropia com a temperatura (adaptada de Kou et al., 1991 e Grössinger et al., 1990).

A dependência do campo de anisotropia com a temperatura apresenta valores máximos para $\mathrm{Gd}_{2} \mathrm{Fe}_{14} \mathrm{~B}, \mathrm{Gd}_{2} \mathrm{Fe}_{14} \mathrm{C}$ e $\mathrm{Lu}_{2} \mathrm{Fe}_{14} \mathrm{~B}$. Este comportamento incomum pode ser explicado de duas maneiras: 
1- Os seis diferentes sítios ocupados por átomos de ferro que contribuem para a anisotropia possuem sinais opostos que dependem da temperatura. O gadolínio e o lutécio não contribuem para a anisotropia magnética;

2- O aumento dos campos de anisotropia com a temperatura esta relacionado com a anomalia do volume abaixo da $\mathrm{T}_{\mathrm{C}}$ (Kou et al., 1991), isto é, o efeito invar ${ }^{3}$ nestes compostos influencia a anisotropia magnética. De acordo com Grössinger et al. (1990) e Kou et al. (1990) a redução do parâmetro de rede $c$ nos compostos com carbono causa um aumento da anisotropia do sub-retículo $3 d$. A redução da razão $c: a$ é evidente em todos os compostos com carbono.

As diferenças na dependência do campo de anisotropia com a temperatura, no $\mathrm{Lu}_{2} \mathrm{Fe}_{14} \mathrm{C}$ e demais compostos, são associadas com a diferença na expansão térmica tipo invar entre os compostos, FIG. 3.22 (Kou et al., 1991).

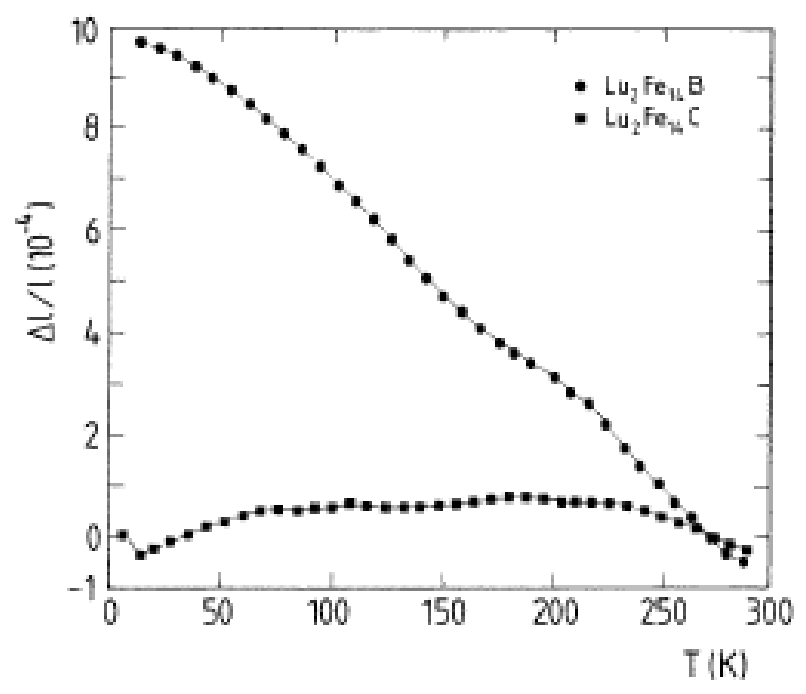

FIGURA 3.22 - Dependência da expansão térmica com a temperatura para o $\mathrm{Lu}_{2} \mathrm{Fe}_{14} \mathrm{~B}$ e o $\mathrm{Lu}_{2} \mathrm{Fe}_{14} \mathrm{C}$ (adaptada de Kou et al., 1991).

O aumento incomum da anisotropia com o aumento da temperatura, como mencionado acima, é freqüentemente atribuído à contribuição dos seis sítios preenchidos com ferro que possuem sinais opostos e dependentes da temperatura. A anisotropia magneto cristalina está relacionada com a pequena contribuição dos momentos médios dos átomos de ferro, os quais por si próprios são anisotrópicos (Givord et al., 1984; Sinnema et al., 1984).

\footnotetext{
${ }^{3}$ Efeito invar: é minimização da energia magnética pelo aumento do volume, efeito dependente da $T_{C}$ (Weiss, 1962).
} 
Zhong e Ching (1990) calcularam os momentos orbitais para o $\mathrm{Nd}_{2} \mathrm{Fe}_{14} \mathrm{~B}$. O maior momento orbital é o do sítio $8 j_{2}$. Os sítios $8 j_{2}$ são deslocados a partir do centro do hexágono dos outros átomos de ferro. Há uma forte preferência ao longo do eixo $z$. Esta condição não se verifica para os outros sítios do ferro. Isto indica que os sítios $8 j_{2}$ têm um papel importante na determinação da anisotropia magnética do sub-retículo de ferro.

Tem sido realizado um grande número de estudos sobre os efeitos dos átomos substituintes sobre a anisotropia. A anisotropia do sub-reticulado do ferro dá uma idéia da importante contribuição para a anisotropia total. Por exemplo, teoricamente a anisotropia do sub-reticulado do ferro no $\mathrm{Nd}_{2} \mathrm{Fe}_{14} \mathrm{~B}$ tem um valor aproximadamente $30 \%$ maior que o da anisotropia do composto a temperatura ambiente.

Uma vez que a presença de cobalto aumenta a $\mathrm{T}_{\mathrm{C}}$ e a magnetização do subreticulado $3 d$ é somente ligeiramente afetada quando se substitui o ferro pelo cobalto, um grande número de estudos foi realizado nos compostos $\mathrm{TR}_{2} \mathrm{Fe}_{14-\mathrm{x}} \mathrm{Co}_{\mathrm{x}} \mathrm{B}$ com $\mathrm{TR}=\mathrm{Y}$ (Bolzoni et al., 1987a; Thuy et al., 1988) e TR = La (Grössinger et al., 1988). A constante de anisotropia $K_{1}$ à temperatura de 4,2 K para TR = Y apresenta um máximo em cerca de $x$ igual a $10,5 \%$ at. e uma mudança no sinal ocorre ao redor de $x$ igual a 4,2 \% at. (Thuy et al., 1988). Resultados similares foram obtidos para o $\mathrm{La}_{2} \mathrm{Fe}_{14-\mathrm{x}} \mathrm{Co}_{\mathrm{x}} \mathrm{B}$ (Grössinger et al., 1988) e tem sido explicado em termos dos sítios de ocupação do cobalto e do ferro. Uma contribuição oposta para a anisotropia dos átomos de ferro e cobalto no sítio $8 j_{2}$ foi apresentada por Thuy et al. (1988). Assim, apesar da $\mathrm{T}_{\mathrm{C}}$ aumentar o campo de anisotropia decresce, na temperatura ambiente, quando o ferro é substituído por cobalto.

Os campos de anisotropia, na temperatura ambiente, dão uma indicação da potencialidade do uso de átomos substituintes para aplicações de magnetos permanentes. A dependência do campo de anisotropia com a composição, $H_{a}(x) / H_{a}(0)$, a temperatura ambiente para alguns compostos $\mathrm{TR}_{2} \mathrm{Fe}_{14-\mathrm{x}} \mathrm{M}_{\mathrm{x}} \mathrm{B}$, é apresentado na FIG. 3.23. Nos compostos com $\mathrm{TR}=\mathrm{Y}$ o aumento de anisotropia é observando para $\mathrm{M}=\mathrm{Si}$ e $\mathrm{Cr}$ para $\mathrm{x}$ menor ou igual a 1 , para $\mathrm{M}=\mathrm{Co}$ observa-se um decréscimo contínuo e para $\mathrm{M}=\mathrm{Cu}$ ocorre inicialmente um decréscimo seguido de um aumento no campo de anisotropia.

Nos compostos baseados em neodímio, o campo de anisotropia apresenta valores máximos para baixas concentrações de níquel, silício, gálio, berílio e alumínio. Um contínuo decréscimo do campo de anisotropia ocorre nos compostos com $\mathrm{M}=\mathrm{Mn}$, Co e Mo. Estes efeitos estão relacionados com a variação de $T_{C}$, o sítio de ocupação do átomo substituinte, e as mudanças na magnetização. 


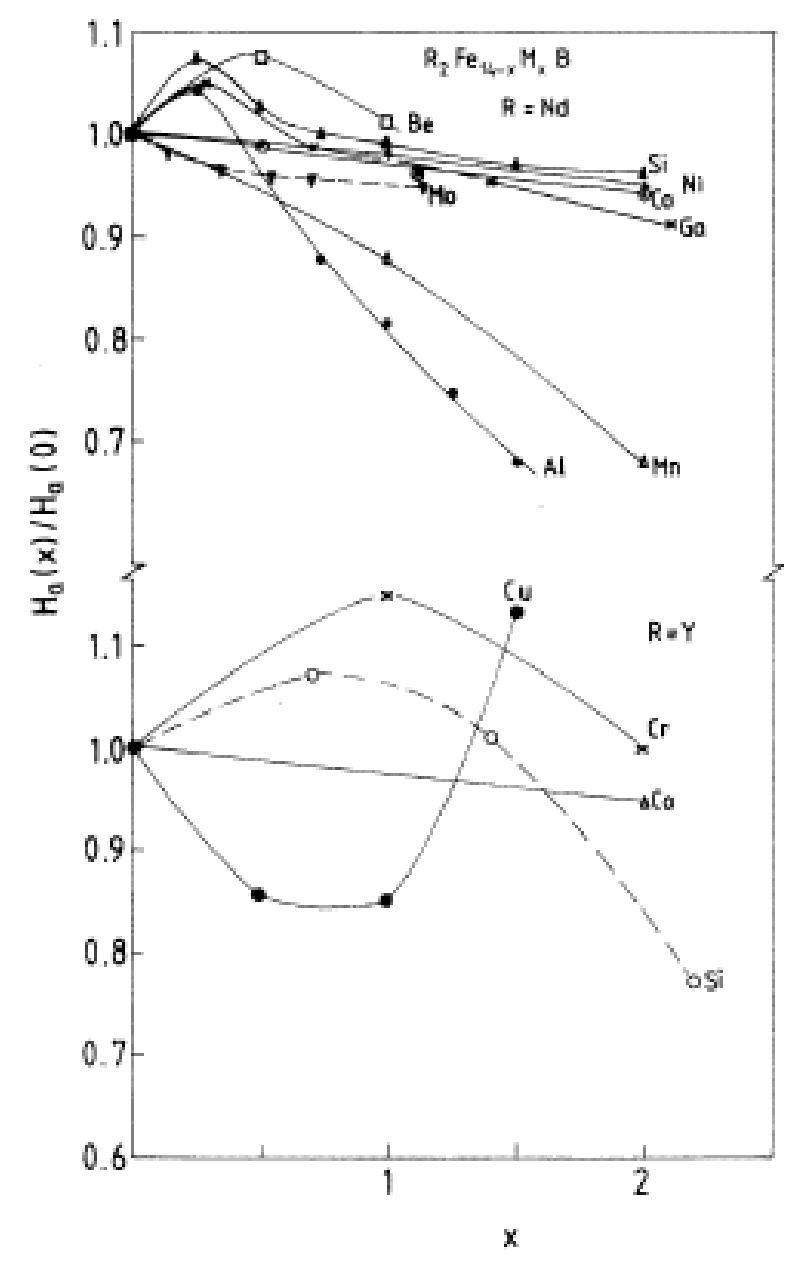

FIGURA 3.23 - Redução do campo de anisotropia em função da composição química para compostos $\mathrm{TR}_{2} \mathrm{Fe}_{14-\mathrm{x}} \mathrm{M}_{\mathrm{x}} \mathrm{B}$, com TR $=\mathrm{Y}$ e Nd (adaptada de Burzo, 1998).

A relação entre a variação da $T_{C}$ e o campo de anisotropia foi estudada por vários autores. Bolzoni et al. (1987a) estudaram comparativamente os campo de anisotropia de $\mathrm{Nd}_{2} \mathrm{Fe}_{14-\mathrm{x}} \mathrm{M}_{\mathrm{x}} \mathrm{B}$ com $\mathrm{M}=\mathrm{Mn}$ e $\mathrm{Ni}$ para a mesma redução da $\mathrm{T}_{\mathrm{C}}$ com razão de $T / T_{c}=0,45$. Nesta temperatura, a dependência do campo de anisotropia com a composição mostra um decréscimo linear para o níquel, enquanto que para o manganês observa-se um aumento. A constante de anisotropia não parece ser afetada pela substituição com manganês. $O$ aumento da anisotropia observado com o aumento da concentração de manganês foi atribuído ao decréscimo da magnetização. De fato, a constante de anisotropia total sofre uma redução linear com o aumento da adição de manganês. Em contraste, a anisotropia do neodímio parece ser mais afetada pela substituição com níquel. A redução linear da anisotropia total pode ser quase que completamente atribuída ao decréscimo na anisotropia do neodímio. 
Grössinger et al. (1986) analisaram a redução do campo de anisotropia como função da redução da temperatura $T / T_{C}$ nos compostos onde o átomo substituinte é o cobalto. A redução do campo de anisotropia comporta-se de uma maneira sistemática, diminuindo quando o teor de cobalto aumenta. A temperatura ambiente o campo de anisotropia no $\operatorname{Pr}_{2} \mathrm{Fe}_{14-\mathrm{x}} \mathrm{Co}_{\mathrm{x}} \mathrm{B}$ primeiro decresce com $\mathrm{x}$, mas após passar por um mínimo em torno de $\mathrm{x}$ aproximadamente 9,8 aumenta acentuadamente.

Os efeitos das múltiplas substituições nos sítios do ferro também foram estudados. Estes têm sido realizados objetivando o aumento da $\mathrm{T}_{\mathrm{C}}$ pela adição de cobalto e para contrabalancear o correspondente decréscimo na anisotropia pela substituição de elementos que em baixas concentrações levam ao aumento da anisotropia.

Os resultados apresentados por diversos autores mostram que a substituição de ferro por cobalto nas ligas tecnológicas exerce influência não apenas por substituição na fase $\mathrm{TR}_{2} \mathrm{Fe}_{14} \mathrm{~B}$, como também nas fases minoritárias. Fuerst e Herbst (1989) sugerem que na substituição de ferro por cobalto em um teor acima de $50 \%$ at. o cobalto atua como um catalisador para a formação da fase $\mathrm{Nd}_{2}(\mathrm{Fe}, \mathrm{Co})_{17}$. Daí a necessidade de otimização das concentrações de neodímio e boro nas ligas. 


\section{4 - MATERIAIS E MÉTODOS}

\section{1 - Composição química das ligas}

Neste trabalho foram investigadas as propriedades magnéticas de ligas baseadas no sistema Pr-Fe-Co-B processada por HDDR e consolidadas com cianoacrilato de baixa viscosidade.

As ligas estudadas foram:

- $\operatorname{Pr}_{14} \mathrm{Fe}_{\text {bal }} \mathrm{Co}_{16} \mathrm{~B}_{6} \mathrm{M}_{0.1}$ onde $\mathrm{M}=\mathrm{Ti}, \mathrm{V}, \mathrm{Cr}, \mathrm{Ni}, \mathrm{Zr}, \mathrm{Nb}$ ou $\mathrm{Mo}$;

- $\operatorname{Pr}_{14} \mathrm{Fe}_{\text {bal }} \mathrm{Co}_{16} \mathrm{~B}_{6} \mathrm{Nb}_{0.1} \mathrm{X}_{0.1}$ onde $\mathrm{X}=\mathrm{Al}, \mathrm{Si}, \mathrm{P}, \mathrm{Cu}$ ou Ga ;

- $\operatorname{Pr}_{14} \mathrm{Fe}_{\mathrm{bal}} \mathrm{Co}_{16} \mathrm{~B}_{6} \mathrm{Nb}_{0.1} \mathrm{X}_{0.3}$ onde $\mathrm{X}=\mathrm{Al}, \mathrm{Si}, \mathrm{P}, \mathrm{Cu}$ ou $\mathrm{Ga}$;

- $\operatorname{Pr}_{14} \mathrm{Fe}_{\mathrm{bal}} \mathrm{Co}_{16} \mathrm{~B}_{6} \mathrm{Nb}_{0.1} \mathrm{X}_{0.5}$ onde $\mathrm{X}=\mathrm{Al}, \mathrm{Si}, \mathrm{P}$ ou $\mathrm{Cu}$.

O elemento ferro serviu de balanço estequiométrico. A composição química de cada liga (\% em massa) pode ser visualizada nas TAB. 4.1, 4.2, 4.3 e 4.4.

As ligas foram adquiridas por encomenda na empresa Less Common Metal, empresa especializada na produção de ligas com terras raras, sediada em Valley Road Business Park, Birkenhead, Inglaterra.

Segundo a empresa fabricante durante o preparo das ligas ocorreu:

1. Contaminação com silício no teor de $(0,01$ a 0,04$) \%$ em massa e com alumínio no teor de $(0,02$ a 0,2$) \%$ em massa, devido interação das ligas com os cadinhos de fusão e resfriamento.

2. Contaminação com neodímio na concentração de $(0,2$ a 0,7$) \%$ em massa. Na natureza este elemento é encontrado em minérios contendo praseodímio, sendo de difícil separação e conseqüentemente a obtenção de alta pureza também.

3. Nas ligas encomendadas com adição do dopante fósforo, este elemento mostrou-se de difícil dissolução, formando sulfetos na superfície quando do 
processo de fusão a vácuo. Por isto as concentrações estão abaixo das requisitadas.

TABELA 4.1 - Composição química em \% em massa, fornecida pelo fabricante, para as ligas $\mathrm{Pr}_{14} \mathrm{Fe}_{\mathrm{bal}} \mathrm{Co}_{16} \mathrm{~B}_{6} \mathrm{M}_{0.1} \quad(\mathrm{M}=\mathrm{Ti}, \mathrm{V}, \mathrm{Cr}, \mathrm{Ni}, \mathrm{Zr}, \mathrm{Nb}$ ou Mo $)$.

\begin{tabular}{|c|c|c|c|c|c|}
\hline Liga & $P r$ & Co & $F e$ & $B$ & $M$ \\
\hline $\operatorname{Pr}_{14} \mathrm{Fe}_{\mathrm{bal}} \mathrm{Co}_{16} \mathrm{~B}_{6}$ & 30,01 & 14,31 & 54,56 & 1,01 & - \\
\hline $\operatorname{Pr}_{14} \mathrm{Fe}_{\mathrm{bal}} \mathrm{Co}_{16} \mathrm{~B}_{6} \mathrm{Ti}_{0,1}$ & 29,83 & 14,25 & 54,76 & 0,98 & 0,070 \\
\hline $\operatorname{Pr}_{14} \mathrm{Fe}_{\mathrm{bal}} \mathrm{Co}_{16} \mathrm{~B}_{6} \mathrm{~V}_{0,1}$ & 30,09 & 14,40 & 54,37 & 1,01 & 0,070 \\
\hline $\operatorname{Pr}_{14} \mathrm{Fe}_{\mathrm{bal}} \mathrm{Co}_{16} \mathrm{~B}_{6} \mathrm{Cr}_{0,1}$ & 30,29 & 14,4 & 54, & 0,96 & $0^{-}$ \\
\hline $\operatorname{Pr}_{14} \mathrm{Fe}_{\mathrm{bal}} \mathrm{Co}_{16} \mathrm{~B}_{6} \mathrm{Ni}_{0,1}$ & 30,08 & 14,35 & 54,4 & 1,00 & 0,110 \\
\hline $\operatorname{Pr}_{14} \mathrm{Fe}_{\mathrm{bal}} \mathrm{Co}_{16} \mathrm{~B}_{6} \mathrm{Zr}_{0,1}$ & 30,06 & 14,42 & 54,32 & 1,01 & 0,110 \\
\hline $\mathrm{Pr}_{14} \mathrm{Fe}_{\mathrm{bal}} \mathrm{Co}_{16} \mathrm{~B}$ & 30,35 & 14,34 & 54,11 & 0,96 & 0,140 \\
\hline $\operatorname{Pr}_{14} \mathrm{Fe}_{\mathrm{bal}} \mathrm{Co}_{16} \mathrm{~B}_{6} \mathrm{Mo}_{0,1}$ & 30,35 & 14,51 & 53,89 & 1,00 & 0,160 \\
\hline
\end{tabular}

TABELA 4.2 - Composição química em \% massa, fornecida pelo fabricante, para as ligas $\mathrm{Pr}_{14} \mathrm{Fe}_{\text {bal }} \mathrm{Co}_{16} \mathrm{~B}_{6} \mathrm{Nb}_{0.1} \mathrm{X}_{0.1}(\mathrm{X}=\mathrm{Al}, \mathrm{Si}, \mathrm{P}, \mathrm{Cu}$ ou $\mathrm{Ga})$.

\begin{tabular}{|c|c|c|c|c|c|c|}
\hline Liga & $\operatorname{Pr}$ & Co & $F e$ & $\boldsymbol{B}$ & $\mathrm{Nb}$ & $X$ \\
\hline $\operatorname{Pr}_{14} \mathrm{FG}_{5}$ & & 4,24 & 54,18 & 0,99 & 18 & \\
\hline $\operatorname{Pr}_{14} \mathrm{Fe}_{\mathrm{ba}}$ & 30 & 1 & 6 & 00 & 16 & 0,073 \\
\hline $\operatorname{Pr}_{14} \mathrm{Fe}_{\mathrm{b}}$ & 30 & 1 & 5 & 2 & 13 & 0,010 \\
\hline $\operatorname{Pr}_{14} \mathrm{Fe}_{\text {ba }}$ & 30,51 & 14,25 & 53,79 & 0,99 & 0,15 & 0,130 \\
\hline $\operatorname{Pr}_{14} \mathrm{Fe}_{\mathrm{bal}} \mathrm{Co}_{16} \mathrm{~B}_{6} \mathrm{Nb}_{0,1} \mathrm{Ga}_{0,1}$ & 30,44 & 14,28 & 53,85 & 1,00 & 0,14 & 0,109 \\
\hline
\end{tabular}

TABELA 4.3 - Composição química em \% massa, fornecida pelo fabricante, para as ligas $\mathrm{Pr}_{14} \mathrm{Fe}_{\text {bal }} \mathrm{Co}_{16} \mathrm{~B}_{6} \mathrm{Nb}_{0.1} \mathrm{X}_{0.3}(\mathrm{X}=\mathrm{Al}, \mathrm{Si}, \mathrm{P}, \mathrm{Cu}$ ou $\mathrm{Ga})$.

\begin{tabular}{l|llllll}
\hline Liga & $\boldsymbol{P r}$ & $\boldsymbol{C o}$ & $\boldsymbol{F e}$ & $\boldsymbol{B}$ & $\boldsymbol{N} \boldsymbol{b}$ & $\boldsymbol{X}$ \\
\hline $\operatorname{Pr}_{14} \mathrm{Fe}_{\mathrm{bal} \mathrm{Co}_{16} \mathrm{~B}_{6} \mathrm{Nb}_{0,1} \mathrm{Al}_{0,3}}$ & 30,02 & 14,44 & 54,18 & 1,00 & 0,14 & 0,023 \\
$\operatorname{Pr}_{14} \mathrm{Fe}_{\text {bal }} \mathrm{Co}_{16} \mathrm{~B}_{6} \mathrm{Nb}_{0,1} \mathrm{Si}_{0,3}$ & 30,74 & 14,18 & 53,25 & 1,00 & 0,19 & 0,125 \\
$\operatorname{Pr}_{14} \mathrm{Fe}_{\text {bal }} \mathrm{Co}_{16} \mathrm{~B}_{6} \mathrm{Nb}_{0,1} \mathrm{P}_{0,3}$ & 30,27 & 14,28 & 53,81 & 1,01 & 0,12 & 0,020 \\
$\operatorname{Pr}_{14} \mathrm{Fe}_{\text {bal }} \mathrm{Co}_{16} \mathrm{~B}_{6} \mathrm{Nb}_{0,1} \mathrm{Cu}_{0,3}$ & 30,65 & 14,28 & 53,31 & 0,97 & 0,12 & 0,290 \\
$\operatorname{Pr}_{14} \mathrm{Fe}_{\text {bal }} \mathrm{Co}_{16} \mathrm{~B}_{6} \mathrm{Nb}_{0,1} \mathrm{Ga}_{0,3}$ & 30,38 & 14,40 & 53,61 & 0.98 & 0.15 & 0,320 \\
\hline
\end{tabular}


TABELA 4.4 - Composição química em \% massa, fornecida pelo fabricante, para as ligas $\mathrm{Pr}_{14} \mathrm{Fe}_{63.6} \mathrm{Co}_{16} \mathrm{~B}_{6} \mathrm{Nb}_{0.1} \mathrm{X}_{0.5}(\mathrm{X}=\mathrm{Al}, \mathrm{Si}, \mathrm{P}, \mathrm{Cu}$ ou $\mathrm{Ga})$.

\begin{tabular}{|c|c|c|c|c|c|c|}
\hline Liga & $\overline{P r}$ & Co & $\overline{F e}$ & $\bar{B}$ & $\overline{N b}$ & $\bar{X}$ \\
\hline $\mathrm{Pr}_{14} \mathrm{Fe}_{\mathrm{bal}} \mathrm{Co}_{16} \mathrm{~B}_{6} \mathrm{Nb}_{0,1} \mathrm{Al}_{0,5}$ & 30,19 & 14,25 & 53,86 & 0,98 & 0,18 & 0,190 \\
\hline $\mathrm{Pr}_{14} \mathrm{Fe}_{\text {bal }} \mathrm{Co}_{16} \mathrm{~B}_{6} \mathrm{Nb}_{0,1} \mathrm{Si}_{0,5}$ & 29,64 & 14,05 & 53,98 & 0,95 & 0,14 & 0,196 \\
\hline $\mathrm{Pr}_{14} \mathrm{Fe}_{\text {bal }} \mathrm{Co}_{16} \mathrm{~B}_{6} \mathrm{Nb}_{0,1} \mathrm{P}_{0,5}$ & 30,16 & 14,32 & 53.94 & 0,98 & 0,14 & 0,120 \\
\hline $\mathrm{Pr}_{14} \mathrm{Fe}_{\mathrm{bal}} \mathrm{Co}_{{ }_{16}} \mathrm{~B}_{6} \mathrm{Nb}_{0,1} \mathrm{Cu}_{0,5}$ & 30,16 & 14,29 & 53,55 & 1,01 & 0,14 & 0,450 \\
\hline 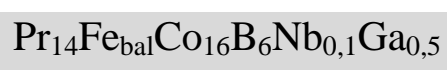 & 30,26 & 14,23 & 53,47 & 1,01 & 0,15 & 0,462 \\
\hline
\end{tabular}

$\mathrm{Na}$ sequiência, também foram investigadas as propriedades magnéticas das ligas $\operatorname{Pr}_{8} \mathrm{Fe}_{55.9-\mathrm{x}} \mathrm{Co}_{\mathrm{x}} \mathrm{Nb}_{0,1} \mathrm{~B}_{4}$ onde $\mathrm{x}=$ 0, 4, 8, 12 ou 16.

Um estudo mais profundo foi feito nestas ligas onde se procurou conhecer a influência da substituição do ferro pelo cobalto na estrutura cristalina. As composições químicas das ligas com variação de ferro-cobalto em porcentagem em massa podem ser visualizadas na TAB. 4.5.

TABELA 4.5 - Composição química em \% massa, fornecida pelo fabricante, para as ligas com variação de cobalto.

\begin{tabular}{|c|c|c|c|c|c|}
\hline Liga & $\overline{P r}$ & Co & $\mathrm{Fe}$ & $\bar{B}$ & $N b$ \\
\hline $\operatorname{Pr}_{14} \mathrm{Fe}_{\mathrm{bal}} \mathrm{B}_{6} \mathrm{Nb}_{0,1}$ & 30,11 & & 68,58 & 0,97 & 0,14 \\
\hline $\mathrm{Pr}_{14} \mathrm{Fe}_{\text {bal }} \mathrm{Co}_{4} \mathrm{~B}_{6} \mathrm{Nb}_{0,1}$ & 30,05 & 3,58 & 65,16 & 0,97 & 0,15 \\
\hline $\mathrm{Pr}_{14} \mathrm{Fe}_{\text {bal }} \mathrm{Co}_{8} \mathrm{~B}_{6} \mathrm{Nb}_{0,1}$ & 30,29 & 7,15 & 61,27 & 0,96 & 0,15 \\
\hline $\mathrm{Pr}_{14} \mathrm{Fe}_{\mathrm{ba}} \mathrm{Co}_{12} \mathrm{~B}_{6} \mathrm{Nb}_{0,1}$ & 30,14 & 10,83 & 75,71 & 0,98 & 0,15 \\
\hline $\operatorname{Pr}_{14} \mathrm{Fe}_{\mathrm{bal}} \mathrm{Co}_{16} \mathrm{~B}_{6} \mathrm{Nb}_{0,1}$ & 30,35 & 14,34 & 54,11 & 0,96 & 0,14 \\
\hline
\end{tabular}

No decorrer deste capitulo as ligas serão referenciadas em função de sua composição nominal expressa em porcentagem atômica.

\section{2 - Condições do processo HDDR}

As ligas como recebidas foram homogeneizadas a temperatura de $1100{ }^{\circ} \mathrm{C}$ por 20 horas, a uma pressão próximo de $0,1 \mathrm{~Pa}\left(1 \times 10^{-6}\right.$ bar $)$, visando eliminar o $\alpha$-Fe existente decorrente da produção da liga. A formação $\alpha$-Fe quando da produção da liga foi explicado no item 3.2. Um exemplo de micrografias típicas da liga $\operatorname{Pr}_{14} \mathrm{Fe}_{\mathrm{bal}} \mathrm{Co}_{16} \mathrm{~B}_{6} \mathrm{Nb}_{0,1}$ como recebida e depois da homogeneização são apresentadas na FIG. 4.1 (a) e (b), respectivamente. 

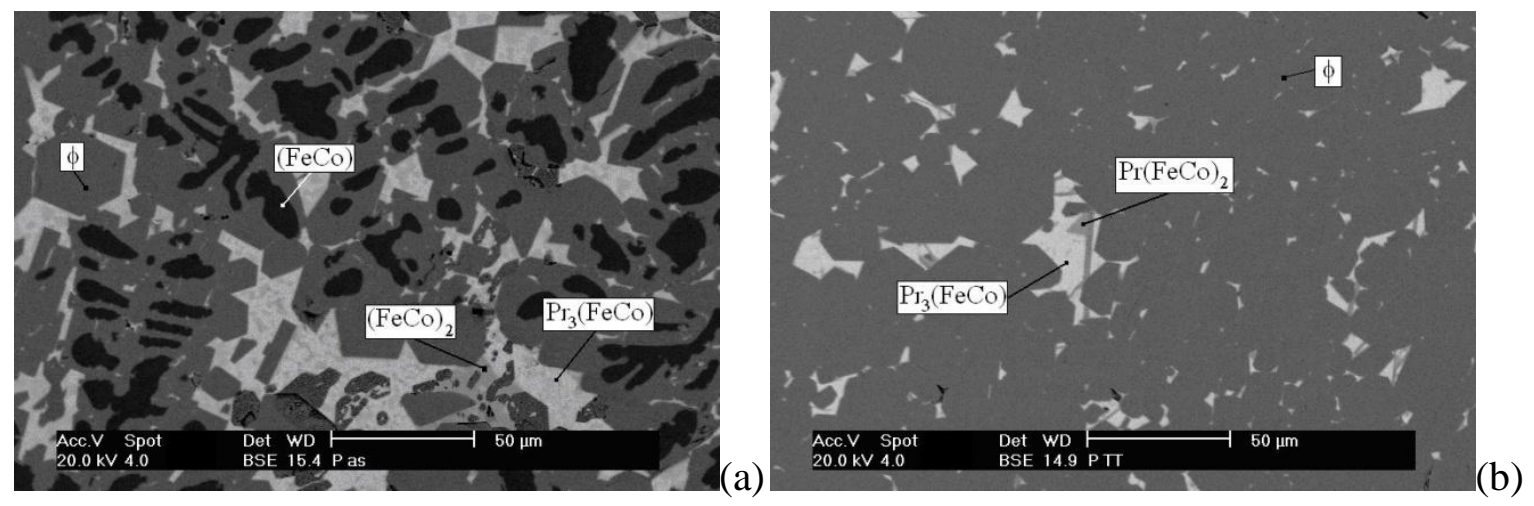

FIGURA 4.1 - Micrografias típicas obtidas por microscopia eletrônica de varredura (MEV) por detector de elétrons retro-espalhados no estado: (a) como recebida e (b) homogeneizada após tratamento térmico à $1100{ }^{\circ} \mathrm{C}$ por $20 \mathrm{~h}$. As fases foram identificadas nas micrografias por dispersão de energia (energy dispersion spectrometer, EDS).

Como indicado na FIG. 4.1 (a) existem visivelmente 4 fases presentes: a fase $\varnothing$ ou fase matriz $\operatorname{Pr}_{2}(\mathrm{Fe}, \mathrm{Co})_{14} \mathrm{~B}$; fase $\alpha-(\mathrm{FeCo})$; fase $(\mathrm{FeCo})_{2}$ e fase rica em $\operatorname{Pr}\left(\operatorname{Pr}_{3}(\mathrm{FeCo})\right)$. A FIG. 4.1(b) mostra que houve eliminação total de todo ferro/cobalto livre após o tratamento térmico, com o desaparecimento das dendritas, fase $\alpha$-(FeCo) e fase $(\mathrm{FeCo})_{2}$, mantendo as fases ricas em praseodímio e a fase matriz. Pode-se observar o crescimento dos grãos após a homogeneização. As ligas de forma geral, independente da adição de dopante ou não, apresentaram o mesmo comportamento após o tratamento térmico, com a eliminação de todo $\alpha$-(FeCo). Este resultado foi verificado neste trabalho $\mathrm{e}$ sistematicamente no estudo realizado por Barbosa (2005), onde se estudou ligas correlatas.

Na FIG. 4.2 apresenta-se o sistema utilizado para a realização do processo HDDR. Neste sistema utiliza-se $8 \mathrm{~g}$ da liga homogeneizada, que foi quebrada em pedaços pequenos com aproximadamente $2 \mathrm{~mm}$ a $4 \mathrm{~mm}$ de diâmetro e acondicionada em uma tela de aço inoxidável para se evitar a perda de material no processo. A liga, envolta pela tela, foi inserida dentro de um cadinho cilíndrico também de aço inoxidável, formando um conjunto. Este conjunto foi introduzido numa retorta de inconel e conectado ao sistema de manipulação da atmosfera. O sistema de manipulação de atmosfera consiste de uma bomba de vácuo, instrumentos de medida de pressão, válvulas e uma micro-válvula para adição do hidrogênio (FIG. 4.2 item 2). A retorta foi inserida no forno (FIG. 4.2 item 1) até a região da zona quente do forno. A seguir, foi feito vácuo mecânico até a pressão de 133,3 Pa $\left(1,33 \times 10^{-3}\right.$ bar). O sistema foi isolado da bomba de vácuo e o hidrogênio introduzido até a pressão de $\sim 7,9 \times 10^{4} \mathrm{~Pa}(\sim 59 \mathrm{cmHg}$ ou $\sim 0,79$ bar). Para se evitar qualquer resquício de ar 
atmosférico, o sistema foi evacuado novamente e o hidrogênio foi re-introduzido à mesma pressão, sendo esta operação repetida por duas vezes.

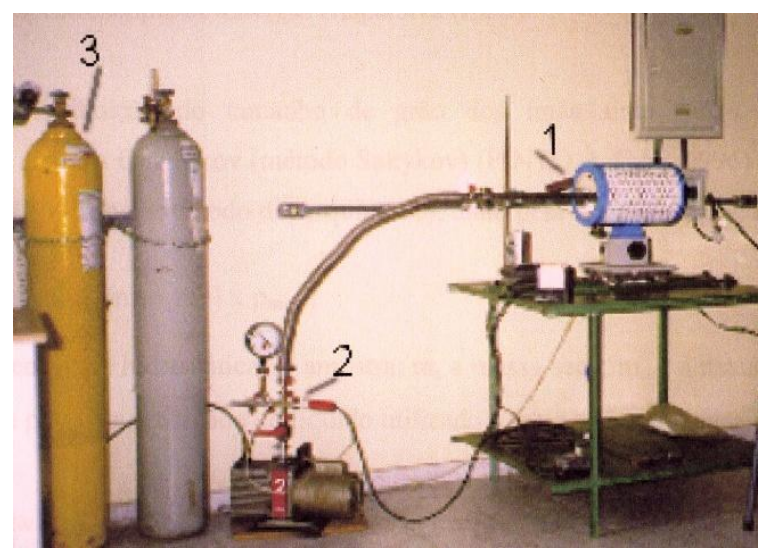

FIGURA 4.2 - Sistema HDDR utilizado neste trabalho, onde: 1 - conjunto forno controlado e retorta; 2 - bomba de vácuo e sistema de manipulação de atmosfera da retorta; 3 - cilindro de gás hidrogênio e regulador (adaptada de Takiishi, 2001).

O forno foi programado para realizar uma rampa de elevação da temperatura até $100{ }^{\circ} \mathrm{C}$ a uma taxa de $10{ }^{\circ} \mathrm{C} / \mathrm{min}$. e mantê-la por $25 \mathrm{~min}$., tempo suficiente para se completar a etapa de hidrogenação. A seguir, o forno foi aquecido até a temperatura de 770 ${ }^{\circ} \mathrm{C}$ a taxa de aquecimento de $15{ }^{\circ} \mathrm{C} / \mathrm{min}$. A partir desta temperatura a taxa de aquecimento foi alterada para $5{ }^{\circ} \mathrm{C} / \mathrm{min}$. até atingir a temperatura de $860{ }^{\circ} \mathrm{C}$ onde a etapa de desproporção ocorre. Esta temperatura foi atingida após $90 \mathrm{~min}$. do início do processo e foi mantida neste patamar. Decorridos 105 min. do início do processo dá-se o bombeamento até que a pressão do sistema atinja o valor inicial de pressão (133,3 $\left.\mathrm{Pa} ; 1,33 \times 10^{-3} \mathrm{bar}\right)$, mantendo-se a temperatura no patamar de $860^{\circ} \mathrm{C}$. Nesta etapa ocorrem a dessorção do hidrogênio e a recombinação. A retorta foi retirada do forno e uma bobina de cobre (por onde circula água corrente à temperatura ambiente) foi introduzida para efetuar o resfriamento mais rápido na região quente. $\mathrm{O}$ material foi retirado após atingir a temperatura ambiente para efetuar os procedimentos seguintes.

Visando estabelecer se as dopagens implicam em alterações significativas das propriedades magnéticas, os parâmetros do processo HDDR foram mantidos constantes para todas as ligas. 


\section{3 - Confecções dos magnetos consolidados}

O material obtido, após o processo HDDR, consiste de um pó com partículas grosseiras e aglomeradas. Este material foi triturado em almofariz de ágata e passado em peneira de 200 mesh, obtendo-se partículas com granulação inferior a $75 \mu \mathrm{m}$, o que favorece o empacotamento dentro da estrutura de Bernal, possibilitando a obtenção de uma amostra do imã com maior densidade.

$\mathrm{Na}$ seqüência, o material foi acondicionado em um pequeno cilindro plástico e tampado nas extremidades com rolhas de borracha onde, através de uma bomba de vácuo mecânica, retira-se o ar e em seguida lacra-se o cilindro com um invólucro de látex. O alinhamento das partículas foi realizado pela aplicação de um pulso magnético de $6 \mathrm{~T}$ (magnetizador LDJ 450-20C) e a compactação final foi realizada pela prensagem isostática

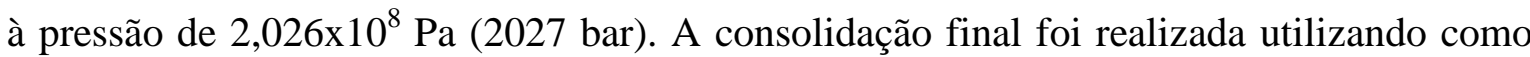
ligante o cianoacrilato de baixa viscosidade, que foi gotejado sobre o material prensado. A seguir o material foi aquecido a $70{ }^{\circ} \mathrm{C}$ por uma hora. A vantagem do uso do cianoacrilato é de se obter um imã mais resistente mecanicamente em comparação com o impregnado com parafina.

Para se medir a densidade dos imãs utilizou-se o princípio de Arquimedes em balança digital de precisão que continha o dispositivo adequado para a medida.

\section{4 - Caracterização das propriedades magnéticas}

A remanência $\left(\mathrm{B}_{\mathrm{r}}\right)$, a coercividade intrínseca $\left({ }_{\mathrm{i}} \mathrm{H}_{\mathrm{c}}\right)$, a coercividade indutiva $\left({ }_{\mathrm{b}} \mathrm{H}_{\mathrm{c}}\right), \mathrm{o}$ produto de energia $\left(\mathrm{BH}_{\max }\right)$ e o fator de quadratura(FQ) foram obtidos a partir da medida do segundo quadrante da curva de desmagnetização utilizando-se o permeâmetro $L D J$ modelo BH5000 (Martin, 1981), acoplado a um graficador XY analógico. Os valores obtidos foram normalizados para a densidade teórica admitindo-se uma relação linear entre densidade e remanência (Takiishi, 2001).

Para amostras com variação de cobalto (TAB. 4.5) foi levantada a curva de histerese nas temperaturas de 4,2 K e $300 \mathrm{~K}$ em magnetômetro de amostra vibrante (MAV) fabricado pela EG\&G Princeton Applied Research, modelo 4500, além das medidas obtidas no permeâmetro LDJ. Este magnetômetro possui uma bobina supercondutora de $\mathrm{Nb}$-Ti que gera campos de até $9 \mathrm{~T}$, fabricada pela empresa American Magnets Inc e um criostato de hélio líquido da Janis Research Company que permite realizar medidas na faixa de temperatura de $(4,2$ a 300$) \mathrm{K}$. O controle de temperatura foi feito por um 
controlador da Lake Shore Cryotronics modelo DRC-91C. A precisão absoluta do MAV, segundo o fabricante, é melhor que $2 \%$. Este equipamento encontra-se no Laboratório de Materiais Magnéticos do Instituto de Física da Universidade de São Paulo. Estas medidas foram feitas nas amostras não consolidadas (em pó).

\section{5 - Preparação das amostras para microscopia}

As amostras, no estado como recebido pelo fornecedor e após tratamento térmico de homogeneização, foram preparadas pelas técnicas convencionais de metalografia (embutimento a frio, lixamento e polimento) e a microestrutura foi observada por microscopia eletrônica de varredura utilizando um microscópio da marca Philips, modelo XL-30. Na análise química semi-quantitativa das fases presentes, pela técnica de dispersão de energia de raios $\mathrm{X}$, foi usado o sistema EDX acoplado ao microscópio de varredura.

A microestrutura das partículas obtidas através do processo HDDR foi analisada na superfície de fratura. Para que ocorra a fratura nas partículas do material obtido pelo processo HDDR foi necessário pressioná-las com a ajuda de uma superfície limpa (lâmina de vidro) de encontro ao suporte de alumínio utilizado no microscópio. Este suporte estava revestido com fita condutora de carbono específica para microscopia eletrônica.

Segundo Takiishi e Barbosa (2005) não é possível utilizar as técnicas convencionais de metalografia para a caracterização da microestrutura do pó obtido pelo processo HDDR e também no magneto consolidado por resina.

\section{6 - Análises por difração de raios $X$.}

$\mathrm{O}$ fator de espalhamento dos raios $\mathrm{X}$ é diferente para cada átomo e seu valor depende da energia dos raios $\mathrm{X}$ incidente. Este fator se decompõe em dois valores sendo um real, $f$ ', e o outro imaginário, $f$ '. Conhecendo-se a energia dos raios $\mathrm{X}$ incidente é possível determinar estes valores (Caticha-Ellis, 1962, 2001). Ao se sintonizar a energia dos raios $\mathrm{X}$ em determinados valores, discrimina-se a intensidade difratada pelos átomos de interesse. Como resultado obtém-se padrões de difração de raios $\mathrm{X}$ diferenciados passíveis de estudo quanto ao fator de ocupação de átomos que "competem" por uma mesma posição na estrutura cristalina.

Com o objetivo de estudar a substituição do ferro pelo cobalto nas ligas especificadas na TAB. 4.5, foram obtidos dois espectros do mesmo material sendo um dos espectros realizado abaixo da borda de absorção do elemento ferro (tipicamente $20 \mathrm{eV}$ 
abaixo desta borda) e outro espectro com energia de $1 \mathrm{keV}$ acima da energia utilizada para a obtenção do primeiro espectro. Assim, foi possível utilizar os coeficientes de espalhamento anômalo dos raios $\mathrm{X}, f^{\prime}$ e $f^{\prime \prime}$, diferentes para cada um dos espectros refinando-os em conjunto pelo método de Rietveld. Devido à necessidade de sintonizar a energia do feixe de raios $\mathrm{X}$ da forma descrita acima, foi necessário utilizar luz síncrotron.

\subsection{1 - Luz síncrotron}

A fonte de luz síncrotron consiste de um anel sob alto vácuo $\left(\sim 10^{-9}\right.$ bar $)$ onde, previamente acelerados por um LINAC (acelerador linear), um feixe de elétrons permanece em circuito fechado em velocidade relativística. A trajetória do anel (também chamado de anel de armazenamento de elétrons) consiste em segmentos retilíneos e curvos, onde o segmento curvo compõe-se de um potente eletroímã. Os elétrons a cada desvio de sua trajetória irradiam energia na forma de radiação que abrange quatro faixas do espectro eletromagnético: a parte do visível, os raios $\mathrm{X}$, os raios ultravioleta e os raios infravermelho. A cada desvio do feixe um sistema repõe a energia perdida mantendo a fonte de luz síncrotron em funcionamento. Através de monocromadores localizados na saída dos magnetos de desvio do síncroton é feito o ajuste da energia requisitada para aplicação com precisão de décimos de $\mathrm{eV}$. Os principais parâmetros do acelerador do Laboratório Nacional de Luz Síncrotron - LNLS podem ser vistos na TAB. 4.6.

Para realização destas medidas, foi submetida e aprovada a proposta número: 4756, projeto 3605, para utilização da linha de luz D10B XPD por três períodos.

A linha de luz D10B XPD, FIG. 4.3, foi desenvolvida para estudos de física do estado sólido, química e biologia. Dedicada a medidas de difração de pó de alta resolução/média intensidade ou alta intensidade/média resolução. Esta linha tem como características básicas:

- Monocromador: monocromador de duplo cristal de Si (111) com saída constante; faixa de energia: 5-14 keV;

- Sistema focalizador: espelhos de luz branca que permitem focalização vertical e colimação do feixe de raios X. Focalização sagital (10 mrad) por curvatura elástica do segundo cristal.

- Goniometria: difratômetro de seis círculos (Huber) com analisador theta-dois theta e analisador de polarização.

- Detetores: cintiladores Cyberstar. 

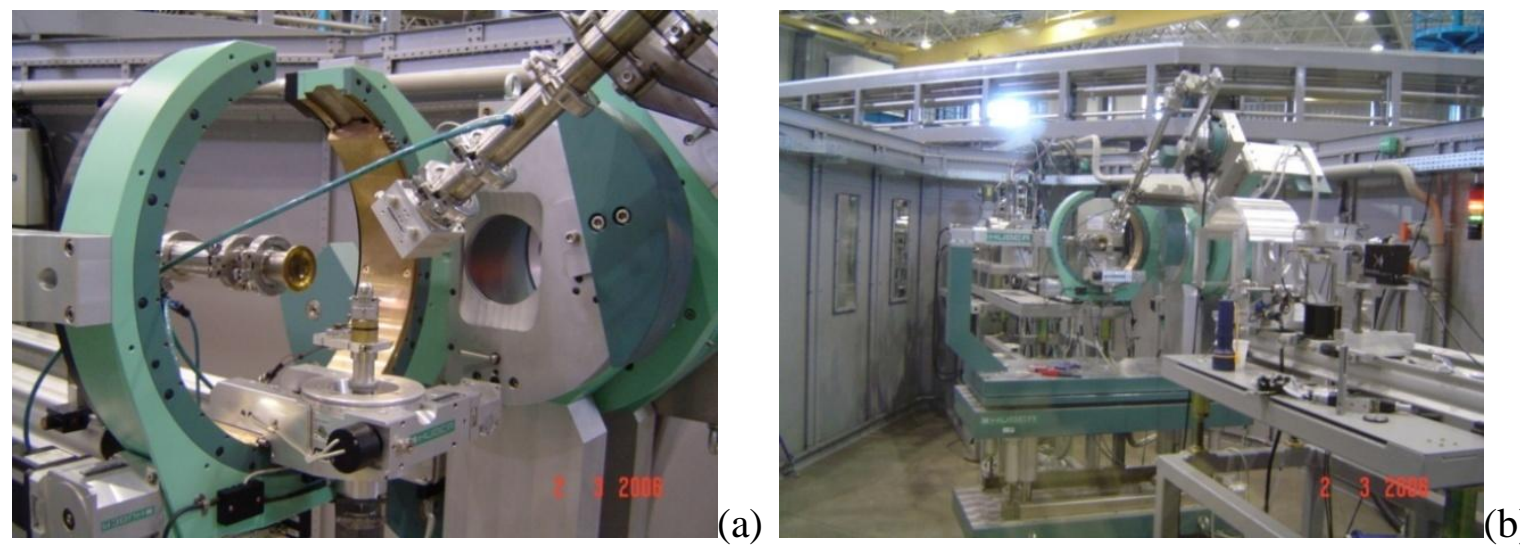

FIGURA 4.3 - Linha D10B XPD: (a) detalhe do goniômetro Huber; (b) vista geral.

TABELA 4.6 - Parâmetros do anel de armazenamento de elétrons do LNLS.

\begin{tabular}{l|cc}
\hline Energia nominal de operação & $\mathbf{1 . 3 7}$ & $\mathbf{G e V}$ \\
\hline Energia de injeção & 500 & $\mathrm{MeV}$ \\
Corrente do feixe de elétrons (máximo) & 250 & $\mathrm{~mA}$ \\
Circunferência & 93,2 & $\mathrm{~m}$ \\
Diâmetro médio & 29,7 & $\mathrm{~m}$ \\
Estrutura magnética & arco acromático de dupla deflexão \\
Simetria da rede magnética & 6 & \\
Frequiência de revolução & 3,2 & $\mathrm{MHz}$ \\
Frequência de RF & 476 & $\mathrm{MHz}$ \\
Emitância natural & 100 & $\mathrm{~nm} . \mathrm{rad}$ \\
Sintonia bétatron horizontal & 5,27 & \\
Sintonia bétatron vertical & 2,17 & \\
Frequiência síncrotron (para tensão de 400 kV) & 24 & $\mathrm{KHz}$ \\
Cromaticidade natural horizontal & $-7,8$ & \\
Cromaticidade natural vertical & $-9,5$ & \\
Fator de compactação de momentum & 0,0083 & \\
Dispersão natural de energia & $0,07 \%$ & $\mathrm{~ms}$ \\
Tempo de amortecimento bétatron horizontal & 7,8 & $\mathrm{~ms}$ \\
Tempo de amortecimento bétatron vertical & 7,5 & $\mathrm{~ms}$ \\
Tempo de amortecimento síncrotron & 3,7 & $\mathrm{~m}$ \\
Raio de curvatura dos dipolos & 2,735 & $\mathrm{~T}$ \\
Campo magnético defletor & 1,67 & \\
Número de dipolos & 12 & $\mathrm{~m}$ \\
Número de trechos retos para dispositivos de inserção & 4 & $\mathrm{keV}$ \\
Comprimento livre para dispositivos de inserção & 2,95 & $\mathrm{~kW}$ \\
Perda de energia por volta nos dipolos & 114 & $\mathrm{keV}$ \\
Potência total irradiada nos dipolos (para I=100 mA) & 11,4 & $\mathrm{~h}$ \\
Energia crítica dos fótons emitidos nos dipolos & 2,08 & \\
Tempo de vida do feixe & 15 & \\
\hline
\end{tabular}

As condições experimentais utilizadas foram baseadas nas sugestões dadas por McCusker et al. (1999). As análises foram realizadas utilizando energia do feixe $\mathrm{E}_{1}=$ $7,092 \times 10^{3} \mathrm{eV}\left(\lambda_{1}=1,7484 \AA\right)$ e $\mathrm{E}_{2}=8,092 \times 10^{3} \mathrm{eV}(\lambda=1,5324 \AA$ ) $)$. A energia $\mathrm{E}_{1}$ está 23 eV abaixo da borda de absorção do ferro, apesar do ideal, neste caso, ser a utilização da 
borda de absorção do cobalto para maior separação dos picos de difração do espectro. Mas as características da linha XPD-10B do LNLS não permitiram utilizar esta energia devido à falta de filtro para os harmônicos superiores provindos do monocromador da luz sincrotron.

A calibração das energias utilizadas e as condições instrumentais do equipamento (necessárias para aplicação do método de Rietveld) foram determinadas utilizando o padrão de silício para difração de raios X do NIST $n^{\circ} 640$ "C ". O tempo de contagem foi ajustado em função da disponibilidade do tempo concedido.

As ligas já processadas por HDDR (mantidas sobre vácuo até o momento da medida) foram trituradas manualmente em almofariz e peneiradas em peneira de 325 mesh ou $44 \mu \mathrm{m}$. Esta etapa foi efetuada em glove box sob atmosfera de argônio (Barthem et al., 2002) para evitar a oxidação da amostra. Em seguida as amostras foram depositadas no porta-amostra de forma a não sofrerem compressão para evitar o mínimo orientação preferencial. Quando da realização das medidas, a rotação do porta-amostra foi acionada com velocidade suficiente para que ocorra no mínimo um giro completo para cada passo medido.

\subsection{2 - Análise pelo método de Rietveld}

O programa utilizado neste trabalho para refinar os espectros foi o programa GSAS (General Structure Analysis System) desenvolvido por Larson e Von Dreele (2004). O GSAS é organizado contendo vários programas; cada qual designado para uma tarefa especifica ou para um de cálculo cristalográfico específico. A versão utilizada neste trabalho foi desenvolvida especificamente para ambiente Microsoft DOS. Toby (2001) desenvolveu um programa de gerenciamento chamado de EXPEGUI (Toby, 2001), para uso em ambiente WINDOWS-XPTM, que consiste em uma interface gráfica entre o usuário e o programa GSAS facilitando o "manejo" dos dados processados e verificações durante o refino.

Para o refinamento pelo método de Rietveld utilizaram-se os dois espectros conseguidos para cada amostra, restringindo os átomos de ferro e cobalto para que concorressem pela mesma posição em cada sítio não equivalente da estrutura cristalina conseguindo-se assim o fator de ocupação de cada átomo nesta posição. Com o refinamento pelo método de Rietveld foi possível conhecer parâmetros cristalográficos importantes, que foram usados na análise teórica, tais como: parâmetros de rede, coordenadas dos sítios, número de átomos substitucionais em cada sítio. 
Pelo método de Rietveld também foi possível determinar o tamanho médio do cristalito (menor monocristal da fase estudada), utilizando os valores dos coeficientes obtidos após a convergência do refino (Larson e Von Dreele, 2004, p. 163). Para isto foi refinado individualmente cada espectro obtido. Para o caso dos espectros da mesma amostra, mas com energias diferentes, foi obtido a media do valor do tamanho do cristalito e desvio padrão.

\section{7 - Análise por simulação teórica}

Nesta etapa do trabalho utilizou-se um programa computacional desenvolvido dentro da teoria do funcional densidade, DFT (veja apêndice I), para a descrição de propriedades do estado fundamental de materiais (ab-initio).

O programa utilizado foi o WIEN2K (Blaha et al., 2001) que processa os dados pelo método LAPW (Linearized Augmented Plane Wave) auto consistente, sendo um dos métodos computacionais de maior precisão no cálculo de estruturas eletrônicas (Cottenier, 2004).

Este programa está escrito em linguagem FORTRAN 90, necessitando ser compilado de acordo com as características do sistema computacional disponível (hardware) e em sistema operacional baseado no UNIX. Para os cálculos envolvidos neste trabalho foi utilizado o cluster de computadores do Centro de Computação Eletrônica da Universidade de São Paulo, localizado no LCCA - Laboratório de Computação Científica Avançada. Para isto foi implantado no cluster o compilador Fortran Intel 9.0, o pacote matemático MKL 1.0 (Mathematic Kernel Library for cluster) que contém os pacotes SCALAPACK+BLAS que vem a ser uma biblioteca de software para aplicações de cálculo em álgebra linear para computadores com memória distribuída. O cluster de nome Alcateia é constituído por dois servidores 2 U INTEL DUAL XEON de 2,4 GHz com 2,5 GB de memória RAM e equipado com disco rígido SCSI possuindo 72 GB de armazenamento. O cluster possui 32 nós de processamento com a mesma configuração dos servidores, mas equipados com disco rígido IDE de 32 GB sem o gerenciamento de fila. Para o gerenciamento de processamento foi utilizado o software OpenPBS- Portable Batch System, desenvolvido pela NASA - Ames Research Center.

Neste trabalho, os valores de interesse calculados teoricamente foram: momento magnético de cada sítio, momento magnético intersticial, momento magnético total, sendo executado o cálculo para cada caso estudado referente as ligas listadas na TAB. 4.5. 
Para se iniciar o processamento foi necessário à geração de um arquivo de dados mestre (master input file) chamado de case.struct onde case é o nome do arquivo que, por conveniência, identifica o estudo. Os principais dados deste arquivo são: o grupo espacial da célula unitária, as coordenadas dos sítios, multiplicidade dos sítios, o átomo ocupante de cada sítio não equivalente, o raio atômico de cada átomo e a matriz rotacional de cada sítio não equivalente.

Os dados da estrutura cristalina para cada concentração de cobalto utilizado nesta etapa foram os obtidos com o refinamento da estrutura cristalina pelo método de Rietveld, descrito no item 4.5.

A desordem ocasionada pelo cobalto substitucional ao ferro foi calculada pelo método da "aproximação do cristal virtual” (Victora e Falicov, 1984). Esta aproximação consiste em se calcular a média ponderada do número atômico dos átomos de ferro e cobalto nos sítios não equivalentes. Por exemplo: no sitio $16 k_{1}$ houve substituição de 4 átomos de ferro por átomos de cobalto, o número atômico acrescentado a este sítio foi (12 x $26+4$ x 27)/16 = 26,25. O número de elétrons dependerá da adição total dos átomos. $\mathrm{Na}$ estrutura cristalografica do $\operatorname{Pr}_{8} \mathrm{Fe}_{56} \mathrm{~B}_{4}$ há 900 elétrons. Quando se substitui um ferro por um cobalto soma-se um elétron. Por exemplo: se na estrutura houve substituição de 16 átomos de ferro por atomos cobalto, haverá uma adição de 16 elétrons na estrutura cristalográfica, logo a estrutura ficará com 916 eletrons.

Na seqüência executa-se um arquivo de lote (init_lapw) que, por sua vez, executa uma série de programas de verificações que precedem a geração de outros arquivos necessários para o cálculo principal:

1. $x n n$ : verifica os primeiros vizinhos relativos aos átomos da estrutura e calcula as suas distancias e determina o raio da esfera atômica por átomo não equivalente, RMT (muffin-tin radius ou atomic sphere radii). Verifica também se há sobreposição (condição esta não permitida para prosseguimento do cálculo). Gera também a expansão dos coeficientes harmônicos da rede cristalina (LM expansion) e as matrizes de rotação local de cada átomo não equivalente;

2. $x$ sgroup: calcula o grupo pontual e espacial ao qual a estrutura pertence e verifica se o operador não incorreu em erro na entrada das posições atômicas;

3. x symmetry: gera, a partir do arquivo case.struct, as operações de simetria do grupo espacial da estrutura, determina o grupo pontual da estrutura para os sítios atômicos individuais (átomos não equivalentes); 
4. x lstart: gera as densidades atômicas e determina quais órbitas serão tratadas no cálculo da estrutura de banda: núcleo ou como banda, com ou sem órbita local;

5. $x$ kgen: gera uma malha dos pontos $k$ (k-mesh) na zona de Brillouin (BZ). Esta malha é gerada em base dos números de pontos $k$ designados pelo operador. Este fator, não diferente dos outros, é tratado de forma a se aperfeiçoar o cálculo da estrutura.

6. $x$ dstart: gera a densidade de partida para o ciclo autoconsistente (SCF) por superposição da densidade atômica gerado no programa $x$ lstart.

A seqüência de processamento pode ser verificada em seu detalhamento na FIG. 4.4. Durante estas verificações, os arquivos gerados estão em forma de texto. Este por sua vez é "aberto" automaticamente por um editor de texto para sua visualização, podendo o operador realizar modificações necessárias para adequar os dados ao problema em estudo.
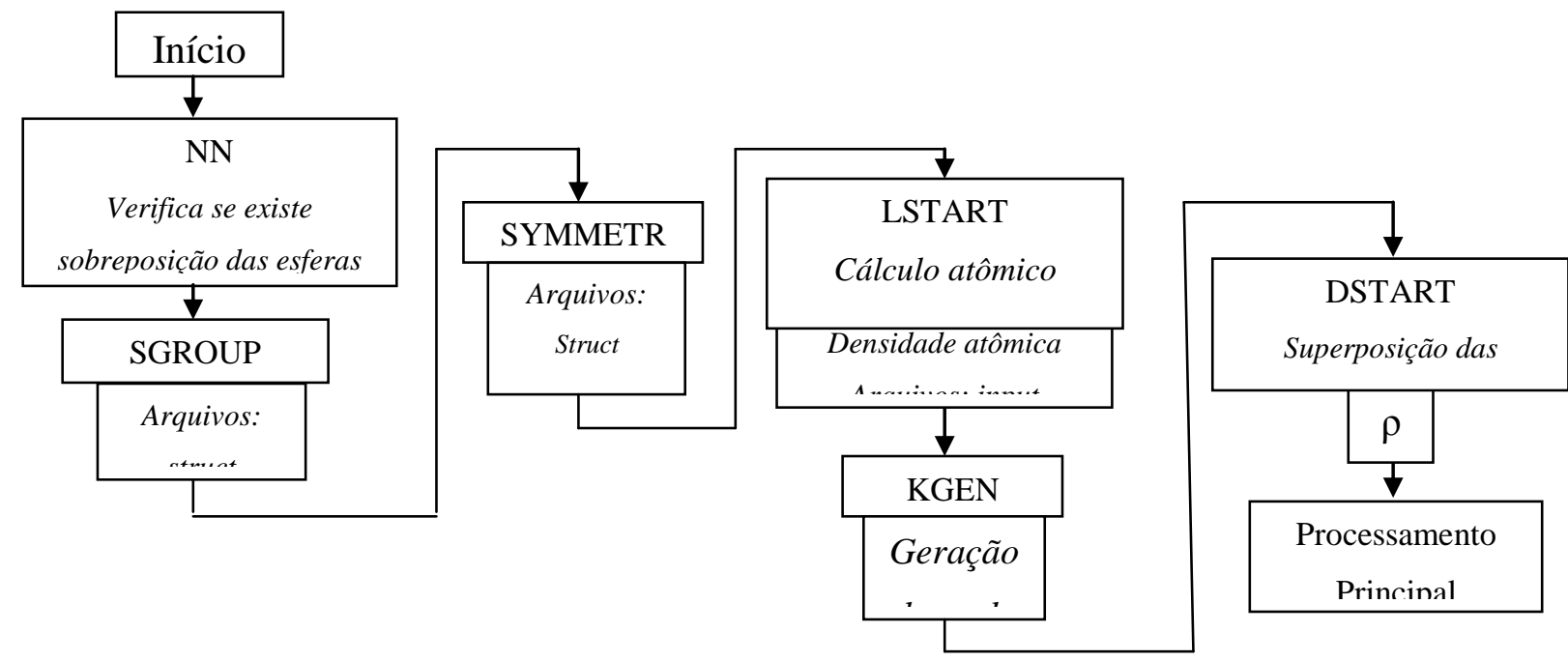

FIGURA 4.4 - Fluxograma de pré-processamento do Wien2k.

O programa principal do WIEN2k consiste de ciclo autoconsistente (SCF). O fluxograma do programa principal executado pelo WIEN2k pode ser visto na FIG. 4.5. Este ciclo se compõe de seguintes passos:

1. LAPW0: (Potencial) gera o potencial a partir da densidade;

2. LAPW1: (BANDS) calcula as bandas de valência (autovalores e autovetores);

3. LAPW2: (RHO) computa a densidade da valência a partir dos autovetores;

4. LCORE: computa os estados do núcleo e as densidades (caroço);

5. MIXER: mistura as densidades de entrada e saída dos cálculos. 
O programa principal é chamado pelo comando run.lapw dando inicio ao SCF, devendo estar para isto obrigatoriamente no mesmo subdiretório do caso estudado. Para se atingir a convergência desejada o operador declara na seqüência do comando run.lapw o tipo de convergência e o valor limite. Por exemplo: run.lapw - cc 0.0001, que vem a ser o limite de convergência para carga, podendo o operador requisitar convergência em energia, $-e c$, ou em força, $-f c$.

O principal interesse no processamento teórico neste trabalho foi as propriedades magnéticas da estrutura cristalina. Por isto, fez-se necessário o cálculo envolvendo a polarização de spin (spin-polarized). O cálculo envolvendo a polarização de spin duplica o número cálculos nas etapas LAPW1, LAPW2 e LCORE, onde são feitos os cálculos para spin-up e spin-down. Para isto a chamada do programa principal passa a ser runsp.lapw, mantendo na seqüência as mesmas declarações para o limite de convergência explicado anteriormente.

Os principais valores de processamento utilizados em todos os casos estudados estão apresentados na TAB. 4.7. Durante o processamento principal, o número de mistura de iteração (mixing factor) do método BROYD/PRATT variou conforme a necessidade até atingir a convergência.

TABELA 4.7 - Variáveis de processamento adotadas no cálculo teórico.

\begin{tabular}{l|l}
\hline Variável & Condição \\
\hline Raio da esfera atômica ou muffin-tin radius & $\begin{array}{l}\mathrm{Pr}=2,5 \\
\mathrm{Fe}=\mathrm{Co}=2,09 \\
\mathrm{~B}=1,8\end{array}$ \\
\hline Potencial de cálculo & GGA of Perdew-Burke-Ernzerhof 96 \\
\hline Energia de separação do semi-núcleo & $-6,0 \mathrm{Ry}$ \\
\hline $\begin{array}{l}\text { Número de pontos na zona de Brillouin (k- } \\
\text { points) }\end{array}$ & 100 \\
\hline $\begin{array}{l}\text { Cálculo de } E_{F} \text { (energia de Fermi) } \\
\text { Método de convergência - por carga } e\end{array}$ & $\begin{array}{l}\text { TETRA (tetrahedron-method, Blöck } \\
94) .\end{array}$ \\
\hline
\end{tabular}




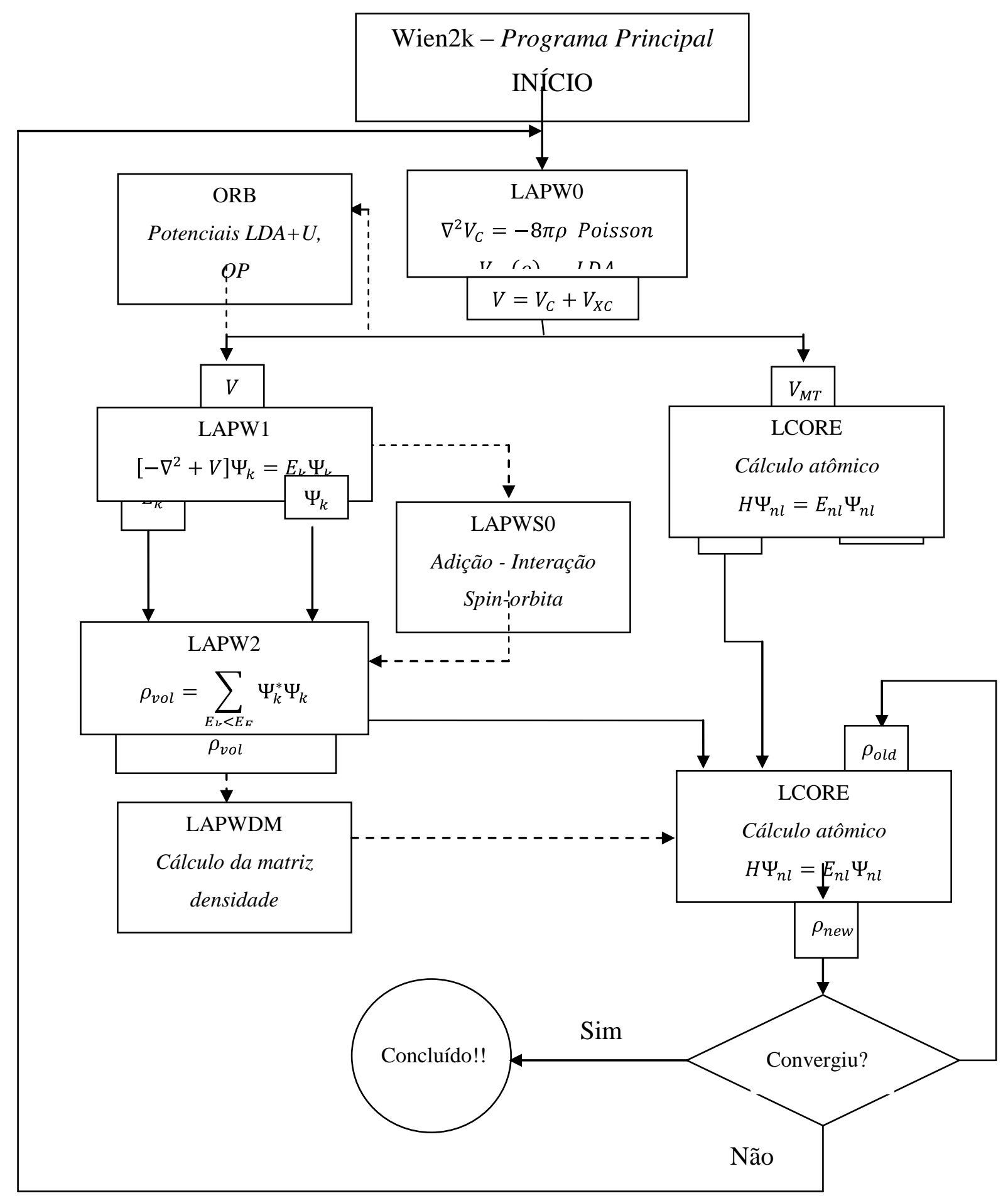

FIGURA 4.5 - Fluxograma do programa principal de cálculo (adaptada de Blaha et al., 2001).

una vez que o sistema estuaduo e magnenco, iol apmcauo o esquema de cancuio teórico descrito no parágrafo anterior. Foi calculada a magnetização: por átomo não equivalente, da região intersticial e a energia total da estrutura. 


\section{5 - RESULTADOS E DISCUSSÕES}

\section{1 - Adição de 0,1\% atômico dos elementos dopantes à liga Pr-Fe-Co-B}

Na TAB. 5.1 apresentam-se os resultados obtidos para as propriedades magnéticas na adição de $0,1 \%$ atômico dos elementos: ${ }_{22} \mathrm{Ti},{ }_{23} \mathrm{~V},{ }_{24} \mathrm{Cr},{ }_{28} \mathrm{Ni},{ }_{40} \mathrm{Zr},{ }_{41} \mathrm{Nb}$ ou ${ }_{42} \mathrm{Mo}$, para as composições indicadas na TAB. 4.1, seguindo a seqüência de processamento descrita nos itens 4.2, 4.3 e 4.4. São apresentados também na TAB 5.1 os valores obtidos para o magneto isotrópico e para o magneto anisotrópico confeccionados com a liga de referência $\operatorname{Pr}_{14} \mathrm{Fe}_{\text {bal }} \mathrm{Co}_{16} \mathrm{~B}_{6}$. O magneto anisotrópico foi submetido ao pulso de magnetização de $6 \mathrm{~T}$ (padrão adotado no laboratório). No caso do magneto isotrópico este não recebeu pulso de magnetização e conseqüentemente de orientação. Ambos foram submetidos a compactação por prensagem isostática a frio.

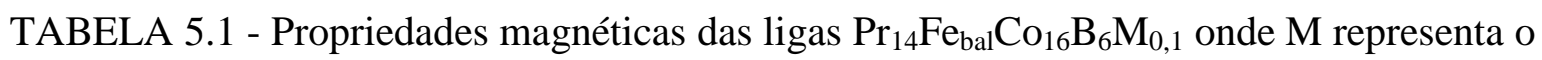
elemento adicionado.

\begin{tabular}{l|ccccc}
\hline \multicolumn{1}{c|}{ Composição } & $\begin{array}{c}\mathbf{B}_{\mathbf{r}} \\
(\mathbf{m T})\end{array}$ & $\begin{array}{c}{ }_{\mathbf{i}} \mathbf{H}_{\mathbf{c}} \\
(\mathbf{k A} / \mathbf{m})\end{array}$ & $\begin{array}{c}{ }_{\mathbf{b}} \mathbf{H}_{\mathbf{c}} \\
(\mathbf{k A} \mathbf{m} / \mathbf{m})\end{array}$ & $\begin{array}{c}(\mathbf{B H})_{\max } \\
\left(\mathbf{k J / m} / \mathbf{m}^{\mathbf{3}}\right)\end{array}$ & $\begin{array}{c}\mathbf{S F} \\
(\mathbf{r a z a ̃ o})\end{array}$ \\
\hline $\mathrm{Pr}_{14} \mathrm{Fe}_{\text {bal }} \mathrm{Co}_{16} \mathrm{~B}_{6}$-isotrópico & $590 \pm 12$ & $748 \pm 15$ & $350 \pm 7$ & $51 \pm 2$ & 0,26 \\
$\mathrm{Pr}_{14} \mathrm{Fe}_{\text {bal }} \mathrm{Co}_{16} \mathrm{~B}_{6}$-anisotrópico & $625 \pm 13$ & $780 \pm 16$ & $350 \pm 7$ & $55 \pm 3$ & 0,23 \\
$\mathrm{Pr}_{14} \mathrm{Fe}_{\text {bal }} \mathrm{Co}_{16} \mathrm{~B}_{6} \mathrm{Ti}_{0,1}$ & $640 \pm 13$ & $708 \pm 14$ & $382 \pm 8$ & $61 \pm 3$ & 0,39 \\
$\mathrm{Pr}_{14} \mathrm{Fe}_{\text {bal }} \mathrm{Co}_{16} \mathrm{~B}_{6} \mathrm{~V}_{0,1}$ & $660 \pm 13$ & $931 \pm 19$ & $432 \pm 9$ & $71 \pm 4$ & 0,44 \\
$\operatorname{Pr}_{14} \mathrm{Fe}_{\text {bal }} \mathrm{Co}_{16} \mathrm{~B}_{6} \mathrm{Cr}_{0,1}$ & $670 \pm 13$ & $788 \pm 16$ & $406 \pm 8$ & $68 \pm 4$ & 0,29 \\
$\operatorname{Pr}_{14} \mathrm{Fe}_{\text {bal }} \mathrm{Co}_{16} \mathrm{~B}_{6} \mathrm{Ni}_{0,1}$ & $690 \pm 13$ & $939 \pm 19$ & $443 \pm 9$ & $73 \pm 5$ & 0,35 \\
$\operatorname{Pr}_{14} \mathrm{Fe}_{\text {bal }} \mathrm{Co}_{16} \mathrm{~B}_{6} \mathrm{Zr}_{0,1}$ & $690 \pm 14$ & $843 \pm 17$ & $415 \pm 8$ & $71 \pm 4$ & 0,28 \\
$\operatorname{Pr}_{14} \mathrm{Fe}_{\text {bal }} \mathrm{Co}_{16} \mathrm{~B}_{6} \mathrm{Nb}_{0,1}$ & $660 \pm 13$ & $860 \pm 17$ & $430 \pm 9$ & $71 \pm 4$ & 0,37 \\
$\operatorname{Pr}_{14} \mathrm{Fe}_{\text {bal }} \mathrm{Co}_{16} \mathrm{~B}_{6} \mathrm{Mo}_{0,1}$ & $650 \pm 13$ & $796 \pm 16$ & $398 \pm 9$ & $65 \pm 4$ & 0,28 \\
\hline
\end{tabular}

Na TAB. 5.2 apresenta-se os valores dos desvios das medidas magnéticas $\Delta B_{r}$ e $\Delta_{\mathrm{i}} \mathrm{H}_{\mathrm{c}}$, indicando se houve ganho ou perda com a adição do dopante nestas propriedades. 
TABELA 5.2 - Valores dos desvios da remanência e coercividade intrínseca em relação à liga de referência $\operatorname{Pr}_{14} \mathrm{Fe}_{\mathrm{bal}} \mathrm{Co}_{16} \mathrm{~B}_{6}$ - isotrópico (iso.) e anisotrópico (anis.).

\begin{tabular}{|c|c|c|c|c|}
\hline Átomo & $\begin{array}{c}\Delta B_{r}-i s o . \\
(m T)\end{array}$ & $\begin{array}{c}\Delta_{i} H_{c}-i s o . \\
(k A / m)\end{array}$ & $\begin{array}{c}\Delta B_{r}-\text { anis. } \\
\quad(m T)\end{array}$ & $\begin{array}{c}\Delta_{i} H_{c}-\text { anis. } \\
(k A / m)\end{array}$ \\
\hline${ }_{22} T i$ & $50 \pm 18$ & $-40 \pm 21$ & $15 \pm 18$ & $-72 \pm 21$ \\
\hline${ }_{23} V$ & $70 \pm 18$ & $183 \pm 24$ & $35 \pm 18$ & $151 \pm 25$ \\
\hline${ }_{24} \mathrm{Cr}$ & $80 \pm 18$ & $40 \pm 22$ & $45 \pm 18$ & $8 \pm 23$ \\
\hline${ }_{28} N i$ & $70 \pm 18$ & $191 \pm 24$ & $35 \pm 18$ & $159 \pm 25$ \\
\hline${ }_{40} Z r$ & $100 \pm 18$ & $95 \pm 23$ & $65 \pm 19$ & $63 \pm 23$ \\
\hline${ }_{41} \mathrm{Nb}$ & $70 \pm 18$ & $112 \pm 23$ & $35 \pm 18$ & $80 \pm 23$ \\
\hline${ }_{42} \mathrm{Mo}$ & $60 \pm 18$ & $48 \pm 22$ & $25 \pm 18$ & $16 \pm 23$ \\
\hline
\end{tabular}

Para uma melhor visualização estão representados na forma gráfica os valores constantes na TAB 5.2 em função do elemento $(Z)$ dopante quanto à variação da remanência $\Delta \mathrm{B}_{\mathrm{r}}$, e quanto à variação da coercividade intrínseca $\Delta_{\mathrm{i}} \mathrm{H}_{\mathrm{c}}$, nas FIG. 5.1 e FIG. 5.2 , respectivamente.

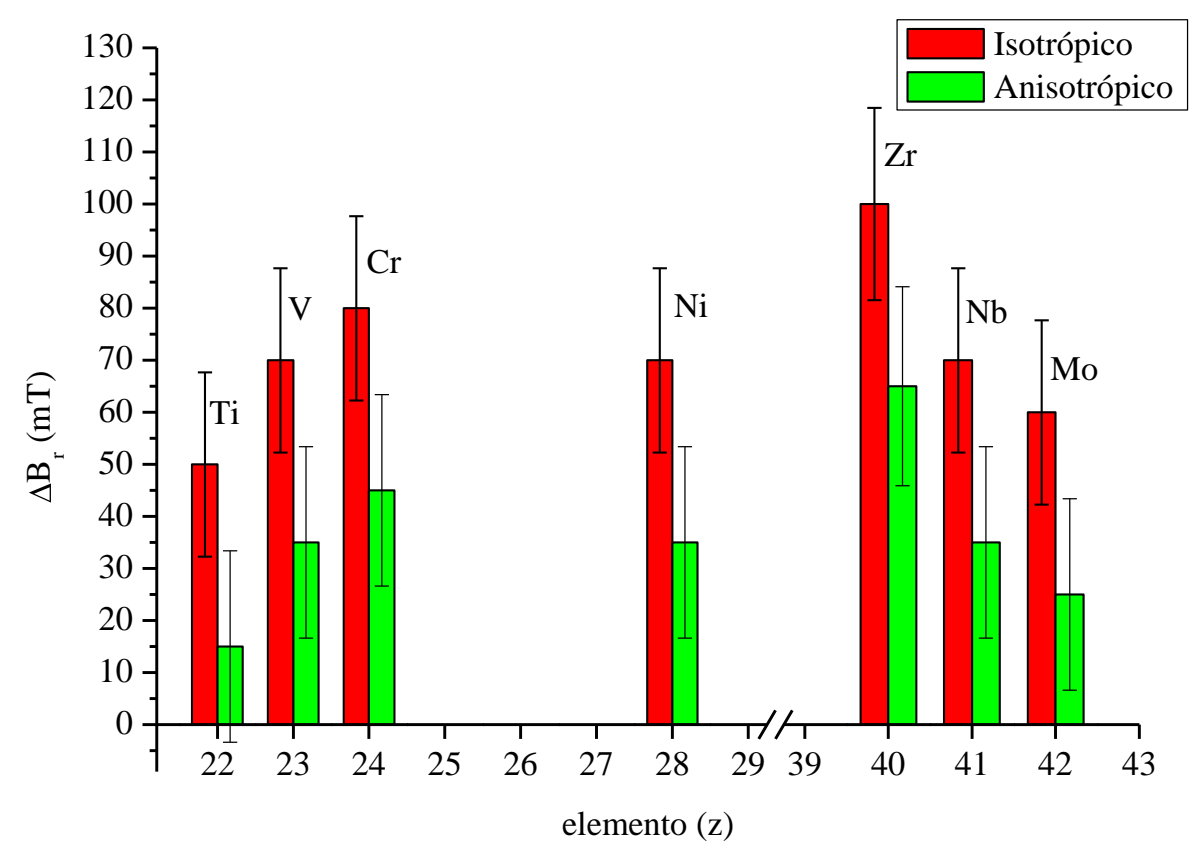

FIGURA 5.1 - Gráfico da variação da remanência $\Delta \mathrm{B}_{\mathrm{r}}$ relativa aos magnetos isotrópico e anisotrópico em função ao elemento dopante $(\mathrm{Z})$ adicionado. 


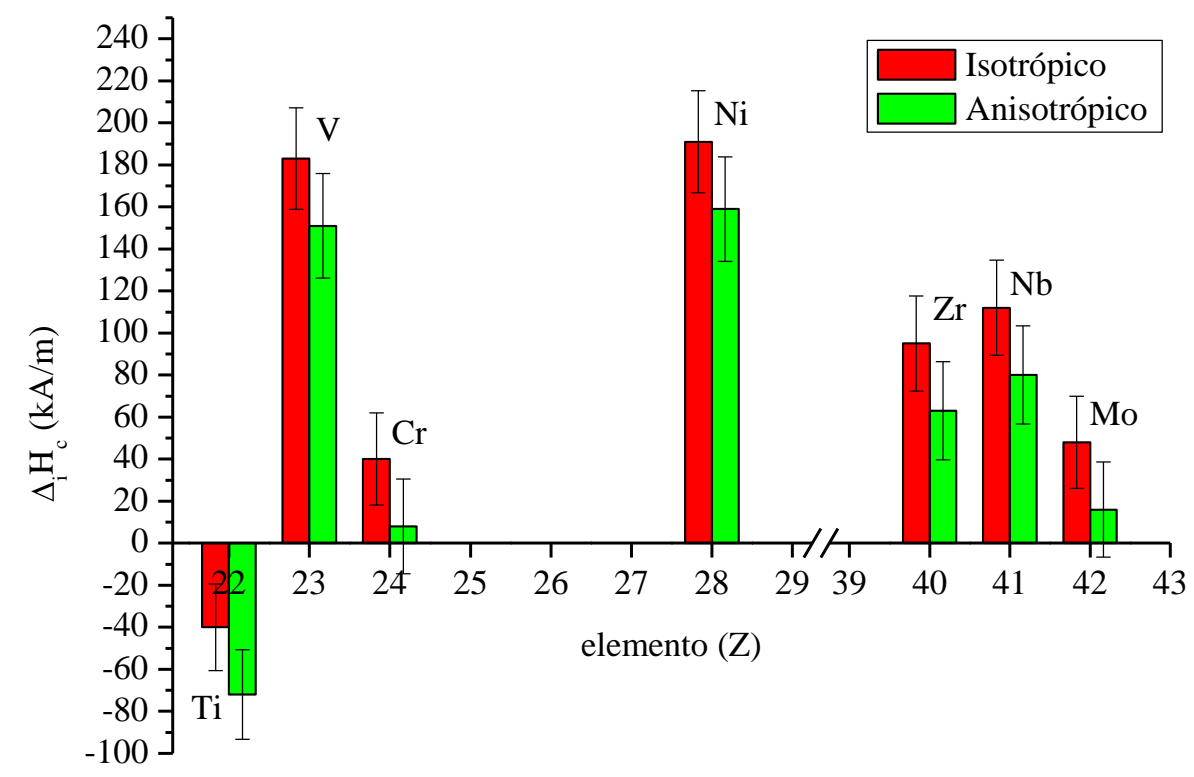

FIGURA 5.2 - Gráfico da variação da coercividade intrínseca $\Delta_{\mathrm{i}} \mathrm{H}_{\mathrm{c}}$ relativa aos magnetos isotrópico e anisotrópico em função ao elemento $(\mathrm{Z})$ dopante adicionado.

Nas discussões realizadas nos itens a seguir a comparação dos valores será realizada com os valores obtidos para o magneto anisotrópico, uma vez que os magnetos com adição de 0,1 \% atômico no sistema Pr-Fe-Co-B estudados neste trabalho foram obtidos pelo procedimento experimental descrito no item 4.3.

\subsection{1 - O efeito da adição do Ti, V, Cr ou Ni}

A adição do titânio aumentou a remanência levemente $(15 \pm 18) \mathrm{mT}$, e reduziu a coercividade $(-72 \pm 21) \mathrm{kA} / \mathrm{m}$. Ku e Yen (1987) observaram que a adição do titânio na liga Nd-Fe-B resultou na diminuição da magnetização de saturação.

De modo inverso, a adição do vanádio intensifica a coercividade intrínseca consideravelmente $(151 \pm 25) \mathrm{kA} / \mathrm{m}$ e aumenta a remanência em $(34 \pm 18) \mathrm{mT}$. Jurczuk et al. (1999) observaram uma melhora na remanência e diminuição da coercividade intrínseca na liga $\mathrm{Nd}_{16} \mathrm{Fe}_{66,275} \mathrm{Co}_{11,6} \mathrm{~B}_{6} \mathrm{~V}_{0,125}$, processada por HDDR. Zhou et al. (1990) estudaram ligas $\operatorname{Pr}_{10} \mathrm{Fe}_{82-\mathrm{x}} \mathrm{V}_{\mathrm{x}} \mathrm{B}_{8}$ obtidas por mechanical alloy, obtendo pós multifásicos onde houve a diminuição da remanência e aumento da coercividade intrínseca com aumento do teor de vanádio. Os autores concluíram que o vanádio atua como desestabilizador da fase 
$\operatorname{Pr}_{2} \mathrm{Fe}_{14} \mathrm{~B}$, induzindo a formação das fases $\operatorname{Pr}(\mathrm{Fe}, \mathrm{V}, \mathrm{B})_{7}$ e $\operatorname{Pr}(\mathrm{Fe}, \mathrm{V}, \mathrm{B})_{12}$ quando a concentração de vanádio for superior a $5 \%$ at..

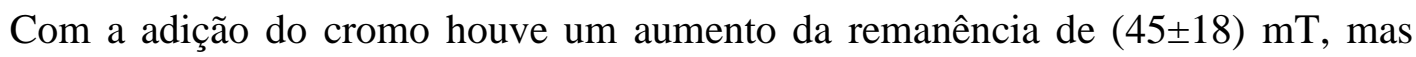
somente um pequeno aumento na coercividade $(8 \pm 23) \mathrm{kA} / \mathrm{m}$. Dados anteriormente reportados por Jurczuk et al. (1999) indicam que para magnetos obtidos pelo processo HDDR a partir da liga $\mathrm{Nd}_{16} \mathrm{Fe}_{66,275} \mathrm{Co}_{11,6} \mathrm{~B}_{6} \mathrm{Cr}_{0,125}$ observou-se um leve aumento da remanência e na coercividade intrínseca. Estudos realizados por Kowalczyk et al. (1988), com a substituição do ferro por cromo ou cobalto, simultaneamente na fase $\operatorname{Pr}_{2} \mathrm{Fe}_{14} \mathrm{~B}$, mostraram que para baixas concentrações de cromo ocorre aumento do campo de anisotropia do cristal levando conseqüentemente ao aumento da remanência. $\mathrm{O}$ valor obtido pelos autores foi maior que o conseguido neste estudo, porém da mesma ordem de grandeza.

A adição de níquel induziu a uma substancial anisotropia no magneto, onde se obteve uma remanência de $(35 \pm 18) \mathrm{mT}$ e coercividade de $(159 \pm 25) \mathrm{kA} / \mathrm{m}$, sendo este o maior valor de coercividade conseguida neste trabalho. Comportamento semelhante foi verificado por Bolzoni et al. (1986) para a substituição de ferro por níquel na fase $\mathrm{Nd}_{2} \mathrm{Fe}_{14} \mathrm{~B}$.

As micrografias de fratura obtidas por microscopia eletrônica de varredura (MEV)

para as ligas $\operatorname{Pr}_{14} \mathrm{Fe}_{\text {bal }} \mathrm{Co}_{16} \mathrm{~B}_{6} \mathrm{Ti}_{0,1} ; \quad \operatorname{Pr}_{14} \mathrm{Fe}_{\text {bal }} \mathrm{Co}_{16} \mathrm{~B}_{6} \mathrm{~V}_{0,1} ; \quad \operatorname{Pr}_{14} \mathrm{Fe}_{\text {bal }} \mathrm{Co}_{16} \mathrm{~B}_{6} \mathrm{Cr}_{0,1} ; \quad$ e $\operatorname{Pr}_{14} \mathrm{Fe}_{\text {bal }} \mathrm{Co}_{16} \mathrm{~B}_{6} \mathrm{Ni}_{0,1}$ são apresentadas nas FIG 5.3: (a), (b), (c) e (d), respectivamente. Pode-se verificar que para todas as ligas o tamanho de grão é da mesma ordem de grandeza e menor que $1 \mu \mathrm{m}$, indicando que a adição destes dopantes não influencia significativa na microestrutura com o emprego do processamento HDDR.

De forma geral, a adição dos elementos citados neste item somente o elemento titânio causou uma pequena perda na coercividade (FIG. 5.2) com um pequeno incremento na remanência. Os demais foram benéficos às propriedades magnéticas destacando: o vanádio, o cromo e o níquel.

A análise por microscopia eletrônica de varredura só forneceu uma indicação se houve uma anormalidade na microestrutura com a adição dos dopantes, uma vez que só foi possível realizar esta análise na superfície de fratura do grão antes de triturá-lo.

No decorrer do trabalho tentou-se analisar o material por microscopia eletrônica de varredura após a moagem. Esta tentativa mostrou-se inadequada devido à alteração da morfologia causada pelo atrito quando da cominuição. Também houve a tentativa de se realizar análise por microscopia eletrônica de transmissão, mas a preparação do material 
em pó mostrou-se difícil de ser realizada. O material, devido as suas características, mostrou-se problemático quando submetido aos campos magnéticos gerados pelo microscópio de transmissão, rompendo-se facilmente devido a delicadeza do preparo levando a uma possível contaminação do equipamento.
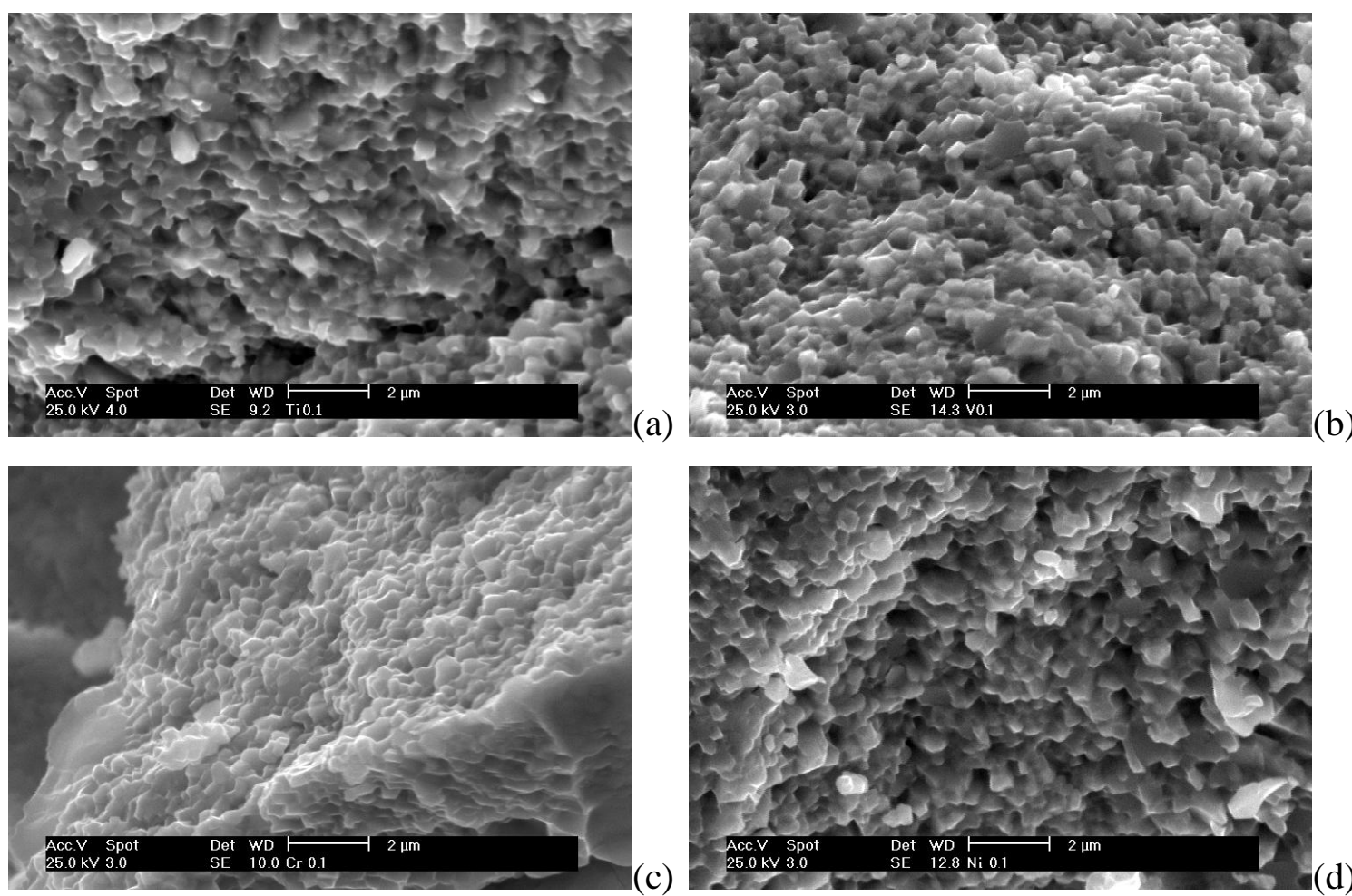

FIGURA 5.3 - Micrografias de fratura do grão dos materiais processados por HDDR das ligas $\operatorname{Pr}_{14} \mathrm{Fe}_{\mathrm{bal}} \mathrm{Co}_{16} \mathrm{~B}_{6} X_{0,1}$ onde (a) $X=\mathrm{Ti}$; (b) $X=\mathrm{V}$; (c) $X=\mathrm{Cr}$; e (d) $X=$ $\mathrm{Ni}$.

\subsection{2 - O efeito da adição do $\mathrm{Zr}$, Nb ou Mo.}

$\mathrm{O}$ nióbio adicionado ao sistema $\mathrm{Nd}-\mathrm{Fe}-\mathrm{B}$, utilizado na confecção de magnetos sinterizados, atua como refinador do grão pela formação da fase $\mathrm{NbFeB}$ (Pandian et al., 2002; Rodewald e Wall, 1989). Ahmed et al. (1996) observaram que o nióbio atua como refinador do grão na etapa de homogeneização da liga $\mathrm{Nd}_{11,8} \mathrm{Fe}_{82.3-\mathrm{x}} \mathrm{Nb}_{\mathrm{x}} \mathrm{B}_{5,9} \mathrm{com} \mathrm{x}=1,2,3$, 4 e 5, promovendo a diminuição do tempo de homogeneização. Os autores sugerem que o nióbio também pode atuar no refino do grão do material recombinado. Comparando-se as micrografias de fratura, FIG. 5.4 (a) com nióbio e (b) sem nióbio para as ligas processadas por HDDR neste trabalho não foi possível observar este efeito. 

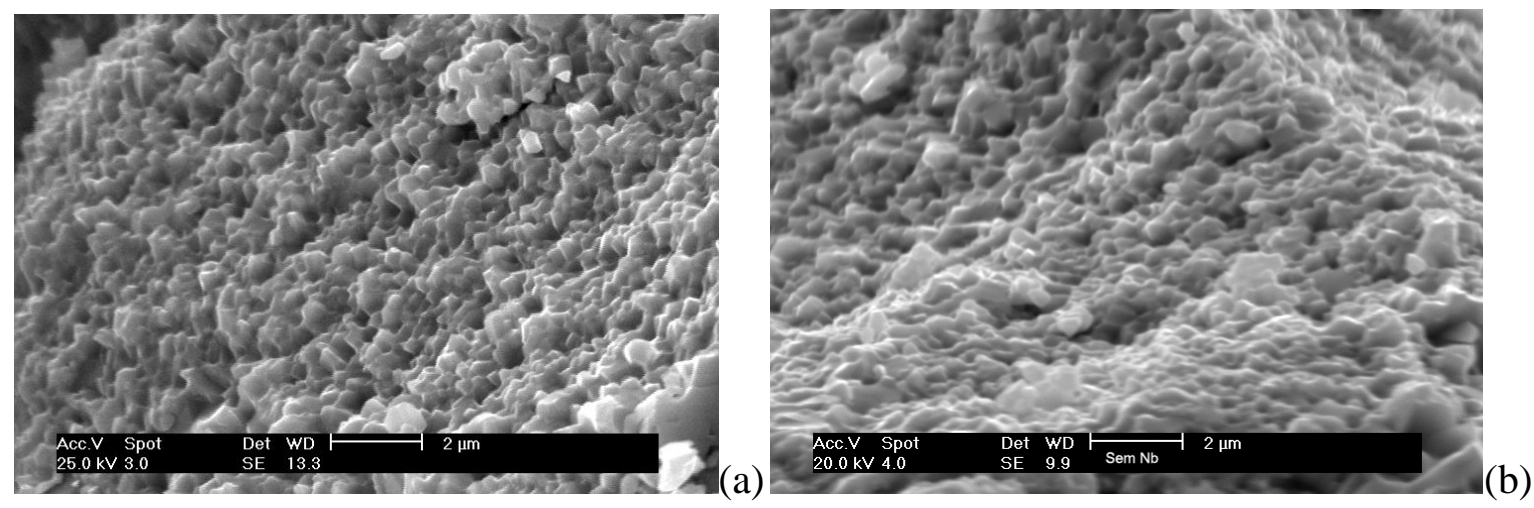

FIGURA 5.4 - Micrografia de fratura do grão das ligas processadas por HDDR: (a) $\mathrm{Pr}_{14} \mathrm{Fe}_{\mathrm{bal}} \mathrm{Co}_{16} \mathrm{~B}_{6} \mathrm{Nb}_{0,1}$ e (b) $\mathrm{Pr}_{14} \mathrm{Fe}_{\mathrm{bal}} \mathrm{Co}_{16} \mathrm{~B}_{6}$.

No sistema Pr-Fe-Co-B tratados pelo processo HDDR, o zircônio atua como estabilizador da fase $\operatorname{Pr}(\mathrm{FeCo}){ }_{12} \mathrm{~B}_{6}$ que, por sua vez, atua como um centro de memória na etapa de recombinação favorecendo o aumento da anisotropia (Cannesan et al., 2001 e 2002). Nakayama et al. (1994) mostraram que a adição de concentrações muito baixas de zircônio a liga $\mathrm{Nd}_{12,6} \mathrm{Fe}_{\text {bal }} \mathrm{Co}_{11,6} \mathrm{~B}_{6} \mathrm{Zr}_{\mathrm{x}}$, obtidas pelo processo HDDR, levou ao aumento da remanência e da coercividade intrínseca. Os autores concluíram que o aumento da remanência não é devido ao aumento da magnetização de saturação por substituição na estrutura cristalina da fase magnética, mas devido à melhora da orientação dos grãos da liga após o tratamento de homogeneização. Para os imãs estudados neste trabalho observou-se um aumento mais acentuado da remanência (65士19) mT em comparação com a coercividade intrínseca $(63 \pm 23) \mathrm{kA} / \mathrm{m}$. No entanto, estes resultados não permitiram avaliar os mecanismos que atuam neste caso. A FIG. 5.5 mostra a micrografia de fratura do material processado por HDDR da liga que contem zircônio a $0,1 \%$ at. Observa-se que os grãos estão abaixo de $1 \mu \mathrm{m}$. Cannesan et al. (2001) em um estudo comparativo entre a adição nióbio e zircônio ao sistema Pr-Fe-Co-B observaram que ambos os elementos atuam com refinadores do grão na etapa de homogeneização das ligas estudas. Para os materiais estudados pelos autores o zircônio apresentou um efeito mais intenso no refino do grão. 


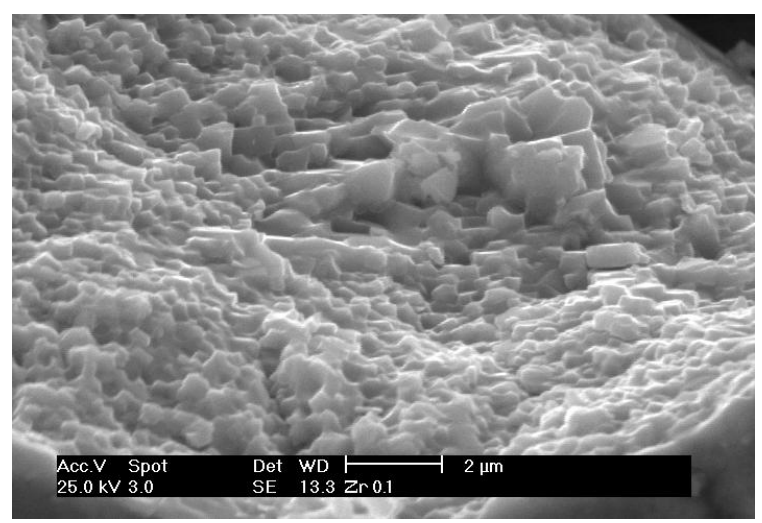

FIGURA 5.5 - Micrografia de fratura do grão do material processado por HDDR da liga $\operatorname{Pr}_{14} \mathrm{Fe}_{\text {bal }} \mathrm{Co}_{16} \mathrm{~B}_{6} \mathrm{Zr}_{0,1}$.

A adição de molibdênio resultou em um moderado aumento das propriedades magnéticas, $(25 \pm 18) \mathrm{mT}$ para remanência e $(16 \pm 23) \mathrm{kA} / \mathrm{m}$ para coercividade intrínseca. Estes resultados foram os menores quando comparado com os outros elementos pesquisados neste trabalho. A FIG. 5.6 mostra a micrografia de fratura do material processado por HDDR da liga que contem molibdênio a $0,1 \%$ at. Observa-se que os grãos estão abaixo de $1 \mu \mathrm{m}$.

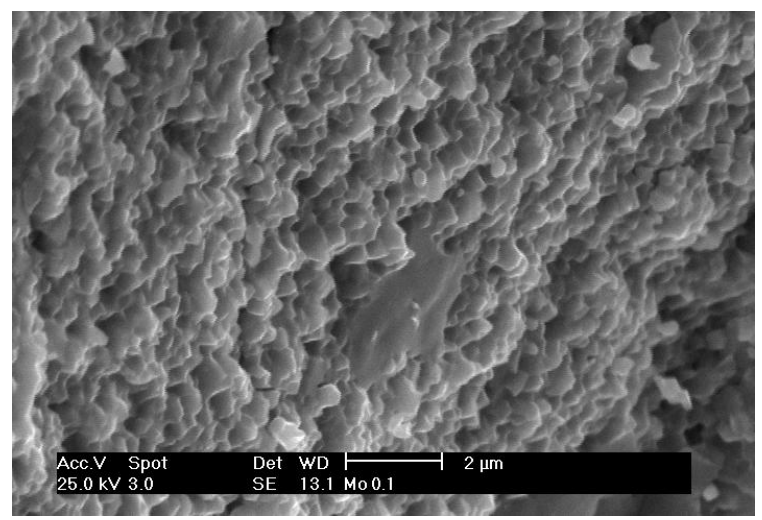

FIGURA 5.6 - Micrografia de fratura do grão do material processado por HDDR da liga $\operatorname{Pr}_{14} \mathrm{Fe}_{\text {bal }} \mathrm{Co}_{16} \mathrm{~B}_{6} \mathrm{Mo}_{0,1}$.

\section{2 - Adição de $0,1 \%, 0,3 \%$ e $0,5 \%$ atômico dos elementos dopantes}

As TAB. 5.3, TAB. 5.4 e TAB. 5.5 contêm os resultados obtidos para as adições de $0,1 \%, 0,3 \%$ e 0,5\% atômico, respectivamente, dos elementos dopantes: ${ }_{13} \mathrm{Al},{ }_{14} \mathrm{Si},{ }_{15} \mathrm{P}$, ${ }_{19} \mathrm{Cu}$ e ${ }_{31} \mathrm{Ga}$ à liga $\operatorname{Pr}_{14} \mathrm{Fe}_{\text {bal }} \mathrm{Co}_{16} \mathrm{~B}_{6} \mathrm{Nb}_{0,1}$, relativo às TABELAS 4.2, 4.3 e 4.4. As ligas foram processadas na seqüência de preparação descrita nos itens 4.2, 4.3 e 4.4. 
TABELA 5.3 - Propriedades magnéticas das ligas $\operatorname{Pr}_{14} \mathrm{Fe}_{\mathrm{bal}} \mathrm{Co}_{16} \mathrm{~B}_{6} \mathrm{Nb}_{0,1} \mathrm{X}_{0,1}$ onde $\mathrm{X}$ representa o elemento dopante adicionado.

\begin{tabular}{|c|c|c|c|c|c|}
\hline Composição & $\begin{array}{c}\mathbf{B}_{\mathbf{r}} \\
(\mathrm{mT})\end{array}$ & $\begin{array}{c}{ }_{\mathbf{i}} \mathbf{H}_{\mathbf{c}} \\
(\mathbf{k A} / \mathbf{m})\end{array}$ & $\begin{array}{c}{ }_{\mathbf{b}} \mathbf{H}_{\mathbf{c}} \\
(\mathbf{k A} / \mathbf{m})\end{array}$ & $\begin{array}{l}(\mathrm{BH})_{\max } \\
\left(\mathrm{kJ} / \mathrm{m}^{\mathbf{3}}\right)\end{array}$ & $\begin{array}{c}\text { SF } \\
\text { (razão) }\end{array}$ \\
\hline $\operatorname{Pr}_{14} \mathrm{Fe}_{{ }_{\text {bal }}} \mathrm{Co}_{16} \mathrm{~B}_{6} \mathrm{Nb}_{0,1} \mathrm{Al}_{0,1}$ & $740 \pm 15$ & $700 \pm 14$ & $406 \pm 8$ & $75 \pm 5$ & 0,33 \\
\hline $\mathrm{Pr}_{14} \mathrm{Fe}_{\mathrm{bal}} \mathrm{Co}_{16} \mathrm{~B}_{6} \mathrm{Nb}_{0,1} \mathrm{Si}_{0,1}$ & $700 \pm 14$ & $795 \pm 16$ & $390 \pm 8$ & $68 \pm 4$ & 0,26 \\
\hline $\mathrm{Pr}_{14} \mathrm{Fe}_{\mathrm{bal}} \mathrm{Co}_{16} \mathrm{~B}_{6} \mathrm{Nb}_{0,1} \mathrm{P}_{0,1}$ & $770 \pm 15$ & $780 \pm 16$ & $447 \pm 9$ & $86 \pm 6$ & 0,36 \\
\hline $\mathrm{Pr}_{14} \mathrm{Fe}_{\mathrm{bal}} \mathrm{Co}_{16} \mathrm{~B}_{6} \mathrm{Nb}_{0,1} \mathrm{Cu}_{0,1}$ & $620 \pm 12$ & $621 \pm 12$ & $350 \pm 7$ & $54 \pm 3$ & 0,36 \\
\hline $\mathrm{Pr}_{14} \mathrm{Fe}_{\mathrm{bal}} \mathrm{Co}_{16} \mathrm{~B}_{6} \mathrm{Nb}_{0,1} \mathrm{Ga}_{0,1}$ & $700 \pm 14$ & $700 \pm 14$ & $390 \pm 8$ & $68 \pm 4$ & 0,30 \\
\hline
\end{tabular}

TABELA 5.4 - Propriedades magnéticas das ligas $\operatorname{Pr}_{14} \mathrm{Fe}_{\mathrm{bal}} \mathrm{Co}_{16} \mathrm{~B}_{6} \mathrm{Nb}_{0,1} \mathrm{X}_{0,3}$ onde $\mathrm{X}$ representa o elemento dopante adicionado.

\begin{tabular}{|c|c|c|c|c|c|}
\hline Composição & $\begin{array}{c}\mathbf{B}_{\mathbf{r}} \\
(\mathbf{m T})\end{array}$ & $\begin{array}{c}\mathrm{i}_{\mathbf{i}} \\
(\mathbf{k A} / \mathbf{m})\end{array}$ & $\begin{array}{c}{ }_{b} \mathbf{H}_{\mathbf{c}} \\
(\mathbf{k A} / \mathbf{m})\end{array}$ & $\begin{array}{c}(\mathrm{BH})_{\max } \\
\left(\mathrm{kJ} / \mathbf{m}^{3}\right)\end{array}$ & $\begin{array}{c}\text { SF } \\
\text { (razão) }\end{array}$ \\
\hline $\mathrm{Pr}_{14} \mathrm{Fe}_{\mathrm{bal}} \mathrm{Co}_{16} \mathrm{~B}_{6} \mathrm{Nb}_{0,1} \mathrm{Al}_{0,3}$ & $720 \pm 14$ & $1011 \pm 20$ & $472 \pm 9$ & $85 \pm 6$ & 0,33 \\
\hline $\operatorname{Pr}_{14} \mathrm{Fe}_{\mathrm{bal}} \mathrm{Co}_{16} \mathrm{~B}_{6} \mathrm{Nb}_{0,1} \mathrm{Si}_{0,3}$ & $660 \pm 13$ & $454 \pm 9$ & $271 \pm 5$ & $45 \pm 2$ & 0,26 \\
\hline $\mathrm{Pr}_{14} \mathrm{Fe}_{\mathrm{bal}_{1}} \mathrm{Co}_{16} \mathrm{~B}_{6} \mathrm{Nb}_{0,1} \mathrm{P}_{0,3}$ & $720 \pm 14$ & $748 \pm 15$ & $438 \pm 9$ & $78 \pm 5$ & 0,36 \\
\hline $\mathrm{Pr}_{14} \mathrm{Fe}_{\mathrm{bal}} \mathrm{Co}_{16} \mathrm{~B}_{6} \mathrm{Nb}_{0,1} \mathrm{Cu}_{0,3}$ & $509 \pm 10$ & $477 \pm 10$ & $318 \pm 6$ & $41 \pm 1$ & 0,38 \\
\hline $\mathrm{Pr}_{14} \mathrm{Fe}_{\mathrm{bal}} \mathrm{Co}_{16} \mathrm{~B}_{6} \mathrm{Nb}_{0,1} \mathrm{Ga}_{0,3}$ & $670 \pm 13$ & $692 \pm 14$ & $338 \pm 7$ & $57 \pm 3$ & 0,25 \\
\hline
\end{tabular}

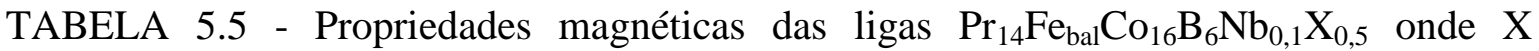
representa o elemento dopante adicionado.

\begin{tabular}{|c|c|c|c|c|c|}
\hline Composição & $\begin{array}{c}\mathbf{B}_{\mathbf{r}} \\
(\mathbf{m T})\end{array}$ & $\begin{array}{c}{ }_{\mathrm{i}} \mathbf{H}_{\mathbf{c}} \\
(\mathbf{k A} / \mathbf{m})\end{array}$ & $\begin{array}{c}{ }_{\mathbf{b}} \mathbf{H}_{\mathbf{c}} \\
(\mathbf{k A} / \mathbf{m})\end{array}$ & $\begin{array}{l}(\mathrm{BH})_{\max } \\
\left(\mathrm{kJ} / \mathrm{m}^{3}\right)\end{array}$ & $\begin{array}{c}\mathbf{S F} \\
\text { (razão) }\end{array}$ \\
\hline $\operatorname{Pr}_{14} \mathrm{Fe}_{\mathrm{bal}} \mathrm{Co}_{16} \mathrm{~B}_{6} \mathrm{Nb}_{0,1} \mathrm{Al}_{0,5}$ & $670 \pm 13$ & $971 \pm 19$ & $448 \pm 9$ & $70 \pm 9$ & 0,39 \\
\hline $\operatorname{Pr}_{14} \mathrm{Fe}_{\mathrm{bal}} \mathrm{Co}_{16} \mathrm{~B}_{6} \mathrm{Nb}_{0,1} \mathrm{Si}_{0,5}$ & $470 \pm 9$ & $247 \pm 5$ & $159 \pm 3$ & $18 \pm 1$ & 0,22 \\
\hline $\mathrm{Pr}_{14} \mathrm{Fe}_{\mathrm{bal}} \mathrm{Co}_{16} \mathrm{~B}_{6} \mathrm{Nb}_{0,1} \mathrm{P}_{0,5}$ & $720 \pm 14$ & $851 \pm 17$ & $438 \pm 9$ & $78 \pm 5$ & 0,30 \\
\hline $\operatorname{Pr}_{14} \mathrm{Fe}_{\mathrm{bal}} \mathrm{Co}_{16} \mathrm{~B}_{6} \mathrm{Nb}_{0,1} \mathrm{Cu}_{0,5}$ & $545 \pm 11$ & $345 \pm 7$ & $274 \pm 4$ & $37 \pm 2$ & 0,42 \\
\hline $\mathrm{Pr}_{14} \mathrm{Fe}_{\mathrm{bal}} \mathrm{Co}_{16} \mathrm{~B}_{6} \mathrm{Nb}_{0,1} \mathrm{Ga}_{0,5}$ & $620 \pm 12$ & $557 \pm 11$ & $302 \pm 6$ & $47 \pm 2$ & 0,26 \\
\hline
\end{tabular}

Os valores de $\mathrm{B}_{\mathrm{r}}$ e ${ }_{\mathrm{i}} \mathrm{H}_{\mathrm{c}}$ do magneto anisotrópico confeccionado com a liga $\operatorname{Pr}_{14} \mathrm{Fe}_{\text {bal }} \mathrm{Co}_{16} \mathrm{~B}_{6} \mathrm{Nb}_{0,1}$ apresentados na TAB. 5.1 foram utilizados como valores de referência para o cálculo do desvio $\Delta \mathrm{B}_{\mathrm{r}}$ e $\Delta_{\mathrm{i}} \mathrm{H}_{\mathrm{c}}$ apresentados na TAB 5.6 relativo às TAB .

\section{$5.3,5.4$ e 5.5}

TABELA 5.6 - Valores de desvio da remanência e coercividade intrínseca em relação à liga de $\operatorname{Pr}_{14} \mathrm{Fe}_{\text {bal }} \mathrm{Co}_{16} \mathrm{~B}_{6} \mathrm{Nb}_{0,1}$.

\begin{tabular}{c|rr|rr|rr}
\hline & \multicolumn{2}{|c|}{ Adição de 0,1 \% } & \multicolumn{2}{c|}{ Adição de 0,3 \% } & \multicolumn{2}{c}{ Adição de 0,5 \% } \\
Átomo & $\Delta \mathbf{B}_{\mathbf{r}}(\mathbf{m T})$ & $\Delta_{\mathbf{i}} \mathbf{H}_{\mathbf{c}}(\mathbf{k A} / \mathbf{m})$ & $\Delta \mathbf{B}_{\mathbf{r}}(\mathbf{m T})$ & $\Delta_{\mathbf{i}} \mathbf{H}_{\mathbf{c}}(\mathbf{k A} / \mathbf{m})$ & $\Delta \mathbf{B}_{\mathbf{r}}(\mathbf{m T})$ & $\Delta_{\mathbf{i}} \mathbf{H}_{\mathbf{c}}(\mathbf{k A} / \mathbf{m})$ \\
\hline$A l$ & $80 \pm 19$ & $-160 \pm 23$ & $60 \pm 19$ & $151 \pm 26$ & $10 \pm 19$ & $111 \pm 25$ \\
$S i$ & $40 \pm 19$ & $-65 \pm 24$ & $0 \pm 19$ & $-406 \pm 21$ & $-190 \pm 15$ & $-613 \pm 17$ \\
$P$ & $110 \pm 19$ & $-80 \pm 24$ & $60 \pm 19$ & $-112 \pm 14$ & $60 \pm 19$ & $-9 \pm 24$ \\
$C u$ & $-40 \pm 18$ & $-239 \pm 22$ & $-151 \pm 16$ & $-383 \pm 22$ & $-115 \pm 17$ & $-515 \pm 18$ \\
$G a$ & $40 \pm 19$ & $-160 \pm 23$ & $10 \pm 17$ & $-168 \pm 25$ & $-40 \pm 18$ & $-303 \pm 20$ \\
\hline
\end{tabular}


As FIG. 5.7 e 5.8 mostram os resultados relativos a TAB. 5.6 de $\Delta B_{r}$ e $\Delta_{i} H_{c}$, respectivamente. Nestas figuras os resultados estão agrupados em função do elemento dopante onde a quantidade adicionada está indicada por cores diferentes: $0,1 \%$ at. (vermelho), $0,3 \%$ at. (verde) e $0,5 \%$ at. (azul).

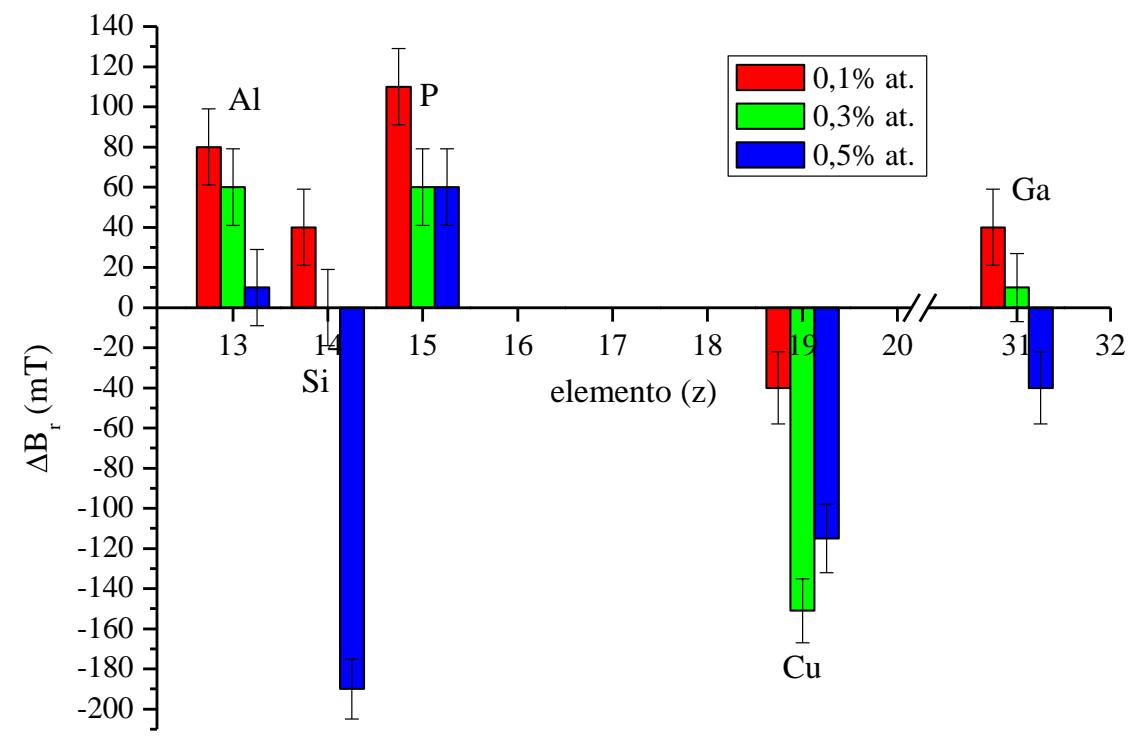

FIGURA 5.7 - Gráfico da variação da remanência $\left(\Delta \mathrm{B}_{\mathrm{r}}\right)$ em comparação com a liga base. As variações quanto a quantidade adicionada estão indicadas por cores: 0,1 $\%$ at. (vermelho), $0,3 \%$ at. (verde) e $0,5 \%$ at. (azul).

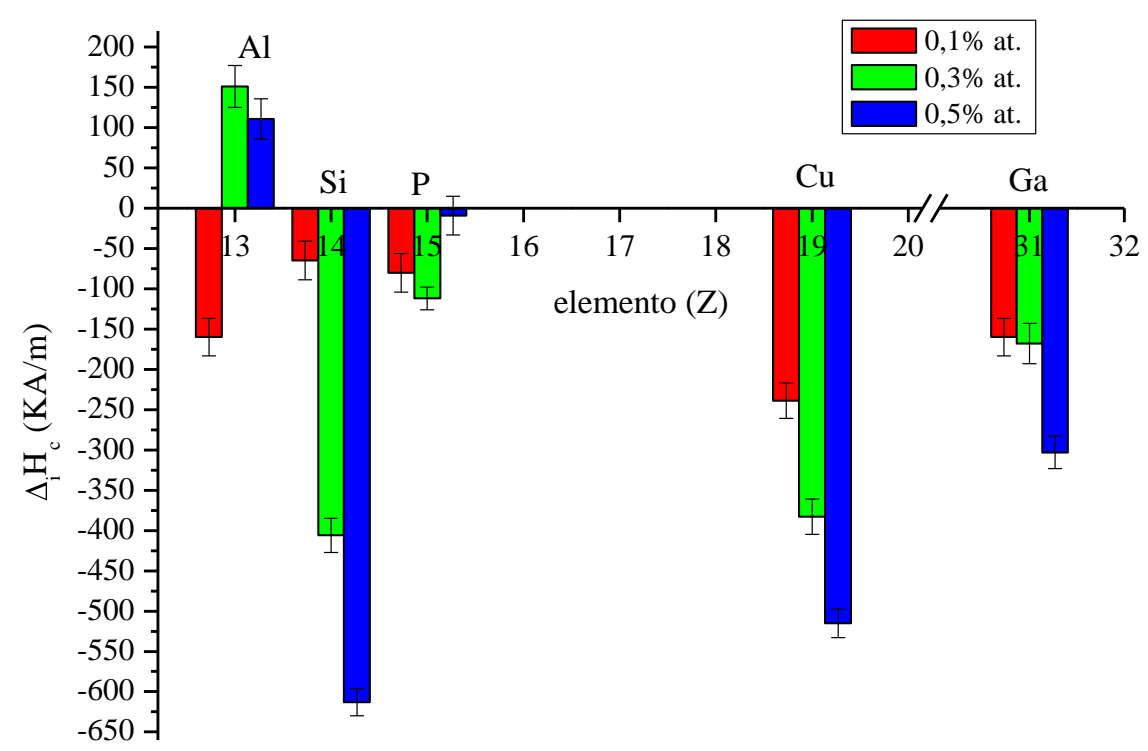

FIGURA 5.8 - Gráfico da variação da coercividade intrínseca $\left(\Delta_{i} \mathrm{H}_{c}\right)$ em comparação com a liga base. As variações quanto a quantidade adicionada estão indicadas por cores: $0,1 \%$ at. (vermelho), $0,3 \%$ at. (verde) e $0,5 \%$ at. (azul). 


\subsection{1 - O efeito da adição Al, Si ou $P$}

A adição de $0,1 \%$ de alumínio na liga $\operatorname{Pr}_{14} \mathrm{Fe}_{\mathrm{bal}} \mathrm{Co}_{16} \mathrm{~B}_{6} \mathrm{Nb}_{0,1}$ resultou no aumento da remanência em $(80 \pm 19) \mathrm{mT}$, embora tenha apresentado redução na coercividade intrínseca $(-160 \pm 23) \mathrm{kA} / \mathrm{m}$.

A adição de alumínio aos sistemas Nd-Fe-B e Pr-Fe-B utilizados na confecção de magnetos sinterizados levou à diminuição da remanência e ao aumento da coercividade intrínseca com o aumento da concentração adicionada (Misoguchi et al., 1986; Szymura et al., 1994; Pandian et al., 2002). Neste estudo observou-se que a adição inicial de 0,1 \% at. resulta em aumento da remanência em relação à liga de referência e que o aumento da concentração implica na diminuição do desvio positivo. Já a coercividade intrínseca resultou em sua diminuição em relação a liga de referência, resultado este contrário ao publicado na literatura. A adição de $0,3 \%$ at. e $0,5 \%$ at. resultaram no aumento da coercividade intrínseca, comportamento observado semelhante ao descrito na literatura.

Misoguchi et al.(1986) sugeriram que o alumínio incorpora-se à fase de Laves, $\mathrm{Nd}(\mathrm{Fe}, \mathrm{Co})_{2}$, presente nos contornos de grão tornando-as não magnéticas, o que justificaria a diminuição da remanência. No caso dos imãs preparados por HDDR, a formação da fase de Laves nos contornos de grão é muito restrita sugerindo que o alumínio possa inicialmente estar sendo incorporado a fase $\varnothing$ da liga e, desta maneira, contribuindo para o aumento da remanência. O aumento da concentração de alumínio leva ao aumento dos defeitos cristalinos na fase $\emptyset$ que ancoram as paredes de domínio provocando o aumento da coercividade intrínseca. A FIG. 5.9 mostra a micrografia da fratura do material processado por HDDR da liga que contem alumínio: (a) $0,1 \%$, (b) $0,3 \%$ e (c) $0,5 \%$ at.. Observa-se semelhança entre as micrografias, estando os grãos abaixo de $1 \mu \mathrm{m}$ em média. 

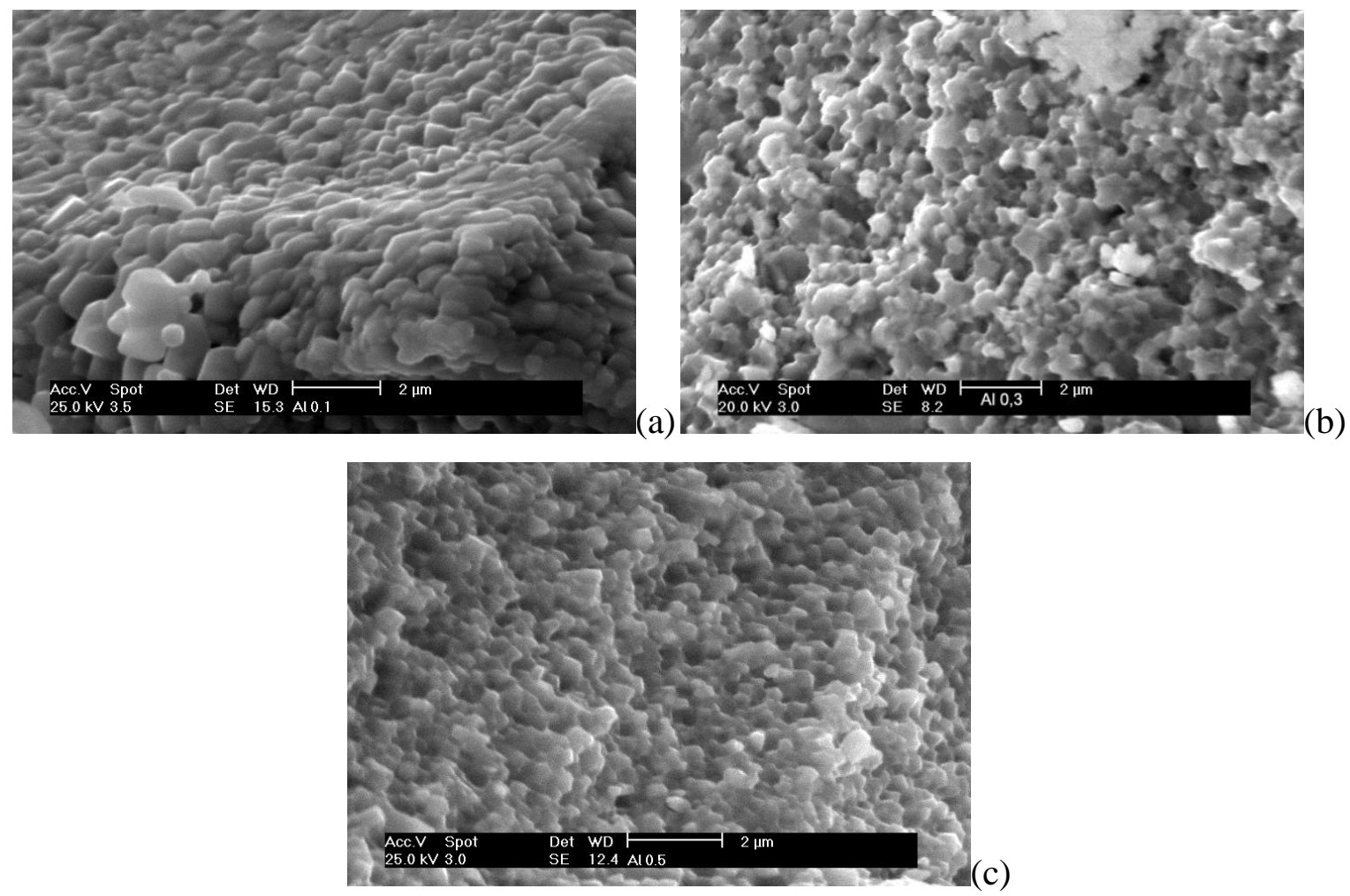

FIGURA 5.9 - Micrografias de fratura do grão das ligas $\operatorname{Pr}_{14} \mathrm{Fe}_{\text {bal }} \mathrm{Co}_{16} \mathrm{~B}_{6} \mathrm{Nb}_{0,1} \mathrm{Al}_{\mathrm{x}}$, onde $\mathrm{x}=$ (a) $0,1 \%$ at.;(b) $0,3 \%$ at.; (c) $0,5 \%$ at. processadas por HDDR.

A adição de $0,1 \%$ at. de silício induziu melhora na anisotropia nos magnetos processados por HDDR com o aumento da remanência em $(40 \pm 19)$ mT e houve uma diminuição na coercividade intrínseca $(-65 \pm 24) \mathrm{kA} / \mathrm{m}$. Estes resultados indicam que nesta concentração o silício deve estar ocupando sítios na estrutura cristalina do $\operatorname{Pr}_{2} \mathrm{Fe}_{14} \mathrm{~B}$ (Pedziwiart et al., 1987c). É bem conhecido que a combinação do ferro com o silício forma uma fase magnética mole induzindo a diminuição da coercividade. $\mathrm{O}$ aumento deste dopante foi deletério para as duas medidas magnéticas (em 0,3\% at. e 0,5\% at.), sendo os piores resultados conseguidos para a coercividade intrínseca. A FIG. 5.10 mostra a micrografia de fratura do material processado por HDDR da liga que contem silício: (a) 0,1 $\%$ at., (b) $0,3 \%$ at. e (c) $0,5 \%$ at. Observa-se semelhança entre as micrografias, estando os grãos com tamanho abaixo de $1 \mu \mathrm{m}$. 

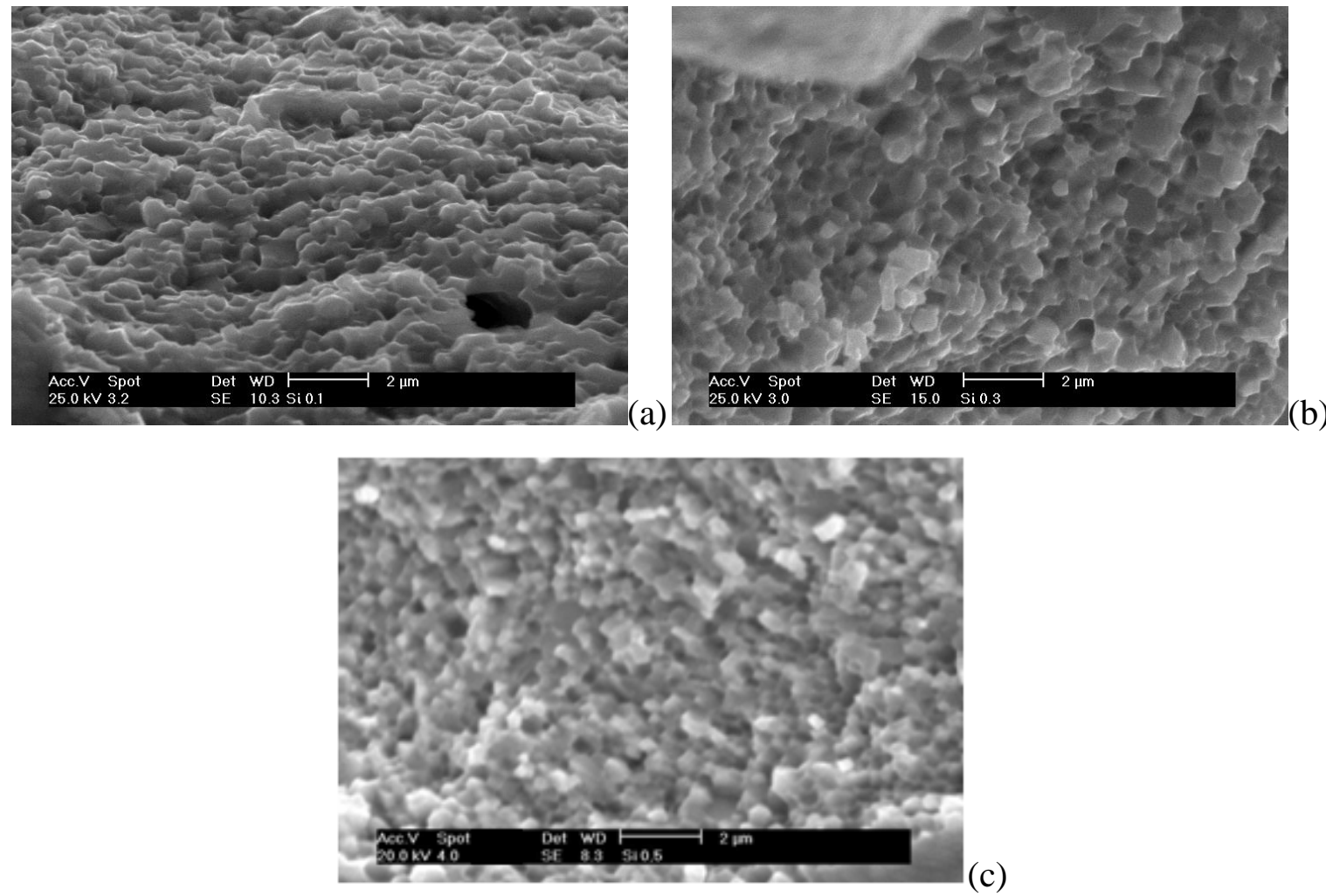

FIGURA 5.10 - Micrografias de fratura do grão das ligas processado por HDDR $\mathrm{Pr}_{14} \mathrm{Fe}_{\text {bal }} \mathrm{Co}_{16} \mathrm{~B}_{6} \mathrm{Nb}_{0,1} \mathrm{Si}_{\mathrm{x}}$, onde $\mathrm{x}=$ (a) $0,1 \%$ at.;(b) $0,3 \%$ at.; (c) $0,5 \%$ at.

A adição de $0,1 \%$ de fósforo a liga $\operatorname{Pr}_{14} \mathrm{Fe}_{\mathrm{bal}} \mathrm{Co}_{16} \mathrm{~B}_{6} \mathrm{Nb}_{0,1}$ ocasionou o maior aumento na remanência $(110 \pm 19)$ mT em comparação com todas as ligas estudadas neste trabalho, diminuindo a coercividade intrínseca $(-80 \pm 24) \mathrm{kA} / \mathrm{m}$. O aumento da remanência mostra que a combinação $\mathrm{Nb} / \mathrm{P}$ foi consideravelmente eficiente para aumento da anisotropia. Segundo Jin et al. (2003) a adição de fósforo na liga $\operatorname{Pr}_{7} \mathrm{~Tb}_{1} \mathrm{Fe}_{87-\mathrm{x}} \mathrm{Nb}_{0,5} \mathrm{P}_{\mathrm{x}} \mathrm{B}_{4}$ preparado pelo processo melt spinning levou a formação da fase $\mathrm{Pr}-\mathrm{P}$, que diminui o ponto de fusão e, também, refina a microestrutura. A coercividade da liga $\operatorname{Pr}_{14} \mathrm{Fe}_{\text {bal }} \mathrm{Co}_{16} \mathrm{~B}_{6} \mathrm{Nb}_{0,1} \mathrm{P}_{0,1}$ foi inferior ao da liga de referência $\operatorname{Pr}_{14} \mathrm{Fe}_{\text {bal }} \mathrm{Co}_{16} \mathrm{~B}_{6} \mathrm{Nb}_{0,1}$ indicando que a combinação $\mathrm{Nb} / \mathrm{P}$ foi ineficiente para aumentar a coercividade, embora os dois elementos atuem como refinadores de grãos. Com a adição de $0,3 \%$ at. de fósforo houve

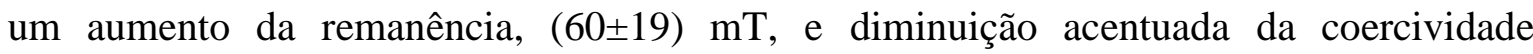
intrínseca, $(-112 \pm 14) \mathrm{kA} / \mathrm{m}$. Com a adição de $0,5 \%$ at. o valor da remanência, $(60 \pm 19)$ mT, manteve-se igual a adição de $0,3 \%$ at., porém com melhora da coercividade intrínseca, $(-9 \pm 24) \mathrm{kA} / \mathrm{m}$ em relação as outras adições. A FIG. 5.11 mostra a micrografia da superfície de fratura do material processado por HDDR da liga que contem fósforo: (a) 0,1\% at., (b) 
$0,3 \%$ at. e (c) $0,5 \%$ at. Observa-se semelhança entre as micrografias, estando os grãos com tamanho abaixo de $1 \mu \mathrm{m}$ em média.
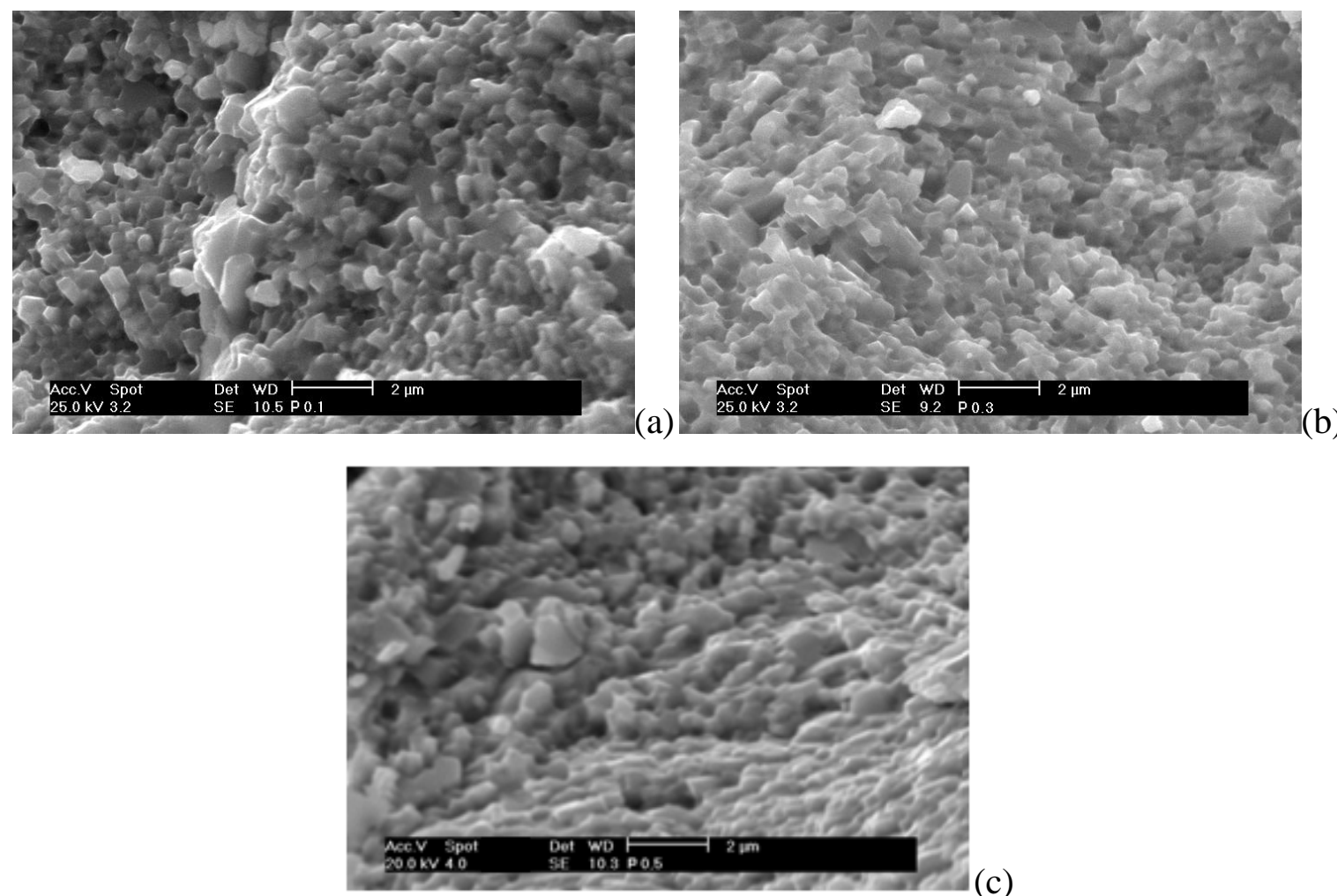

FIGURA 5.11 - Micrografia de fratura do grão das ligas processadas por HDDR $\operatorname{Pr}_{14} \mathrm{Fe}_{\text {bal }} \mathrm{Co}_{16} \mathrm{~B}_{6} \mathrm{Nb}_{0,1} \mathrm{P}_{\mathrm{x}}$, onde $\mathrm{x}=$ (a) $0,1 \%$ at.; (b) $0,3 \%$ at. e (c) $0,5 \%$ at.

\subsection{2 - O efeito da adição do $\mathrm{Cu}$ ou Ga}

A adição de cobre à liga de referência mostrou ser deletéria para as propriedades magnéticas. Houve decréscimo na remanência: $(-40 \pm 18)$ mT; $(-151 \pm 16)$ mT; e $(-115 \pm 17)$ mT, para adição de 0,1\% at.; 0,3\% at.; e 0,5\% at., respectivamente. Na coercividade intrínseca este decréscimo foi acentuado: $(-239 \pm 22) \mathrm{kA} / \mathrm{m} ;(-383 \pm 22) \mathrm{kA} / \mathrm{m}$; e $(-515 \pm 18)$ kA/m, para adição de $0,1 \%$ at.; $0,3 \%$ at. ; e 0,5\% at., respectivamente. $\mathrm{Na}$ análise microestrutural da liga após processamento HDDR, o pó exibiu um tamanho de grão até 10 vezes maior em relação ao que foi verificado nas outras ligas. Este efeito pode ser visto nas FIG. 5.12(a) e (b). A adição de cobre a magnetos sinterizados é reportada na literatura como responsável pelo refino de grão (Shimoda et al., 1988) e esperava-se que no processo HDDR o cobre tivesse o mesmo efeito. No entanto, os resultados obtidos para o tamanho grão observado nas micrografias sugerem que ocorre a formação de fase líquida eutética, 
$\operatorname{Pr}-\mathrm{Cu}$, na temperatura de recombinação responsável pelo crescimento de grão através de um mecanismo de sinterização em presença de fase líquida, explicando desta maneira o decréscimo drástico da coercividade intrínseca. Esta sinterização leva à formação de partículas angulares que resultando no aumento da porosidade que é responsável pela diminuição da remanência. A FIG. 5.13 mostra a micrografia de fratura do material processado por HDDR da liga que contem cobre: (a) $0,3 \%$ at. e (b) $0,5 \%$ at.
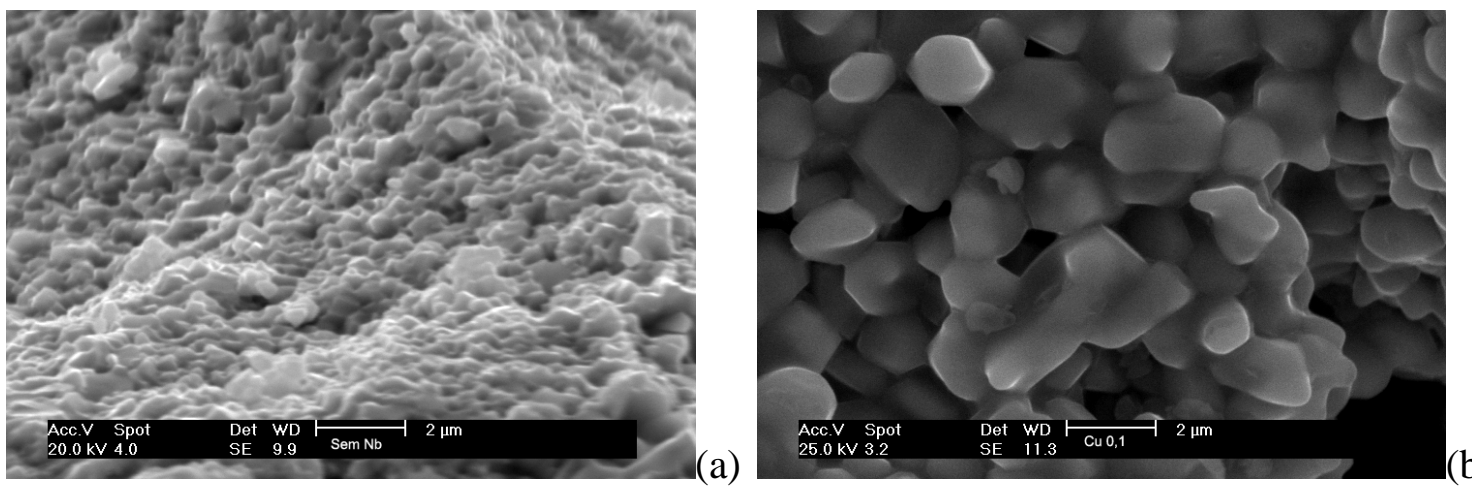

FIGURA 5.12 - Micrografia de fratura do grão da ligas processadas por HDDR (a) $\mathrm{Pr}_{14} \mathrm{Fe}_{\mathrm{bal}_{\mathrm{C}}} \mathrm{Co}_{16} \mathrm{~B}_{6} \mathrm{Nb}_{0,1}$ (b) $\mathrm{Pr}_{14} \mathrm{Fe}_{\text {bal }} \mathrm{Co}_{16} \mathrm{~B}_{6} \mathrm{Nb}_{0,1} \mathrm{Cu}_{0,1}$
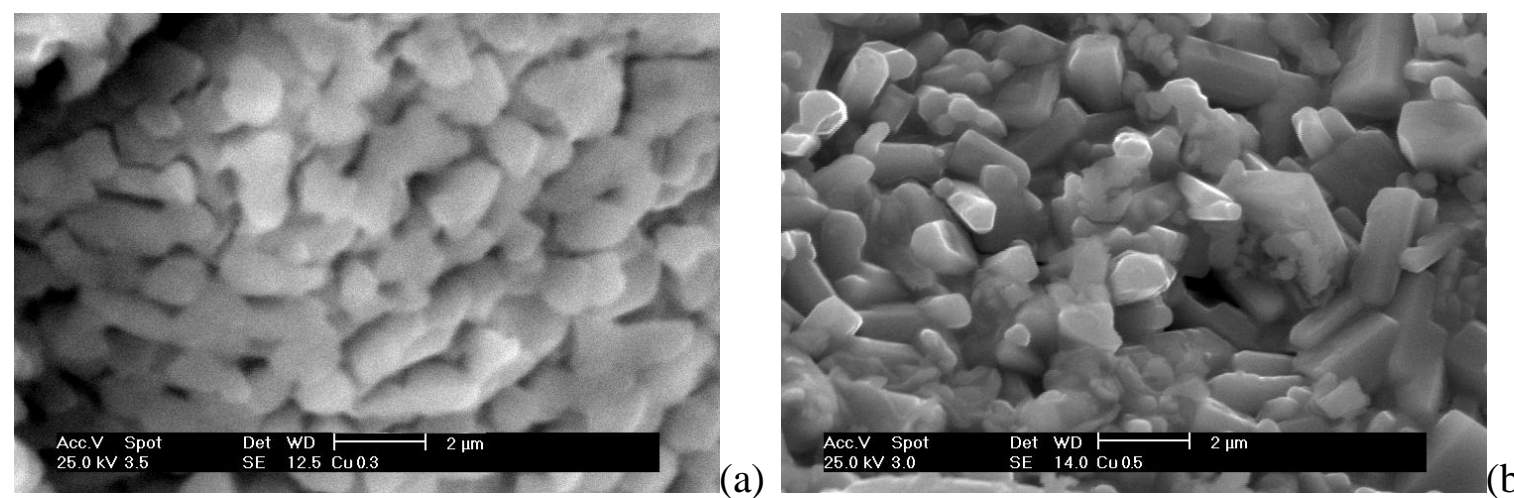

FIGURA 5.13 - Micrografia de fratura do grão das ligas processadas por HDDR $\operatorname{Pr}_{14} \mathrm{Fe}_{\text {bal }} \mathrm{Co}_{16} \mathrm{~B}_{6} \mathrm{Nb}_{0,1} \mathrm{Cu}_{\mathrm{x}}$, onde $\mathrm{x}=$ (a) $0,3 \%$ at.; (b) $0,5 \%$ at.

Segundo Uehara et al. (1993) o gálio no sistema Nd-Fe-B atua como retardador da desproporção da fase $\mathrm{Nd}_{2} \mathrm{Fe}_{14} \mathrm{~B}$, proporcionando a formação de núcleos orientados que levam ao aumento da anisotropia. Neste estudo a adição de gálio ao sistema Pr-Fe-B sugere que ocorre o inverso. O gálio diminui a anisotropia, para as condições de processamento utilizadas. A FIG. 5.14 mostra a micrografia de fratura do material processado por HDDR da liga que contem gálio: (a) $0,1 \%$, (b) $0,3 \%$ e (c) 0,5\% atômico. Observa-se semelhança entre as micrografias, estando os grãos abaixo de $1 \mu \mathrm{m}$ em média. 

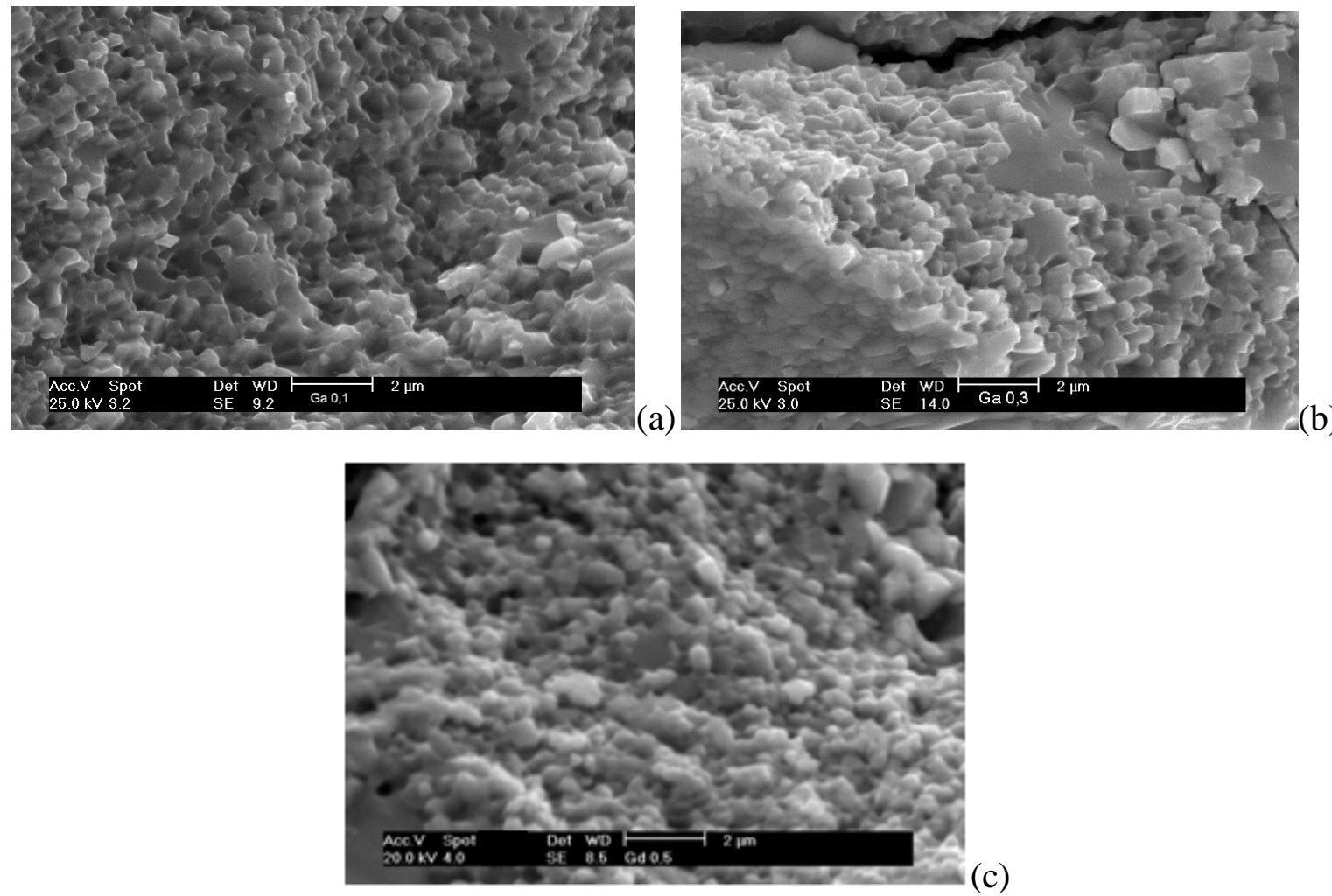

FIGURA 5.14 - Micrografia de fratura do grão das ligas processadas por HDDR $\mathrm{Pr}_{14} \mathrm{Fe}_{\text {bal }} \mathrm{Co}_{16} \mathrm{~B}_{6} \mathrm{Nb}_{0,1} \mathrm{Ga}_{\mathrm{x}}$, onde $\mathrm{x}=$ (a) $0,1 \%$ at.; (b) $0,3 \%$ at. e (c) $0,5 \%$ at.

\section{3 - Adição de cobalto à liga Pr-Fe-B-Nb}

A adição do cobalto na liga Pr-Fe-B-Nb teve como objetivo inicial aumentar a temperatura de Curie $\left(\mathrm{T}_{\mathrm{C}}\right)$. A adição de cobalto no sistema $\mathrm{Pr}_{8} \mathrm{Fe}_{56-\mathrm{x}} \mathrm{Co}_{\mathrm{x}} \mathrm{B}_{4}$ para $\mathrm{x} \leq 16$ aumenta a $\mathrm{T}_{\mathrm{C}}$ em $50 \mathrm{~K}$ e para valores de $\mathrm{x}>16$ a $\mathrm{T}_{\mathrm{C}}$ aumenta em $11 \mathrm{~K}$ por átomo de ferro substituído (Pedziwiatr et al., 1986a; Overfeld e Becker, 1984). O ganho no aumento da $\mathrm{T}_{\mathrm{C}}$ a partir de $\mathrm{x}>16$ fica inviável do ponto de vista comercial devido ao alto custo do cobalto.

Conforme descrito no item 4.6, a adição do cobalto visou determinar os parâmetros cristalográficos das ligas $\operatorname{Pr}_{14} \mathrm{Fe}_{\text {bal- } \mathrm{x}} \mathrm{Co}_{\mathrm{x}} \mathrm{B}_{6} \mathrm{Nb}_{0,1}$ com $\mathrm{x}=0,4,8,12$ e 16 disponibilizadas no laboratório, dando base para a avaliação da utilização de métodos teóricos na estudo da adição de outros elementos químicos ao sistema ternário Pr-Fe-B.

\subsection{1 - Medidas magnéticas das ligas com variação de cobalto}

As propriedades magnéticas para as ligas com variação de cobalto foram medidas nos equipamentos descritos no item 4.4. Com as curvas de histerese medidas para cada liga foi possível obter a coercividade intrínseca e a remanência e comparar os resultados obtidos entre os equipamentos. 
No permeâmetro $L D J$, só é possível realizar medidas no imã consolidado a partir do material já magnetizado, obtendo-se os resultados através da medida do segundo quadrante da curva de desmagnetização.

No MAV as medidas foram realizadas diretamente no pó em duas temperaturas, 4,2 K e $300 \mathrm{~K}$, sendo possível realizar a curva de histerese completa a partir da amostra não magnetizada. A 4,2 $\mathrm{K}$ não se observou a magnetização de saturação mesmo com a aplicação do campo de $9 \mathrm{~T}$ (máximo campo conseguido no equipamento).

As curvas de histerese realizadas no MAV das ligas $\operatorname{Pr}_{14} \mathrm{Fe}_{\mathrm{bal}} \mathrm{B}_{6} \mathrm{Nb}_{0,1}$, $\operatorname{Pr}_{14} \mathrm{Fe}_{\text {bal }} \mathrm{Co}_{4} \mathrm{~B}_{6} \mathrm{Nb}_{0,1}, \operatorname{Pr}_{14} \mathrm{Fe}_{\text {bal }} \mathrm{Co}_{8} \mathrm{~B}_{6} \mathrm{Nb}_{0,1}, \operatorname{Pr}_{14} \mathrm{Fe}_{\text {bal }} \mathrm{Co}_{12} \mathrm{~B}_{6} \mathrm{Nb}_{0,1}$ e $\operatorname{Pr}_{14} \mathrm{Fe}_{\text {bal }} \mathrm{Co}_{16} \mathrm{~B}_{6} \mathrm{Nb}_{0,1}$ são apresentadas nas FIG. 5.15; 5.16; 5.17; 5.18 e 5.19, respectivamente. A falta do quarto quadrante e parte do primeiro quadrante nos gráficos da histerese a 4,2 $\mathrm{K}$ foi devida à limitação do uso de hélio líquido, não implicando em problemas no levantamento das medidas.
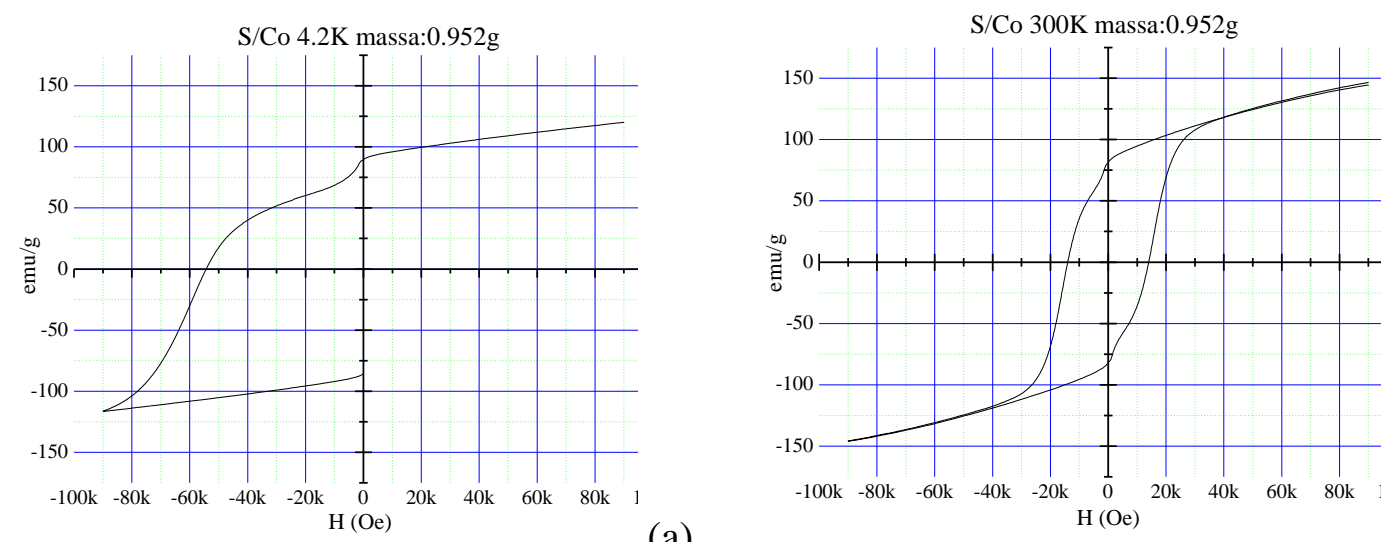

(a)

FIGURA 5.15 - Curvas de histerese da liga Pr14FebalB6Nb0,1 nas temperaturas: (a) $4,2 \mathrm{~K}$ e (b) $300 \mathrm{~K}$.

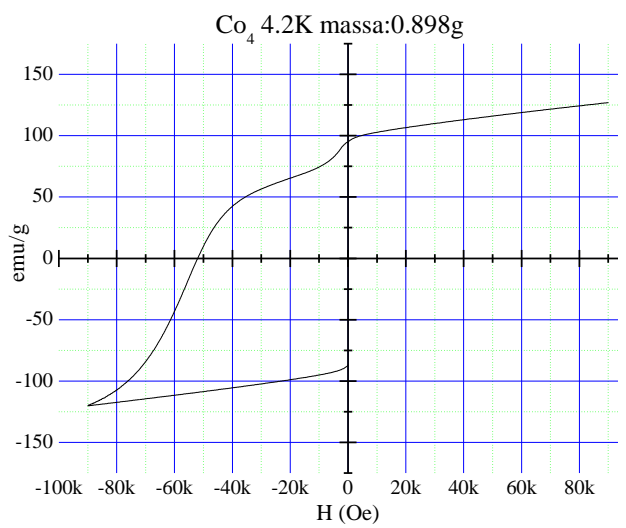

(a)

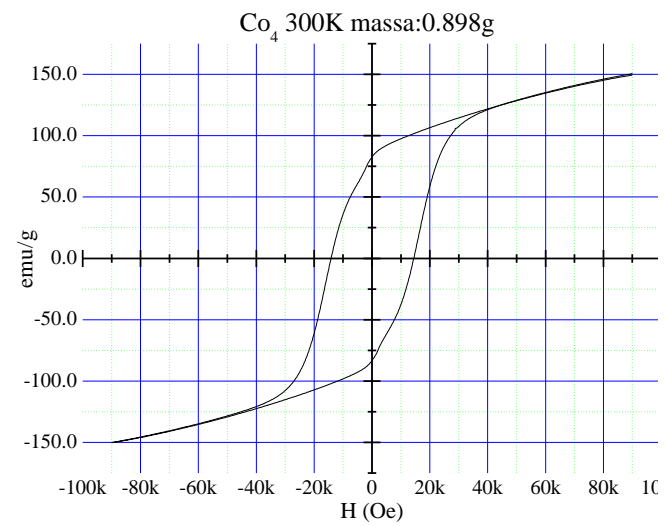

FIGURA 5.16 - Curvas de histerese da liga $\operatorname{Pr}_{14} \mathrm{Fe}_{\mathrm{bal}} \mathrm{Co}_{4} \mathrm{~B}_{6} \mathrm{Nb}_{0,1}$ nas temperaturas: (a) 4,2 K e (b) $300 \mathrm{~K}$. 

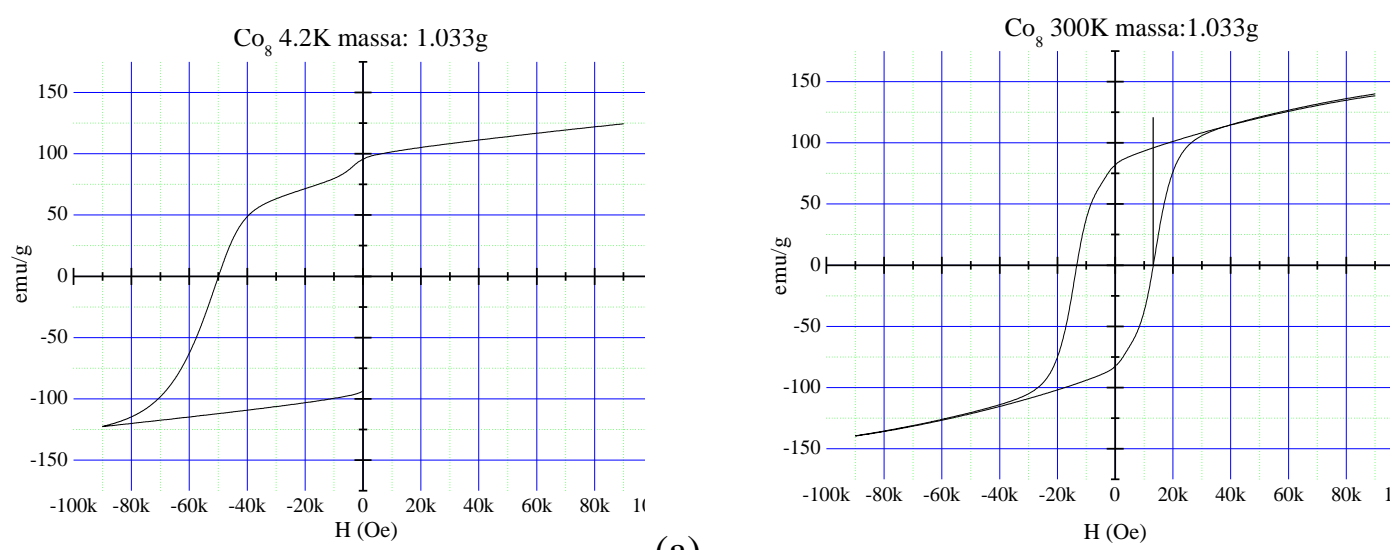

(a)

FIGURA 5.17 - Curvas de histerese da liga $\operatorname{Pr}_{14} \mathrm{Fe}_{\mathrm{bal}} \mathrm{Co}_{8} \mathrm{~B}_{6} \mathrm{Nb}_{0,1}$ nas temperaturas: (a) $4,2 \mathrm{~K}$ e (b) $300 \mathrm{~K}$.
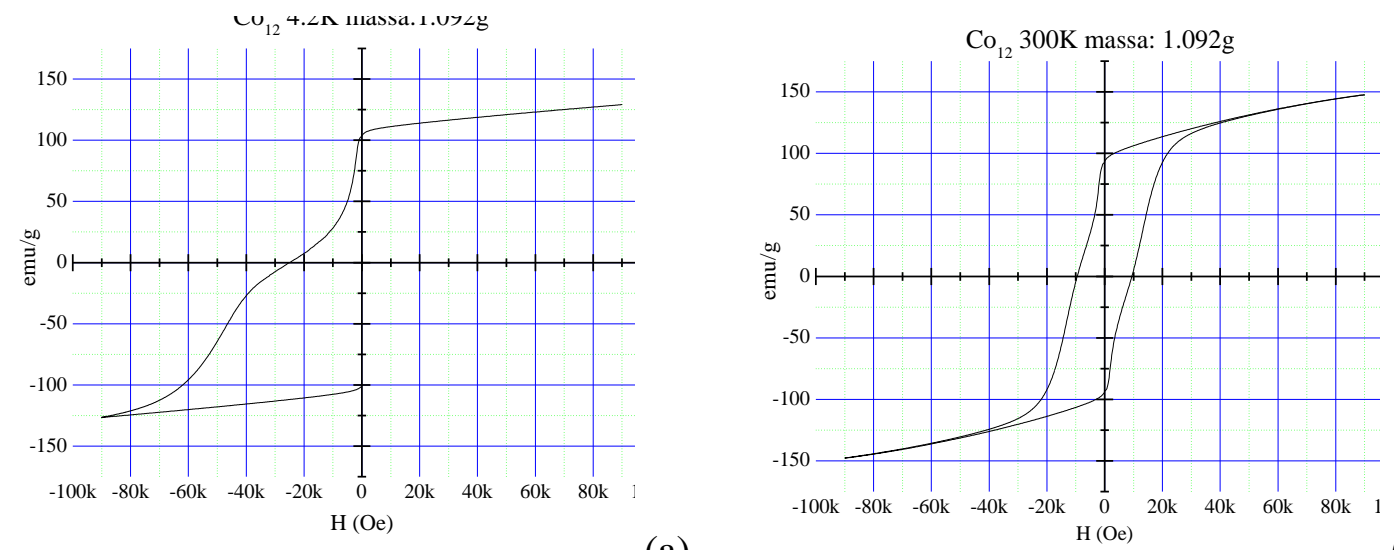

(a)

FIGURA 5.18 - Curvas de histerese da liga $\operatorname{Pr}_{14} \mathrm{Fe}_{b_{b a l}} \mathrm{Co}_{12} \mathrm{~B}_{6} \mathrm{Nb}_{0,1}$ nas temperaturas: (a) $4,2 \mathrm{~K}$ e (b) $300 \mathrm{~K}$.
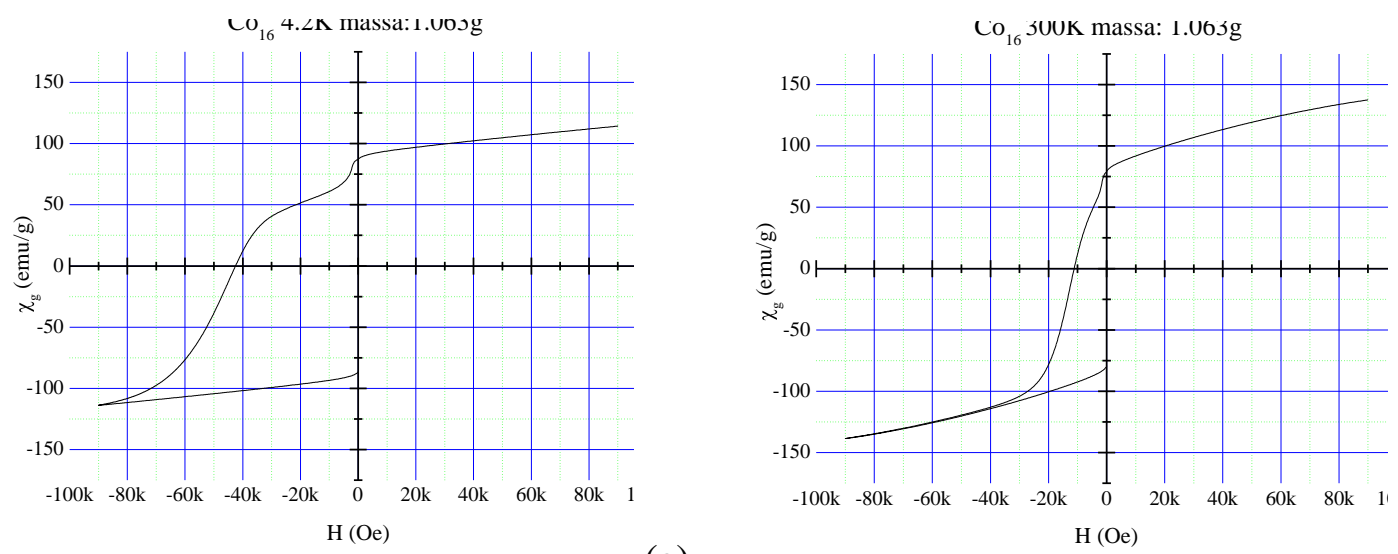

(a)

(b)

FIGURA 5.19 - Curvas de histerese da liga $\operatorname{Pr}_{14} \mathrm{Fe}_{\text {bal }} \mathrm{Co}_{16} \mathrm{~B}_{6} \mathrm{Nb}_{0,1}$ nas temperaturas: (a) $4,2 \mathrm{~K}$ e (b) $300 \mathrm{~K}$. 
Os resultados obtidos para as amostras consolidadas estão apresentados na TAB. 5.7. Os resultados para as amostras em pó estão apresentados na TAB. 5.8.

TABELA 5.7 - Propriedades magnéticas para os magnetos com variação de Co obtidas no permeâmetro da LDJ

\begin{tabular}{|c|c|c|c|c|c|}
\hline Composição & $\begin{array}{c}B_{r} \\
(m T)\end{array}$ & $\begin{array}{c}{ }_{i} H_{c} \\
(k A / m)\end{array}$ & $\begin{array}{c}{ }_{b} H_{c} \\
(k A / m)\end{array}$ & $\begin{array}{c}(B H)_{\max } \\
\left(k J / m^{3}\right)\end{array}$ & $\begin{array}{c}S F \\
(\text { razãa })\end{array}$ \\
\hline $\mathrm{Pr}_{14} \mathrm{Fe}_{\mathrm{bal}} \mathrm{B}_{6} \mathrm{Nb}_{0,1}$ & $801 \pm 10$ & $859 \pm 12$ & $429 \pm 9$ & $96 \pm 9$ & 0,39 \\
\hline $\mathrm{Pr}_{14} \mathrm{Fe}_{\mathrm{bal}} \mathrm{Co}_{4} \mathrm{~B}_{6} \mathrm{Nb}_{0,1}$ & $845 \pm 10$ & $946 \pm 11$ & $510 \pm 3$ & $140 \pm 1$ & 0,41 \\
\hline $\mathrm{Pr}_{14} \mathrm{Fe}_{\mathrm{bal}} \mathrm{Co}_{8} \mathrm{~B}_{6} \mathrm{Nb}_{0,1}$ & $803 \pm 14$ & $872 \pm 14$ & $493 \pm 9$ & $135 \pm 5$ & 0,45 \\
\hline $\mathrm{Pr}_{14} \mathrm{Fe}_{\mathrm{bal}} \mathrm{Co}_{12} \mathrm{~B}_{6} \mathrm{Nb}_{0,1}$ & $753 \pm 11$ & $779 \pm 10$ & $493 \pm 4$ & $121 \pm 2$ & 0,42 \\
\hline $\mathrm{Pr}_{14} \mathrm{Fe}_{\mathrm{bal}} \mathrm{Co}_{16} \mathrm{~B}_{6} \mathrm{Nb}_{0,1}$ & $701 \pm 12$ & $700 \pm 11$ & $446 \pm 6$ & $47 \pm 2$ & 0,25 \\
\hline
\end{tabular}

TABELA 5.8 - Propriedades magnéticas das ligas com variação de Co obtidas no MAV.

\begin{tabular}{|c|c|c|c|c|}
\hline Composição & $\begin{array}{c}T \\
(K)\end{array}$ & $\begin{array}{c}B_{r} \\
(m T)\end{array}$ & $\begin{array}{c}{ }_{i} \boldsymbol{H}_{c} \\
(k A / m)\end{array}$ & $\begin{array}{c}M_{s} \\
\left(\mu_{B}\right)\end{array}$ \\
\hline \multirow{2}{*}{$\mathrm{Pr}_{14} \mathrm{Fe}_{\mathrm{bal}} \mathrm{B}_{6} \mathrm{Nb}_{0,1}$} & 4,2 & $919 \pm 28$ & $4321 \pm 130$ & \\
\hline & 300 & $857 \pm 26$ & $1119 \pm 34$ & $123 \pm 2$ \\
\hline \multirow{2}{*}{ 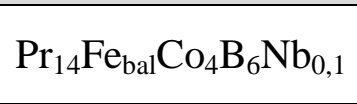 } & 4.2 & $1014 \pm 30$ & $4138 \pm 124$ & - \\
\hline & 300 & $922 \pm 28$ & $1153 \pm 35$ & $125 \pm 3$ \\
\hline \multirow{2}{*}{$\mathrm{Pr}_{14} \mathrm{Fe}_{\mathrm{bal}} \mathrm{Co}_{8} \mathrm{~B}_{6} \mathrm{Nb}_{0,1}$} & 4.2 & $912 \pm 27$ & $3974 \pm 119$ & - \\
\hline & 300 & $826 \pm 25$ & $1052 \pm 32$ & $122 \pm 2$ \\
\hline \multirow{2}{*}{$\operatorname{Pr}_{14} \mathrm{Fe}_{\mathrm{bal}} \mathrm{Co}_{12} \mathrm{~B}_{6} \mathrm{Nb}_{0,1}$} & 4.2 & $904 \pm 27$ & $2990 \pm 90$ & - \\
\hline & 300 & $795 \pm 24$ & $954 \pm 29$ & $120 \pm 2$ \\
\hline \multirow{2}{*}{$\operatorname{Pr}_{14} \mathrm{Fe}_{\text {bal }} \mathrm{Co}_{16} \mathrm{~B}_{6} \mathrm{Nb}_{0,1}$} & 4.2 & $817 \pm 25$ & $2390 \pm 72$ & - \\
\hline & 300 & $746 \pm 22$ & $891 \pm 27$ & $118 \pm 2$ \\
\hline
\end{tabular}

Os valores obtidos para o magneto $\operatorname{Pr}_{14} \mathrm{Fe}_{\text {bal }} \mathrm{Co}_{16} \mathrm{~B}_{6} \mathrm{Nb}_{0,1}$ constantes na TAB 5.7 diferem dos valores obtidos para a mesma liga constante na TAB. 5.1 podendo ser explicado pela preparação do material antes da confecção do magneto. Quando da preparação do material para análise por difração de raios X utilizou-se peneira de $44 \mu \mathrm{m}$ (325 mesh), enquanto normalmente utiliza-se (como padrão do laboratório) a peneira de 75 $\mu \mathrm{m}$ (200 mesh). A necessidade de se utilizar a peneira de $44 \mu \mathrm{m}$ para análise de difração de raios $\mathrm{X}$ foi explicada no item 4.6. A coercividade intrínseca diminui com a diminuição do tamanho de partícula e este fato foi atribuído aos defeitos estruturais induzidos nas partículas e pela oxidação destas durante o processo de moagem. Por outro lado, o grau de alinhamento que representa o grau de anisotropia do material aumenta gradativamente com a diminuição do tamanho de partícula, em conseqüência aumenta a remanência. Esta variação pode ser explicada pelo fato de que partículas grosseiras são constituídas 
provavelmente por um aglomerado de grãos finos recombinados formados por diferentes grãos da liga original (Kown, 1996).

A comparação entre os resultados obtidos forneceu indícios da influência do aglomerante utilizado para a confecção dos magnetos consolidados, mostrando que há uma perda significativa da remanência e coercividade. Entretanto os resultados mostraram que o comportamento em função do aumento da concentração de cobalto na liga não é influenciado pelo método de medida, isto é, se o material está consolidado ou em pó.

As FIG. 5.20 (a) e (b) mostram o comportamento da remanência e da coercividade intrínseca em função da variação da concentração de cobalto, respectivamente.

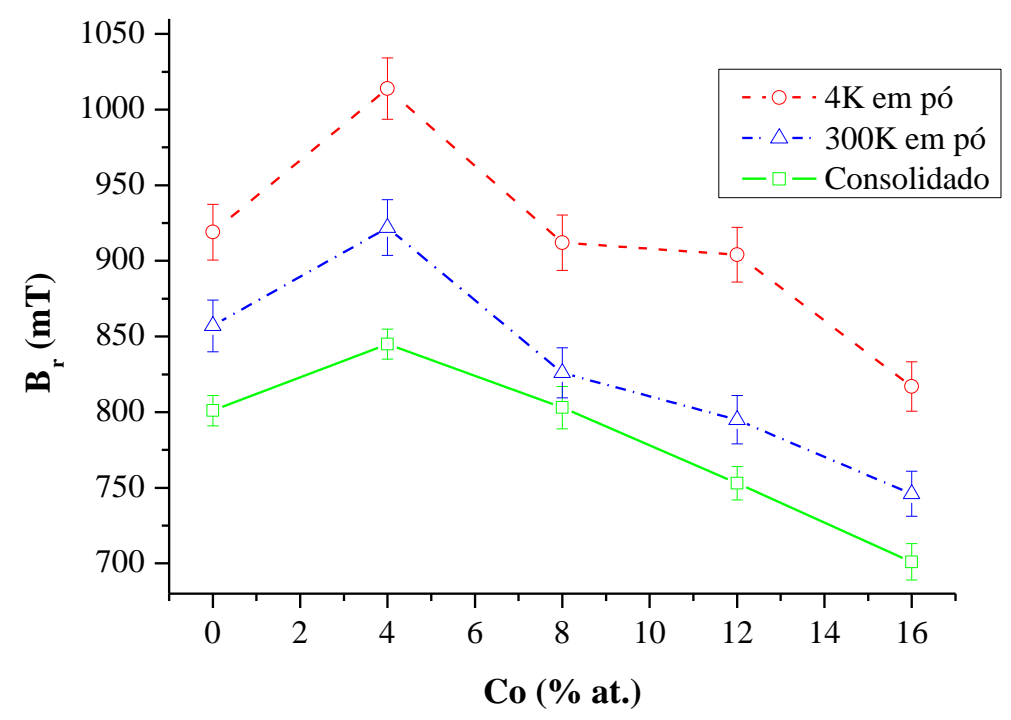

(a)

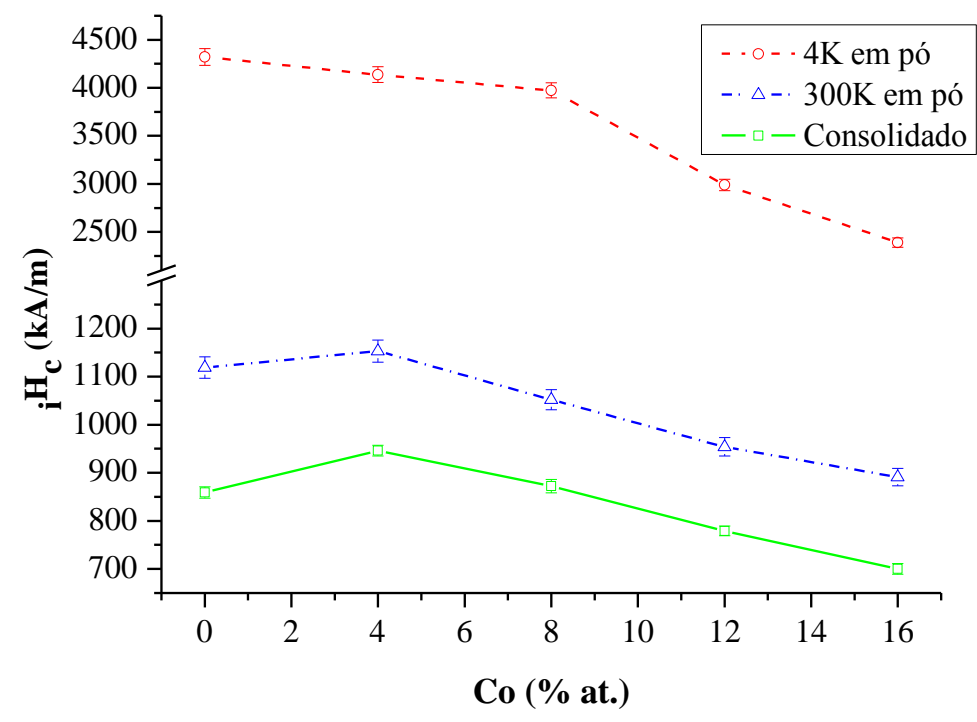

(b)

FIGURA 5.20 - Gráficos da remanência (a) e da coercividade intrínseca (b) para as ligas em função da variação de cobalto. 
Analisando a FIG. 5.20 (a) verifica-se que a remanência, tanto nas amostras consolidadas quanto em pó, se comporta semelhantemente ocorrendo um pico máximo na concentração de $4 \%$ at. diminuindo até a concentração de $16 \%$ at. $\mathrm{O}$ aumento dos valores de remanência no pó a $300 \mathrm{~K}$ em relação ao consolidado pode ser explicado devido à liberdade que os grãos do material tem de se alinharem ao campo aplicado. Os maiores valores obtidos no pó a 4,2 K são devido a diminuição da agitação térmica dos átomos.

Segundo Pedziwiatr et al. (1986a), a liga $\operatorname{Pr}_{14} \mathrm{Fe}_{\text {bal-x }} \mathrm{Co}_{\mathrm{x}} \mathrm{B}_{6}$ pode ser tratada como uma situação intermediária entre $\mathrm{o}$ sistema binário $\mathrm{Fe}_{1-\mathrm{x}} \mathrm{Co}_{\mathrm{x}}$, que mostra como característica um momento magnético máximo em $30 \%$ at. de cobalto, e o sistema ternário $\mathrm{Fe}_{1-\mathrm{x}} \mathrm{Co}_{\mathrm{x}} \mathrm{B}$, que mostra um decréscimo no momento magnético. Já, segundo Bolzoni et al. (1987a) o momento magnético do ferro aumenta na presença do cobalto até a concentração de $20 \%$ at. e depois decresce monotonicamente, estando em concordância com a curva de Slater-Pauling (Collins e Forsyth, 1963). Baseado nestas referências pode-se supor que o valor máximo da remanência observado a $4 \%$ at. de cobalto é explicado pelo aumento da magnetização do ferro devido à presença do cobalto e decrescendo com o aumento da adição do cobalto devido ao menor momento magnético do cobalto em relação ao ferro.

Analisando o gráfico apresentado na FIG. 5.20 (b), foi possível verificar a forte dependência da coercividade intrínseca com a temperatura (agitação térmica dos átomos), ocorrendo um aumento de aproximadamente 4 vezes o valor medido a 4,2 $\mathrm{K}$ em relação à $300 \mathrm{~K}$.

\subsection{2 - Determinação dos parâmetros cristalográficos}

O refinamento da estrutura cristalina da fase magneticamente dura objetivou determinar parâmetros cristalográficos como: parâmetros de rede, posições atômicas e porcentagem de substituição em cada sítio do ferro por átomos de cobalto.

Os gráficos obtidos dos refinamentos, conforme procedimento descrito no item 4.6, são apresentados nas FIG. 5.21; 5.22; 5.23; 5.24 e 5.25, onde o espectro (a) foi obtido na energia de $7 \mathrm{keV}$ e (b) foi obitido na energia de $8 \mathrm{keV}$. Os dados experimentais são apresentados na forma de símbolo (x) na cor azul, o padrão calculado é apresentado pela linha sólida de cor preta e a curva abaixo do eixo x representa a diferença entre a intensidade observada e calculada para cada ponto (resíduo). 

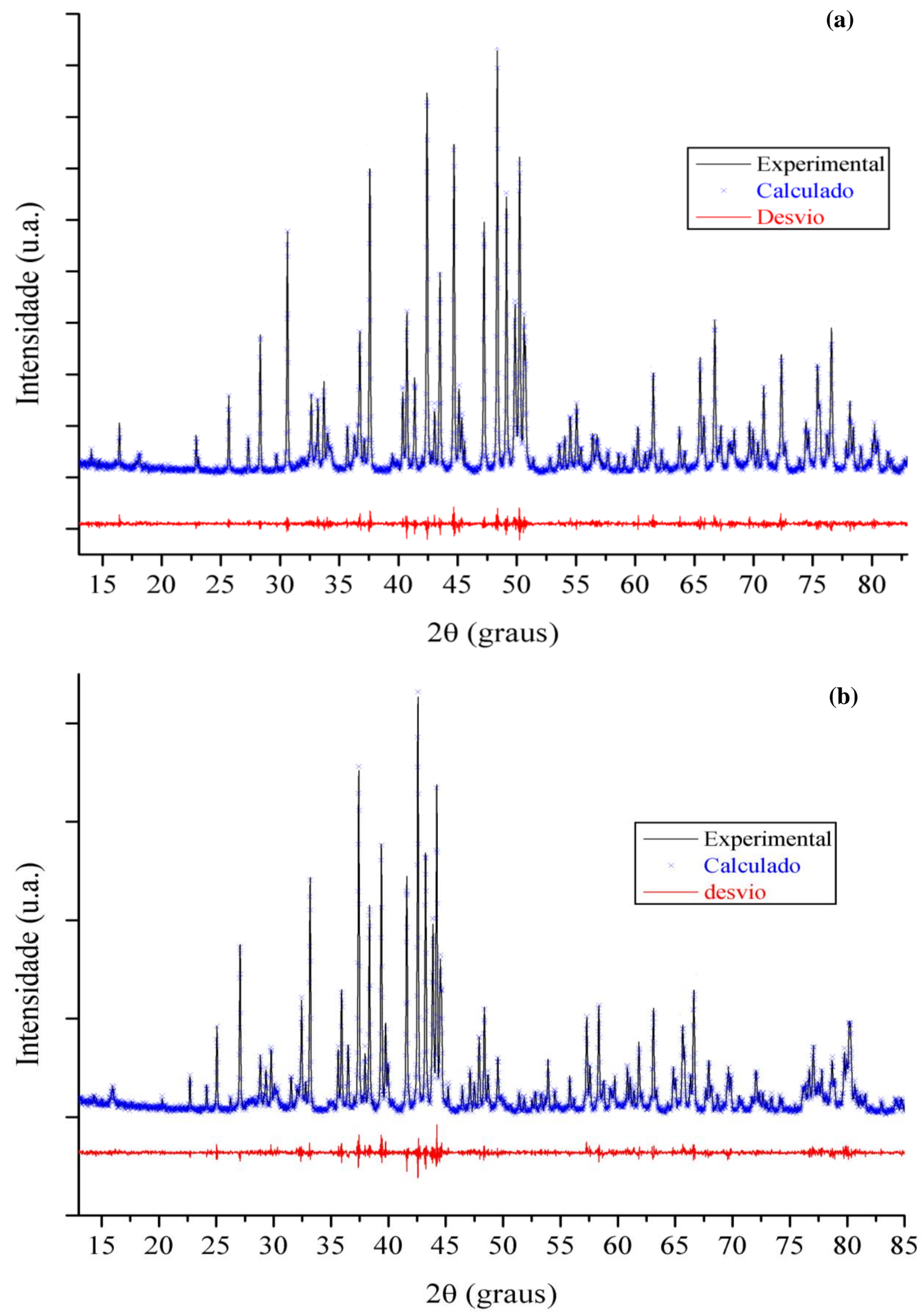

FIGURA 5.21 - Gráficos dos refinamentos da amostra $\operatorname{Pr}_{14} \mathrm{Fe}_{\text {bal }} \mathrm{B}_{6} \mathrm{Nb}_{0,1}$ - (a) $7 \mathrm{keV}$ e (b) 8 $\mathrm{keV}$. 

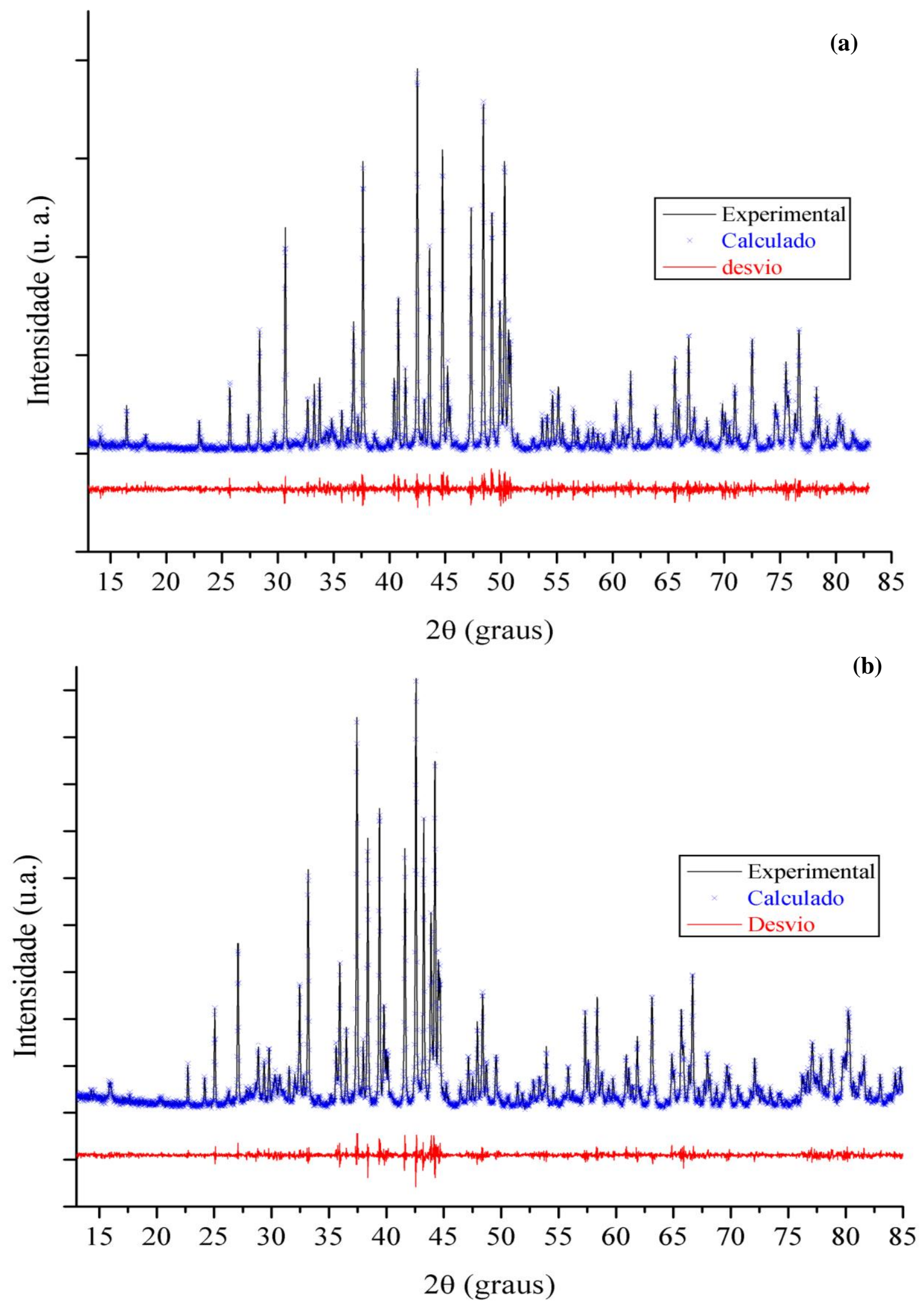

FIGURA 5.22 - Gráficos dos refinamentos da amostra $\operatorname{Pr}_{14} \mathrm{Fe}_{\mathrm{bal}} \mathrm{Co}_{4} \mathrm{~B}_{6} \mathrm{Nb}_{0,1}$ - (a) $7 \mathrm{keV}$ e (b) $8 \mathrm{keV}$. 

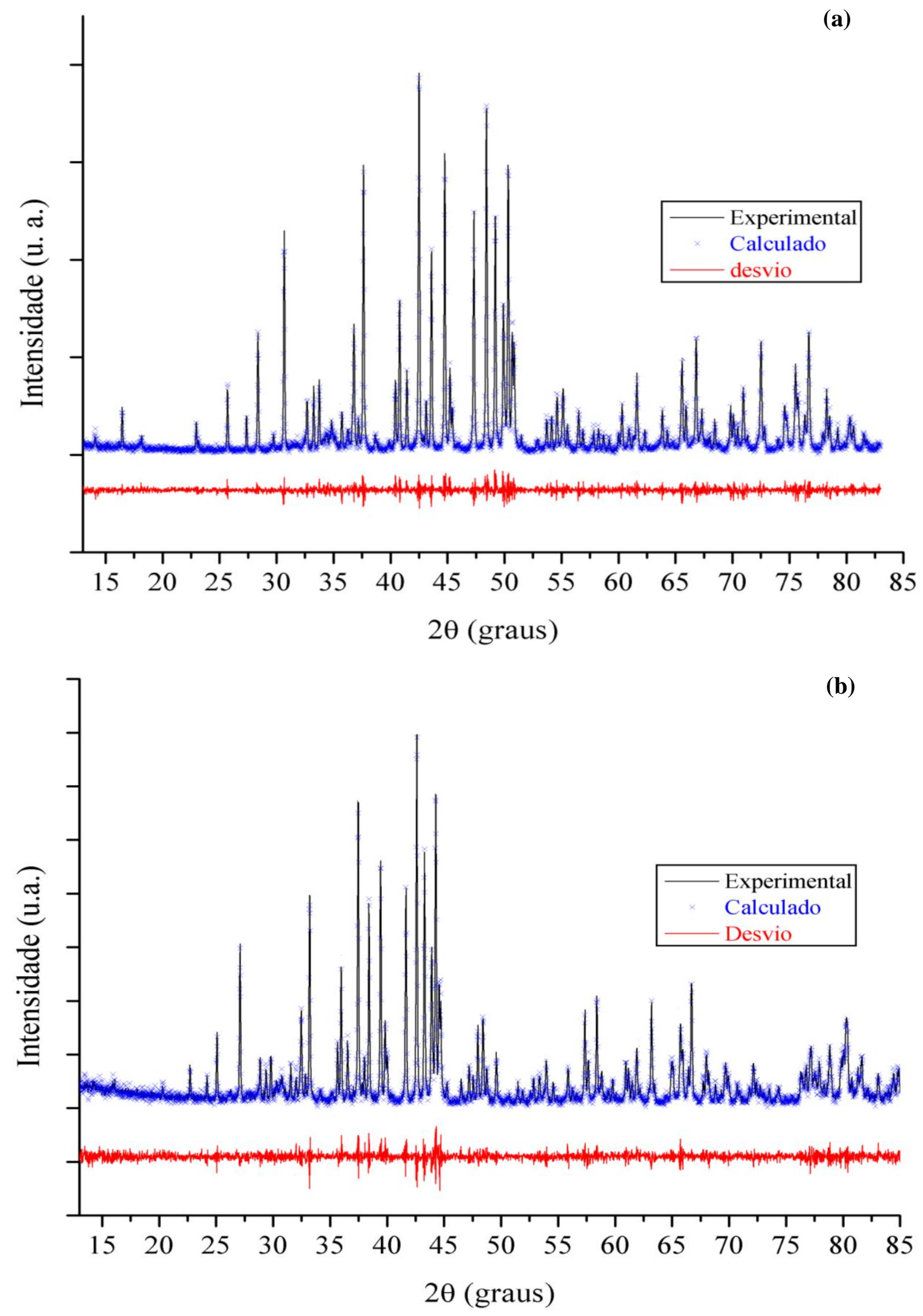

FIGURA 5.23 - Gráficos dos refinamentos da amostra $\operatorname{Pr}_{14} \mathrm{Fe}_{\text {bal }} \mathrm{Co}_{8} \mathrm{~B}_{6} \mathrm{Nb}_{0,1}$ - (a) $7 \mathrm{keV}$ e (b) $8 \mathrm{keV}$. 

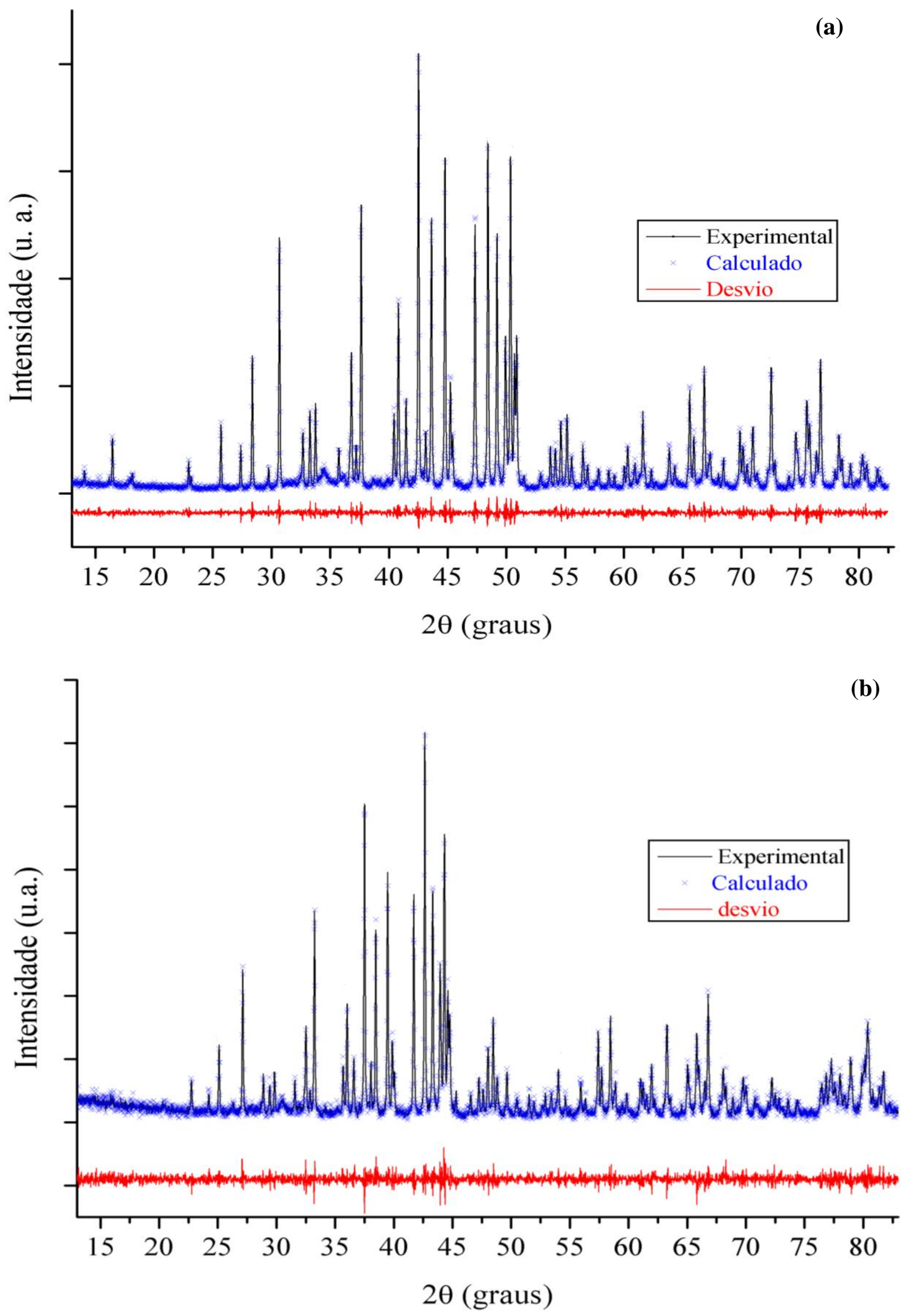

FIGURA 5.24 - Gráficos dos refinamentos da amostra $\operatorname{Pr}_{14} \mathrm{Fe}_{\mathrm{bal}} \mathrm{Co}_{12} \mathrm{~B}_{6} \mathrm{Nb}_{0,1}$ - (a) $7 \mathrm{keV}$ e (b) $8 \mathrm{keV}$. 

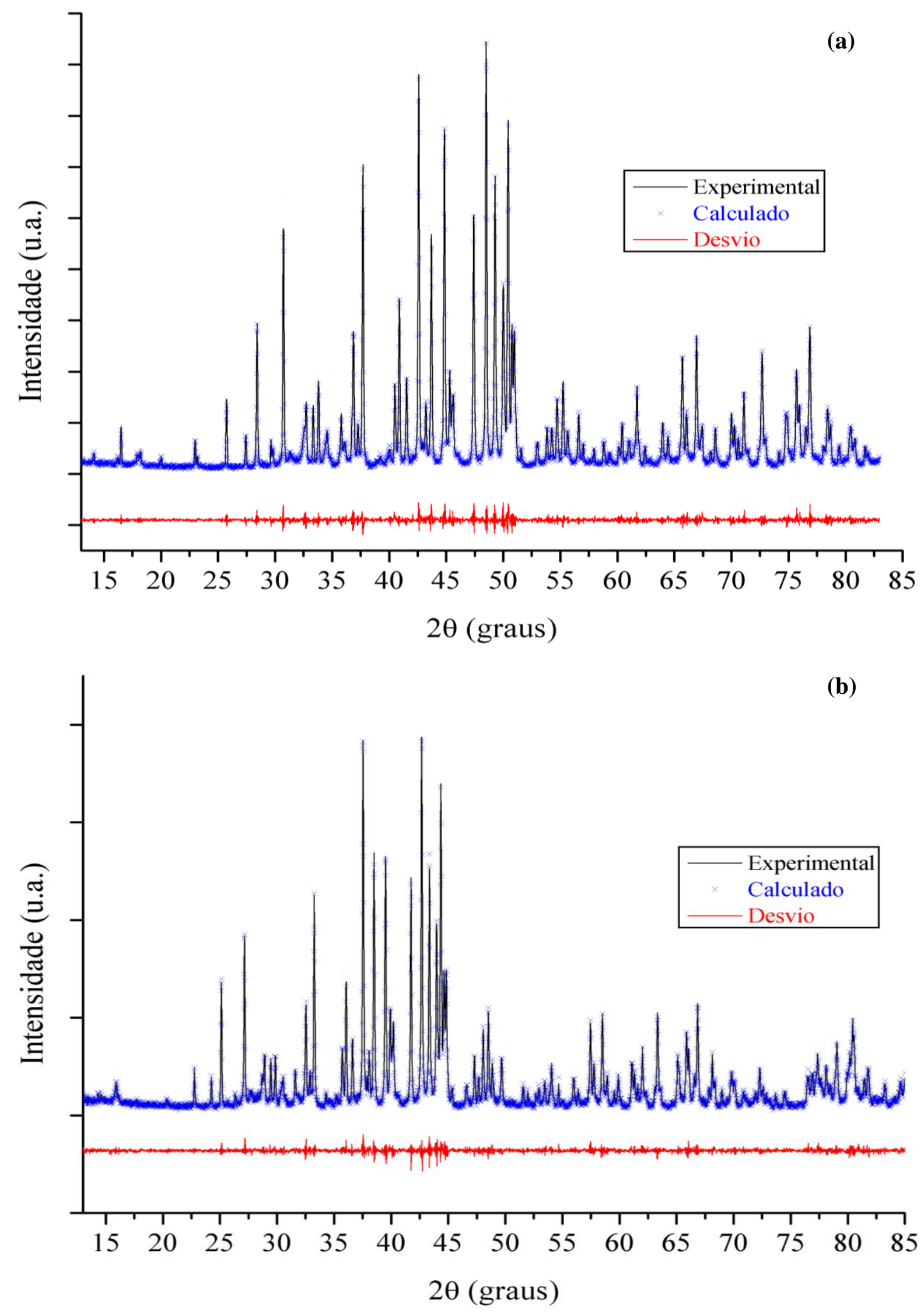

FIGURA 5.25 - Gráficos dos refinamentos da amostra $\operatorname{Pr}_{14} \mathrm{Fe}_{\text {bal }} \mathrm{Co}_{16} \mathrm{~B}_{6} \mathrm{Nb}_{0,1}$ - (a) $7 \mathrm{keV}$ e (b) $8 \mathrm{keV}$. 
O decréscimo dos parâmetros de rede em função do aumento da concentração de cobalto (vide TAB. 5.9) mostra que a incorporação do cobalto à fase magnética ocorre de maneira proporcional ao aumento de concentração de cobalto na liga. A variação do parâmetro $c$ mostrou sofrer uma redução duas vezes maior que do parâmetro $a$ com o aumento da concentração do cobalto, mais facilmente visto na FIG. 5.26. Este comportamento também foi observado por Pedwiatriz et al. (1986a) no estudo da incorporação de cobalto no composto $\operatorname{Pr}_{2} \mathrm{Fe}_{14-\mathrm{x}} \mathrm{Co}_{\mathrm{x}} \mathrm{B}$.

TABELA 5.9 - Parâmetros de rede obtidos para ligas com variação de cobalto.

\begin{tabular}{|c|c|c|c|}
\hline Composição & $a(\AA)$ & $b(\AA)$ & $c(\AA)$ \\
\hline $\operatorname{Pr}_{14} \mathrm{Fe}_{\mathrm{bal}} \mathrm{B}_{6} \mathrm{Nb}_{0,1}$ & $8.80410(6)$ & $8.80410(6)$ & $12.24679(15)$ \\
\hline $\mathrm{Pr}_{14} \mathrm{Fe}_{\mathrm{bal}} \mathrm{Co}_{4} \mathrm{~B}_{6} \mathrm{Nb}_{0,1}$ & $8.80152(6)$ & $8.80152(6)$ & $12.23759(14)$ \\
\hline $\mathrm{Pr}_{14} \mathrm{Fe}_{\mathrm{bal}} \mathrm{Co}_{8} \mathrm{~B}_{6} \mathrm{Nb}_{0,1}$ & $8.79607(5)$ & $8.79607(5)$ & $12.22539(12)$ \\
\hline $\mathrm{Pr}_{14} \mathrm{Fe}_{\mathrm{bal}} \mathrm{Co}_{12} \mathrm{~B}_{6} \mathrm{Nb}_{0,1}$ & $8.78866(5)$ & $8.78866(5)$ & $12.21119(11)$ \\
\hline $\mathrm{Pr}_{14} \mathrm{Fe}_{\mathrm{bal}} \mathrm{Co}_{16} \mathrm{~B}_{6} \mathrm{Nb}_{0,1}$ & $8.78309(6)$ & $8.78309(6)$ & $12.19957(14)$ \\
\hline
\end{tabular}

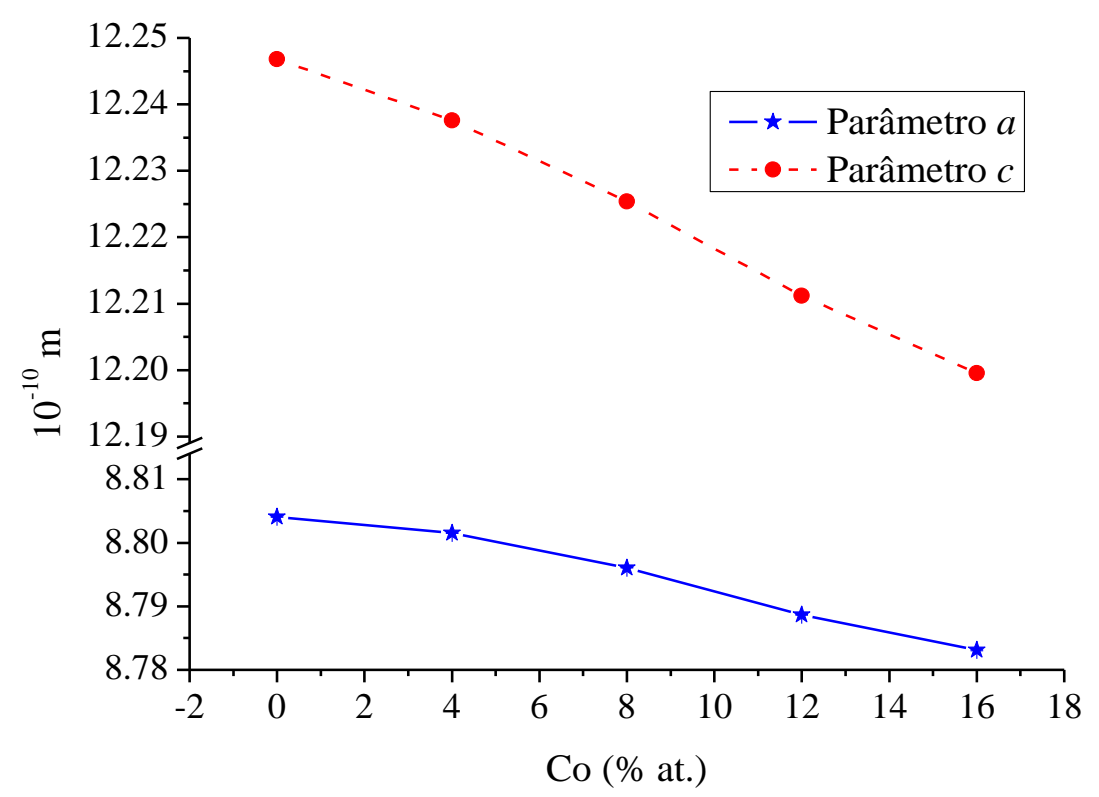

FIGURA 5.26 - Variação dos parâmetros de rede das ligas com variação de cobalto.

A diminuição do parâmetro de rede resulta na mudança das posições dos sítios e conseqüentemente das distâncias interatômicas que são cruciais para as interações de troca diretamente ligada à temperatura de Curie. As TAB. 5.10; 5.11; 5.12; 5.13 e 5.14 
apresentam os valores das posições dos sítios para cada átomo não equivalentes obtidos pelo refinamento da estrutura pelo método de Rietveld.

TABELA 5.10 - Posição dos átomos não equivalentes para a fase magnética $\mathrm{Pr}_{8} \mathrm{Fe}_{56}$ ${ }_{\mathrm{x}} \mathrm{Co}_{\mathrm{x}} \mathrm{B}_{4}$ na liga $\mathrm{Pr}_{14} \mathrm{Fe}_{\mathrm{bal}} \mathrm{B}_{6} \mathrm{Nb}_{0,1}$.

\begin{tabular}{l|lll}
\hline Átomo & \multicolumn{1}{|c}{$\boldsymbol{x}$} & \multicolumn{1}{c}{$\boldsymbol{y}$} & \multicolumn{1}{c}{$\boldsymbol{z}$} \\
\hline $\operatorname{Pr}(f)$ & $0.26989(20)$ & $0.26989(20)$ & 0.0 \\
$\operatorname{Pr}(g)$ & $0.14154(22)$ & $-0.14154(22)$ & 0.0 \\
$\mathrm{Fe}\left(k_{1}\right)$ & $0.2234(4)$ & $0.5667(4)$ & $0.12832(27)$ \\
$\mathrm{Fe}\left(k_{2}\right)$ & $0.0379(4)$ & $0.3609(4)$ & $0.17703(26)$ \\
$\mathrm{Fe}\left(j_{1}\right)$ & $0.0969(4)$ & $0.0969(4)$ & $0.2046(4)$ \\
$\mathrm{Fe}\left(j_{2}\right)$ & $0.3171(4)$ & $0.3171(4)$ & $0.2462(4)$ \\
$\mathrm{Fe}(c)$ & $0.5(0)$ & $0.5(0)$ & $0.1154(6)$ \\
$\mathrm{Fe}(e)$ & $0.0(0)$ & $0.5(0)$ & $0.0(0)$ \\
$\mathrm{B}(g)$ & $0.372(4)$ & $-0.372(4)$ & $0.0(0)$ \\
\hline
\end{tabular}

TABELA 5.11 - Posição dos átomos não equivalentes para a fase magnética $\operatorname{Pr}_{8} \mathrm{Fe}_{56}$ ${ }_{x} \mathrm{Co}_{\mathrm{x}} \mathrm{B}_{4}$ na liga $\operatorname{Pr}_{14} \mathrm{Fe}_{\text {bal }} \mathrm{Co}_{4} \mathrm{~B}_{6} \mathrm{Nb}_{0,1}$.

\begin{tabular}{l|lll}
\hline Átomo & \multicolumn{1}{|c}{$\boldsymbol{x}$} & \multicolumn{1}{c}{$\boldsymbol{y}$} & \multicolumn{1}{c}{$\boldsymbol{z}$} \\
\hline $\operatorname{Pr}(f)$ & $0.26928(17)$ & $0.26928(17)$ & 0.0 \\
$\operatorname{Pr}(g)$ & $0.14117(18)$ & $-0.14117(18)$ & 0.0 \\
$\operatorname{Fe}\left(k_{1}\right)$ & $0.2246(4)$ & $0.5679(4)$ & $0.12751(28)$ \\
$\mathrm{Fe}\left(k_{2}\right)$ & $0.03707(35)$ & $0.3601(4)$ & $0.17622(25)$ \\
$\operatorname{Fe}\left(j_{1}\right)$ & $0.09742(34)$ & $0.09742(34)$ & $0.20433(34)$ \\
$\operatorname{Fe}\left(j_{2}\right)$ & $0.31729(35)$ & $0.31729(35)$ & $0.2467(4)$ \\
$\operatorname{Fe}(c)$ & $0.5(0)$ & $0.5(0)$ & $0.1133(6)$ \\
$\operatorname{Fe}(\mathrm{e})$ & $0.0(0)$ & $0.5(0)$ & $0.0(0)$ \\
$\mathrm{B}(g)$ & $0.370(5)$ & $-0.370(5)$ & $0.0(0)$ \\
\hline
\end{tabular}

TABELA 5.12 - Posição dos átomos não equivalentes para a fase magnética $\operatorname{Pr}_{8} \mathrm{Fe}_{56}$ ${ }_{x} \mathrm{Co}_{\mathrm{x}} \mathrm{B}_{4}$ na liga $\mathrm{Pr}_{14} \mathrm{Fe}_{\mathrm{bal}} \mathrm{Co}_{8} \mathrm{~B}_{6} \mathrm{Nb}_{0,1}$.

\begin{tabular}{l|lll}
\hline Átomo & \multicolumn{1}{|c}{$\boldsymbol{x}$} & \multicolumn{1}{c}{$\boldsymbol{y}$} & \multicolumn{1}{c}{$\boldsymbol{z}$} \\
\hline $\operatorname{Pr}(f)$ & $0.27058(16)$ & $0.27058(16)$ & $0.0(0)$ \\
$\operatorname{Pr}(g)$ & $0.14137(17)$ & $-0.14137(17)$ & $0.0(0)$ \\
$\mathrm{Fe}\left(k_{l}\right)$ & $0.22432(34$ & $0.56792(33)$ & $0.12710(25)$ \\
$\mathrm{Fe}\left(k_{2}\right)$ & $0.03729(32)$ & $0.35908(32)$ & $0.17614(23)$ \\
$\mathrm{Fe}\left(j_{1}\right)$ & $0.09812(32)$ & $0.09812(32)$ & $0.20393(31)$ \\
$\mathrm{Fe}\left(j_{2}\right)$ & $0.31759(33)$ & $0.31759(33)$ & $0.24643(35)$ \\
$\mathrm{Fe}(c)$ & $0.5(0)$ & $0.5(0)$ & $0.1150(5)$ \\
$\mathrm{Fe}(\mathrm{e})$ & $0.0(0)$ & $0.5(0)$ & $0.0(0)$ \\
$\mathrm{B}(g)$ & $0.3770(32)$ & $-0.3770(32)$ & $0.0(0)$ \\
\hline
\end{tabular}


TABELA 5.13 - Posição dos átomos não equivalentes para a fase magnética $\mathrm{Pr}_{8} \mathrm{Fe}_{56}$ ${ }_{\mathrm{x}} \mathrm{Co}_{\mathrm{x}} \mathrm{B}_{4}$ na liga $\mathrm{Pr}_{14} \mathrm{Fe}_{\mathrm{bal}} \mathrm{Co}_{12} \mathrm{~B}_{6} \mathrm{Nb}_{0,1}$.

\begin{tabular}{l|lll}
\hline Átomo & \multicolumn{1}{c}{$\boldsymbol{x}$} & \multicolumn{1}{c}{$\boldsymbol{y}$} & \multicolumn{1}{c}{$\boldsymbol{z}$} \\
\hline $\operatorname{Pr}(f)$ & $0.27006(16)$ & $0.27006(16)$ & 0.0 \\
$\operatorname{Pr}(g)$ & $0.14131(18)$ & $-0.14131(18)$ & 0.0 \\
$\mathrm{Fe}\left(k_{1}\right)$ & $0.2241(4)$ & $0.56799(35)$ & $0.12779(27)$ \\
$\mathrm{Fe}\left(k_{2}\right)$ & $0.0377(4)$ & $0.3593(4)$ & $0.17622(26)$ \\
$\mathrm{Fe}\left(j_{1}\right)$ & $0.09681(33)$ & $0.09681(33)$ & $0.20387(34)$ \\
$\mathrm{Fe}\left(j_{2}\right)$ & $0.31786(34)$ & $0.31786(34)$ & $0.2463(4)$ \\
$\mathrm{Fe}(c)$ & $0.5(0)$ & $0.5(0)$ & $0.1127(5)$ \\
$\mathrm{Fe}(\mathrm{e})$ & $0.0(0)$ & $0.5(0)$ & $0.0(0)$ \\
$\mathrm{B}(c)$ & $0.3603(31)$ & $-0.3603(31)$ & $0.0(0)$ \\
\hline
\end{tabular}

TABELA 5.14 - Posição dos átomos não equivalentes para a fase magnética $\operatorname{Pr}_{8} \mathrm{Fe}_{56}$ ${ }_{x} \mathrm{Co}_{\mathrm{x}} \mathrm{B}_{4}$ na liga $\mathrm{Pr}_{14} \mathrm{Fe}_{\text {bal }_{1}} \mathrm{Co}_{16} \mathrm{~B}_{6} \mathrm{Nb}_{0,1}$.

\begin{tabular}{l|lll}
\hline Átomo & \multicolumn{1}{|c}{$\boldsymbol{x}$} & \multicolumn{1}{c}{$\boldsymbol{y}$} & \multicolumn{1}{c}{$\boldsymbol{z}$} \\
\hline $\operatorname{Pr}(f)$ & $0.26969(17)$ & $0.26969(17)$ & $0.0(0)$ \\
$\operatorname{Pr}(g)$ & $0.14177(18)$ & $-0.14177(18)$ & $0.0(0)$ \\
$\mathrm{Fe}\left(k_{l}\right)$ & $0.2229(4)$ & $0.5673(4)$ & $0.12681(27)$ \\
$\mathrm{Fe}\left(k_{2}\right)$ & $0.03758(34)$ & $0.36099(34)$ & $0.17627(25)$ \\
$\mathrm{Fe}\left(j_{1}\right)$ & $0.09728(33)$ & $0.09728(33)$ & $0.20495(33)$ \\
$\mathrm{Fe}\left(j_{2}\right)$ & $0.31784(35)$ & $0.31784(35)$ & $0.2465(4)$ \\
$\mathrm{Fe}(c)$ & $0.5(0)$ & $0.5(0)$ & $0.1141(6)$ \\
$\mathrm{Fe}(\mathrm{e})$ & $0.0(0)$ & $0.5(0)$ & $0.0(0)$ \\
$\mathrm{B}(c)$ & $0.364(5)$ & $-0.364(5)$ & $0.0(0)$ \\
\hline
\end{tabular}

Como resultado do processamento obteve-se as distâncias relativas de cada átomo não equivalente em relação aos seus primeiros vizinhos. Os valores são apresentados para cada liga processada nas TAB. 5.15; 5.16; 5.17; 5.18 e 5.19. Nestas tabelas são indicados: o átomo base, o átomo eqüidistante, o número destes átomos eqüidistante pertencente a um mesmo sítio e a distância interatômica em angstroms. Como exemplo, na TAB. 5.15 o praseodímio do sítio $f, \operatorname{Pr}(f)$, tem como vizinho dois átomos de praseodímio do sítio $g$, $\operatorname{Pr}(g)$, e as suas distância são de 3,7944(25) ̊.

O cobalto apresenta uma tendência a ocupar preferencialmente (mantendo certa aleatoriedade) os sítios cristalográficos de metais com camada $3 d$ (van-Noort e Buschow, 1985). As mudanças das distâncias interatômicas no sistema $\operatorname{Pr}_{2} \mathrm{Fe}_{14-\mathrm{x}} \mathrm{Co}_{\mathrm{x}} \mathrm{B}$, resultam em alterações nas interações de trocas magnéticas envolvendo diferentes sítios $3 d$, sendo 
importante considerar que as interações de troca $3 d-3 d$ são fortes e determinam, principalmente, o valor de $\mathrm{T}_{\mathrm{C}}$.

TABELA 5.15 - Distâncias interatômicas entre o átomo base e seu(s) vizinho(s) para a fase magnética $\operatorname{Pr}_{8} \mathrm{Fe}_{56} \mathrm{~B}_{4}$ para a liga $\operatorname{Pr}_{14} \mathrm{Fe}_{\mathrm{bal}} \mathrm{B}_{6} \mathrm{Nb}_{0,1}$.

\begin{tabular}{|c|c|c|c|c|c|c|c|}
\hline $\begin{array}{c}\text { Átomo } \\
\text { base }\end{array}$ & $\begin{array}{c}\text { Número de } \\
\text { átomos }\end{array}$ & Átomo & $\begin{array}{c}\text { Distância } \\
(\AA)\end{array}$ & $\begin{array}{c}\text { Átomo } \\
\text { base }\end{array}$ & $\begin{array}{c}\text { Número de } \\
\text { átomos }\end{array}$ & Átomo & $\begin{array}{c}\text { Distância } \\
(\AA)\end{array}$ \\
\hline $\operatorname{Pr}(f)$ & $\begin{array}{l}2 \\
4 \\
4 \\
2 \\
2 \\
2 \\
2\end{array}$ & $\begin{array}{l}\operatorname{Pr}(g) \\
\operatorname{Fe}\left(k_{1}\right) \\
\operatorname{Fe}\left(k_{2}\right) \\
\operatorname{Fe}\left(j_{1}\right) \\
\operatorname{Fe}\left(j_{2}\right) \\
\operatorname{Fe}(e) \\
\operatorname{Fe}(c)\end{array}$ & $\begin{array}{l}3.7944(25) \\
3.076(4) \\
3.0841(33) \\
3.304(5) \\
3.071(5) \\
3.195(4) \\
3.12256(20)\end{array}$ & $\operatorname{Fe}\left(j_{1}\right)$ & $\begin{array}{l}1 \\
2 \\
2 \\
2 \\
1 \\
1 \\
2 \\
1\end{array}$ & $\begin{array}{l}\operatorname{Pr}(\mathbf{f}) \\
\operatorname{Pr}(g) \\
\mathrm{Fe}\left(k_{1}\right) \\
\mathrm{Fe}\left(k_{2}\right) \\
\mathrm{Fe}\left(j_{1}\right) \\
\mathrm{Fe}\left(j_{2}\right) \\
\mathrm{Fe}\left(j_{2}\right) \\
\mathrm{Fe}(e)\end{array}$ & $\begin{array}{l}3.304(5) \\
3.292(4) \\
2.600(5) \\
2.405(4) \\
2.413(9) \\
2.789(6) \\
2.647(4) \\
2.513(9)\end{array}$ \\
\hline $\operatorname{Pr}(g)$ & $\begin{array}{l}2 \\
1 \\
4 \\
4 \\
4 \\
2 \\
2 \\
1\end{array}$ & $\begin{array}{l}\operatorname{Pr}(f) \\
\operatorname{Pr}(g) \\
\operatorname{Fe}\left(k_{1}\right) \\
\operatorname{Fe}\left(k_{2}\right) \\
\operatorname{Fe}\left(j_{1}\right) \\
\operatorname{Fe}\left(j_{2}\right) \\
\operatorname{Fe}(c) \\
\mathrm{B}(g)\end{array}$ & $\begin{array}{l}3.7944(25) \\
3.525(5) \\
3.097(4) \\
3.3054(32) \\
3.292(4) \\
3.151(5) \\
3.3930(11) \\
2.87(5)\end{array}$ & $\mathrm{Fe}\left(j_{2}\right)$ & $\begin{array}{l}1 \\
1 \\
2 \\
2 \\
4 \\
1 \\
2 \\
1\end{array}$ & $\begin{array}{l}\operatorname{Pr}(f) \\
\operatorname{Pr}(g) \\
\mathrm{Fe}\left(k_{1}\right) \\
\mathrm{Fe}\left(k_{1}\right) \\
\mathrm{Fe}\left(k_{2}\right) \\
\mathrm{Fe}\left(j_{1}\right) \\
\mathrm{Fe}\left(j_{l}\right) \\
\mathrm{Fe}(e)\end{array}$ & $\begin{array}{l}3.071(5) \\
3.151(5) \\
2.755(4) \\
2.711(5) \\
2.628(4) \\
2.789(5) \\
2.647(5) \\
2.784(6)\end{array}$ \\
\hline $\operatorname{Fe}\left(k_{1}\right)$ & $\begin{array}{l}1 \\
1 \\
1 \\
1 \\
1 \\
1\end{array}$ & $\begin{array}{l}\operatorname{Pr}(f) \\
\operatorname{Pr}(g) \\
\operatorname{Fe}\left(k_{1}\right) \\
\operatorname{Fe}\left(k_{2}\right) \\
\operatorname{Fe}\left(k_{2}\right) \\
\operatorname{Fe}\left(k_{2}\right)\end{array}$ & $\begin{array}{l}3.076(4) \\
3.097(4) \\
2.614(7) \\
2.511(5) \\
2.461(5) \\
2.509(5)\end{array}$ & $\operatorname{Fe}(e)$ & $\begin{array}{l}2 \\
4 \\
2 \\
2 \\
1 \\
2\end{array}$ & $\begin{array}{l}\operatorname{Pr}(f) \\
\operatorname{Fe}\left(k_{l}\right) \\
\operatorname{Fe}\left(j_{1}\right) \\
\operatorname{Fe}\left(j_{2}\right) \\
\operatorname{Fe}(e) \\
\operatorname{B}(g)\end{array}$ & $\begin{array}{l}.195(4) \\
2.5101(33) \\
2.513(8) \\
2.784(6) \\
2.827(14) \\
2.13(4)\end{array}$ \\
\hline & $\begin{array}{l}1 \\
1 \\
1 \\
1\end{array}$ & $\begin{array}{l}\mathrm{Fe}\left(j_{1}\right) \\
\operatorname{Fe}\left(j_{2}\right) \\
\operatorname{Fe}\left(j_{2}\right) \\
\operatorname{Fe}(e)\end{array}$ & $\begin{array}{l}2.600(5) \\
2.755(4) \\
2.711(5) \\
2.5101(33)\end{array}$ & $\mathrm{Fe}(c)$ & $\begin{array}{l}2 \\
2 \\
4 \\
4\end{array}$ & $\begin{array}{l}\operatorname{Pr}(f) \\
\operatorname{Pr}(g) \\
\operatorname{Fe}\left(k_{1}\right) \\
\operatorname{Fe}\left(k_{2}\right)\end{array}$ & $\begin{array}{l}3.12256(20) \\
3.3930(11) \\
2.5850(33) \\
2.5125(32)\end{array}$ \\
\hline & $\begin{array}{l}1 \\
1\end{array}$ & $\begin{array}{l}\mathrm{Fe}(c) \\
\mathrm{B}(g)\end{array}$ & $\begin{array}{l}2.5850(33) \\
2.116(14) \\
\end{array}$ & $\mathbf{B}(g)$ & $\begin{array}{l}1 \\
4\end{array}$ & $\begin{array}{l}\operatorname{Pr}(g) \\
\operatorname{Fe}\left(k_{l}\right)\end{array}$ & $\begin{array}{l}2.87(5) \\
2.116(14)\end{array}$ \\
\hline $\operatorname{Fe}\left(k_{2}\right)$ & $\begin{array}{l}1 \\
1 \\
1 \\
1 \\
1 \\
1 \\
2 \\
1 \\
1 \\
1 \\
1\end{array}$ & $\begin{array}{l}\operatorname{Pr}(f) \\
\operatorname{Pr}(g) \\
\operatorname{Fe}\left(k_{1}\right) \\
\operatorname{Fe}\left(k_{1}\right) \\
\operatorname{Fe}\left(k_{1}\right) \\
\operatorname{Fe}\left(k_{2}\right) \\
\operatorname{Fe}\left(k_{2}\right) \\
\operatorname{Fe}\left(j_{1}\right) \\
\operatorname{Fe}\left(j_{2}\right) \\
\operatorname{Fe}\left(j_{2}\right) \\
\operatorname{Fe}(c)\end{array}$ & $\begin{array}{l}3.0841(33) \\
3.3054(32) \\
2.511(5) \\
2.461(5) \\
2.509(5) \\
2.540(6) \\
2.534(5) \\
2.405(4) \\
2.628(4) \\
2.668(4) \\
2.5125(32)\end{array}$ & & $\begin{array}{l}2 \\
2\end{array}$ & $\begin{array}{l}\mathrm{Fe}(e) \\
\mathrm{Fe}(e)\end{array}$ & $\begin{array}{l}2.13(4) \\
2.13(4)\end{array}$ \\
\hline
\end{tabular}

Obs.: Estão incluídos os vizinhos com distância interatomica menor de $4 \AA$ 
TABELA 5.16 - Distâncias interatômicas entre o átomo base e seu(s) vizinho(s) para a fase magnética $\mathrm{Pr}_{8} \mathrm{Fe}_{56-\mathrm{x}} \mathrm{Co}_{\mathrm{x}} \mathrm{B}_{4}$ para a liga $\mathrm{Pr}_{14} \mathrm{Fe}_{\mathrm{bal}} \mathrm{Co}_{4} \mathrm{~B}_{6} \mathrm{Nb}_{0,1}$.

\begin{tabular}{|c|c|c|c|c|c|c|c|}
\hline $\begin{array}{c}\text { Átomo } \\
\text { base }\end{array}$ & $\begin{array}{c}\text { Número } \\
\text { de } \\
\text { átomos }\end{array}$ & Átomo & $\begin{array}{c}\text { Distância } \\
(\stackrel{\circ}{A})\end{array}$ & $\begin{array}{c}\text { Átomo } \\
\text { base }\end{array}$ & $\begin{array}{c}\text { Número } \\
\text { de } \\
\text { átomos }\end{array}$ & Átomo & $\begin{array}{c}\text { Distância } \\
(\AA)\end{array}$ \\
\hline \multirow[t]{8}{*}{$\operatorname{Pr}(f)$} & 2 & $\operatorname{Pr}(g)$ & $3.7845(21)$ & \multirow[t]{8}{*}{$\operatorname{Fe}\left(j_{1}\right) / \mathrm{Co}\left(j_{1}\right)$} & 1 & $\operatorname{Pr}(f)$ & $3.291(4)$ \\
\hline & 4 & $\operatorname{Fe}\left(k_{l}\right)$ & $3.0822(34)$ & & 2 & $\operatorname{Pr}(g)$ & $3.288(4)$ \\
\hline & 4 & $\mathrm{Fe}\left(k_{2}\right)$ & $3.0768(31)$ & & 2 & $\operatorname{Fe}\left(k_{1}\right)$ & $2.599(5)$ \\
\hline & 2 & $\mathrm{Fe}\left(j_{1}\right)$ & $3.291(4)$ & & 2 & $\operatorname{Fe}\left(k_{2}\right)$ & $2.397(4)$ \\
\hline & 2 & $\mathrm{Fe}\left(j_{2}\right)$ & $3.078(5)$ & & 1 & $\mathrm{Fe}\left(j_{1}\right)$ & $2.425(8)$ \\
\hline & 2 & $\mathrm{Fe}(c)$ & $3.189(4)$ & & 1 & $\mathrm{Fe}\left(j_{2}\right)$ & $2.786(6)$ \\
\hline & \multirow[t]{2}{*}{2} & \multirow[t]{2}{*}{$\operatorname{Fe}(e)$} & \multirow[t]{2}{*}{$3.12105(16)$} & & 2 & $\mathrm{Fe}\left(j_{2}\right)$ & $2.646(4)$ \\
\hline & & & & & 1 & $\operatorname{Fe}(e)$ & $2.540(7)$ \\
\hline \multirow[t]{8}{*}{$\operatorname{Pr}(g)$} & 2 & $\operatorname{Pr}(f)$ & $3.7845(21)$ & \multirow[t]{8}{*}{$\mathrm{Fe}\left(\boldsymbol{j}_{2}\right) / \mathrm{Co}\left(\boldsymbol{j}_{2}\right)$} & 1 & $\operatorname{Pr}(f)$ & $3.078(5)$ \\
\hline & 1 & $\operatorname{Pr}(g)$ & $3.514(5)$ & & 1 & $\operatorname{Pr}(g)$ & $3.142(5)$ \\
\hline & 4 & $\operatorname{Fe}\left(k_{1}\right)$ & $3.087(4)$ & & 2 & $\operatorname{Fe}\left(k_{1}\right)$ & $2.768(4)$ \\
\hline & 4 & $\operatorname{Fe}\left(k_{2}\right)$ & $3.2901(31)$ & & 2 & $\operatorname{Fe}\left(k_{1}\right)$ & $2.706(5)$ \\
\hline & 4 & $\mathrm{Fe}\left(j_{1}\right)$ & $3.288(4)$ & & 2 & $\mathrm{Fe}(\mathrm{k} 2)$ & $2.640(4)$ \\
\hline & 2 & $\operatorname{Fe}\left(j_{2}\right)$ & $3.142(5)$ & & 2 & $\mathrm{Fe}(\mathrm{k} 2)$ & $2.659(4)$ \\
\hline & 2 & $\mathrm{Fe}(c)$ & $3.3939(9)$ & & 1 & $\operatorname{Fe}\left(j_{1}\right)$ & $2.786(6)$ \\
\hline & 1 & B & $2.85(6)$ & & 2 & $\operatorname{Fe}\left(j_{1}\right)$ & $2.646(4)$ \\
\hline \multirow[t]{10}{*}{$\operatorname{Fe}\left(k_{l}\right) / \operatorname{Co}\left(k_{l}\right)$} & 1 & $\operatorname{Pr}(f)$ & $3.0822(34)$ & \multirow[t]{6}{*}{$\mathrm{Fe}(e) / \mathrm{Co}(e)$} & 2 & $\operatorname{Pr}(f)$ & $3.189(4)$ \\
\hline & 1 & $\operatorname{Pr}(g)$ & $3.087(4)$ & & 4 & $\operatorname{Fe}\left(k_{1}\right)$ & $2.5026(33)$ \\
\hline & 1 & $\mathrm{Fe}\left(k_{1}\right)$ & $2.582(6)$ & & 2 & $\operatorname{Fe}\left(j_{1}\right)$ & $2.540(7)$ \\
\hline & 1 & $\mathrm{Fe}\left(k_{2}\right)$ & $2.535(4)$ & & 2 & $\operatorname{Fe}\left(j_{2}\right)$ & $2.800(6)$ \\
\hline & 1 & $\mathrm{Fe}\left(k_{2}\right)$ & $2.462(4)$ & & 1 & $\operatorname{Fe}(e)$ & $2.773(14)$ \\
\hline & 1 & $\mathrm{Fe}\left(k_{2}\right)$ & $2.529(5)$ & & 2 & $\mathbf{B}$ & $2.13(5)$ \\
\hline & 1 & $\operatorname{Fe}\left(j_{2}\right)$ & $2.768(4)$ & \multirow[t]{4}{*}{$\mathrm{Fe}(c) / \mathrm{Co}(c)$} & 2 & $\operatorname{Pr}(f)$ & $3.12105(16)$ \\
\hline & 1 & $\operatorname{Fe}\left(j_{2}\right)$ & $2.706(5)$ & & 2 & $\operatorname{Pr}(g)$ & $3.3939(9)$ \\
\hline & 1 & $\operatorname{Fe}(c)$ & $2.5026(33)$ & & 4 & $\operatorname{Fe}\left(k_{1}\right)$ & $2.5886(32)$ \\
\hline & 1 & $\operatorname{Fe}(e)$ & $2.5886(32)$ & & 4 & $\mathrm{Fe}\left(k_{2}\right)$ & $2.5046(31)$ \\
\hline \multirow[t]{11}{*}{$\mathrm{Fe}\left(k_{2}\right) / \mathrm{Co}\left(k_{2}\right)$} & 1 & $\operatorname{Pr}(f)$ & $3.0768(31)$ & \multirow[t]{11}{*}{$\mathrm{B}(\mathrm{g})$} & 1 & $\operatorname{Pr}(g)$ & $2.85(6)$ \\
\hline & 1 & $\operatorname{Pr}(g)$ & $3.2901(31)$ & & 4 & $\mathbf{F e}\left(k_{1}\right)$ & $2.092(16)$ \\
\hline & 1 & $\operatorname{Fe}\left(k_{l}\right)$ & $2.535(4)$ & & 2 & $\operatorname{Fe}(e)$ & $2.13(5)$ \\
\hline & 1 & $\operatorname{Fe}\left(k_{l}\right)$ & $2.462(4)$ & & & & \\
\hline & 1 & $\operatorname{Fe}\left(k_{l}\right)$ & $2.529(5)$ & & & & \\
\hline & 1 & $\mathrm{Fe}\left(k_{2}\right)$ & $2.548(6)$ & & & & \\
\hline & 2 & $\operatorname{Fe}\left(k_{2}\right)$ & $2.551(5)$ & & & & \\
\hline & 1 & $\mathrm{Fe}\left(j_{1}\right)$ & $2.397(4)$ & & & & \\
\hline & 1 & $\mathbf{F e}\left(j_{2}\right)$ & $2.640(4)$ & & & & \\
\hline & 1 & $\operatorname{Fe}\left(j_{2}\right)$ & $2.659(4)$ & & & & \\
\hline & 1 & $\operatorname{Fe}(e)$ & $2.5046(31)$ & & & & \\
\hline
\end{tabular}

Obs.: Estão incluídos os vizinhos com distância interatomica menor de $4 \AA$ 
TABELA 5.17 - Distâncias interatômicas entre o átomo base e seu(s) vizinho(s) para a fase magnética $\operatorname{Pr}_{8} \mathrm{Fe}_{56-\mathrm{x}} \mathrm{Co}_{\mathrm{x}} \mathrm{B}_{4}$ para a liga $\operatorname{Pr}_{14} \mathrm{Fe}_{\mathrm{bal}} \mathrm{Co}_{8} \mathrm{~B}_{6} \mathrm{Nb}_{0,1}$

\begin{tabular}{|c|c|c|c|c|c|c|c|}
\hline $\begin{array}{c}\text { Átomo } \\
\text { base }\end{array}$ & $\begin{array}{c}\text { Número } \\
\text { de } \\
\text { átomos }\end{array}$ & Átomo & $\begin{array}{c}\text { Distância } \\
(\stackrel{\AA}{A})\end{array}$ & $\begin{array}{c}\text { Átomo } \\
\text { base }\end{array}$ & $\begin{array}{c}\text { Número } \\
\text { de } \\
\text { átomos }\end{array}$ & Átomo & $\begin{array}{c}\text { Distância } \\
(\AA)\end{array}$ \\
\hline \multirow[t]{7}{*}{$\operatorname{Pr}(f)$} & 2 & $\operatorname{Pr}(g)$ & $3.7976(19)$ & \multirow[t]{8}{*}{$\operatorname{Fe}\left(j_{1}\right) / \operatorname{Co}\left(j_{1}\right)$} & 1 & $\operatorname{Pr}(f)$ & $3.289(4)$ \\
\hline & 4 & $\operatorname{Fe}\left(k_{1}\right)$ & $3.0692(31)$ & & 2 & $\operatorname{Pr}(g)$ & $3.2861(35)$ \\
\hline & 4 & $\operatorname{Fe}\left(k_{2}\right)$ & $3.0747(29)$ & & 2 & $\mathrm{Fe}\left(k_{1}\right)$ & $2.603(4)$ \\
\hline & 2 & $\operatorname{Fe}\left(j_{1}\right)$ & $3.289(4)$ & & 2 & $\operatorname{Fe}\left(k_{2}\right)$ & $2.3813(34)$ \\
\hline & 2 & $\mathbf{F e}\left(j_{2}\right)$ & $3.069(4)$ & & 1 & $\mathrm{Fe}\left(j_{1}\right)$ & $2.441(8)$ \\
\hline & 2 & $\mathrm{Fe}(e)$ & $3.1816(35)$ & & 1 & $\mathbf{F e}\left(j_{2}\right)$ & $2.779(6)$ \\
\hline & 2 & $\mathrm{Fe}(c)$ & $3.12040(16)$ & & 2 & $\mathbf{F e}\left(j_{2}\right)$ & $2.647(4)$ \\
\hline \multirow[t]{8}{*}{$\operatorname{Pr}(g)$} & 2 & $\operatorname{Pr}(f)$ & $3.7976(19)$ & & 1 & $\mathrm{Fe}(e)$ & $2.527(7)$ \\
\hline & 1 & $\operatorname{Pr}(g)$ & $3.517(4)$ & \multirow[t]{9}{*}{$\operatorname{Fe}\left(j_{2}\right) / \operatorname{Co}\left(j_{2}\right)$} & 1 & $\operatorname{Pr}(f)$ & $3.069(4)$ \\
\hline & 4 & $\operatorname{Fe}\left(k_{1}\right)$ & $3.0799(34)$ & & 1 & $\operatorname{Pr}(g)$ & $3.142(4)$ \\
\hline & 4 & $\operatorname{Fe}\left(k_{2}\right)$ & $3.2824(29)$ & & 2 & $\mathrm{Fe}\left(k_{1}\right)$ & $2.766(4)$ \\
\hline & 4 & $\mathbf{F e}\left(j_{1}\right)$ & $3.2861(35)$ & & 2 & $\mathrm{Fe}\left(k_{1}\right)$ & $2.711(5)$ \\
\hline & 2 & $\mathrm{Fe}\left(\boldsymbol{j}_{2}\right)$ & $3.142(4)$ & & 2 & $\mathrm{Fe}\left(k_{2}\right)$ & $2.636(4)$ \\
\hline & 2 & $\mathrm{Fe}(c)$ & $3.3908(8)$ & & 2 & $\mathrm{Fe}\left(k_{2}\right)$ & $2.6543(33)$ \\
\hline & 1 & $\mathrm{~B}(\mathrm{~g})$ & $2.93(4$ & & 1 & $\mathrm{Fe}\left(j_{1}\right)$ & $2.779(6)$ \\
\hline \multirow[t]{10}{*}{$\overline{F e}\left(k_{l}\right) / \operatorname{Co}\left(k_{l}\right)$} & 1 & $\operatorname{Pr}(f)$ & $3.0692(31)$ & & 2 & $\operatorname{Fe}\left(j_{1}\right)$ & $2.647(4)$ \\
\hline & 1 & $\operatorname{Pr}(g)$ & $3.0799(34)$ & & 1 & $\operatorname{Fe}(e)$ & $2.780(6)$ \\
\hline & 1 & $\operatorname{Fe}\left(k_{1}\right)$ & $2.584(5)$ & \multirow[t]{9}{*}{$\operatorname{Fe}(e) / \operatorname{Co}(e)$} & 2 & $\operatorname{Pr}(f)$ & $3.1816(35)$ \\
\hline & 1 & $\operatorname{Fe}\left(k_{2}\right)$ & $2.538(4)$ & & 4 & $\mathrm{Fe}\left(k_{1}\right)$ & $2.5017(31)$ \\
\hline & 1 & $\operatorname{Fe}\left(k_{2}\right)$ & $2.463(4)$ & & 2 & $\mathrm{Fe}\left(j_{1}\right)$ & $2.527(7)$ \\
\hline & 1 & $\operatorname{Fe}\left(k_{2}\right)$ & $2.529(4)$ & & 2 & $\mathbf{F e}\left(j_{2}\right)$ & $2.780(6)$ \\
\hline & 1 & $\operatorname{Fe}\left(j_{2}\right)$ & $2.711(5)$ & & 1 & $\operatorname{Fe}(e)$ & $2.813(13)$ \\
\hline & 1 & $\operatorname{Fe}(e)$ & $2.5017(31)$ & & 2 & $\mathrm{~B}(\mathrm{~g})$ & $2.078(29)$ \\
\hline & 1 & $\mathrm{Fe}(c)$ & $2.5816(29)$ & & 2 & $\operatorname{Pr}(g)$ & $3.3908(8)$ \\
\hline & 1 & $\mathrm{~B}(\mathrm{~g})$ & $2.110(11)$ & & 4 & $\mathbf{F e}\left(k_{l}\right)$ & $2.5816(29)$ \\
\hline \multirow{11}{*}{$\operatorname{Fe}\left(k_{2}\right) / \operatorname{Co}\left(k_{2}\right)$} & 1 & $\operatorname{Pr}(f)$ & $3.0747(29)$ & & 4 & $\mathrm{Fe}\left(k_{2}\right)$ & $2.5062(28)$ \\
\hline & 1 & $\operatorname{Pr}(g)$ & $3.2824(29)$ & \multirow[t]{10}{*}{$\mathbf{B}(g)$} & 1 & $\operatorname{Pr}(g)$ & $2.93(4)$ \\
\hline & 1 & $\mathrm{Fe}\left(\boldsymbol{k}_{1}\right)$ & $2.538(4)$ & & 4 & $\mathbf{F e}\left(k_{l}\right)$ & $2.110(11)$ \\
\hline & 1 & $\operatorname{Fe}\left(k_{1}\right)$ & $2.463(4)$ & & 2 & $\mathrm{Fe}(e)$ & $2.078(29)$ \\
\hline & 1 & $\mathrm{Fe}\left(k_{l}\right)$ & $2.529(4)$ & & & & \\
\hline & 1 & $\mathrm{Fe}\left(k_{2}\right)$ & $2.564(6)$ & & & & \\
\hline & 2 & $\operatorname{Fe}\left(k_{2}\right)$ & $2.559(5)$ & & & & \\
\hline & 1 & $\operatorname{Fe}\left(j_{1}\right)$ & $2.3813(34)$ & & & & \\
\hline & 1 & $\operatorname{Fe}\left(j_{2}\right)$ & $2.6543(33)$ & & & & \\
\hline & 1 & $\mathbf{F e}\left(i_{2}\right)$ & $2.636(4)$ & & & & \\
\hline & 1 & $\mathbf{F e}(c)$ & $2.5062(28)$ & & & & \\
\hline
\end{tabular}

Obs.: Estão incluídos os vizinhos com distância interatomica menor de $4 \AA$ 
TABELA 5.18 - Distâncias interatômicas entre o átomo base e seu(s) vizinho(s) para a fase magnética $\mathrm{Pr}_{8} \mathrm{Fe}_{56-\mathrm{x}} \mathrm{Co}_{\mathrm{x}} \mathrm{B}_{4}$ para a liga $\mathrm{Pr}_{14} \mathrm{Fe}_{\mathrm{bal}} \mathrm{Co}_{12} \mathrm{~B}_{6} \mathrm{Nb}_{0,1}$.

\begin{tabular}{|c|c|c|c|c|c|c|c|}
\hline $\begin{array}{c}\text { Átomo } \\
\text { base }\end{array}$ & $\begin{array}{c}\text { Número } \\
\text { de } \\
\text { átomos }\end{array}$ & Átomo & $\begin{array}{c}\text { Distância } \\
(\AA)\end{array}$ & $\begin{array}{c}\text { Átomo } \\
\text { base }\end{array}$ & $\begin{array}{c}\text { Número } \\
\text { de } \\
\text { átomos }\end{array}$ & Átomo & $\begin{array}{c}\text { Distância } \\
(\AA)\end{array}$ \\
\hline \multirow[t]{7}{*}{$\operatorname{Pr}(f)$} & 2 & $\operatorname{Pr}(g)$ & $3.7883(21)$ & \multirow[t]{8}{*}{$\mathrm{Fe}\left(j_{1}\right) / \mathrm{Co}\left(j_{1}\right)$} & 1 & $\operatorname{Pr}(f)$ & $3.292(4)$ \\
\hline & 4 & $\operatorname{Fe}\left(k_{l}\right)$ & $3.0748(33)$ & & 2 & $\operatorname{Pr}(g)$ & $3.276(4)$ \\
\hline & 4 & $\operatorname{Fe}\left(k_{2}\right)$ & $3.0682(32)$ & & 2 & $\operatorname{Fe}\left(k_{l}\right)$ & $2.601(5)$ \\
\hline & 2 & $\operatorname{Fe}\left(j_{1}\right)$ & $3.292(4)$ & & 2 & $\operatorname{Fe}\left(k_{2}\right)$ & $2.388(4)$ \\
\hline & 2 & $\operatorname{Fe}\left(j_{2}\right)$ & $3.066(5)$ & & 1 & $\mathrm{Fe}\left(j_{1}\right)$ & $2.406(8)$ \\
\hline & 2 & $\operatorname{Fe}(e)$ & $3.1719(34)$ & & 1 & $\operatorname{Fe}\left(j_{2}\right)$ & $2.796(6)$ \\
\hline & 2 & $\mathrm{Fe}(c)$ & $3.11725(16)$ & & 2 & $\mathbf{F e}\left(j_{2}\right)$ & $2.635(4)$ \\
\hline \multirow[t]{8}{*}{$\operatorname{Pr}(g)$} & 2 & $\operatorname{Pr}(f)$ & $3.7883(21)$ & & 1 & $\operatorname{Fe}(e)$ & $2.543(7)$ \\
\hline & 1 & $\operatorname{Pr}(g)$ & $3.513(4)$ & \multirow[t]{9}{*}{$\mathrm{Fe}\left(j_{2}\right) / \mathrm{Co}\left(j_{2}\right)$} & 1 & $\operatorname{Pr}(f)$ & $3.066(5)$ \\
\hline & 4 & $\operatorname{Fe}\left(k_{1}\right)$ & $3.081(4)$ & & 1 & $\operatorname{Pr}(g)$ & $3.139(5)$ \\
\hline & 4 & $\operatorname{Fe}\left(k_{2}\right)$ & $3.2827(32)$ & & 2 & $\operatorname{Fe}\left(k_{1}\right)$ & $2.758(4)$ \\
\hline & 4 & $\operatorname{Fe}\left(j_{1}\right)$ & $3.276(4)$ & & 2 & $\operatorname{Fe}\left(k_{l}\right)$ & $2.706(5)$ \\
\hline & 2 & $\operatorname{Fe}\left(j_{2}\right)$ & $3.139(5)$ & & 2 & $\operatorname{Fe}\left(k_{2}\right)$ & $2.632(4)$ \\
\hline & 2 & $\mathbf{F e}(c)$ & $3.3882(9)$ & & 2 & $\operatorname{Fe}\left(k_{2}\right)$ & $2.656(4)$ \\
\hline & 1 & $\mathbf{B}(g)$ & $2.72(4)$ & & 1 & $\mathbf{F e}\left(j_{1}\right)$ & $2.796(6)$ \\
\hline \multirow[t]{12}{*}{$\operatorname{Fe}\left(k_{1}\right) / \operatorname{Co}\left(k_{l}\right)$} & 1 & $\operatorname{Pr}(f)$ & $3.0748(33)$ & & 2 & $\operatorname{Fe}\left(j_{1}\right)$ & $2.635(4)$ \\
\hline & 1 & $\operatorname{Pr}(g)$ & $3.081(4)$ & & 1 & $\operatorname{Fe}(e)$ & $2.791(6)$ \\
\hline & 1 & $\operatorname{Fe}\left(k_{l}\right)$ & $2.584(6)$ & \multirow[t]{6}{*}{$\mathrm{Fe}(e) / \mathrm{Co}(e)$} & 2 & $\operatorname{Pr}(f)$ & $3.1719(34)$ \\
\hline & 1 & $\mathrm{Fe}\left(k_{2}\right)$ & $2.529(4)$ & & 4 & $\operatorname{Fe}\left(k_{1}\right)$ & $2.5041(32)$ \\
\hline & 1 & $\mathrm{Fe}\left(k_{2}\right)$ & $2.461(4)$ & & 2 & $\operatorname{Fe}\left(j_{1}\right)$ & $2.543(7)$ \\
\hline & 1 & $\mathrm{Fe}\left(k_{2}\right)$ & $2.517(5)$ & & 2 & $\operatorname{Fe}\left(j_{2}\right)$ & $2.791(6)$ \\
\hline & 1 & $\operatorname{Fe}\left(j_{1}\right)$ & $2.601(5)$ & & 1 & $\operatorname{Fe}(e)$ & $2.752(13)$ \\
\hline & 1 & $\operatorname{Fe}\left(j_{2}\right)$ & $2.758(4)$ & & 2 & B & $2.215(30)$ \\
\hline & 1 & $\operatorname{Fe}\left(j_{2}\right)$ & $2.706(5)$ & \multirow[t]{4}{*}{$\mathrm{Fe}(c) / \mathrm{Co}(c)$} & 2 & $\operatorname{Pr}(f)$ & $3.11725(16)$ \\
\hline & 1 & $\mathrm{Fe}(e)$ & $2.5041(32)$ & & 2 & $\operatorname{Pr}(g)$ & $3.3882(9)$ \\
\hline & 1 & $\mathrm{Fe}(c)$ & $2.5829(32)$ & & 4 & $\operatorname{Fe}\left(k_{l}\right)$ & $2.5829(32)$ \\
\hline & 1 & $\mathrm{~B}(\mathrm{~g})$ & $2.065(8)$ & & 4 & $\mathrm{Fe}\left(k_{2}\right)$ & $2.5040(32)$ \\
\hline \multirow{8}{*}{$\mathrm{Fe}\left(k_{2}\right) / \mathrm{Co}\left(k_{2}\right)$} & 1 & $\operatorname{Pr}(f)$ & $3.0682(32)$ & \multirow[t]{8}{*}{$\mathrm{B}(\mathrm{g})$} & 1 & $\operatorname{Pr}(g)$ & $2.72(4)$ \\
\hline & 1 & $\operatorname{Pr}(g)$ & $3.2827(32)$ & & 4 & $\operatorname{Fe}\left(k_{l}\right)$ & $2.065(8)$ \\
\hline & 1 & $\mathrm{Fe}\left(k_{1}\right)$ & $2.529(4)$ & & 2 & $\operatorname{Fe}(e)$ & $2.215(30)$ \\
\hline & 1 & $\operatorname{Fe}\left(k_{l}\right)$ & $2.461(4)$ & & & & \\
\hline & 1 & $\operatorname{Fe}\left(k_{l}\right)$ & $2.517(5)$ & & & & \\
\hline & 1 & $\operatorname{Fe}\left(k_{2}\right)$ & $2.561(6)$ & & & & \\
\hline & 2 & $\mathrm{Fe}\left(k_{2}\right)$ & $2.555(6)$ & & & & \\
\hline & 1 & $\mathrm{Fe}(c)$ & $2.5040(32)$ & & & & \\
\hline
\end{tabular}

Obs.: Estão incluídos os vizinhos com distância interatomica menor de $4 \AA$ 
TABELA 5.19 - Distâncias interatômicas entre o átomo base e seu(s) vizinho(s) para a fase magnética $\operatorname{Pr}_{8} \mathrm{Fe}_{56-\mathrm{x}} \mathrm{Co}_{\mathrm{x}} \mathrm{B}_{4}$ para a liga $\mathrm{Pr}_{14} \mathrm{Fe}_{\mathrm{bal}} \mathrm{Co}_{16} \mathrm{~B}_{6} \mathrm{Nb}_{0,1}$.

\begin{tabular}{|c|c|c|c|c|c|c|c|}
\hline $\begin{array}{c}\text { Átomo } \\
\text { base }\end{array}$ & $\begin{array}{c}\text { Número } \\
\text { de } \\
\text { átomos }\end{array}$ & Átomo & $\begin{array}{c}\text { Distância } \\
(\AA)\end{array}$ & $\begin{array}{c}\text { Átomo } \\
\text { base }\end{array}$ & \begin{tabular}{|c|} 
Número \\
de \\
átomos
\end{tabular} & Átomo & $\begin{array}{c}\text { Distância } \\
(\AA)\end{array}$ \\
\hline \multirow[t]{7}{*}{$\operatorname{Pr}(f)$} & 2 & $\operatorname{Pr}(g)$ & $3.7845(21)$ & \multirow[t]{8}{*}{$\mathrm{Fe}\left(j_{1}\right) / \mathrm{Co}\left(j_{1}\right)$} & 1 & $\operatorname{Pr}(f)$ & $3.292(4)$ \\
\hline & 4 & $\operatorname{Fe}\left(k_{1}\right)$ & $3.0651(34)$ & & 2 & $\operatorname{Pr}(g)$ & $3.288(4)$ \\
\hline & 4 & $\operatorname{Fe}\left(k_{2}\right)$ & $3.0697(31)$ & & 2 & $\operatorname{Fe}\left(k_{1}\right)$ & $2.603(4)$ \\
\hline & 2 & $\operatorname{Fe}\left(j_{1}\right)$ & $3.292(4)$ & & 2 & $\operatorname{Fe}\left(k_{2}\right)$ & $2.400(4)$ \\
\hline & 2 & $\operatorname{Fe}\left(j_{2}\right)$ & $3.066(5)$ & & 1 & $\mathrm{Fe}\left(j_{1}\right)$ & $2.417(8)$ \\
\hline & 2 & $\mathrm{Fe}(c)$ & $3.11491(17)$ & & 1 & $\operatorname{Fe}\left(j_{2}\right)$ & $2.786(6)$ \\
\hline & 2 & $\operatorname{Fe}(e)$ & $3.181(4)$ & & 2 & $\operatorname{Fe}\left(j_{2}\right)$ & $2.633(4)$ \\
\hline \multirow[t]{8}{*}{$\operatorname{Pr}(g)$} & 2 & $\operatorname{Pr}(f)$ & $3.7845(21)$ & & 1 & $\operatorname{Fe}(e)$ & $2.517(7)$ \\
\hline & 1 & $\operatorname{Pr}(g)$ & $3.522(5)$ & \multirow[t]{9}{*}{$\operatorname{Fe}\left(j_{2}\right) / \operatorname{Co}\left(j_{2}\right)$} & 1 & $\operatorname{Pr}(f)$ & $3.066(5)$ \\
\hline & 4 & $\operatorname{Fe}\left(k_{1}\right)$ & $3.071(4)$ & & 1 & $\operatorname{Pr}(g)$ & $3.133(5)$ \\
\hline & 4 & $\operatorname{Fe}\left(k_{2}\right)$ & $3.2883(31)$ & & 2 & $\operatorname{Fe}\left(k_{l}\right)$ & $2.762(4)$ \\
\hline & 4 & $\operatorname{Fe}\left(j_{1}\right)$ & $3.288(4)$ & & 2 & $\operatorname{Fe}\left(k_{l}\right)$ & $2.713(5)$ \\
\hline & 2 & $\operatorname{Fe}\left(j_{2}\right)$ & $3.133(5)$ & & 2 & $\operatorname{Fe}\left(k_{2}\right)$ & $2.634(4)$ \\
\hline & 2 & $\mathbf{F e}(c)$ & $3.3838(9)$ & & 2 & $\operatorname{Fe}\left(k_{2}\right)$ & $2.661(4$ \\
\hline & 1 & $\mathrm{~B}(\mathrm{~g})$ & $2.76(6)$ & & 1 & $\mathbf{F e}\left(j_{1}\right)$ & $2.786(6)$ \\
\hline \multirow[t]{12}{*}{$\operatorname{Fe}\left(k_{l}\right) / \operatorname{Co}\left(k_{l}\right)$} & 1 & $\operatorname{Pr}(f)$ & $3.0651(34)$ & & 2 & $\operatorname{Fe}\left(j_{1}\right)$ & $2.633(4)$ \\
\hline & 1 & $\operatorname{Pr}(g)$ & $3.071(4)$ & & 1 & $\operatorname{Fe}(e)$ & $2.780(6)$ \\
\hline & 1 & $\operatorname{Fe}\left(k_{1}\right)$ & $2.606(6)$ & \multirow[t]{6}{*}{$\operatorname{Fe}(e) / \operatorname{Co}(e)$} & 2 & $\operatorname{Pr}(f)$ & $2.780(6)$ \\
\hline & 1 & $\operatorname{Fe}\left(k_{2}\right)$ & $2.509(4)$ & & 4 & $\operatorname{Fe}\left(k_{l}\right)$ & $2.5091(32)$ \\
\hline & 1 & $\operatorname{Fe}\left(k_{2}\right)$ & $2.449(4)$ & & 2 & $\operatorname{Fe}\left(j_{1}\right)$ & $2.517(7)$ \\
\hline & 1 & $\operatorname{Fe}\left(k_{2}\right)$ & $2.526(4)$ & & 2 & $\operatorname{Fe}\left(j_{2}\right)$ & $2.780(6)$ \\
\hline & 1 & $\operatorname{Fe}\left(j_{1}\right)$ & $2.603(4)$ & & 1 & $\operatorname{Fe}(e)$ & $2.784(14)$ \\
\hline & 1 & $\operatorname{Fe}\left(j_{2}\right)$ & $2.762(4)$ & & 2 & $\mathrm{~B}(\mathrm{~g})$ & $2.19(5)$ \\
\hline & 1 & $\operatorname{Fe}\left(j_{2}\right)$ & $2.713(5)$ & \multirow[t]{4}{*}{$\mathrm{Fe}(c) / \mathrm{Co}(c)$} & 2 & $\operatorname{Pr}(f)$ & $3.11491(17)$ \\
\hline & 1 & $\mathrm{Fe}(e)$ & $2.5091(32)$ & & 2 & $\operatorname{Pr}(g)$ & $3.3838(9)$ \\
\hline & 1 & $\mathrm{Fe}(c)$ & $2.5645(30)$ & & 4 & $\operatorname{Fe}\left(k_{l}\right)$ & $2.5645(30)$ \\
\hline & 1 & $\mathrm{~B}(\mathrm{~g})$ & $2.071(14)$ & & 4 & $\operatorname{Fe}\left(k_{2}\right)$ & $2.4947(29)$ \\
\hline \multirow{10}{*}{$\mathrm{Fe}\left(k_{2}\right) / \mathrm{Co}\left(k_{2}\right)$} & 1 & $\operatorname{Pr}(f)$ & $3.0697(31)$ & \multirow[t]{10}{*}{$\mathrm{B}(\mathrm{g})$} & 1 & $\operatorname{Pr}(g)$ & $2.76(6)$ \\
\hline & 1 & $\operatorname{Pr}(g)$ & $3.2883(31)$ & & 4 & $\operatorname{Fe}\left(k_{1}\right)$ & $2.071(14)$ \\
\hline & 1 & $\operatorname{Fe}\left(k_{1}\right)$ & $2.509(4)$ & & 2 & $\mathrm{Fe}(e)$ & $2.19(5)$ \\
\hline & 1 & $\operatorname{Fe}\left(k_{1}\right)$ & $2.449(4)$ & & & & \\
\hline & 1 & $\operatorname{Fe}\left(k_{1}\right)$ & $2.526(4)$ & & & & \\
\hline & 1 & $\operatorname{Fe}\left(k_{2}\right)$ & $2.529(4)$ & & & & \\
\hline & 2 & $\operatorname{Fe}\left(k_{2}\right)$ & $2.537(5)$ & & & & \\
\hline & 1 & $\operatorname{Fe}\left(j_{1}\right)$ & $2.400(4)$ & & & & \\
\hline & 2 & $\operatorname{Fe}\left(j_{2}\right)$ & $2.634(4)$ & & & & \\
\hline & 1 & $\mathrm{Fe}(c)$ & $2.4947(29)$ & & & & \\
\hline
\end{tabular}

Obs.: Estão incluídos os vizinhos com distância interatomica menor de $4 \AA$

Os valores para o fator de ocupação (F.O.) de todos os sítios não-equivalente para os átomos de cobalto, após o refinamento da estrutura cristalina da fase magneticamente dura pelo método de Rietveld, são apresentados na TAB. 5.20. Nesta tabela é apresentada a fração de átomos (F.A.) do cobalto para cada sítio. A F.A. é o produto do fator de 
ocupação pelo número dos átomos do sítio. Por exemplo, para o sítio $16 k_{1}($ para $\mathrm{x}=4$ ), o fator de ocupação é igual 0,0440 logo: 16 x 0,0440=0,70.

TABELA 5.20 - Fator de ocupação (F.O.) e fração de átomos (F.A.) para os sítios não equivalentes da fase magnética $\operatorname{Pr}_{8} \mathrm{Fe}_{56-x} \mathrm{Co}_{\mathrm{x}} \mathrm{B}_{4}$ para as ligas $\operatorname{Pr}_{14} \mathrm{Fe}_{\text {bal-x }} \mathrm{Co}_{\mathrm{x}} \mathrm{B}_{6} \mathrm{Nb}_{0,1}$.

\begin{tabular}{l|ll|ll|ll|ll}
\hline $\mathrm{Pr}_{14} \mathrm{Fe}_{\text {bal- } \mathrm{x}} \mathrm{Co}_{\mathrm{x}} \mathrm{B}_{6} \mathrm{Nb}_{0,1 .}$ & \multicolumn{2}{|c|}{$\mathbf{x = 4}$} & \multicolumn{2}{c|}{$\mathbf{x = 8}$} & \multicolumn{2}{c}{$\mathbf{x = 1 2}$} & \multicolumn{2}{c}{$\mathbf{x = 1 6}$} \\
\hline Sítio & $\boldsymbol{F . O .}$ & $\boldsymbol{F . A .}$ & $\boldsymbol{F . O .}$ & $\boldsymbol{F . A .}$ & $\boldsymbol{F . O .}$ & $\boldsymbol{F . A .}$ & $\boldsymbol{F . O .}$ & $\boldsymbol{F . A .}$ \\
\hline $16 k_{1}$ & 0,0440 & 0,70 & 0,1110 & 1,76 & 0,0550 & 0,88 & 0,2029 & 3,25 \\
$16 k_{2}$ & 0,0950 & 1,52 & 0,1728 & 2,76 & 0,2602 & 4,16 & 0,2924 & 4,68 \\
$8 j_{1}$ & 0,0739 & 0,59 & 0,1043 & 0,83 & 0,2175 & 1,74 & 0,0974 & 0,78 \\
$8 j_{2}$ & 0,1122 & 0,90 & 0,2141 & 1,71 & 0,3735 & 2,99 & 0,4650 & 3,72 \\
$4 e$ & 0,0094 & 0,04 & 0,1452 & 0,58 & 0,3395 & 1,36 & 0,3443 & 1,38 \\
$4 c$ & 0,0010 & 0,00 & 0,0551 & 0,22 & 0,1210 & 0,48 & 0,4024 & 1,61 \\
\hline
\end{tabular}

O cobalto ocupou preferencialmente o sítio $16 k_{2}$ como pode ser verificado pela análise dos resultados apresentados na TAB. 5.20. Este resultado também foi constatado por Pedziwatr et al. (1986a). Em seu trabalho Bolzoni et al. (1987a) constataram que o ferro tem preferência a ocupar os sítios $8 j_{2}$ situado entre as camadas de Kagomé $e^{4}$ formadas pelo ferro. Os autores van-Noort e Buschow (1985) sugerem que, considerado o tamanho atômico e a eletronegatividade, o átomo do ferro prefere sítios maiores com menores números de praseodímio como primeiros vizinhos. Em conseqüência, os átomos de cobalto ocupam os sítios inversos de preferência do átomo ferro, sendo os sítios onde existe um maior número de átomos de praseodímio como primeiros vizinhos.

A partir do fator de ocupação do átomo de cobalto foi possível determinar a estequiometria da fase magnética $\operatorname{Pr}_{8} \mathrm{Fe}_{56-\mathrm{x}} \mathrm{Co}_{\mathrm{x}} \mathrm{B}_{4}$, apresentada na TAB. 5.21.

TABELA 5.21 - Estequiometria das fases $\operatorname{Pr}_{8} \mathrm{Fe}_{56-\mathrm{x}} \mathrm{Co}_{\mathrm{x}} \mathrm{B}_{4}$.

\begin{tabular}{c|cr}
\hline $\boldsymbol{P r}_{\boldsymbol{8}} \boldsymbol{F} \boldsymbol{e}_{56-\boldsymbol{x}} \boldsymbol{C o}_{\boldsymbol{x}} \boldsymbol{B}_{\boldsymbol{4}}$ & $\boldsymbol{F e}$ & $\boldsymbol{C o}$ \\
\hline $\mathrm{X}=4$ & $53.232(2)$ & $3.754(2)$ \\
$\mathrm{X}=8$ & $46.350(2)$ & $7.889(2)$ \\
$\mathrm{X}=12$ & $44.387(2)$ & $11.613(2)$ \\
$\mathrm{X}=16$ & $40.590(2)$ & $15.411(2)$ \\
\hline
\end{tabular}

Analisando os valores da TAB. 5.21, pode-se concluir que nem todo cobalto foi incorporado à fase magnética $\left(\operatorname{Pr}_{8} \mathrm{Fe}_{56-\mathrm{x}} \mathrm{Co}_{\mathrm{x}} \mathrm{B}_{4}\right)$ das ligas, indicado que o cobalto pode ter-se ligado às outras possíveis fases existentes.

\footnotetext{
${ }^{4}$ Camada de Kagomé: é um arranjo estrutural em forma de um reticulado, composto por triângulos entrelaçados de maneira que um ponto de cruzamento desta tela tem quatro pontos como primeiros vizinhos.
} 


\subsection{3 - Alargamento devido ao tamanho de cristalito}

No pó utilizado para fabricar imãs consolidados, existem duas importantes dimensões a serem consideradas: $d_{p}$ o tamanho da partícula do pó utilizado para a confecção do magneto consolidado e $d_{c}$ o tamanho dos cristalitos deste material. Existe um tamanho critico de domínio $d_{m}$ deduzido pela formula:

$$
d_{m}=\kappa l_{e x}
$$

onde: $l_{e x}$ é o distância de troca dada por $\left(A / \mu_{0} M_{S}^{2}\right)^{1 / 2}$ e $\kappa$ é o parâmetro de "dureza" $\left(\mathrm{K}_{1} / \mu_{0} \mathrm{M}_{\mathrm{S}}^{2}\right)^{1 / 2}$ sendo de $1 \mu \mathrm{m}$ ou menor para a maioria dos materiais magnéticos (Coey e O'Donnell, 1997). Para $d_{p}=d_{c}$ diz-se que o pó está monocristalino e o campo de anisotropia $\left(H_{a}=2 M_{l} / \mu_{o} M_{s}\right)$ próximo da ordem grandeza da magnetização de saturação $M_{s}$. Este tipo de pó apresenta na sua forma cantos agudo que atuam como sítios de nucleação quando da magnetização reversa. Segundo Coey e O'Donnell (1997) não é possível produzir este pó monocristalino em ligas de $\mathrm{TR}_{2} \mathrm{Fe}_{14} \mathrm{~B}$. Para $d_{p} \gg d_{c}$ o pó é chamado de isotrópico coercivo de grão fino. Este pó é composto de cristalitos aleatoriamente orientado com $d_{c} \lesssim d_{m}$ que pode ser conseguido pela técnica HDDR onde se obtém tamanho de cristalito da ordem de $300 \mathrm{~nm}$ a $500 \mathrm{~nm}$. O tamanho do cristalino, $d_{c}$, tem influência direta no ancoramento das paredes de domínio do grão.

Com o uso do método de Rietveld, ao se refinar a estrutura cristalina foi possível determinar o tamanho de cristalito e a anisotropia de forma do cristalito do material analisado. Os resultados para o tamanho do cristalito estão apresentados na TAB. 5.22.

TABELA 5.22 - Tamanho do cristalito (grão) obtido pelo refino da estrutura cristalina da fase magneticamente dura pelo método de Rietveld, onde: Trepresenta o eixo paralelo do elipsóide e Frepresenta o eixo ortogonal do elipsóide.

\begin{tabular}{c|cc}
\hline $\boldsymbol{F a s e}$ & $\left(\boldsymbol{d}_{\boldsymbol{c}} \| \pm \mathbf{1 0}\right) \boldsymbol{n m}$ & $\left(\boldsymbol{d}_{\boldsymbol{c}} \perp \pm \mathbf{1 0}\right) \boldsymbol{n m}$ \\
\hline $\mathrm{Pr}_{8} \mathrm{Fe}_{56} B_{4}$ & 260 & 300 \\
$\mathrm{Pr}_{8} \mathrm{Fe}_{52} \mathrm{Co}_{4} B_{4}$ & 310 & 205 \\
$\mathrm{Pr}_{8} \mathrm{Fe}_{48} \mathrm{Co}_{8} B_{4}$ & 300 & 240 \\
$\mathrm{Pr}_{8} \mathrm{Fe}_{44} \mathrm{Co}_{12} \mathrm{~B}_{4}$ & 230 & 220 \\
$\mathrm{Pr}_{8} \mathrm{Fe}_{40} \mathrm{Co}_{16} B_{4}$ & 180 & 165 \\
\hline
\end{tabular}

Pode-se verificar que quase todos os cristalitos apresentaram-se quase equiaxiais, a não ser pelo $\operatorname{Pr}_{8} \mathrm{Fe}_{44} \mathrm{Co}_{4} \mathrm{~B}_{4}$ que apresentou a dimensão paralela maior em relação a ortogonal. 
Para a liga $\mathrm{Pr}_{8} \mathrm{Fe}_{40} \mathrm{Co}_{16} \mathrm{~B}_{4}$ o tamanho do cristalito foi o menor em comparação com os outros, seguido pelo $\operatorname{Pr}_{8} \mathrm{Fe}_{40} \mathrm{Co}_{12} \mathrm{~B}_{4}$. Este resultado sugere que o cobalto atua como refinador do cristalito da fase magneticamente dura em maiores concentrações.

\section{4 - Análise pelo método teórico}

O cálculo teórico do momento magnético total para as ligas com variação da concentração de cobalto, objetivou comparar os resultados obtidos com os resultados experimentais obtidos neste trabalho e com os publicados (Pedwiwatr et al., 1986a; Bolzoni et al., 1987a), visando avaliar a possibilidade de aplicação do método para o estudo comparativo da influência dos dopantes adicionados sobre as propriedades magnéticas da fase $\operatorname{Pr}_{2}(\mathrm{Fe}, \mathrm{Co})_{14} \mathrm{~B}$. Para uma melhor comparação com a literatura, adotouse a notação da célula reduzida $\operatorname{Pr}_{2}\left(\mathrm{Fe}_{\text {bal- } x} \mathrm{Co}_{x}\right)_{14} \mathrm{~B} \operatorname{com} x$ variando de 0 a 1 .

Na simulação da estrutura só é possível informar um número inteiro de elétrons na estrutura em conseqüência um número inteiro de átomos. Com base na fração de átomos (F.A.) constante na TAB. 5.20, determinou-se o número de átomos inteiros de cobalto em cada sítio apresentado na TAB. 5.23.

TABELA 5.23 - Número de átomos utilizados em cada sítio não equivalente no cálculo teórico.

\begin{tabular}{c|cccc}
\hline $\operatorname{Pr}_{2}\left(\mathbf{F e}_{\text {bal-x }} \mathbf{C o}_{\mathbf{x}}\right)_{\mathbf{1 4}} \mathbf{B}$ & $\begin{array}{l}\mathbf{x = 0 . 0 7 1} \\
\text { Sítio }\end{array}$ & $\begin{array}{l}\mathbf{x}=\mathbf{0 . 1 4 3} \\
\text { Át. } \text { Átio }\end{array}$ & $\begin{array}{l}\mathbf{x}=\mathbf{0 . 2 1 4} \text {.Sítio } \\
\text { Át./Sítio }\end{array}$ & $\begin{array}{c}\mathbf{x = 0 . 2 8 6} \\
\text { Át./Sítio }\end{array}$ \\
\hline $16 k_{1}$ & 1 & 2 & 1 & 3 \\
$16 k_{2}$ & 2 & 3 & 4 & 5 \\
$8 j 1$ & 0 & 1 & 2 & 1 \\
$8 j_{2}$ & 1 & 2 & 3 & 4 \\
$4 e$ & 0 & 0 & 1 & 1 \\
$4 c$ & 0 & 0 & 1 & 2 \\
\hline
\end{tabular}

Como foi explicado no item 4.6, a partir da TAB. 5.23 calculou-se o número atômico ponderado entre o ferro e o cobalto que foi utilizado no arquivo da estrutura de processamento.

Na FIG. 5.27 encontram-se, na forma de gráfico, os resultados calculados para a variação do momento magnético por átomo em cada sítio não equivalente devido à desordem causada pela introdução do cobalto na estrutura cristalina. Pode-se observar que houve uma aleatoriedade nos valores do momento magnético em cada sítio/átomo com a variação de cobalto, não indicando uma tendência individual. Somente o sítio $4 e$ sofre uma 
acentuada queda em $\mathrm{x}=0,286$ de cobalto (16 \% at.). Já o magnetização de saturação intersticial diminui assintoticamente até a concentração em $\mathrm{x}=0,143$ (8\% at.) mantendose constante até $\mathrm{x}=0,286$ (16\% at.).

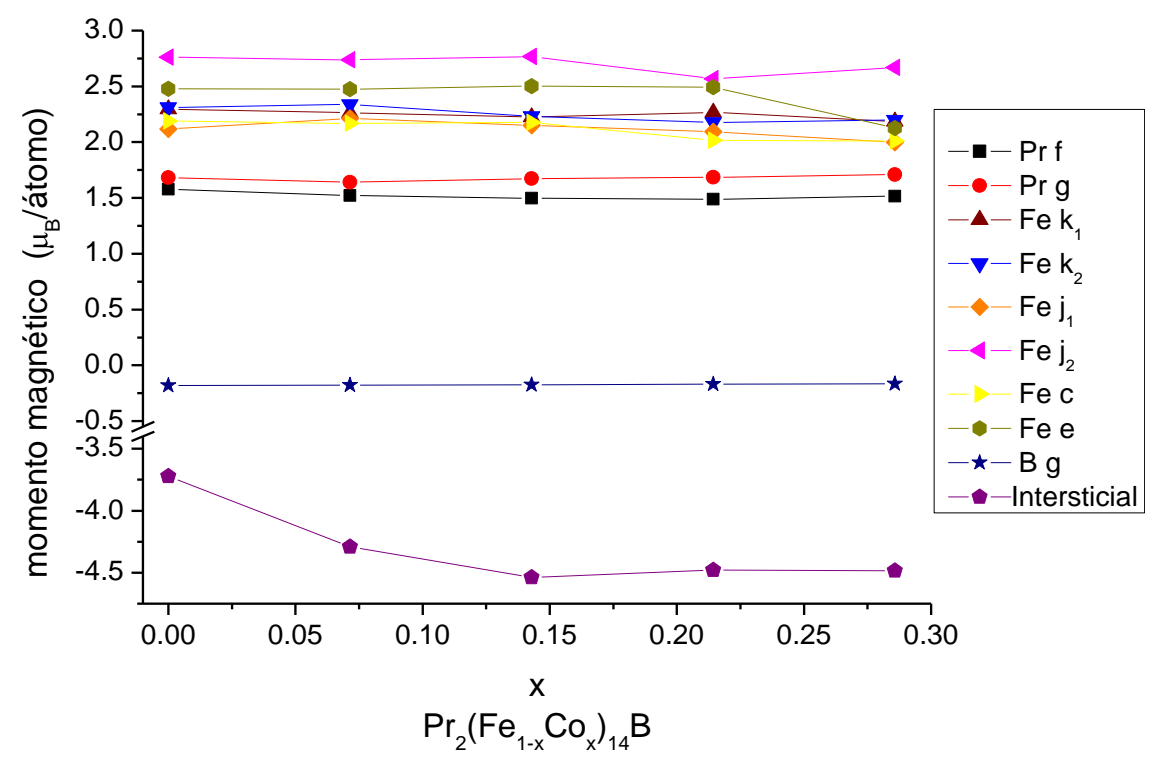

FIGURA 5.27 - Gráfico da variação do momento magnético por átomo de cada sítio não equivalente em função da variação da concentração de cobalto.

O produto do número de átomos do sítio pelo momento magnético do átomo mais o momento magnético intersticial resulta no momento magnético total da célula. Para a fórmula reduzida este valor foi dividido por quatro. Na FIG. 5.28, observa-se a variação do $\mathrm{M}_{\mathrm{S}}$ total por célula unitária obtido no processamento (temperatura $0 \mathrm{~K}$ - teórica) e os valores referentes às medidas realizadas experimentalmente e publicados na literatura.

A diferença relativa entre as curvas é devido à dependência da temperatura do momento magnético. Analisando os valores verificados experimentalmente a $77 \mathrm{~K}$ e 295 $\mathrm{K}$ por Pedziwiatr et al. (1986a), observa-se que ocorreu um pico em $\mathrm{x}=0,07143$ (equivalente a $4 \%$ at.). Este pico é atribuído pelos autores ao efeito Slater-Pauling já discutido anteriormente. Verifica-se que o pico foi mais pronunciado na curva de $295 \mathrm{~K}$ em relação à curva de $77 \mathrm{~K}$, indicando a dependência deste fenômeno com a temperatura.

A momento magnético verificado por Bolzoni et al. (1987a) a 4,2 $\mathrm{K}$, em x $=0$ e x $=0,2$ (equivalente a 11,2 \% at.), manteve-se quase constante inicialmente diminuindo monotonicamente com o aumento da concentração de cobalto. A $300 \mathrm{~K}$ os valores comportaram-se semelhantes às medidas realizadas por Pedziwiatr et al. (1986a), 
ocorrendo um pico do momento magnético em baixas concentrações de cobalto mostrando a dependência do efeito Slater-Pauling com a temperatura.

No cálculo teórico (calculado a $0 \mathrm{~K}$ ), a momento magnético diminui monotonicamente com o aumento da concentração de cobalto. O efeito Slater-Pauling não foi observado indicando concordância com os valores experimentais realizados por Bolzoni (1987a) a 4,2 K. Com esta observação pode-se deduzir que o efeito Slater-Pauling é dependente da temperatura.

A curva teórica ajusta-se próximo aos valores de Pediziwiatr et al. (1986a) a 77 K, sendo relativamente maiores em valor devido a menor temperatura.

Com os resultados obtidos no estudo teórico, comparados com os experimentais, confirma-se a possibilidade de uso do método para caracterização magnética das ligas $\mathrm{Pr}_{14} \mathrm{Fe}_{\text {bal }} \mathrm{Co}_{\mathrm{x}} \mathrm{B}_{6} \mathrm{Nb}_{0,1}$, pois descreveu a curva do momento magnético corretamente.

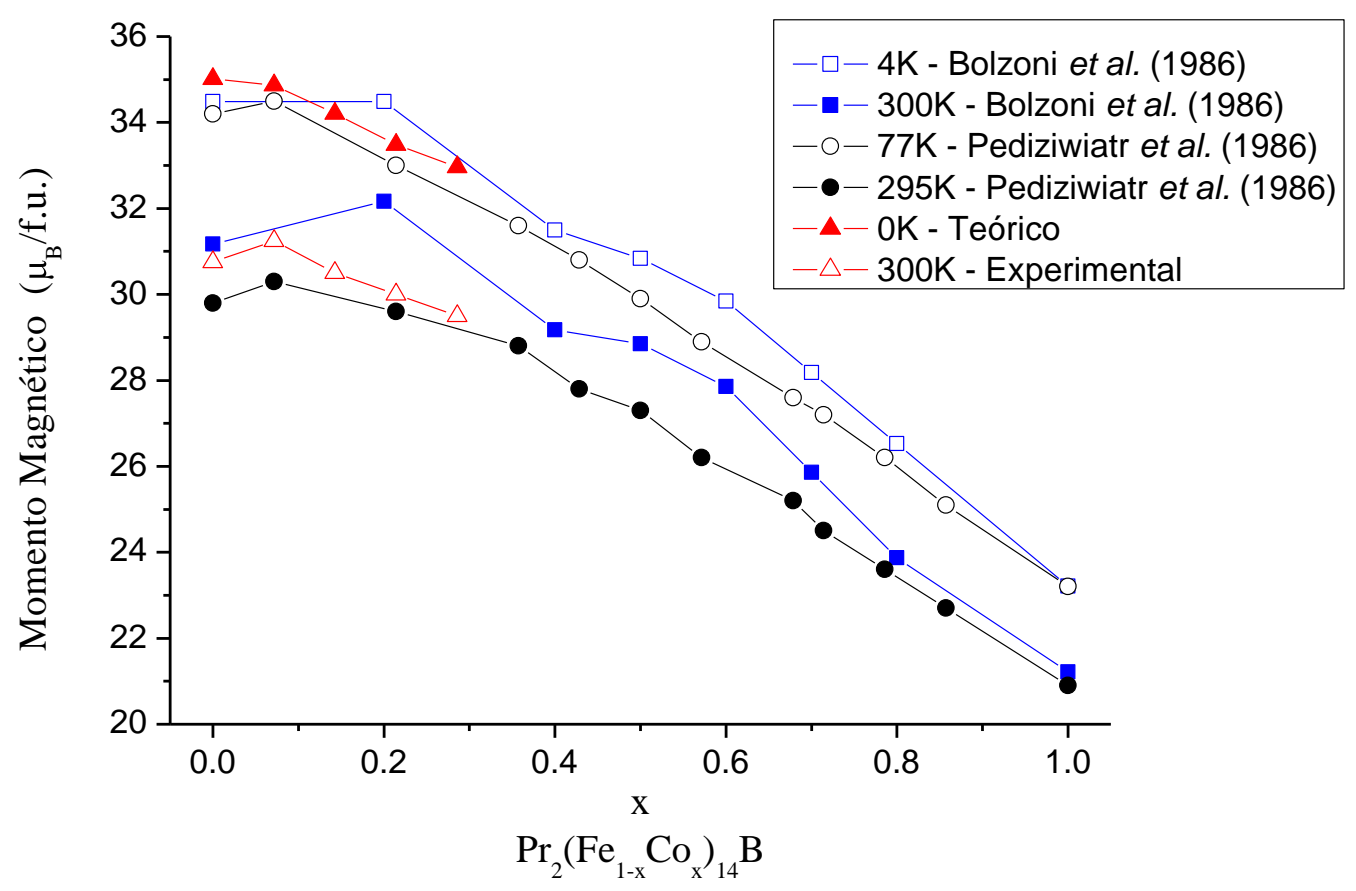

FIGURA 5.28 - Gráfico do momento magnético total em função variação da concentração do cobalto. São apresentados os valores calculados teoricamente e obtidos experimentalmente neste trabalho e os valores apresentados por Bolzoni et al. (1987a) e Pediziwiatr et al. (1986a). 


\section{6 - CONCLUSÕES.}

\section{Adição de elementos dopantes:}

A adição de dopante no composto $\operatorname{Pr}_{14} \mathrm{Fe}_{\text {bal }} \mathrm{Co}_{16} \mathrm{~B}_{6}$ na concentração de $0,1 \%$ at. dos elementos: vanádio, cromo, níquel, zircônio, nióbio ou molibdênio, foi benéfica para as propriedades magnéticas das ligas processadas pelo processo HDDR. Somente a adição do titânio ocasionou diminuição das propriedades magnéticas.

A adição de dopante no composto $\operatorname{Pr}_{14} \mathrm{Fe}_{\text {bal }} \mathrm{Co}_{16} \mathrm{~B}_{6} \mathrm{Nb}_{0,1}$ nas concentrações de $0,1 \%$ at.; $0,3 \%$ at. e $0,5 \%$ at. de alumínio e fósforo foram favoráveis para o aumento da remanência com o aumento da concentração do dopante, embora tenha causado variações na coercividade intrínseca sem uma tendência especificas. Os demais elementos: silício, cobre e gálio adicionados a liga, foram deletérios para as propriedades magnéticas com o aumento da concentração.

Considerando-se as discussões apresentadas na literatura e as curvas de pressão levantadas durante o processo HDDR foi possível afirmar que: a adição de dopantes nos compostos $\operatorname{Pr}_{14} \mathrm{Fe}_{\text {bal }} \mathrm{Co}_{16} \mathrm{~B}_{6}$ e $\operatorname{Pr}_{14} \mathrm{Fe}_{\text {bal }} \mathrm{Co}_{16} \mathrm{~B}_{6} \mathrm{Nb}_{0,1}$ necessita de adequação do processo HDDR no que tange as condições de pressão inicial de hidrogênio, tempo, temperaturas de processo, taxa de aquecimento e de resfriamento, individualizados para cada dopante e porcentagem de adição de forma a se conseguir resultados satisfatórios.

\section{Estudo da estrutura cristalina com adição de Co a liga:}

Os resultados conseguidos no estudo da estrutura cristalina foram satisfatórios reproduzindo os valores da literatura por um método diferente ao usado por outros 
pesquisadores. Com a substituição do ferro pelo cobalto houve a diminuição dos parâmetros de rede com o aumento da concentração do cobalto. Nota-se que o parâmetro $c$ decresce mais rapidamente que o parâmetro $a$, resultando que a variação da relação $c / a$ não é linear. Foi observado que o cobalto tem preferência em substituir o ferro nos sitos, na seqüência decrescente: $16 k_{2}, 8 j_{2}, 16 k_{1}$ e $8 j_{1}$, fato também observado por outros autores. Também, foi possível conhecer o balanço estequiométrico entre os dois átomos, constatando que nem todo cobalto foi incorporado a fase magnética das ligas indicando que o cobalto pode ter-se ligado a outras fases.

\section{Avaliação do método teórico:}

Os resultados mostraram-se satisfatórios, abrindo a possibilidade de uso do método no estudo da influência dos dopantes adicionados nas ligas quanto às suas propriedades magnéticas. 


\section{7 - PROPOSTAS PARA TRABALHOS FUTUROS}

- Adequar as variáveis do processo HDDR para cada dopante e elemento de liga estudado neste trabalho;

- Estudar por microscopia eletrônica de varredura de alta-resolução as ligas processada por HDDR quanto a morfologia dos pós;

- Estudar o comportamento da liga quanto ao aumento da dopagem dos elementos com melhores resultados estudados neste trabalho;

- Estudar por método teórico o comportamento das ligas quanto ao dopante utilizado para direcionar futuros elementos dopantes. 


\section{8 - TRABALHOS PUBLICADOS}

GALEGO, E.; TAKIISHI, H.; FARIA, R.N. Magnetic Properties of Pr-Fe-Co-B Bonded HDDR Magnets with Alloying Additions. Materials Research, v.10, n.3, p. 269-272, 2007.

GALEGO, E.; TAKIISHI, H.; FARIA, R. N. The influence of Si, Ga and Gd content on the magnetic properties of Pr-Fe-Co-B-Nb HDDR bonded magnets, Materials Science Forum. v. 530-531, p. 164-169, 2006. 


\section{REFERÊNCIAS BIBLIOGRÁFICAS}

AHMED, F.M.; ATAIE, A.; HARRIS, I.R. HDDR behaviour of Nb-containing Nd-Fe-B near-stoichiometric alloys. Jornal of Alloys and Compounds, v.237, p.93-100, 1996.

AHMED, F.M.; EDGLEY, D.S.; HARRIS, I.R., Effect of niobium addition on the Nd-FeB alloy and magnet. J. Alloys and Compounds, v. 209, p. 363-368, 1994.

ANGELO, J.D. Estudo das Propriedades e Microestrutura de Imãs Permanentes de Terras Raras e Metais de Transição Preparados pelo Processo de Decrepitação Hidrogênio.Tese (Doutorado). Instituto de Pesquisas Energéticas e Nucleares, 2005.

ASTI, G.; BOLZONI, F. Theory of 1st Order Magnetization Processes - Uniaxial Anisotropy. Journal of Magnetism And Magnetic Materials, v.20, p. 29-43, 1980.

BARBOSA, L.P. Estudo das Propriedades e Microestrutura de Imãs permanentes de PrFe-B-(Co, Nb) Preparados pelo Processo de Hidrogenação, Desproporção, Dessorção e Recombinação (HDDR). Tese (Doutorado), Instituto de Pesquisas Energéticas e Nucleares, 2005.

BARBOSA, L.P.; TAKIISHI, H.; FARIA, R.N. The Effect of Cobalt Content on the Microstruture of Pr-Fe-Co-B Alloys and Magnetic Properties of HDDR Magnets. Journal of Magnetism and Magnetic Materials, v.268, 132-139, 2004.

BARBOSA, L.P.; TAKIISHI, H.; FARIA, R.N. The Effect of Praseodymium Content on the Microstructure and Magnetic Properties of PrFeCoBNb HDDR Magnets, Journal of Magnetism and Magnetic Materials, v.270, p.291-297, 2004a

BARTHEM, V.M.T.S.; GIVORD, D.; EYRAUD, E., Magnetisation reversal in lowcoercivity PrFeB materials. Physica B-Condensed Matter, v.320, n. (1-4), p. 304307, 2002.

BLAHA, P.; SCHAWARZ, K.; MADSEN, G.K.H.; KVASNICKA, D.; LUITZ, J. WIEN2K, An Augmented Plane Wave + Local Orbitals Program for Calculationg Crystal Properties, Karlheinz Schawarz, Techn. Universität Wien, Austria, ISBN 395501031-1-2, 2001.

BOLZONI, F.; CABASSI R.; Review of singular point detection techniques. Physica $\boldsymbol{B}$, v.346-347, p. 524-527, 2004.

BOLZONI, F.; COEY, J.M.D.; GAVIAN, J.; GIVORD, D.; MOZE, O.; PARETI, L.; VIADIEU, T. Magnetic properties of $\operatorname{Pr}_{2}\left(\mathrm{Fe}_{1-\mathrm{x}} \mathrm{Co}_{\mathrm{x}}\right)_{14} \mathrm{~B}$ Compounds. Journal of Magnetism and Magnetic Materials, v.65, p.123-127, 1987a. 
BOLZONI, F.; LECCABUE, F.; MOZE, O.; PARET, L.; SOLZI, M. Magnetocrystalline Anisotropy of $\mathrm{Ni}$ and $\mathrm{Mn}$ Substituted $\mathrm{Nd}_{2} \mathrm{Fe}_{14} \mathrm{~B}$ Compounds. Journal of Magnetism and Magnetic Materials, v.67, p. 373-377, 1987c.

BOLZONI, F.; MOZE, O.; PARETI, L. 1st-Order Field-Induced Magnetization Transitions in Single-Crystal $\mathrm{Nd}_{2} \mathrm{Fe}_{14}$ B. J. Appl. Phys., v. 62, p. 615-620,1987b.

BURZO, E. Permanent magnets based on R-Fe-B and R-Fe-C alloys. Rep. Prog. Phys., v.61, p.1099-1266, 1998.

BURZO, E.; PEDZIWIATR, A.T.; WALLACE, W.E. Magnetic-Properties of $\mathrm{Nd}_{2} \mathrm{Fe}_{14-\mathrm{x}-\mathrm{y}} \mathrm{Co}_{\mathrm{x}} \mathrm{Al}_{\mathrm{y}} \mathrm{B}$. Solid State Communications, v.61, n.1, p.57-59, 1987.

BURZO, E.; PLUGARU, N. Magnetic-Properties of $\mathrm{R}_{2} \mathrm{Fe}_{14-\mathrm{X}} \mathrm{Cu}_{\mathrm{x}} \mathrm{B}$ Compounds with $\mathrm{R}=$ Nd or Er. Journal of Magnetism And Magnetic Materials, v.86, p. 97-101, 1990.

BURZO, E.; STANCIU, L.; WALLACE, W.E. On the Magnetic-Behavior of $\mathrm{Y}_{2} \mathrm{Fe}_{14-\mathrm{x}} \mathrm{Ni}_{\mathrm{x}} \mathrm{B}$ and $\mathrm{Y}_{2} \mathrm{Fe}_{14-\mathrm{x}} \mathrm{Co}_{\mathrm{x}} \mathrm{B}$. Journal of the Less-Common Metals, v.111, p. 83-86, 1985.

CANNESAN, N.; BROWN, D.N.; WILLIAMS, A.J.; HARRIS, I.R. The Evolution of the Disproportionated Microstructure of PrFeB-based Alloys. Journal of Magnetism and Magnetic Materials, v. 242-245, p. 1372-1374, 2002.

CANNESAN, N.; BROWN, D.N.; WILLIAMS, A.J.; HARRIS, I.R. The Production and Characterization of Highly Anisotropic PrFeCoB-type HDDR Powders. Journal of Magnetism and Magnetic Materials, v.233, p.209-218, 2001.

CATICHA-ELLIS, S. Anomalous Dispersion of in Crystallography X-rays. (Published for the International Union of Crystallography by University College Cardiff Press Cardiff, Wales), 2001, ISBN 090644912 X, (to be found at http://www.iucr.org/iucrtop/comm/cteach/pamphlets/8/8.pdf ) acessado em 05 de julho de 2007.

CATICHA-ELLIS, S. On the Use of Anomalous Scattering of X-Rays in the Solution of Centrosymmetric Structures. Acta Cryst., v.15, p. 863-865, 1962.

CHEN, Z.; SHI, Z.; WANG, L.; FU, H. Microstructure and Magnetic Properties Developed by Hot Pressing of Cast Pr-Fe-B Magnets. J. Appl. Phys, v.71, n.6, p.2799-2803, 1992.

CHUANG Y.C.; WU C.H.; XIE J.Q. Structure and Magnetic Properties of $\mathrm{R}_{2}(\mathrm{M}, \mathrm{Ni})_{14} \mathrm{~B}$ Pseudoternary Compounds $(\mathrm{R}=\mathrm{Nd}, \mathrm{Pr} ; \mathrm{M}=\mathrm{Fe}$, Co). Journal of the Less-Common Metals, v.144, p.235-248, 1988.

COEY, J.M.D.; O`DONNELL, K. New bonded magnet materials (invited). Journal of Applied Physics, v.81, n.8, p. 4810-4815, 1997. 
COLLINS, M.F.; FORSYTH, J.B. The Magnetic Moment Distribution in some Transition Metal Alloys. Philosophical Magazine, v.8, p.401-410, 1963.

CORTEFIELD, M. R.; WILLIAMS, A.J.; HARRIS, I. R. The effects of long term annealing at $1000^{\circ} \mathrm{C}$ for $24 \mathrm{~h}$ on the Microstructure and Magnetic Properties of Pr-Fe$\mathrm{B}$; Nd-Fe-B magnets based and $\mathrm{Nd}_{16} \mathrm{Fe}_{76} \mathrm{~B}_{8}$ and $\operatorname{Pr}_{16} \mathrm{Fe}_{76} \mathrm{~B}_{8}$. J. Alloys and Compounds, v. 296, p. 138, 2000.

COTTENIER, S. Density Functional Theory and the family of (L)APW-methods; a stepby-step introduction. (Instituut voor Kern- en Stralingsfysica, K.U.Leuven, Belgium), 2002, ISBN 90-807215-1-4 (to be found at http://www.wien2k.at/reg_user/textbooks) acessado em 03 de julho de 2007.

CROAT, J.J.; HERBST, R.W.L.; PINKERTON, F.E. Pr-Fe and Nd-Fe-based materials: A new class of high-performance permanent magnets (invited), J. Appl. Phys., v.55, n.6, p.2078-2082, 1984.

CULLITY, B.D. Introduction to Magnetic Materials, Addison-Wesley Publishing Company, 1972.

DESCLAUX, J.P. Hartree Fock Slater Self Consistent Field Calculations. Comp. Phys. Commun. v.1, p.216-222; 1970.

DOSER, M.; RIBITCH, R.W.; CROAT, J.J; PANCHANATHAN, V. Bonded anisotropic Nd-Fe-B magnets from rapidly solidified powders. Journal of Applied Physics, v.69, p.5835-5837 Part 2B, 1991.

FANTINI, M.C.A. Estudo das Propriedades Ópticas, Elétricas e Estruturais de FilmesVaporizados de $\mathrm{SnO}_{2}: F$, Tese de Doutorado, IFGW/UNICAMP, 1985.

FUERST, C. D.; HERBST, J. F.; ALSON, E. A. Magnetic properties of $\mathrm{Nd}_{2}\left(\mathrm{Co}_{\mathrm{x}} \mathrm{Fe}_{1-\mathrm{x}}\right)_{14} \mathrm{~B}$ alloys. Journal of Magnetism and Magnetic Materials, v.54-57, p. 567-569, 1986.

FUERST, C.D.; HERBST, J.F.; Magnetic Hardening of $\mathrm{Nd}_{2}\left(\mathrm{Co}_{\mathrm{x}} \mathrm{Fe}_{1-\mathrm{x}}\right)_{14} \mathrm{~B}$ Systems. Applied Physics Letters, v.54. n.11, p. 1068-1070, 1989.

GASKELL, P.H. Similarities in Amorphous and Crystalline Transition Metal-Metalloid Alloy Structures. Nature, v.289, p.474-476, 1981.

GIVORD, D.; LI, H.S.; DELABATHIE, R.P. Magnetic-Properties of $\mathrm{Y}_{2} \mathrm{Fe}_{14} \mathrm{~B}$ and $\mathrm{Nd}_{2} \mathrm{Fe}_{14} \mathrm{~B}$ Single-Crystals. Solid State Commun., v.51 p.857-860, 1984.

GRÖSSINGER, R.; KIRCHMAYR, H.R.; BUSCHOW, K.H.J. Magnetic anisotropy in the

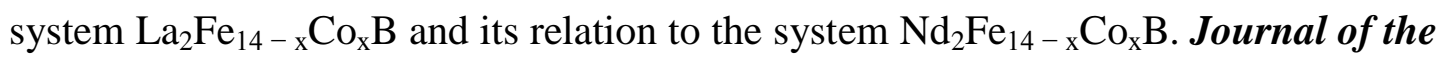
Less-Common Metals, v.136, p.367-73, 1988. 
GRÖSSINGER, R.; KREWENKA, R.; KIRCHMAYR, H.R.; SINNEMA, S.; YANG, F.M.; HUANG Y, K.; DeBOER, F.R.; BUSCHOW, K.H.J. Magnetic anisotropy in $\operatorname{Pr}_{2}\left(\mathrm{Fe}_{1-\mathrm{x}} \mathrm{Co}_{\mathrm{x}}\right)_{14} \mathrm{~B}$ compounds, Journal of the Less-Common Metals. v.123, p. 265$72,1987$.

GRÖSSINGER, R.; KREWENKA, R.; KOU, X.C.; BUSCHOW, K.H.J. A Comparison of the Magnetic Anisotropy of $\mathrm{R}_{2} \mathrm{Fe}_{14} \mathrm{~B}$ with $\mathrm{R}_{2} \mathrm{Fe}_{14} \mathrm{C}$ Compounds $(\mathrm{R}=\mathrm{Nd}, \mathrm{Gd}, \mathrm{Tb}, \mathrm{Dy}$, Ho, Er, Tm, Lu). Journal of Magnetism and Magnetic Materials, v.83, p.130-132, 1990.

GRÖSSINGER, R.; KREWENKA, R.; SUN, X.K.; EIBLER, R.; KIRCHMAYR, H.R.; BUSCHOW, K.H.J. Magnetic phase transitions and magnetic anisotropy in $\mathrm{Nd}_{2} \mathrm{Fe}_{14-\mathrm{x}} \mathrm{Co}_{\mathrm{x}} \mathrm{B}$ compounds. Journal of the Less-Common Metals., v.124, p.165$72,1986$.

GUTTFLEISCH, O.; HARRIS, I.R. Fundamental and Practical Aspects of the Hydrogenation, Disproportionation, Desorption and Recombination Process. J. Phys. D Appl. Phys., v. 29, p. 2255-2265, 1996.

HANDSTEIN, A.; MÜLLER, .K.H; GRÖSSINGER, R.; KIRCHMAYR, H.R.; KREWENKA, R. Influence of particle size on the properties of polymer bonded Nd-Fe-B magnets. Journal of Magnetism and Magnetic Materials, v.101, p.377378, 1991.

HARRIS, I.R.; MCGUINESS, P.J. Hydrogen - Its Use in the Processing of NdFeB-Type Magnets Journal of the Less-Common Metals, v.172, p. 1273-1284 Part C, 1991.

HERBST, J.F. $\mathrm{R}_{2} \mathrm{Fe}_{14} \mathrm{~B}$ materials - intrinsic properties and technological aspects. Reviews of Modern Physics, v.63, n.4, p.819-898, 1991.

HERBST, J.F.; CROAT, J.J.; PINKERTON, F.E.; YELON, W.B. Relationships Between Crystal-Structure and Magnetic Properties in $\mathrm{Nd}_{2} \mathrm{Fe}_{14}$ B. Physical Review B, v.29, n.7, p.4176-4178, 1984.

HERBST, J.F.; CROAT, J.J.; YELON, W.B. Structural and magnetic properties of $\mathrm{Nd}_{2} \mathrm{Be}_{14}$ B. Journal of Applied Physics, v.57, n.1, p.4086-4090, 1985b.

HERBST, J.F.; YELON, W.B. Crystal and magnetic structure of $\operatorname{Pr}_{2} \mathrm{Fe}_{14} \mathrm{~B}$ and $\mathrm{Dy}_{2} \mathrm{Fe}_{14} \mathrm{~B}$. Journal of Applied Physics, v.57, n.6, p.2343-2345, 1985.

HERBST, J.F.; YELON, W.B. Preferential Site Occupation and Magnetic-Structure of $\mathrm{Nd}_{2}\left(\mathrm{Co}_{\mathrm{x}} \mathrm{Fe}_{1-\mathrm{x}}\right)_{14} \mathrm{~B}$ Systems. Journal of Applied Physics, v. 60, n. 12, p. 4224-4229, 1986. 
HIROSAWA, S.; TOKUHARA, K.; MATSUURA, Y.; YAMAMOTO, H.; FUJIMURA, S. Magnetization and magnetic anisotropy of $\mathrm{R}_{2} \mathrm{Fe}_{14} \mathrm{~B}$ measured on single crystals. Journal of Applied Physics, v.59, p. 873-879, 1986.

HIROSAWA, S; TOMIZAWA, H.; MINO, S.; HAMAMURA, T. High-coercivity Nd-Fe-B-type Permanent Magnets With less Dysprosium. IEEE Trans. Magn., v.26, p.1960-1962, 1990.

HIROYOSHI. H; KATO, H.; YAMADA, M.; SAITO, N.; NAKAGAWA, Y.; HIROSAWA, S.; SAGAWA, M., First order magnetization process in $\operatorname{Pr}_{2} \mathrm{Fe}_{14} \mathrm{~B}$ single crystal. Solid State Commun. v.62, p.475-478,1987a.

HIROYOSHI. H; KATO, H.; YAMADA, M.; SAITO, N.; NAKAGAWA, Y.; HIROSAWA, S.; SAGAWA, M., High-field magnetization and crystalline field of $\mathrm{R}_{2} \mathrm{Fe}_{14} \mathrm{~B}$ and $\mathrm{R}_{2} \mathrm{Co}_{14} \mathrm{~B}$. Journal of Magnetism and Magnetic Materials, v.70 p.337$339,1987 b$.

HOHENBERG, P.; KOHN, W. Inhomogeneous Electron Gas. Phys. Rev. B, v.136, p.B864, 1964.

ISNARD, O.; YELON, W.B.; MIRAGLEA, S.; FRUCHART, D. Neutron-diffration Study of the Insertion Scheme of Hidrogen in $\mathrm{Nd}_{2} \mathrm{Fe}_{14}$ B. J. Appl. Phys., v.78, n. 3, p.1892$1898,1995$.

JIANG, S.Y.; WALLACE, W.E. Crystallographic and Magnetic Properties of PrCo4-xFex Alloys. Journal of magnetism and Magnetic Materials, v. 61, p. 257-259, 1986.

JIN, Z. Q.; ZHANG, Y.; WANG, H.L.; KLAESSIG, A.; BONDER, M.; HADJIPANAYIS, G.C. The Improved Magnetic Properties in Phosphorus Substituted Pr-Fe-P-B Nanocomposites. Journal of Applied Physics, v.93, n.10, p. 6492-6494, 2003.

JINGHUA, T.; YIYING, H.; JINGKUI, L. The Pr-Fe-B Ternary System. Scientia Sinica, v. XXX, n. 6, (series A), p. 607, 1987.

JURCZYK, M.; CHISTJAKOV, O.D. Crystallographic and magnetic properties of $\mathrm{R}_{2}(\mathrm{Fe}, \mathrm{Co}, \mathrm{Nb}){ }_{14} \mathrm{~B}$-based system $(\mathrm{R}=\mathrm{Pr}$, Pr-Dy), Journal of Magnetism and Magnetic Materials, v.78, p279-282, 1989.

JURCZYK, M.; JAKUBOWICZ, J.; GEBEL, B.; HANDSTEIN, A.; GUTFLEISCH, O.; MÜLLER, K. M. $\mathrm{Nd}_{2}(\mathrm{Fe}, \mathrm{Co}, \mathrm{M})_{14} \mathrm{~B}$-type magnet powders produced by the HDDR process. Journal of Alloy and Compounds, v.292, p.296-300, 1999.

JURCZYK, M.; KOVALCZYK, A.; WRZECIONO, A. Proc. $9^{\text {th }}$ Int. Workshop on RareEarth Magnets and their Applications (Bad Soden) p.701-707, 1987. 
KIM, A.S. High coercivity Nd-Fe-B magnets with lower dysprosium content. Journal of Applied Physics, v.63, n.8, p.3519-3521, 1988.

KIM, B.Y.; JEUNG, W.Y. Hydrogen absorption and desorption behavior in Pr-Fe-B alloys. Journal of Applied Physics, v.83, n.11, p.6405-6407, 1998.

KLUG, H.P.; ALEXANDER, L.E. X-Ray Diffraction Procedures For Polycrystalline andAmorphous Materials, 2nd. ed., Wiley-Interscience, New York, 1974.

KOHN, W.; SHAM, L.J. Self-Consistent Equations Including Exchange and Correlation Effects. Phys. Rev. v.140, p.A1133, 1965.

KOU, X. C.; GRÖSSINGER, R.; MÜLLER, H.; BUSCHOW, K. H. J. Anomalous 3d anisotropy of $\mathrm{R}_{2} \mathrm{Fe}_{14} \mathrm{C}$ and $\mathrm{R}_{2} \mathrm{Fe}_{14} \mathrm{~B}$ compounds. Journal of Magnetism and Magnetic Materials, v.101 p.349-351, 1991.

KOU, X. C.; SUN, X. K.; CHUANG, Y. C.; ZHAO, T. S.; GRÖSSINGER, R.; KIRCHMAYR, H. R. Magnetic anisotropy and exchange interaction in $\mathrm{Gd}_{2} \mathrm{Fe}_{14} \mathrm{C}$ and $\mathrm{Gd}_{2} \mathrm{Fe}_{14} \mathrm{~B}$ compounds. Solid State Commun., v.73, p.87-99. 1990.

KOWALCZYK, A. Magnetic and crystallographic properties of substituted $\operatorname{Pr}_{2} \mathrm{Fe}_{14-\mathrm{x}} \mathrm{M}_{\mathrm{x}} \mathrm{B}$ compounds $(\mathrm{M}=\mathrm{Si}, \mathrm{Ga}, \mathrm{Cr}$ and $\mathrm{Cu})$. Journal of Magnetism and Magnetic Materials v.82, p.L1-L4, 1989.

KOWALCZYK, A.; STEFANSKI, P.; WRZECIONO, A. Magnetic Properties of $\mathrm{Pr}_{2} \mathrm{Fe}_{14-\mathrm{x}} \mathrm{Co}_{\mathrm{x}} \mathrm{Cr}_{\mathrm{y}} \mathrm{B}$ Compounds. Phys. Stat. Sol. (a), v.107, p.K61-k64, 1968.

KOWALCZYK, A.; WRZECIONO, A. Magnetic properties of $\mathrm{R}_{2} \mathrm{Fe}_{14-\mathrm{x}} \mathrm{M}_{\mathrm{x}} \mathrm{B}, \mathrm{R}=\mathrm{Y}, \mathrm{Gd}$; M=Si, Cr, Cu alloys. Journal de Physique, v.49 (C-8), p.605-606 Part 1, 1988a.

KOWALCZYK, A.; WRZECIONO, A. Structural and magnetic characteristics of $\mathrm{R}_{2} \mathrm{Fe}_{14-\mathrm{x}} \mathrm{Cu}_{\mathrm{x}} \mathrm{B}$ systems $(\mathrm{R}=\mathrm{Y}, \mathrm{Nd}$ and $\mathrm{Gd})$. Journal of Magnetism and Magnetic Materials, v. 74, p.260-263, 1988b.

KU, H.C.; CHEN, J.C.; YEN, L.S. Magnetic Properties of Pseudoternary Compounds $\mathrm{Nd}_{2}\left(\mathrm{Fe}_{1-\mathrm{x}} \mathrm{Ru}_{\mathrm{x}}\right)_{14} \mathrm{~B}$. Journal of Magnetism and Magnetic Materials, v.54-57, p.533-534, 1986.

KU, H.C.; YEN, L.S. Magnetic Properties of the New Permanent Magnet Compounds $\mathrm{Nd}_{2}\left(\mathrm{Fe}_{0.2} \mathrm{M}_{0.1}\right)_{14} \mathrm{~B}(\mathrm{M} \equiv \mathrm{Sc}, \mathrm{Ti}, \mathrm{V}, \mathrm{Cr}, \mathrm{Mn}, \mathrm{Co}, \mathrm{Ni})$. J. Less-Common Met., v.127, p.43-48, 1987.

KWON, H. Anisotropy and Magnetic Properties of $\mathrm{Nd}_{16} \mathrm{Fe}_{76} \mathrm{~B}$ and $\mathrm{Nd}_{16} \mathrm{Fe}_{75.9} \mathrm{~B}_{8} \mathrm{Zr}_{0,1}$ HDDR Materials. IEEE Transations on Magnetics, v.32, n.5, p 4398, 1996.

LARSON, A.C.; VON DREELE, R.B. General Structure Analysis System (GSAS), Los Alamos Nationa Laboratory Report LAUR 86-748, 2004 . 
LEE, R.W.; BREWER, E.G.; SCHAFFEL, N. A Processing of Neodymium-Iron-Boron Melt-Spun Ribbons to Fully Dense Magnets. IEEE Trans. Magn., v.21, p.19581961, 1985.

MacDONAlD, A. H.; PICKETT,W. E.; KOELling, D. D. A Linearized Relativistic Augmented-Plane-Wave Method Utilizing Approximate Pure Spin Basis Functions. Journal of Physics C - Solid State Physics, v.13, p. 2675-2683, 1980.

MARTIN, D.L. Permanent Magnet Characterization Measurements. Paper VIII-1 at the Fifth International on Rare Earth Cobalt Permanent Magnets and theirs Applications; Roanoke, VA, June 1981.

MATSUURA, Y.; HIROSAWA, S.; YAMAMOTO, H.; FUJIMURA, S.; SAGAWA, M. Magnetic properties of the $\mathrm{Nd}_{2}\left(\mathrm{Fe}_{1-\mathrm{x}} \mathrm{Co}_{\mathrm{x}}\right)_{14} \mathrm{~B}$ system. Appl.Phys.Lett., v.46, n.3, p.308-310, 1985.

McCALLUM, R.W.; KADIN, A.M.; CLEMENTE, G.B.; KEEM, J.E. High Performance Isotropic Permanent Magnet Based on Nd-Fe-B. Journal of Applied Physics, v.61, n.8, p.3577-3579, 1987.

McCUSKER, L.B.; VonDREELE, R.B.; COX, D.E.; LOUËR, D.; SCARDI, P., Rietveld refinement guidelines. Journal of Applied Crystallography, v.32, p.36-50, 1999.

McGUINESS, P.J.; ZHANG, X.J.; FORSYTH, H.; HARRIS, I.R. Disproportionation in $\mathrm{Nd}_{16} \mathrm{Fe}_{76} \mathrm{~B}_{8}$-type Hydrides. J. Less-Common Metals, v.162, p.379-387, 1990a.

McGUINESS, P.J.; ZHANG, X.J.; YIN, X.J.; HARRIS, I.R. Hydrogenation Disproportionation And Desorption (DD): An Effective Processing Route for Nd-FeB-type Magnets. J. Less-Common Metals, v.158, p.359-365, 1990 b.

MISHRA, R. K. Microstructure of Hot-Pressed and Die-upset NdFeB Magnets. Journal of Applied Physics, v.62, n.3, p.967-971, 1987.

MIZOGUCHI, T.; SAKAI, I.; NIU, H.; INOMATA K. Nd-Fe-B-Co-Al Based Permanent Magnets with Improved Magnetic Properties and Temperature Characteristics, IEEE Transaction on Magnetics, v.22, n.5, p.919-921, 1986.

MOZE, O.; PARETI L, L.; SOLZI, M.; BOLZONI, F.; DAVID, W.I.F.; HARRISON, W. T.A.; HEWAT, A.W. Magnetic Structure and Preferential Site Occupation in Manganese and Chromium-Substituted $\mathrm{Y}_{2} \mathrm{Fe}_{14} \mathrm{~B}$ compounds J. Less-Common Met., v.136, p.375-383, 1988.

MOZE, O.; PARETI, L.; MARUSI, G.; SOLZI, M.; DAVID, W.I.F. Preferential Site Occupation in Y-Substituted and La-Substituted $\operatorname{Pr}_{2} \mathrm{Be}_{14} \mathrm{~B}$ Intermetallic Compounds. Physica B, v.156, p.747-750, 1989. 
NAKAYAMA, R.; TAKESHITA, T.; ITAKURA, M.; KUWANA, N; OKI, K. Microstructures and Crystallographic Orientation of Crystalline Grains in Anisotropic Nd-Fe-Co-B-(Ga or $\mathrm{Zr})$ Magnet Powders Produced by the Hydrogenation-Decomposition-Desorption-Recombination Process. Journal Applied Physics, v.76, n.1, p.412-417, 1994.

NAKAYAMA, R.; TAKESHITA, T.; ITAKURA, M.; KUWANA, N; OKI, K., Magnetic Properties and Microstructures of the Nd-Fe-B Magnet Powder Produced by Hydrogen Treatment. Journal Applied Physics, v.70, n.7, p.3770-3774, 1991.

NEIVA, A.C.; TSCHIPTSCHIN, A.P.; MISSELL, F.P. Phase Diagram Pr-Fe-B system. Journal of alloys and Compounds, v.217, p. 273, 1995.

NOH, T.H.; JEUNG, W.Y.; KANG, I.K.; SHIN, S.H.; LEE, J.J. Magnetic Properties of PrFe-B Alloy Powders Prepared by Mechanical Grinding. Journal of Applied Physics, v.70, n.10, p.6591-6593, 1991.

NOVAK, P. manual eletrônico: \$WIENROOT/SRC/novak lecture on spinorbit.ps, 1997.

OVERFELT, R.A.; BECKER, J.J.; Thermal Effects of Moderate Substitutions of Cobalt for Iron in Fe76Pr16B8. Applied Physics Letter, v.44, n.9, p.925-926, 1984.

PANCHANATHAN, V.; MCMULLEN, A.T.; CROAT, J.J.; DOSER, M.; RIBIETCH, R. W. Properties of Bonded Anisotropic Magnets. J. Appl. Phys., v.70 p.6465-6467, 1991.

PANDIAN, S.; CHANDRASEKARAN, V.; MARKANDEYULU, G.; IYER, K.J.L; RAO, K.V.S.R. Effect of $\mathrm{Al}, \mathrm{Cu}, \mathrm{Ga}$, and $\mathrm{Nb}$ Additions on the Magnetic Properties and Microstructural Features of Sintered Nd-Fe-B, Journal Of Applied Physics, v.92, p.6082-6086, 2002.

PARETI, L.; BOLZONI, F.; MOZE, O. Direct Observations of 1st-Order Magnetization Processes in Single-Crystal $\mathrm{Nd}_{2} \mathrm{Fe}_{14}$ B. Physical Review B, v.32, p.7604-7606, 1985.

PEDZIWIATR, A. T.; WALLACE, W. E., Spin Reorientations in $\mathrm{R}_{2} \mathrm{Fe}_{14-\mathrm{x}} \mathrm{Co}_{\mathrm{x}} \mathrm{B}$ Systems $(\mathrm{R}=\mathrm{Pr}, \mathrm{Nd}$ and Er). Journal of Magnetism and Magnetic Materials, v.65, p.13944, 1987b.

PEDZIWIATR, A.T.; JIANG, S.Y.; WALLACE, W.E. Structure and Magnetism of the $\operatorname{Pr}_{2} \mathrm{Fe}_{14-\mathrm{x}} \mathrm{Co}_{\mathrm{x}} \mathrm{B}$ System. Journal of Magnetism and Magnetic Materials, v.62, p.2935, 1986a.

PEDZIWIATR, A.T.; WALLACE, W.E. Structure and Magnetism of the $\mathrm{R}_{2} \mathrm{Fe}_{14-\mathrm{x}} \mathrm{Co}_{\mathrm{x}} \mathrm{B}$ ferromagnetic system $\mathrm{R}=(\mathrm{Dy}$ and Er). Journal of Magnetism and Magnetic Materials, v.66, p.63-68, 1987a. 
PEDZIWIATR, A.T.; WALLACE, W.E.; BURZO, E. Structure and Magnetic Properties of R2Fe14-xSixB Compounds ( R = Pr, Nd, and Er). IEEE Trans. Magn., v. MAG23, n.2, p.1795-1800, 1987c.

PERDEW, J.P.; BURKE S.; ERNZERHOF, M. Generalized Gradient Approximation Made Simple. Phys. Rev. Let. v.77, p.3865-3868. 1996.

PERDEW, J.P.; KURTH, S.; ZUPAN, J.; BLAHA, P. Accurate Density Functional with Correct Formal Properties: a Step Beyond the Generalized Gradient Approximation. Phys.Rev.Let. v.82, p.2544, 1999.

PERDEW, J.P.; WANG, Y. Accurate and Simple Analytic Representation of the ElectronGas Correlation. Phys.Rev. B, v.45, p.13244, 1992

RAGG, O. M.; KEEGAN, G.; NAGEL, H.; HARRIS, I. R. The HD and HDDR process in the production of $\mathrm{Nd}-\mathrm{Fe}-\mathrm{B}$ permanent magnets. Int. J. Hydrogen Energy, v. 22, n.2/3, p. 333-342, 1997.

RODEWALD, W.; WALL, B. Structure and Magnetic Properties of Sintered Nd-Fe-B Magnets. Journal of Magnetism and Magnetic Materials, v.80, p.57-60, 1989.

SAGAWA, M.; FUJIMURA, S.; TOGAWA, M.; YAMAMOTO, H.; MATSUURA, Y. New material for permanent magnets on a base of $\mathrm{Nd}$ and $\mathrm{Fe}$ (invited). J. Appl. Phys. v.55, p.2083-2087, 1984.

SAGAWA, M.; MATSUURA, Y.; FUJIMURA, S.; YAMAMOTO, H.; HIROSAWA, S.; TOKUHARA, H.; HIRAGA, K. Magnetic Propertites of BCC Phase at Grain Boundaries in the Nd-Fe-B Permanent Magnet. IEEE Trans. Magn. v.MAG-22, n. 5, p. 910-912, 1986.

SAGAWA, M.; TENAUD, P.; VIAL, F.; HIRAGA, K. High coercivity Nd-Fe-B Sintered Magnet Containing Vanadium with New Microstructure. IEEE Transation on Magnetics, v. 26, n. 5, p. 1957-1959, 1990.

SAGAWA; M. The Dependence of Coercivity on Anisotropy Field in Sintered R-Fe-B Permanent Magnets. Journal of Magnetism and Magnetic Materials V.61, p.363369, 1986.

SCHREY, P. On the Precipitation Of Intermetallic Phases in Nb-containing Nd-Fe-B Magnets. Journal of Magnetism and Magnetic Materials, v.73, p.260-262, 1988.

SHIMODA, T.; AKIOKA, K.; KOBAYASHI, O.; YAMAGAMI, T. Microstructure of Cast Pr-Fe-B Magnets. Journal de Physique, v.49 (C-8), p.631-632 Part 1, 1988.

SHOEMAKER, C. B.; SHOEMAKER, D. P.; FRUCHART, R. The Structure of a New Magnetic Phase Related to the Sigma Phase - Iron Neodymium Boride $\mathrm{Nd}_{2} \mathrm{Fe}_{14} \mathrm{~B}$. 
Acta Crystallographica Section C - Crystal Structure Communications, v.40, p.1665-1668, 1984.

SINGH, D. Ground-State Properties of Lanthanum: Treatment of Extended-Core States. Phys.Rev. B, v. 43, p.6388-6392, 1991.

SINNEMA. S.; RADWANSKI, R.J.; FRANSE, J.J.M.; DeMOOIJ, D.B.; BUSCHOW, K.H.J. Magnetic properties of ternary rare-earth compounds of the type $\mathrm{R}_{2} \mathrm{Fe}_{14} \mathrm{~B}$. Journal of Magnetism and Magnetic Materials, v.44, p.333-341, 1984.

STRNAT, K.; HOFFER, G.; OLSON, J.; OSTERTAG, W.; BECKER, J.J. A Family of New Cobalt-Base Permanent Magnet Materials. Journal of Applied Physics, v. 38, n.3, p. 1001-1004, 1967.

SUZUKI, P.A. Contribuições da Difração de Raios X ao Estudo de Compostos Bi-Sr-CoO e de Fitas Supercondutoras a Base de Bismuto, Tese de Mestrado, Instituto de Física da USP, 1992.

SZYMURA, S; RABINOVICH, Y.M.; BALA, H.; WYSLOCKI, J.J. Magnetic-Properties and Microstructural Characterization of Sintered $\operatorname{Pr}_{16} \mathrm{Fe}_{76-\mathrm{X}-\mathrm{Y}} \mathrm{Co}_{\mathrm{x}} \mathrm{Al}_{\mathrm{y}} \mathrm{B}_{8}$ (0-Less-ThanX-Less-Than-20, 0-Less-Than-Y-Less-Than-8) Magnets. Physica Status Solidi AApplied Research, v.146(2), p.815-824, 1994.

TAKESHITA, T.; MORIMOTO, K. Anisotropic Nd-Fe-B Bonded Magnets Made from HDDR powders, J. Appl. Phys, v. 79, n.8, p. 5040-5044, 1996.

TAKESHITA, T.; NAKAYAMA, R., Magnetic Properties and Microstructure of the $\mathrm{NdFeB}$ Magnet Powder Produced by Hydrogen Treatment. In: $10^{\text {th }}$ INTERNATIONAL WORKSHOP ON TATE-EARTH MAGNETS AND THEIR APPLICATIONS, May 16-19, 1989, Kyoto, Japan. Proceedings... Kyoto, Japan: THE SOCIETY OF NON-TRADITIONAL TECHNOLOGY, p. 551-557, 1989.

TAKIISHI, H. Estudo da Microestrutura e Propriedades Magnéticas de Ligas Magnéticas e Imãs Permanentes de Terras Raras - Metais de Transição- Boro Processados com Hidrogênio. Tese (Doutorado), Instituto de Pesquisas Energéticas e Nucleares, 2001.

TAKIISHI, H.; BARBOSA, L.P. Comunicação Oral, 2005.

THUY, N.P.; HIEN, T.D,; HONG, N.M.; FRANSE, J. J. M. On the Magnetic-Anisotropy of ohe $\mathrm{Y}_{2}\left(\mathrm{Co}_{1-\mathrm{x}} \mathrm{Fe}_{\mathrm{x}}\right)_{14} \mathrm{~B}$ Compounds. Journal De Physique, v.49, p.579-580, 1988.

TOBY, B. H., EXPGUI, A Graphical User Interface for GSAS, J. Appl Cryst., v.34, p.210221, 2001 
TOMKA, G.J.; BISSELL, P.R.; CHANTRELL, R.W.; O’GRADY, K. Interaction phenomena in polymer bonded permanent magnet powders. IEEE Trans. Magn. v.29, p.2869-2871, 1993.

UEHARA, M.; TOMIZAWA, H.; HIROSAWA, S.; TOMIDA, T. MAEHARA, Y. Origin of Anisotropy in the HDDR Process of $\mathrm{Nd}_{2} \mathrm{Fe}_{14} \mathrm{~B}$-based alloys, v.29, n.6, p.27702772, 1993.

VAN NOORT, H.M.; BUSCHOW, K.H.J., On the Site Preference of 3d Atoms in Compounds of the $\mathrm{R}_{2}\left(\mathrm{Co}_{1-\mathrm{x}} \mathrm{Fe}_{\mathrm{x}}\right)_{14} \mathrm{~B}$ Type. Journal of the less-Common Metals, v.113, L9-L12, 1985.

VERHOEF, R.; FRANSE, J.J.M.; DEBOER, F.R.; HEEROOMS, H.J.M.; MATTHAEI, B.; SINNEMA, S. High Field and temperature Dependent Magnetization Measurements on Some $\mathrm{RE}_{2} \mathrm{Co}_{17}$ Single-Crystals. IEEE Transactions on Magnetics, v.24, n.2, p.1948-1950, 1988.

VICTORIA, R.H.; FALICOV, L.M. Calculated Magnetization of Iron-Cobalt Disordered Alloys. Physical Review B, v.30, p.259-262, 1984.

XIE, J.Q.; WU, C.H.; CHUANG, Y.C.; ZHANG, Z.D.; DEBOER, F.R. Effect Of Partial Ga Substitution For $\mathrm{Fe}$ on the Magnetic-Properties of $\mathrm{Nd}_{2} \mathrm{Fe}_{14} \mathrm{~B}$. Journal de Physique, v.49, p.603-604 Part 1, 1988.

YAO, J.M.; HSIE, M.F.; CHIN, T.S.; CHEN, S.K. Proc. 14th Int. Workshop on RareEarth Magnets and Their Applications (Sao Paulo) ed. E. P. Missell et al (Singapore: World Scientific) p. 459-466, 1996.

YELON, W.B.; FOLEY, B.; ABACHE, C.; OESTERREICHER, H. Spin reorientation in $\mathrm{NdDyFe}_{14}$ B. J. Appl. Phys., v.60 p.2982-2984, 1986.

ZACHARIASEN, W. H. Theory of X-Ray Diffraction in Crystals, Dover Publ., Inc., NewYork, reprinted in 1994.

ZHONG, X.F.; CHING, W.Y. Calculation of Local Orbital Moments of Conduction Electrons in $\mathrm{Nd}_{2} \mathrm{Fe}_{14}$ B. J. Appl. Phys., v.67, p.4768-4770, 1990.

ZHOU, S.X.; JOHANSSON, P.; SAVAGE, S.J.; CUI, L.Y. Effect of Ga, Si and Nb Additions on the Phases and Magnetic-Properties of Melt-spun Nd-Fe-B alloys. IEEE Transactions on Magnetics, v.26, p. 1739-1741, 1990. 